Portland State University

PDXScholar

\title{
The Effects of Urbanization and Human Disturbance Upon Plant Community Structure and Bird Species Richness, Diversity, and Abundance in a Natural Forested Area (Forest Park) in Portland, Oregon
}

Nancy Ellen Broshot Portland State University

Follow this and additional works at: https://pdxscholar.library.pdx.edu/open_access_etds

Part of the Environmental Monitoring Commons, and the Natural Resources Management and Policy Commons

Let us know how access to this document benefits you.

\section{Recommended Citation}

Broshot, Nancy Ellen, "The Effects of Urbanization and Human Disturbance Upon Plant Community Structure and Bird Species Richness, Diversity, and Abundance in a Natural Forested Area (Forest Park) in Portland, Oregon" (1999). Dissertations and Theses. Paper 3962.

https://doi.org/10.15760/etd.5846

This Dissertation is brought to you for free and open access. It has been accepted for inclusion in Dissertations and Theses by an authorized administrator of PDXScholar. Please contact us if we can make this document more accessible: pdxscholar@pdx.edu. 


\title{
THE EFFECTS OF URBANIZATION AND HUMAN DISTURBANCE UPON PLANT COMMUNITY STRUCTURE AND BIRD SPECIES RICHNESS, DIVERSITY, AND ABUNDANCE IN A NATURAL FORESTED AREA (FOREST PARK) IN PORTLAND, OREGON
}

\author{
by \\ NANCY ELLEN BROSHOT
}

A dissertation submitted in partial fulfillment of the requirements for the degree of

DOCTOR OF PHILOSOPHY

in

ENVIRONMENTAL SCIENCES AND RESOURCES: BIOLOGY

Portland State University

(C) 1999 


\section{DISSERTATION APPROVAL}

The abstract and thesis of Nancy Ellen Broshot for the Doctor of Philosophy in Environmental Sciences and Resources: Biology were presented January 15, 1999 and accepted by the dissertation committee and the doctoral program.

COMMITTEE APPROVALS:
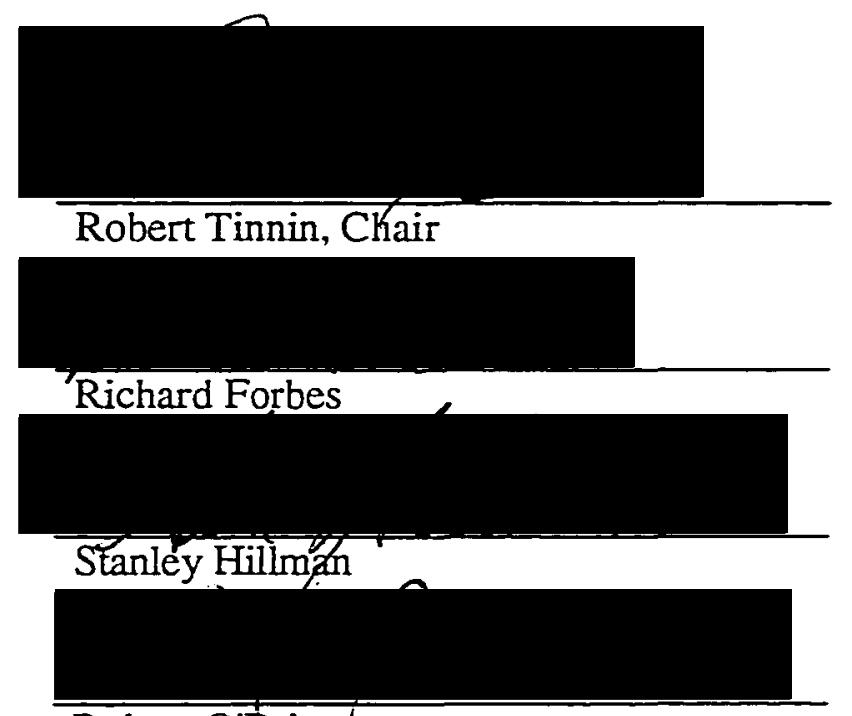

Robert O'Brien

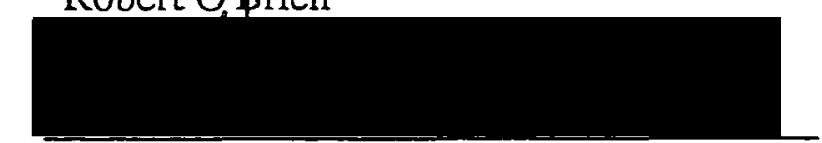

Scott Burns

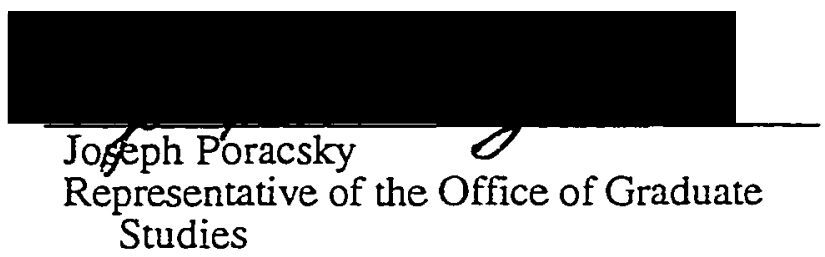

DOCTORAL PROGRAM APPROVAL:

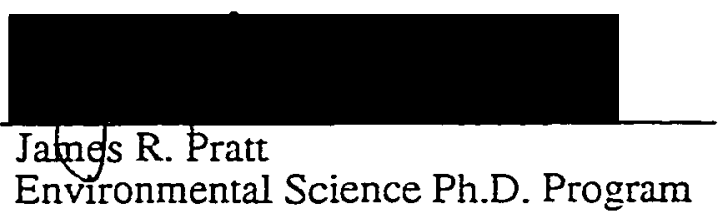




\begin{abstract}
An abstract for the dissertation of Nancy Ellen Broshot for the Doctor of Philosophy in Environmental Sciences and Resources: Biology presented January 15, 1999.
\end{abstract}

Title: The Effects of Urbanization and Human Disturbance upon Plant Community Structure and Bird Species Richness, Diversity, and Abundance in a Natural Forested Area (Forest Park) in Portland, Oregon.

The effects of urbanization and continual human disturbance on the plant and avian communities of Forest Park and forested lands surrounding Portland, Oregon, were studied. I examined characteristics of plant and avian communities at 25 sites, 24 which were in Forest Park and surrounding areas and one which was in the Ancient Forest Preserve (old-growth stand) northwest of Forest Park. Data were analyzed using multiple regression, ANOVA, and Bonferonni/Dunn. Seven variables were selected representing different urbanization gradients. An additional covariable coded for the old-growth stand, allowing it to be used as a control.

Many tree variables, especially those related to shade-tolerant species, were positively correlated with both the distance from downtown Portland and the number of houses in the surrounding area, and negatively correlated with the distance from the nearest forest edge; however, many shrub and herbaceous variables were negatively correlated with the distance from downtown Portland. Species diversity 
for herbaceous and shrub species was greater at more urban sites, but diversity of trees was lower at more urban sites. There were significantly more non-native species of plants in the city section. I found significantly fewer saplings and small trees, especially shade-tolerant species, in the section of Forest Park closest to downtown Portland, although tree mortality was positively correlated with distance from Portland.

Summer bird data revealed significant increases in the abundances of urban and edge species at more urban sites, with concomitant reductions in forest species. There were significantly more ground gleaning birds and short distance migratory species. I also found a significantly greater abundance of birds in the old-growth stand during the winter. This increase was positively correlated with the depth of snow in the nearby Cascade Mountains.

My results indicate that Forest Park is apparently progressing in a normal successional pattern with the exception of the city section. The reduction in shade tolerant saplings and small trees in the city section suggest that rate of succession has been slower at more urban sites. Avian data suggest that urbanization affects bird species abundance and guild composition in the more urban areas. 


\section{ACKNOWLEDGMENTS}

I would like to thank everyone who has helped me with this dissertation. To begin with, I want to thank all the people who helped me conduct the research -- measuring plants and counting birds. This list includes Karen Bachman, Steve Engels, Morgan Hamilton, Christine Hamilton, Noreen Johannson, and last but not least, Peggy Sedlak, who accompanied me countless hours through all forms of weather, and without whom this would never have been completed. I also want to thank Jim Sjulin, Fred Nilson, and Sandy Dietrich of Portland Parks and Recreation for their cooperation and assistance. I would also like to thank Portland Parks and Recreation for their financial support that helped fund my research in part. I would like to thank all the members of Friends of Forest Park for granting me permission to access the Ancient Forest Preserve, and for allowing me to spend countless hours in such a magical place. I would like to thank all those who helped with statistical analyses including Nancy Perrin, David Morgan, and Tim Baker. I also want to thank Dave Drescher of Metro who went out of his way provide me with the maps used in this dissertation. Special thanks are due to those who helped me edit this dissertation, especially Jack Keyes. In addition, a big thank you goes to my colleagues who have encouraged me and sometimes covered for me -- Jack, Bill, Debbi, Barbara, John, and many others. I also wish to thank Robert Tinnin, my advisor, whose patience, guidance and encouragement have been of inestimable value to me. I would also like to thank the rest of my committee (Drs. Forbes, Hillman, Burns, O'Brien and Poracsky) for their help and guidance in setting up my experimental design, analysis 
of the data, and editing of this document. And finally, I wish to thank my family, especially my husband Morgan and my daughter Christine, for their unwavering support and tolerance throughout this process. 


\section{TABLE OF CONTENTS}

PAGE

LIST OF TABLES ................................................... xii

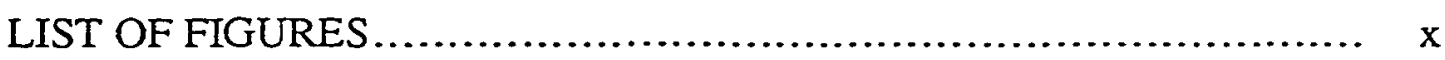

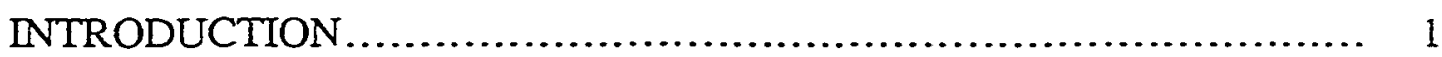

CHAPTER 1. The Effects of Humans on Natural Ecosystems ............... 2

CHAPTER 2. Study Area............................................. 10

Geology .................................................. 10

Climate ........................................................ 12

Plant Community ............................................. 14

CHAPTER 3. Past Influences of Humans on Forest Park ................ 17

CHAPTER 4. General Methods and Analysis of Data ........................ 22

CHAPTER 5. The Effects of Human Disturbance and Urbanization upon the Structure of the Plant Community ................................. 34

Methods for Measuring the Plant Community ...................... 39

Results ...................................................... 41

Data Analysis ............................................. 41

Human Usage Gradients and Variables........................... 41

Multiple Regression Analysis of Plant Community Variables ..... 43

Plant Community Structure -- Differences Between Sections...... 52

Discussion ..................................................... 60 
CHAPTER 6. The Effects of Human Disturbance and Urbanization on the Population Dynamics and Vigor of Trees in the Forest ............... 79

Methods for Population Dynamics ............................... 82

Results .......................................................... 84

Data Analysis ............................................ 84

Multiple Regression Analysis of Tree Demographics -- Age

Structure, Mortality, and Growth Rates...................... 84

Tree Demographics -- Age Structure, Recruitment, Mortality, and Growth Rates -- Differences Between Sections .......... 89

Age Structure.......................................... 89

Mortality ......................................... 93

Increment Growth Rate and Live Crown Ratio ............... 93

Discussion ................................................ 97

CHAPTER 7. The Effects of Human Disturbance and Urbanization Upon the Richness, Abundance, and Species Diversity of Birds.............. 114

Methods....................................................... 123

Results ..................................................... 130

Breeding Birds (Spring Counts).............................. 130

Winter Birds .............................................. 138

Plant Community Structure and Avian Distribution................ 142

Discussion .................................................... 147

Breeding Bird Community ................................... 147

Winter Bird Community .................................. 157 
CHAPTER 8. Conclusions, Management Implications and Future

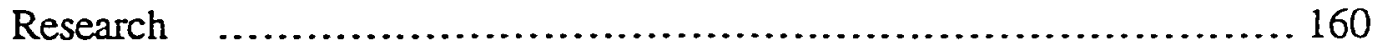

Management Implications ......................................... 162

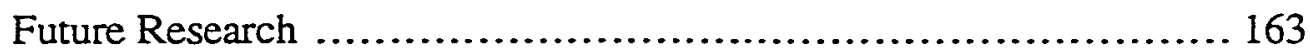

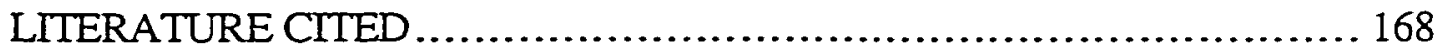

APPENDICES

A Scientific and Common Names of Species of Trees

Observed in Forest Park and the Old-Growth Stand

B Scientific and Common Names of Species of Shrubs

Observed in Forest Park and the Old-Growth Stand

C Scientific and Common Names of Species of Herbaceous

Plants Observed in Forest Park and the Old-Growth Stand .... 216

D Regression Coefficients for Plant Community

Characteristics

E Regression Coefficients for Tree Population

Demographics -- Recruitment, Size Class Structure, Mortality,

Growth Rate, and Live Crown Ratio (LCR)

F The Mean Number of Saplings and Trees by Size Class

Category in the Different Sections

G Mean Increment Growth Rate ( $\mathrm{cm} /$ year) by Decade for the

Previous Ten Decades by Tree Species

H Guild Status and Migratory Status of all Birds Observed in Forest Park and the Old-Growth Stand 
PAGE

I Common and Scientific Names of Bird Species Counted

at Sites, and Abbreviations Used in Text and Tables........... 237

J Regression Coefficients for Bird Species Abundance,

Richness, and Diversity ................................ 241

K Regression Coefficients for Plant Community

Characteristics as Applied to the Avian Community ............ 243 


\section{LIST OF TABLES}

TABLE

PAGE

4-1 Correlation matrix for the seven urbanization variables............. 30

4-2 Transformations and abbreviations of the seven urbanization variables................................................... 31

5-1 Mean values of urbanization variables by section ................ 42

5-2 Human usage values by section .............................. 44

5-3 Multiple regression results. Tree density, richness and diversity. 45

5-4 Multiple regression results. Total tree diameter variables......... 46

5-5 Multiple regression results. Mean tree diameters and importance values................................................ 47

5-6 Multiple regression results. Shrub variables .................... 49

5-7 Multiple regression results. Herbaceous species variables ....... 50

5-8 Multiple regression results. Vegetation cover and foliage height diversity.............................................. 51

5-9 Mean tree density, richness, and diversity by section.............. 53

5-10 Mean total tree diameter by section............................ 54

5-11 Mean tree diameter by section................................. 55

5-12 Mean tree importance values (IV) by section..................... 56

5-13 Mean shrub density, richness, diversity, basal area and height

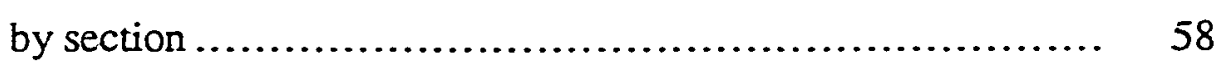

5-14 Mean cover by herbaceous species by section ................... 59 
5-15 Mean vegetative cover at different canopy heights by section......

5-16 Mean foliage diversity (FD) and foliage height diversity (FHD)

by section

5-17 Evidence of disturbance at each site

6-1 Multiple regression results. Tree population structure

6-2 Multiple regression results. Tree mortality

6-3 Multiple regression results. Tree increment growth rates (IGR).. 88

6-4 Multiple regression results. Live crown ratio (LCR) ............. 90

6-5 Distribution of seedlings.................................. 91

6-6 Mean age of trees by section ................................. 94

6-7 Mean number of dead trees by section........................ 95

6-8 Mean live crown ratio (LCR) by section........................... 98

6-9 Distribution of sites into different seral stages ................... 103

6-10 Total number of sites in each seral stage.......................... 105

7-1 Birds used as indicator species for urban, edge and forest

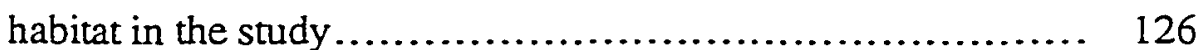

7-2 Transformation of vegetation variables used to examine avian community distribution........................................

7-3 Total avian abundance and richness for breeding season birds

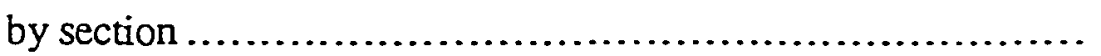

7-4 Multiple regression results. Abundance of breeding season birds by categories.

7-5 Multiple regression results. Abundance of breeding season birds for individual bird species 
7-6 Mean abundance of breeding season bird species by section ..... 136

7-7 Mean abundance of breeding season birds by categories by section................................................ 137

7-8 Total avian abundance and richness for winter birds by section... 139

7-9 Multiple regression results. Abundance of winter birds .......... 140

7-10 Mean abundance of winter birds by section.................... 141

7-11 Multiple regression results. Breeding season bird abundance by by categories as analyzed by vegetative parameters............ 145

7-12 Multiple regression results. Breeding season bird abundance by species as analyzed by vegetative parameters.................. 146

7-13 Multiple regression results. Winter bird abundance as analyzed by vegetative parameters ............................. 148 


\section{LIST OF FIGURES}

FIGURE

PAGE

2-1 Orthophoto map of location of Forest Park and the Ancient

Forest Preserve showing adjacent land development...........

4-1 Location of sites in Forest Park and the Ancient Forest

Preserve (Old-Growth Stand) ............................. 23

5-1 Forest interior habitat in the different sections of Forest Park ..... 74

5-2 Percent of forest edge habitat in the different sections of

Forest Park

5-3 Mean site usage in the different sections of Forest Park......... 76

5-4 Density of trails (miles per acre) in the different sections of

Forest Park

77

6-1 The distribution of trees into the size class categories based on shade tolerance in the different sections of the study ........

6-2 Time series graph showing increment growth rate $(\mathrm{cm} /$ year) for the previous seven decades for bigleaf maple and Douglas-fir in the different sections of the study.

6-3 Size class distribution of trees in the city section of Forest Park and the old-growth stand . 101

6-4 Mean number of multi-trunk bigleaf maples in the different sections................................................ 108

6-5 Tree mortality versus total trees.................................... 111

7-1 Mean number of winter birds in the old-growth stand versus Forest Park 
7-2 Birds in the old-growth stand versus snow depth at Government

Camp four days earlier .................................... 144

7-3 The distribution of brown-headed cowbirds in the different sections of the study ..................................... 156 


\section{INTRODUCTION}

Forested lands in the Portland Metropolitan area are under ever increasing pressure to be cleared for human use. Concern over loss of the remaining natural areas has prompted several government agencies and conservation groups to buy parcels of forest land to ensure their preservation. One of the largest projects, Metro's Greenspaces Plan, a bond measure, was passed by the public to buy selected "natural" lands for public use, enjoyment, education and preservation. The manner in which these lands are managed will determine if the biological integrity of these natural systems will be maintained. However, there have been few scientific studies addressing such concerns. Indeed, few studies have carefully examined how forested systems change with increasing human pressure.

Portland, Oregon, is fortunate in that since 1948 the city has protected within its boundaries a large forested reserve, Forest Park. In this study, Forest Park was used as a natural laboratory to examine how population dynamics, community structure and biodiversity of Pacific Northwest coniferous forests are changing in relation to human pressure and increased urbanization along an urbanization gradient. This study focused on changed in the plant community and bird species richness, diversity, and abundance as correlated with measures of urbanization. 


\section{CHAPTER I}

\section{THE EFFECTS OF HUMANS ON NATURAL ECOSYSTEMS}

Throughout the history of ecology, researchers have concentrated their efforts on the investigation of "natural" ecosystems that were unaffected by human activity (Ludwig 1989; McDonnell and Pickett 1990; McDonnell et al. 1993). As people continue to develop land, it is becoming more difficult to find pristine landscapes that have not been influenced by humans. All wilderness areas, even those in remote locations are increasingly affected by human activities (Cole 1995; Cole and Landres 1996; Weaver and Dale 1978). In light of the increasingly dominant role that humans are having upon Earth, it has become crucially important for scientists to investigate the consequences that humans have upon ecosystems.

As human-affected ecosystems become more prevalent, researchers have begun to address the role of humans as components in ecosystems. Most of the work on this subject has been conducted outside of North America, mostly in Europe, where ecosystems significantly unaffected by humans are virtually impossible to find (Becher and Brandes 1985; Blanco and Velásco 1996; Gutte 1990; Hong et al. 1995; Kowarik 1990; Kubantsev and Kolyakin 1995; Natuhara and Imai 1996; Nuorteva 1971; Pysèk 1989; Pysèk and Pysèk 1990; Reijnen and Foppen 1994; Solinska-

Górnicka and Symonides 1990; Sukopp 1972; Sukopp 1990; Supuka 1994). However, investigations into the effects of humans on ecosystems have been conducted in this country as well (Airola and Buchholz 1984; Blair 1996; Davis and 
Glick 1978; Friesen et al. 1995; Lancaster and Rees 1979; Matlack 1993b; McDonnell et al. 1993; Pouyat and Zipperer 1991; Pouyat et al. 1994; Pouyat et al. 1995a, 1995b; Rowntree 1986; Rudnicky and McDonnell 1989; Sharpe et al. 1986).

One of the problems inherent in studying human-affected ecosystems is how to assess urbanization. For this study, I have defined urbanization as the increasing density of both humans and their accompanying accouterments in cities. Urbanization is accompanied by increasing expanses of impermeable surfaces (e.g., roofs, driveways, roads, and parking lots) as land is cleared and developed. Land cleared of vegetation for development will be greatly altered. But what is the impact of humans upon land that is not cleared of native vegetation -- so-called "green spaces"? Effects of humans on these lands may be direct (e.g., feral cats preying on bird populations) or indirect (e.g., air pollution affecting plant growth rates). In most cases, both direct and indirect factors operate in conjunction with natural factors to produce the community observed at a site. Factors relating to urbanization interact with the ecological community in complex ways. Some factors are easily identified and measured: examples include percent of vegetation removal, the number of buildings, or the distance from structures such as the city, the nearest road, or the nearest building. Other factors are more difficult to ascertain and to quantify. These have been called "subtle factors" (McDonnell et al. 1993) and may play a major role in community structure in urban areas. In addition, the combined effects of many factors may be synergistic and not merely additive (Cole and Landres 1996).

The idea of using a quantifiable gradient such as moisture or elevation to investigate an ecological problem has been a cornerstone in ecological studies for years (Smith 
1996; Whittaker 1967; Wilson and Keddy 1986). A similar concept is now being applied in studies on the effects of humans on ecosystems by using various factors of urbanization as a gradient. Examples of quantifiable gradients include the distance from a city (Airola and Buchholz 1984; Pouyat et al. 1994; Pouyat et al. 1995b), the distance from a road (Foppen and Reijnen 1994; Matlack 1993b; Reijnen and Foppen 1994, 1995; Reijnen et al. 1995), and the relative human population density of the surrounding area (Blair 1996; Friesen et al. 1995; Kowarik 1990; Natuhara and Imai 1996; Pouyat et al. 1995b; Pysèk 1989; Pysèk and Pysèk 1990).

Such studies address questions of whether or not urbanization affects an ecosystem and frequently examine how one factor in particular is important. However, urbanization is accompanied by many factors that could impact the ecosystem. West of the Cascade Mountains, in the Pacific Northwest, the natural community that would be expected in most undisturbed areas is a coniferous ecosystem. Forest Park, in Portland, Oregon, provides an excellent area in which to investigate effects of urbanization on a forest adjacent to a city and along an urbanization gradient.

Some effects of urbanization on forests are readily apparent. For example, urbanization is frequently accompanied by increased habitat fragmentation and increases in the amount of "edge" habitat. Human presence is often accompanied by weedy, non-native species of plants and animals which tend to be aggressive competitors, frequently outcompeting native species. Introduced species often have no naturally occurring predators or parasites that could slow their growth and expansion. The result is often rapid overpopulation of exotic species at the expense of native flora and fauna (Bagnall 1979; Cole and Landres 1996; Greller et al. 1990; 
Harris 1984; Kowarik 1990; Liebhold et al. 1995; Moran 1984; Sukopp 1990). Examples of exotic species that are problematic in the Portland area include the rock dove (Columba livia Gmelin), house sparrow (Passer domesticus L.), European starling (Sturnus vulgaris L.), English ivy (Hedera helix L.), English holly (Ilex aquifolium L.), Scotch broom (Cytisus scoparius L.), and laurel (Prunus laurocerasus L). As an example, English ivy has become such a problem in forested areas in the Portland area that Portland Parks and Recreation has created a "No Ivy League" to remove ivy and to help educate the public about its impact. In addition to its inevitable negative impact on the native herbaceous plant community, ivy is also believed to have a negative impact on the trees upon which it grows. Fred Nilson (Portland Parks and Recreations, personal communication, March 1994) believes that trees that are covered with ivy are more susceptible to windthrow and that heavy ivy coverage may lead to tree death by covering the plant's apical meristems. As a result, the effects that such exotic species such as English ivy have upon the native plant community may have broader ramifications for the entire community structure of the forest as natural wildlife habitat is altered or lost.

As forested areas outside of Forest Park's jurisdiction are cleared and developed, the once continuous forested landscape of Portland's West Hills is becoming a patchwork of small forest fragments surrounded by cleared and developed (nonforest) landscape. Increased habitat fragmentation causes the abundance and diversity of native species to decrease as forested areas decrease in size (Askins and Philbrick 1987; Blair 1996; Dzwonko and Loster 1988, 1989; Friesen et al. 1995; Gavareski 1976; Harris 1984; Lehmkuhl and Ruggiero 1991; Lynch and Whigham 1984; McIntyre 1995; McLellan et al. 1986; Robinson et al. 1995; Rosenberg and 
Raphael 1986; Solinska-Gómicka and Symonides 1990; Terborgh 1989; Weaver and Kellman 1981; Wiens 1994; Wilcove 1985; Zacharias and Brandes 1990; Zipperer 1993).

Fragmentation has been shown to cause significant changes in both the abiotic and biotic conditions in forests due largely to increases in forest edge. Forest edge is subjected to higher diurnal fluctuations of light, wind intensity, and moisture than the forest interior (Chen et al. 1995; Matlack 1993a; Ranney et al. 1981). Plants in the edge habitat are subjected to environmental stresses such as decreased soil moisture, increased light, and increased temperature fluctuations that frequently result in decreased vigor and increased mortality rates (Chen et al. 1992; Chen et al. 1995; Ranney et al. 1981). Edge environments are frequently invaded by exotic species better adapted to the new environmental conditions than are the original native species (Chen et al. 1995; Kroodsma 1984; Moran 1984; Ranney et al. 1981; Rich et al. 1994; Zipperer 1993).

Although this so-called edge effect decreases with distance into the forest, it can extend for a considerable distance into the stand. Chen et al. (1995) demonstrated that the edge effects can extend over 500 meters into an old-growth Douglas-fir forest. Such effects produce a community that is different from the original forest interior community (Rosenberg and Raphael 1986; Temple and Wilcox 1986; Terborgh 1989). Edge effects commonly result in a loss of species that are adapted to the forest interior in favor of "edge species" that enter the area, many of which are common in earlier successional stages (e.g., red alder and song sparrows). The resultant ecotonal community may consequently show greater species diversity as 
more common and frequently weedy species of both plants and animals appear, often at the expense of more sensitive forest interior species (Askins 1994; Askins and Philbrick 1987; Donovan et al. 1995a; Friesen et al. 1995; Harris 1984; Lynch and Whigham 1984; McIntyre 1995; McLellan et al. 1986; Ranney et al. 1981; Robinson et al. 1995; Rosenberg and Raphael 1986; Temple 1986; Wilcove 1985). As the degree of fragmentation increases and the size of the resulting forest fragments becomes smaller, the fragments will cease to function as a normal forest ecosystem and will convert entirely to "edge" (Chen et al. 1992; Chen et al. 1995; Harris 1984; Hoover et al. 1995; Matlack 1993b; Matlack 1994; Ranney et al. 1981; Rosenberg and Raphael 1986; Wilcove 1985). The size and shape at which of the forest becomes essentially all edge is called the minimum critical area. Estimates of the minimum critical area for equilateral tracts range from 10 to 20 hectares (Aldrich and Coffin 1980; Lehmkuhl and Ruggiero 1991; Levenson 1981; Lovejoy and Oren 1981; Matlack 1994; McIntyre 1995; Peterken and Game 1984; Ranney et al. 1981) to 100 hectares or more (Brown and Robinson 1996; Chen et al. 1992; Chen et al. 1995; Dobkin and Wilcox 1986; Donovan et al. 1995a; Harris 1984; Hoover et al. 1995; Rosenberg and Raphael 1986; Wilcove 1985). Forest fragments with small forest to edge ratios, regardless of total area, have been reported to function as essentially edge systems (Blake 1983; Dzwonko and Loster 1989; Gotfryd and Hansell 1986; Harris 1984; Johnson et al. 1981; Ranney et al. 1981; Rosenberg and Raphael 1986; Temple 1986; Tilghman 1987; Whitcomb et al. 1981).

A key point is that, for the most part, humans disturb natural ecosystems. Disturbance is most often defined as "any relatively discrete event in time that disrupts ecosystem, community, or population structure and changes resources, 
substrate availability, or the physical environment" (White and Pickett 1985). Disturbance, both natural and human-caused, frequently causes communities to revert to earlier successional stages. The degree of setback often depends on both the intensity and frequency of disturbance. Highly disturbed ecosystems will typically be in earlier seral stages than will less disturbed (or undisturbed) ecosystems (Abrams and Nowacki 1992; Dale and Doyle 1987; Hong et al. 1995; Kowarik 1990; Leak and Smith 1996; Matlack 1993b; Petraitis et al. 1989, Swindel et al. 1986).

Variables of urbanization in Forest Park include air pollution, direct trampling or damage to plants, invasion by non-native plant species such as English ivy or English holly, direct disturbance of animals by humans or their pets or by animals that are typically associated with humans such as Norway rats (Rattus norvegicus), increased nest parasitism by brown-headed cowbirds (Molothrus ater Boddaert), increased predation rates by feral cats (Felis domesticus), feral dogs (Canis domesticus), or other natural predators such as coyotes (Canis latrans) and raccoons (Procyon lotor) whose populations react favorably to human presence, and increased traffic noise. Most of these factors are subtle and hard to quantify, but they can affect the structure of the community in important ways.

In addition to spatial gradients, urbanization produces temporal gradients. Many researchers have concentrated on the history of a site in an attempt to determine the reasons for the present community structure (Dale and Doyle 1987; Fain et al. 1994; Glitzenstein et al. 1990; Levenson 1981; McBride and Jacobs 1986; Peart et al. 1992; Peterken and Game 1984; Peterken and Jones 1989; Rudnicky and McDonnell 1989; Sharpe et al. 1986; White et al. 1990; Yost et al. 1991; Zipperer et al. 1990). 
Disturbance has been positively correlated with the length of human occupation. Europe has had permanent communities and agricultural homesteads for considerably longer than North America and has more disturbed ecosystems (Kowarik 1990; Martin and Clobert 1996; McLellan et al. 1986; Monkkonen and Welsh 1994). Some scientists think that Europe's slower rate of development (almost 5000 years) has allowed plants and animals to adapt to human disturbance (Monkkonen and Welsh 1994), but others question whether we are merely seeing a subset of the original spectrum of species -- those that could adapt to human disturbance (Martin and Clobert 1996; McLellan et al. 1986). Although the historical pattern may never be explained, it illustrates the importance of examining the history of a site, such as Forest Park, in response to the effects of urbanization.

The objectives of this study were to identify a selection of specific, quantifiable factors of urbanization, and to determine the effects those factors have on the plant and avian communities in Forest Park. I investigated the effects of urbanization on plant community structure, and on the breeding and winter resident avian communities. 


\section{CHAPTER 2}

STUDY AREA

Forest Park is located northwest of downtown Portland, Oregon (Figure 2-1) and covers an area of about 1980 hectares. It is approximately $11.3 \mathrm{~km}$ in length and ranges from 0.8 to $2.4 \mathrm{~km}$ wide, although the perimeter is very dissected and irregular (Sjulin, J., Portland Parks and Recreation, personal communication, January 1997). The area surrounding the park has various land uses including urban northwest Portland residential neighborhoods at the southern end, rural and suburban lands to the west and north, and urban residential and industrial areas to the east (Portland Parks and Recreation 1995). Forest Park is dissected by several roads. Some, such as Comell and Germantown Roads, are public roads that have moderate to heavy vehicular use. Others, such as Leif Erikson Drive and Saltzman Road, are presently only open to bicyclists, pedestrians, and vehicles operated by park personnel.

\section{GEOLOGY}

Forest Park is located on the east side of the Tualatin Mountains (also called the West Hills) and extends in a northwesterly direction along the Willamette River floodplain. Elevations within the park range from 20 meters near the base of the Tualatin Mountains to 335 meters above sea level at the crest of the Tualatin Mountains near Skyline Boulevard. The Tualatin Mountains are composed of lava flows of the Columbia River Basalt Group that may reach 30 meters or more in thickness (Green 1983). These lava flows are covered by thick deposits of fine textured loess called 

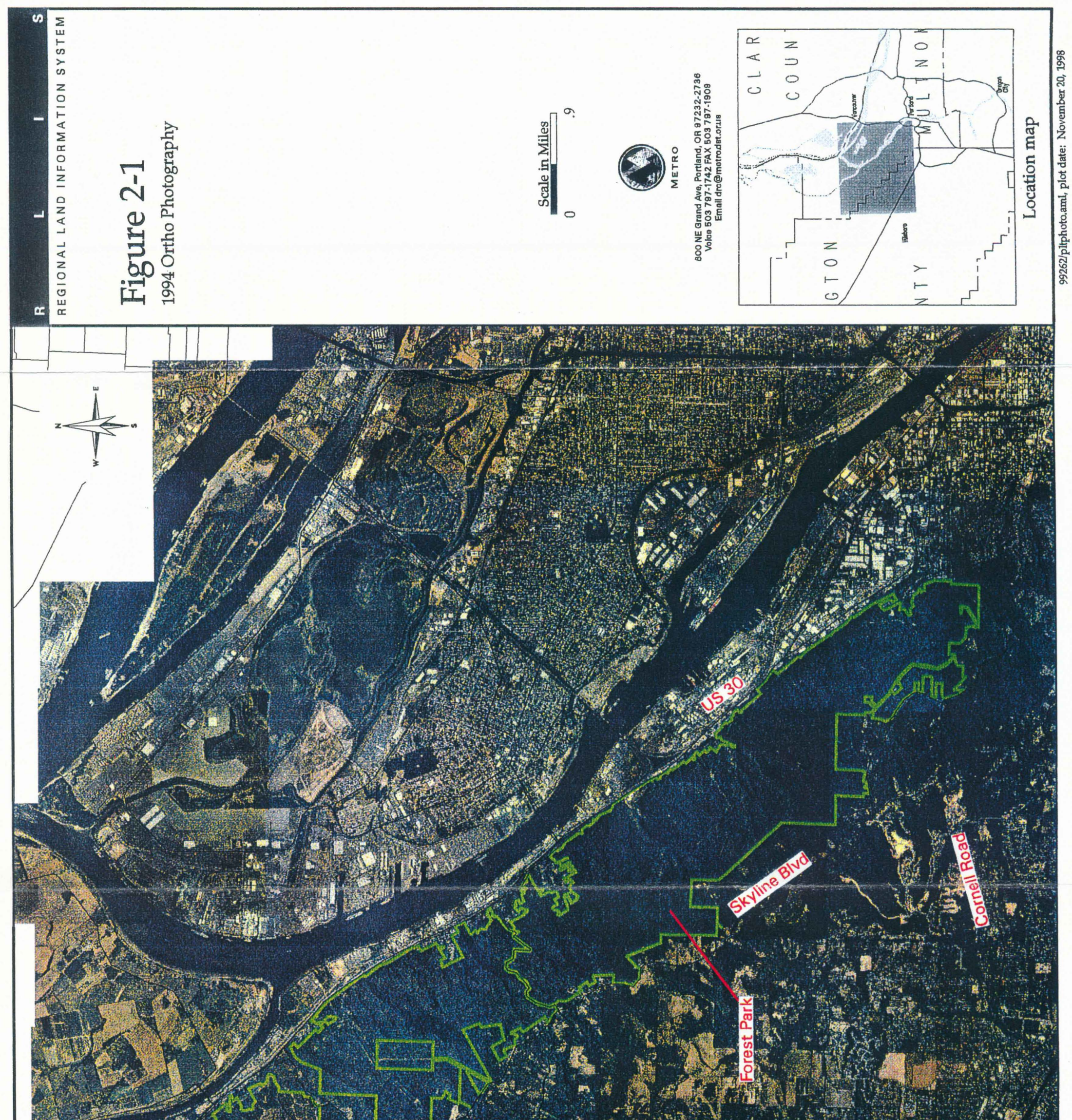

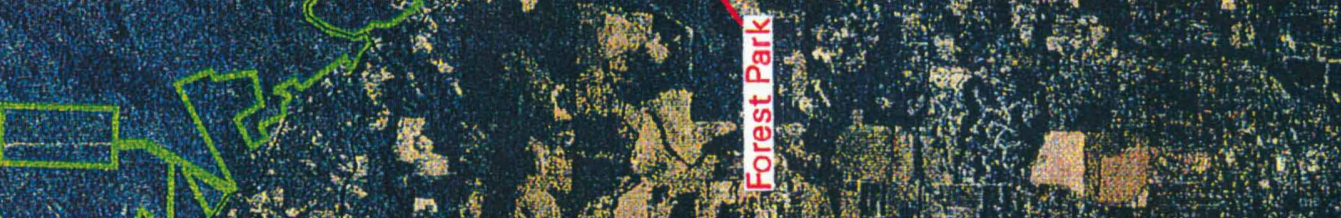

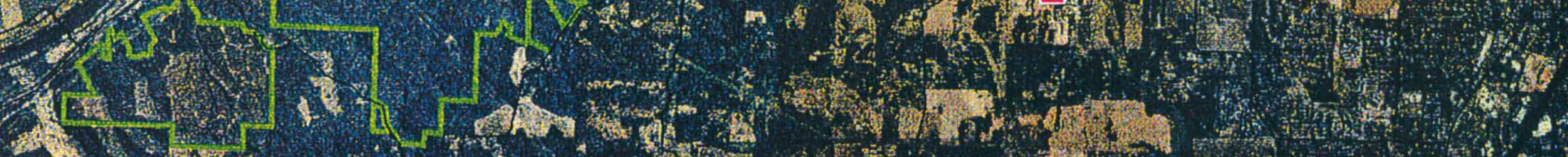

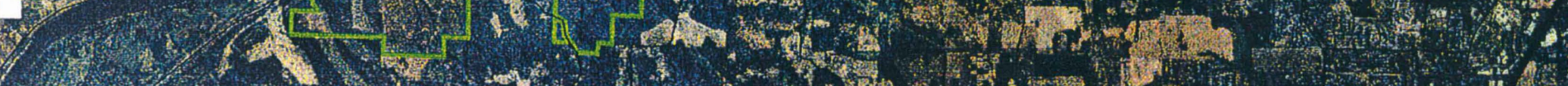

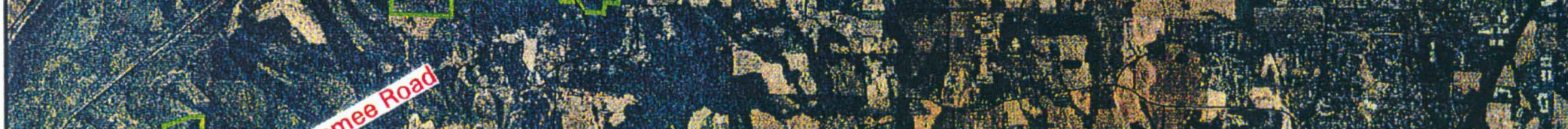

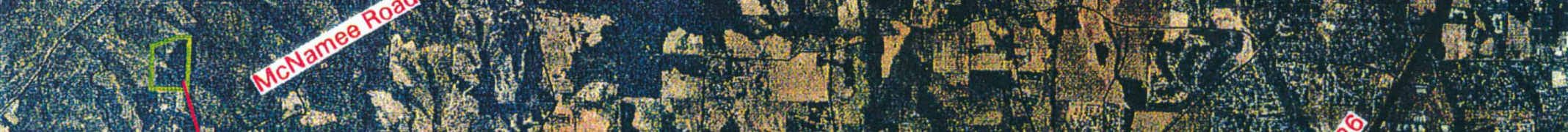

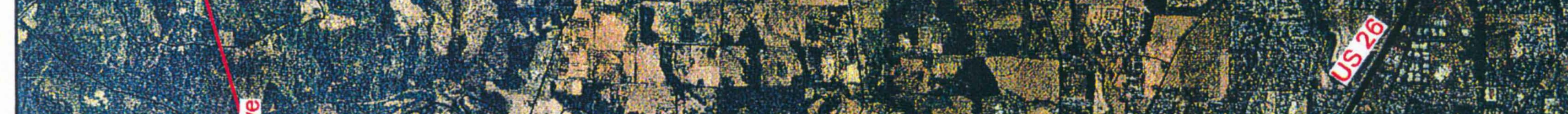

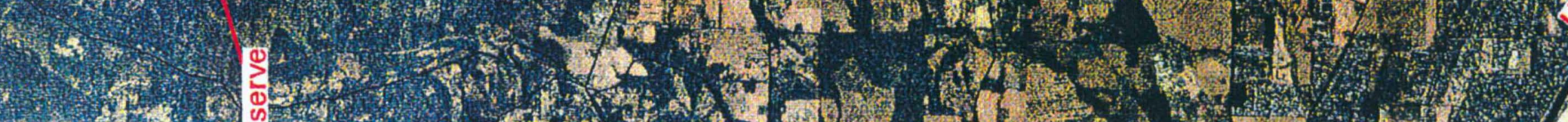

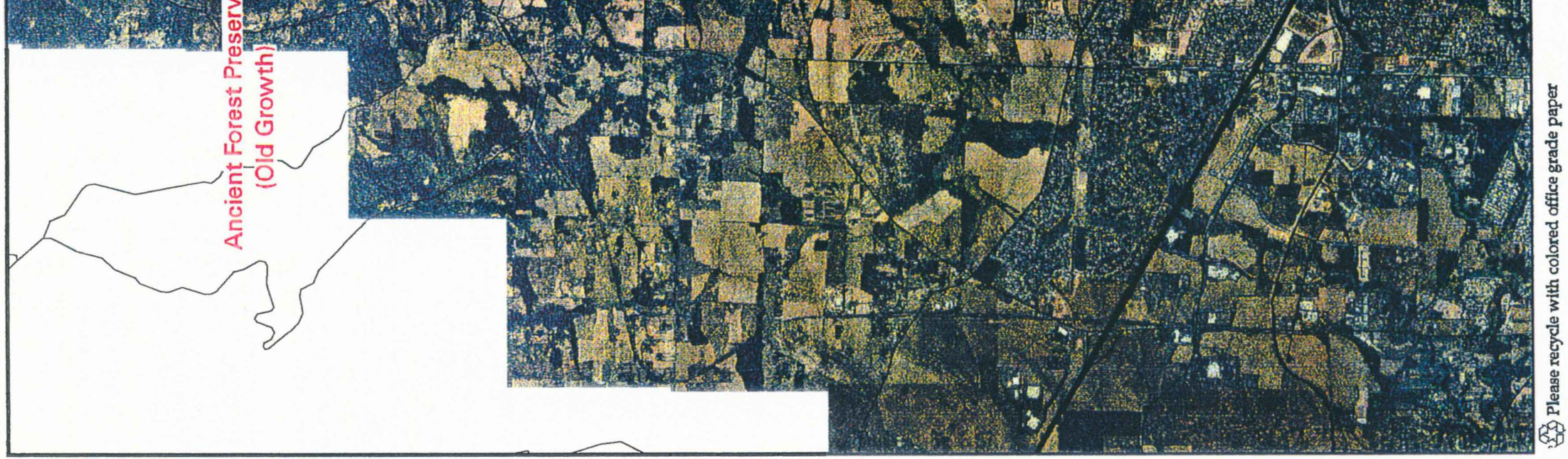


Portland Hills Silt that are believed to have originated as wind deposits during the last two million years with the last major pulse being after the Lake Missoula floods 15,300 to 12,700 years before present (Waitt 1985). The deposits range in thickness from a few feet along the lower edge of the Tualatin Mountains to over 30 meters near the crest (Green 1983; Portland Parks and Recreation 1995).

Forest Park has three dominant soil types: Cascade, Goble, and Wauld (Green, 1983). Cascade and Goble soils are often referred to as Portland Hills Silt and share many characteristics. Both soils have silt loam textures and an underlying fragipan (dense silt layer on the soil) that prevents water penetration. The fragipan varies in depth from $51-76 \mathrm{~cm}$ deep in Cascade soils to $76-114 \mathrm{~cm}$ deep in Goble soils. Wauld soils have a gravel loam texture and no fragipan. Erosion, slumping, and landslide hazards are high with the Cascade and Goble soils and slight to high with the Wauld type soil (Green 1983). Much of the park includes slopes that exceed 30 percent grade. When soil is saturated during wet winter months, severe landslide potential exists in many areas (Bureau of Planning 1992).

Forest Park is dissected by many streams that drain mostly northeast toward the Willamette River. Major watersheds in the park include Balch, Saltzman, Doane, and Miller Creeks (Bureau of Planning 1992).

\section{CLIMATE}

Western Oregon is characterized by a maritime climate with mild temperatures, prolonged cloudy periods, relatively cool dry summers, and wet mild winters with moderate to heavy precipitation (Green 1983). In Portland, temperatures range from 
an average January temperature of $4.9^{\circ} \mathrm{C}$ to an average July temperature of $19.8^{\circ} \mathrm{C}$. The minimum and maximum temperatures range from $-13.3^{\circ} \mathrm{C}$ in December to $41.1^{\circ} \mathrm{C}$ in August (Anonymous $1997 \mathrm{~b}$ ). The majority of precipitation falls between October 1 and March 31, mostly as rain. The average annual precipitation in Portland is 1045 millimeters (Anonymous 1997a). Snowfall occurs in the winter months, averaging 130 millimeters per year in Portland and increasing with elevation in the Tualatin Mountains. Severe storms are rare, although one or two ice storms commonly occur annually as the result of cold air flowing west through the Columbia River Gorge (Anonymous 1997a, 1997b; Franklin and Dyrness 1988). Storms with winds over $60 \mathrm{mph}$ are rare in the Portland area, although one occurs every five to ten years. The most damaging wind storm recorded was the October 12, 1962 "Columbus Day Storm." Since that time, five severe wind storms have occurred in the Portland area, with the most recent occurring during the tenure of this study. On December 12, 1995, winds in the Portland area gusted to over $60 \mathrm{mph}$. Because the strong winds followed a period of higher than normal rainfall, many windthrown trees resulted from water logged soils (Anon 1997c; Taylor 1995). The wind event was followed by one of the wettest winters on record. Winter rainfall levels were 141 percent of normal in Portland. The heavy rains were followed by a cold snap that resulted in large accumulations of snow in the mountains and icy conditions in the Portland area. Then, on February 6, 1996, a subtropical jet stream brought warm air and more record rainfall. The Portland Airport recorded a four day total of 177.8 millimeters of rain -- 50.8 millimeters above the previous record. The combination of weather caused rivers to rise rapidly, resulting in flooding (Taylor 1996). This storm complex resulted in frequent episodes of soil slumpage and landslides in Forest Park (Burns and Fiedorowicz 1997). 


\section{PLANT COMMUNTTY}

Forest Park lies in the western hemlock (Tsuga heterophylla Raf. Sarg.) vegetation zone (Franklin and Dyrness 1988). Although western hemlock and western red cedar (Thuja plicata Donn.) are considered the climax species for the area, most forests are dominated by Douglas-fir (Pseudotsuga menziesii Mirbel Franco) (Franklin and Dyrness 1988). Douglas-fir is capable of living on a site for over 500 years. As a result, old-growth forests often are dominated this species. In addition, Douglas-fir is a fire-adapted species that can survive fires that kill other tree species such as western hemlock and western red cedar (Agee 1991; Franklin and Dyrness 1988; Spies and Franklin 1991). In western Oregon, the return time for fire is estimated to have been 230 years before Europeans began a policy of fire suppression (Agee 1991).

Today, much forested land in western Oregon is covered with early successional (seral) stands that have followed clearing, logging, and/or fires. The composition and density of the seral forests depend on the type of disturbance, the available seed source, whether or not the stand was replanted, and environmental conditions. It is common to find dense stands of essentially even-aged Douglas-firs that result from extensive planting of the species after logging and/or fires. Douglas-fir is a shadeintolerant tree species, meaning that it cannot germinate and grow in the shade of the forest understory; hence, it cannot regenerate in its own presence if the canopy is continuous. Shade-tolerant tree species (e.g., western hemlock) can grow in the shade of larger trees and are more likely to survive in the understory. Western

hemlock, the climax species, often exists as an understory tree in these early 
successional forests, but it will not begin to dominate until tree mortality begins to open the stand, often 100 to 150 years into stand development (Franklin and Dymess 1988). In the Portland area, many sites are dominated by shade-intolerant deciduous tree species such as bigleaf maple (Acer macrophyllum Pursh) and red alder (Alnus rubra Bong) due to the effects of continual disturbance by logging and/or fire (Houle 1996). Douglas-fir may be present, but usually it is not dominant. Shade-tolerant conifers such as western hemlock, western red cedar, and Pacific yew (Taxus brevifolia Nuttall) occasionally occur but remain suppressed until mortality begins to open the sites at 50 to 100 years of age (Franklin and Dyrness 1988; Franklin and Pechanec 1967; Houle 1996; Newton et al. 1967).

True climax forests -- forests composed of and dominated by shade-tolerant climax tree species -- are rare in the Pacific Northwest's western hemlock zone due to the extremely long life span of Douglas-fir and the frequent occurrence of fire and other disturbance. Old-growth forests -- forests in later stages of development -- do occur, but most in the Portland area are dominated by Douglas-fir. During the last decade, forest scientists have attempted to define an old-growth forest. An exact definition is elusive and varies with locality (Franklin and Spies 1991a; Franklin and Spies 1991b; Norse 1990). Among the criteria for defining an old-growth forest are the presence of many trees over 100 centimeters in diameter (including shade-tolerant species), a large number of shade-tolerant trees, a large number of large snags (dead standing trees), and a large amount of downed woody debris (Franklin and Spies 1991a; Franklin and Spies 1991b; Norse 1990). Throughout the 1980's, the Forest Service routinely defined areas of only four hectares as sufficient to meet old-growth criteria. Today, researchers have stressed the need for a minimum area of at least 32 
hectares to overcome edge effects (Marcot et al. 1991, Norse 1990, Old-Growth Definition Task Group 1986). In the area surrounding Portland, no large expanses of old-growth forests remain, as most were logged shortly after the influx of European settlers. However, a few remnant stands of mature to old-growth forest can be found in areas such as Oxbow Park, the Ancient Forest Preserve, and Forest Park. All of these sites are dominated by large Douglas-firs, but large western hemlocks and western red cedars also are common. 


\section{CHAPTER 3}

\section{PAST INFLUENCES OF HUMANS ON FOREST PARK}

Humans are believed to have inhabited the Pacific Northwest for about 10,000 years. The native people used many of the resources in the forest, although it is believed that they did not modify the coniferous forests substantially (Portland Parks and Recreation 1995). There are some reports of native people setting fires, but it is believed that lightning was the major source of ignition of forest fires in the area (Agee 1991).

Records from the expedition of Lewis and Clark (1805-1806) described the hillsides that are currently the location of Forest Park as being composed of several species of fir that grew to very large heights and diameters. Journal entries also reported that the Portland area was inhabited by about 4,000 native people. The nearest village housed about 100 inhabitants and was located on the bluff across the Willamette River from Forest Park in the area occupied today by the University of Portland (DeVoto 1953).

In the mid-1800's, settlers constructed trails across the Tualatin Mountains to bring crops to the settlements of Linnton (established 1843), Springville (established 1843), and Portland (established 1845) from the Tualatin Valley. These trails included what later became Germantown, Springville, Cornell, and Newberry Roads. In the 1850 s, the government deeded much of the Tualatin Mountain land to settlers under the Donation Land Claims Act. The more level land was rapidly 
converted to agricultural and residential uses. The first subdivision, Mountain View Park, was recorded in 1882. By 1910, several housing subdivisions had been marketed. Most of these developments avoided steep slopes (Munger 1960).

In 1903, the Municipal Park Commission of Portland hired John Charles Olmsted and Frederick Law Olmsted to conduct a city planning study. The Olmsted brothers proposed a system of parks for the city of Portland that included the recommendation that the eastern slope of the Tualatin Mountains be preserved as a forested park. In 1912, E.H. Bennett, in the Greater Portland Plan, had reiterated the Olmsteds' earlier proposal. Both proposals were ignored by the city for many years (Munger 1960).

Hillside Drive, now called Leif Erikson Drive, was built in 1915. This road connected N.W. Thurman Street and Germantown Road. Several large subdivisions were platted along the drive. However, the steep terrain of the hillside made building and road construction and maintenance difficult. Many land owners refused to pay assessments for property they could not use. Slightly over 1000 hectares of the land was subsequently forfeited to the City of Portland or Multnomah County (Munger 1960).

The original forests were exploited early by the European settlers. The wood was used mostly for fuel for steamboats, mills, and homes, and for building materials. The forests closest to the river were exploited first and to the greatest extent. As the easily accessible forests were depleted, logging expanded upslope. In 1914, the city of Portland ran a wood-cutting camp that provided work for the unemployed and wood for the poor. In 1937, a second wood-cutting camp was operated between 
Springville and Saltzman roads west of Leif Erikson Drive (Munger 1960). In addition to the city sanctioned wood-cutting camps, widespread illegal cutting of trees occurred throughout the area (Keil, W., retired forester for Portland Parks and Recreation, personal communication, Dec. 1997). Most of the logging that was done in the park was by clearcutting. Today, many areas of the park still have large rotting stumps with springboard "notches" and skid roads as evidence of logging. Many logging operations were finished with slash burns that often resulted in forest fires (Munger 1960).

In 1944, the Portland City Club appointed a committee to study land use alternatives for the east slope of the Tualatin Mountains. This group, which ultimately became known as the Forest Park Committee of Fifty, strongly supported the creation of a large forested park for the "benefit of the community". In 1947, the committee recommended that the city dedicate over 2300 hectares to park purposes. The land that had been forfeited in the failed Hillside Drive subdivision ultimately became a major part of Forest Park. City and county lands within the proposed boundaries were withdrawn from sale, city land that was held by the Assessment Collection Division was transferred to the Park Bureau, and similar county land was declared park and deeded over to the city. Dedication ceremonies for Forest Park were held on September 25, 1948 (Munger 1960).

The two largest fires in Forest Park occurred in 1940 and 1951. In August 1940, the Bonny Slope fire consumed approximately 405 hectares (1000 acres) on both sides of the Tualatin Mountain ridge. The extent of the burn into Forest Park is uncertain. In August 1951, an even larger fire started near the St. Johns Bridge, ultimately 
burning over 480 hectares (1200 acres) (Keil, W., retired forester for Portland Parks and Recreation, personal communication, Dec. 1997; Munger 1960). The 1951 fire was extremely hot and devastated 260 hectares (640 acres) of land in the central portion of the park. It raised fire awareness, however, and the following years brought the construction of the fire lanes, water tanks, and lookout towers. Two areas of the park were salvage logged the year following the blaze (near firelanes 3 and 5). Grade school children helped replant the forest. Quality trees were scarce, however, and anything that could be purchased was planted including ponderosa pine (Pinus ponderosa Dougl) and Port Orford cedar (Chamaecyparis lawsoniana Parl) (Keil, W., retired forester for Portland Parks and Recreation, personal communication, Dec. 1997).

The U.S. Forest Service produced the first management plan for Forest Park in 1950. This report, "Management Recommendations for Portland City Forest Park", outlined procedures and recommendations for the park and included plans for recreational development such as campgrounds and trails, timber harvest, planting, and forest protection against fire and insect damage. Logging was seen as a means of providing revenue for the park. It was believed that the park was capable of sustained yield harvests. Several timber harvests, some illegal and some legal, took place in 1951 and 1952 (Munger 1960). According to William Keil (retired forester, Portland Parks and Recreation, personal communication, Dec. 1997), the only "legal" logging operation in the most northern section of the park (the section furthest from the city) between 1952 and 1956 occurred near firelane 13. During this same time, no logging occurred in the most southern section of the park (the section closest to the city) and only salvage logging was done in the central portion of the park. The 
last logging operation was a small salvage logging project in the Macleay and Holman areas of the park undertaken after the Columbus Day storm in 1962 (Keil, W., retired forester for Portland Parks and Recreation, personal communication, Dec. 1997; Sjulin, J., Portland Parks and Recreation, personal communication, Jan. 1997).

In November of 1976, a new "Management Plan for Forest Park" was adopted by the City of Portland. This plan stressed conservation and preservation of the "naturalness" of the park. Although the goal was an "undisturbed, natural forest", human disturbances were permitted such as the removal of trees to open scenic vistas, the salvage of damaged trees, clearing of rights of way, and removal and sale of forest products (Portland Parks and Recreation 1995).

In February 1995, the City of Portland adopted the "Forest Park Natural Resource Management Plan". This new plan outlined plans and goals for Forest Park's future. The plan was designed to accommodate recreational uses of the park while ensuring protection of the park's forest ecosystem. The goals of the plan include the following: to "establish and maintain a natural and stable ecosystem within the park and surrounding natural areas. It is vital that the flora, fauna and habitat elements remain as free as possible from disturbance related to human activity" (Portland Parks and Recreation 1995). 


\section{CHAPTER 4 \\ GENERAL METHODS AND ANALYSIS OF DATA}

I selected 24 study sites in Forest Park and adjacent forested areas that are managed with Forest Park by Portland Parks and Recreation. One additional study site was located in a stand of mature (called old-growth for the remainder of this study) Douglas-fir approximately 4 kilometers northwest of Forest Park, a short distance east of McNamee Road (Figure 2-1, page 11). This site was purchased by the Friends of Forest Park in 1993 but is being transferred to METRO, the regional government, for management. This forested area, called the Ancient Forest Preserve, is approximately 12 hectares. It is almost entirely surrounded by a clear cut that was replanted in 1991, although some land with second growth remains adjacent to the stand. Although this stand has some very large Douglas-firs, it is not technically classified as old-growth because there are too few very large trees, too few large snags, too few large downed logs, and, most important, the stand is too small (Franklin and Dymess 1988; Franklin and Spies 1991b; Spies 1991).

Each study site was randomly located. The procedure used was to stratify the park by dividing it approximately into thirds and randomly assigning eight sites to each third (Figure 4-1). Thereby, the sites were distributed along the perceived urbanrural land use gradient. The most southeasterly third of the park is closest to the city (i.e., the city section). The most northwesterly third is farthest from the city (i.e., the far section). A northeast to southwest urbanization gradient could be a factor in this study because Portland's Northwest industrial area lies adjacent to the northeast 

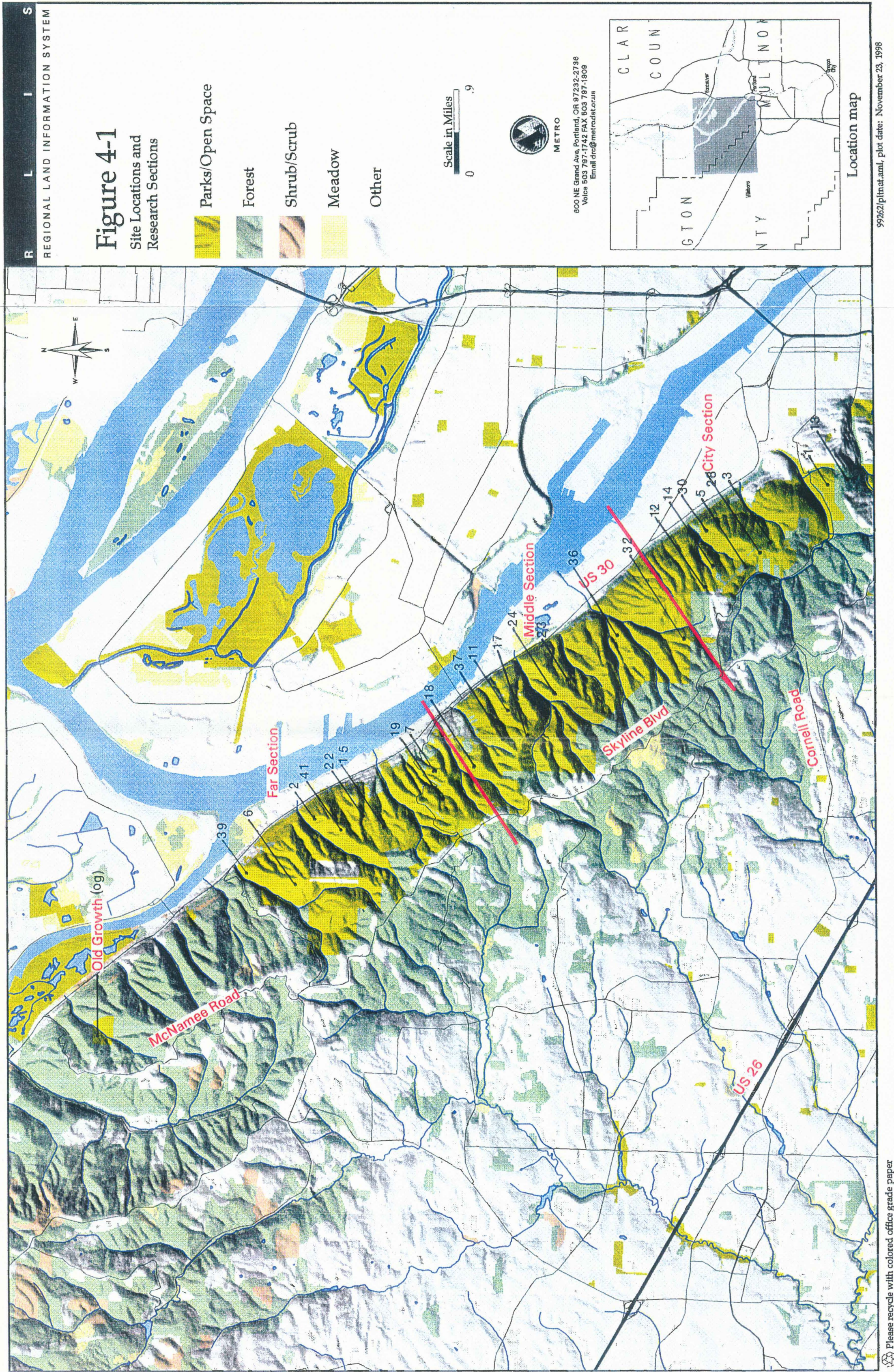
boundary of Forest Park for several kilometers. However, there were approximately the same number of sites on both the northeast (13 sites) and the southwest (11 sites) sides of the park so this alternative could be examined.

Three, 30 meter long transects were established at each study site. At most sites, transects were established in a parallel fashion 20 meters apart. However, sites 7 , 18,36 , and 60 were located along ridges. At these four sites, transects were laid end to end along the ridgeline to reduce variance of the sample. At each site, vegetative structure and avian species abundance and richness were measured.

All trees and saplings, living or dead, within a 500 square meter quadrat ( 8.3 meters on either side of the 30 meter transect) were measured and counted. I defined trees as plants that were greater than 3 meters tall with a dbh (diameter at breast height, 1.4 meters above the ground) greater than or equal to 10 centimeters. I defined saplings as plants that were between 0.5 meters and 3 meters in height or, if 3 meters or taller, had a dbh of less than 10 centimeters, but that were members of arboreal species. Tree diameter was measured with a diameter tape $( \pm 0.1$ centimeter $)$. Tree height and the height to the lowest living branch were measured using a rangefinder \pm 10 centimeters) for each tree or sapling and used to calculate the live crown ratio by dividing the length of the bole with living branches by the height of the tree. In addition, randomly selected trees and saplings within each quadrat were cored and the core used to estimate tree age and increment growth rate. All tree seedlings that were present on the transect were identified to species and counted. 
All shrubs within a 100 square meter quadrat (1.67 meters on each side of the transect) were measured and counted. I defined shrubs as woody species greater than one but rarely more than four meters in height. Some species, such as vine maple (Acer circinatum Pursh.) and English holly (Ilex aquifolium L.), that have the capacity to exceed the height limitation, were classified as shrubs due to their habit of sending up numerous small shoots and their relatively small size at maturity on my sites. The diameter of the stem at ground level was measured using a diameter tape for all shrubs. For shrubs that sent out numerous shoots, a measurement of the diameter of the entire clump was made. In addition, the height of each shrub was measured.

Herbaceous species were recorded as percent cover along each 30 meter transect. I defined herbaceous species as all non-woody species of any height, or woody species that rarely exceeded one meter in height at my sites (e.g., salal (Gaultheria shallon Pursh), Oregon grape (Berberis nervosa Pursh).

Researchers have used various measures to estimate the extent of urbanization. Measures that have been cited in the literature include the distance from a city (Airola and Buchholz 1984; Pouyat et al. 1994; Pouyat et al. 1995b), the distance from a road (Foppen and Reijnen 1994; Matlack 1993b; Reijnen and Foppen 1994; Reijnen et al. 1995), and the relative population density of the area surrounding the study site (Blair 1996; Friesen et al. 1995; Kotz 1990; Kowarik 1990; Pysèk 1989; Pysèk and Pysèk 1990). I thought that these variables were insufficient to fully investigate the impact of human activities on Forest Park. Therefore, additional variables were used that I deemed representative of the degree of forest fragmentation, edge effects, 
possible pollution effects, and the degree of human use of the park and surrounding landscape. From each site, I estimated the distance on U.S.G.S. 7.5 minute series topographic maps (Portiand Quadrangle, Linnton Quadrangle, and Sauvie Island Quadrangle) from the Multnomah County Courthouse, located at 1021 S.W. Fourth Avenue in Portland, Oregon, to each site as an indication of the distance from downtown Portland. I determined all other distances either from infrared aerial photographs taken in 1989 that were provided by the Portland State University Geography Department or from an orthophoto map ( 1 inch $=1200$ feet) created from 1994 data by METRO. On the 1994 map, I measured the distance from each site to the nearest edge of contiguous (unfragmented) forest, as well as the distance to any forest edge (including small openings) that was visible on the photos or orthophoto map. I also noted the usage category of that edge (e.g., residential, industrial, farm, road, etc.). I assessed the amount of edge habitat by measuring the distance from each site to the nearest public road and noting the degree of usage of that road, to the nearest building and its usage (e.g., industrial or residential), and to the nearest point of the Northwest industrial section of Portland bordering the park. Because Forest Park and the forested lands surrounding it vary in width, I measured the width of contiguous forest along the narrow axis of the park (northeast to southwest) relative to each site. I also measured the distance from each site to both the northeastern and southwestern edges of contiguous forest and used these measurements to calculate the percent of the distance that each site was from the center of the forested area. Because it is recognized that a minimum critical area is important in maintaining species diversity, land use in a 20 hectare and a 100 hectare circular area around each site was determined (e.g., rural, forest, residential, industrial). Most of these measurements were done as percentages, but I counted the number of buildings 
within a 100 hectare circular area to determine housing density. I also determined the amount of forest interior habitat for the three sections of Forest Park (i.e., the city, middle, and far sections) assuming that the edge effect can extend either 250 meters or 500 meters into the forest.

Disturbance has been shown to dramatically affect plant communities (Agee 1991; Dale and Doyle 1987; Fain et al. 1994; Glitzenstein et al. 1990; McBride and Jacobs 1986; Peart et al. 1992; Peterken and Game 1984; Rudnicky and McDonnell 1989; Sharpe et al. 1986; Solinska-Górnicka and Symonides 1990; White et al. 1990; Yost et al. 1991; Zipperer et al. 1990). I attempted to determine the last known date of logging or fire, and if possible, the size, severity, and frequency of such past disturbance at each site using aerial photographs, old maps, data provided by Portland Parks and Recreation, ages of tree cores, and interviews with individuals who were well acquainted with park history.

I attempted to determine the immediate and direct effects that humans inside the park may be having at each site. The number of humans on foot and on bicycle, and the number of dogs that passed each site within a ten minute period were counted. Each count lasted ten minutes and was done simultaneously with the bird counts. Fourteen human usage counts were conducted at each site over a four year period (1993-1996). I also counted the number of aircraft that passed overhead in the same ten minute period. The background noise level at each site over the same ten minute period was judged subjectively using a scale of zero to ten. A zero was recorded when no human-associated noise was detected in the background. A ten was recorded when the background noise was so loud and continuous that only the 
loudest natural sounds could be heard. Human-associated noise included automobiles, trucks, sirens, whistles, voices, barking dogs, and industrial noise, but did not include aircraft as they were recorded separately. An estimate of total human effects was calculated by summing the numbers of human usage (determined by the number of humans and dogs), overhead noise (the number of aircraft), and background noise (the level of background sounds).

In total, I measured 29 different variables related to urbanization. Twenty-five of these were continuous. I used multiple regression to test for relationships between urbanization variables (i.e., independent variables) and measurements of vegetative or avian community structure (i.e., dependent variables). Multiple regression tests for the importance of several different factors simultaneously (Abacus Concepts 1992; Draper and Smith 1966; Johnson and Wichern 1982; Jongman et al. 1995; Sokal and Rohlf 1969; Steel and Torrie 1960). It is unlikely that a single variable of urbanization is uniquely important. In most cases, different variables of urbanization jointly affect one another to produce the observed results (Draper and Smith 1966; Johnson and Wichern 1982; Pimentel 1979). Before multiple regression analysis could be used, it was necessary to determine which of the urbanization variables were both important and independent of one another (Abacus Concepts 1992; Draper and Smith 1966; Johnson and Wichern 1982; Jongman et al. 1995; Morrison 1976; Pimentel 1979; Steel and Torrie 1960). Using a correlation matrix, I reduced the number of useful variables of urbanization to seven by selecting variables that had less than 60 percent collinearity. I also selected variables that I felt best measured different components of urbanization. Of the seven variables selected to be used in this study, the distance from the nearest forest edge and the percent of surrounding 
forest were the two most highly correlated with a correlation coefficient of 0.57 (see Table 4-1 for correlation matrix). This level of collinearity is acceptable in the regression model used (Abacus Concepts 1992). The seven urbanization variables that were chosen functioned as the independent variables in all multiple regression analyses used throughout the study.

The seven independent variables of urbanization used in all the multiple regression analyses (and their abbreviations used throughout the paper) were: the distance from the Multnomah County Courthouse (PDX), the distance from the nearest road (ROAD), the distance from the nearest section of the Northwest industrial area (NWT), the distance from the nearest forest edge of any type that was large enough to be observed on the aerial photographs (approximately $3 \mathrm{~m}$ ) (EDGE), the number of houses in the surrounding 100 hectares (HOUSE), the percentage of forest in the surrounding 100 hectares (FOREST), and the proportionate distance from the center of contiguous forest to the forest edge (CENTER). Each variable represents some degree of influence by humans and helps define a gradient of urbanization. A higher degree of human influence at a site could be expected to be positively correlated with the proximity to Portland, the nearest road, the Northwest industrial section, the nearest forest edge, and the number of surrounding houses; and inversely correlated with the percent of surrounding forest and the distance from the center of the forest.

To meet the assumptions of normality, some of the independent variables were transformed so that they exhibited a normal distribution when graphed (Table 4-2) (Draper and Smith 1966; Jongman et al. 1995; Sokal and Rohlf 1969; Steel and Torrie 1960; Tabachnick and Fidell 1996). These transformations were used 
Table 4-1. Correlation matrix for the seven urbanization variables. PDX is the distance from downtown Portland; ROAD is the distance from the nearest road; NWI is the distance from the nearest section of the Northwest industrial area; EDGE is the distance from the nearest forest edge of any kind that is evident on aerial photos; FOREST is the percent of forest in the 100 hectare circular area surrounding the site; CENTER is the percent of the distance from the center of the park to the edge of contiguous forest; and HOUSE is the number of houses in the 100 hectare circular area surrounding the site.

$\begin{array}{lcccccc} & \text { ROAD } & \text { NWI } & \text { EDGE } & \text { FOR100 } & \text { CENTER } & \text { HOUSE } \\ \text { PDX } & 0.385 & 0.473 & 0.108 & -0.172 & -0.219 & -0.427 \\ \text { ROAD } & - & -0.028 & 0.345 & 0.524 & -0.428 & -0.498 \\ \text { NWI } & - & - & -0.111 & -0.439 & -0.346 & 0.008 \\ \text { EDGE } & - & - & - & 0.566 & -0.111 & -0234 \\ \text { FOR100 } & - & - & - & - & -0.385 & -0.532 \\ \text { CENTER } & - & - & - & - & - & 0.105\end{array}$


Table 4-2. The seven independent variables, their abbreviations as utilized throughout the paper, and the transformations done to meet assumptions of normality. These transformations were used in all statistical analyses.

Urbanization Variable (Abbreviation)

Distance from downtown Portland (PDX)

Distance from the nearest road (ROAD)

Distance from the Northwest industrial area (NWI)

Distance from the nearest forest edge (EDGE)

Percent of forest in the surrounding 100ha (FOREST)

Percent of distance from center of forest (CENTER)

Number of houses in surrounding 100ha (HOUSE)
Transformation

none

none

square root $(\mathrm{NWI})$

square root (EDGE)

$\arcsin ($ FOREST)

square root (CENTER)

In (HOUSE + 1) 
consistently in all data analyses. Dependent variables that were not normally distributed were also transformed (Draper and Smith 1966; Jongman et al. 1995; Sokal and Rohlf 1969; Steel and Torrie 1960; Tabachnick and Fidell 1996). The various transformations are reported in the results as they are presented throughout the paper. Species or categories that were detected too infrequently or were absent from too many sites were considered rare and were omitted from statistical analyses. The exact method of determining rare species varied between different types of data and will be reported for each.

In addition, an eighth independent variable was added. This was a covariable that was highly correlated (correlation coefficient of 0.83 ) with the old-growth stand. This variable coded all sites as being either in the old-growth stand or in Forest Park and is abbreviated as OG throughout the paper. The addition of this covariable to all multiple regression analyses allowed me to determine whether or not significant findings were due to the urbanization variables or were the result of the old-growth stand being very different from the other sites. The addition of this variable also allowed the old-growth stand to be used as a control against which Forest Park could be compared (Perrin, N., Professor of Psychology, Portland State University, personal communication, Nov. 1998).

The results of each significant regression are presented in tabular form by the degree of significance, whether the correlation was negative or positive, the squared multiple regression coefficient $\left(R^{2}\right)$, and the $p$-value for the regression. The $R^{2}$ value represents the proportion of the dependent variable's variability that is explained by the independent variables. The $\mathrm{p}$-value is the probability that $\mathrm{R}^{2}$ is significantly 
greater than zero as determined by t-test. All statistically significant $(p<0.05)$ dependent variables that had $R^{2}$ values greater than or equal to 0.25 were considered important and are presented in the tables. All statistical tests were conducted using Statview, version 4.5 (Abacus Concepts 1992).

All dependent variables that were significant by multiple regression were analyzed further by analysis of variance (ANOVA) using section of the park as a nominal variable (Steel and Torrie 1960). This variable divided the park into three sections relative to the distance from downtown Portland (city end, middle section, and far end) with a fourth category for the old-growth stand. These divisions were in accord with the manner in which I initially selected sites (figure 4-1). Bonferroni/Dunn values were used to determine significance among the categorical variables in each ANOVA. This particular test was used due to its strict method of discriminating among variables (i.e., it is a very conservative test) and because I did not have equal numbers of samples in each group (Abacus Concepts 1992; Johnson and Wichern 1982; Morrison 1976). All determinations of significance are reported at the 95 percent confidence interval. 


\section{CHAPTER 5}

\section{THE EFFECTS OF HUMAN DISTURBANCE AND URBANIZATION UPON THE STRUCTURE OF THE PLANT COMMUNITY}

Many scientists have examined how land use history affects plant community structure in forests (Abrams and Nowacki 1992; Agee 1991; Dale and Doyle 1987; Fain et al., 1994; Fralish et al., 1991; Glitzenstein et al. 1990; Greller et al. 1990; Gutte 1990; Kowarik 1990; Levenson 1981; McBride and Jacobs 1986; Nowacki and Abrams 1992; Palik and Pregitzer 1992; Peart et al. 1992; Peterken and Game 1984; Peterken and Jones 1989; Rudnicky and McDonnell 1989; Sharp et al. 1986; Sukopp 1972; Weaver and Kellman 1981; White et al. 1990; Whitney 1986; Yost et al. 1991; Zipperer et al. 1990). Some investigators found that forests resulting from clearcuts or burns appear to be very similar to pre-disturbance forests (Glitzenstein et al. 1990; Leak and Smith 1996; Weaver and Kellman 1981; White et al. 1990), whereas others have reported that present day regrown mature forests represent very different communities from pre-settlement forests (Abrams and Nowacki 1992; Dzwonko and Loster 1989; Fralish et al. 1991; Greller et al. 1990; Nowacki and Abrams 1992; Palik and Pregitzer 1992; Peterken and Game 1984; Rudnicky and McDonnell 1989; Sachse et al. 1990; Seidling 1990; Yost et al. 1991). Both fire management (Abrams and Nowacki 1992; Fralish et al. 1991; Nowacki and Abrams 1992; Palik and Pregitzer 1992) and the introduction of exotic species (Greller et al. 1990; Sachse et al. 1990; Seidling 1990; Yost et al. 1991) have been implicated as reasons for differences in forest structure. Other causes proposed include the effects 
of trampling, predation, and pollution (Kubikova 1990; Rudnicky and McDonnell 1989).

As urbanization increases, frequently accompanied by increased fragmentation of the existing forest, the number of native species decreases, whereas the number of exotic species increases (Bagnall 1979; Becher and Brandes 1985; Greller et al. 1990; Johnson et al. 1981; Kowarik 1990; Levenson 1981; Moran 1984; Seidling 1990; Sukopp 1990; Yost et al. 1991; Zacharias and Brandes 1990; Zipperer et al. 1990). Ecosystems that have been subjected to frequent and/or severe disturbances have been reported to exhibit reduced species diversity (Airola and Buchholz 1984; Davis and Glick 1978; Dzwonko and Loster 1988; Hoehne 1981; Rao et al. 1990; Sharp et al. 1986; Solinska-Gornicka and Symonides 1990; Swindel et al. 1986). However, moderate levels of human disturbance may cause reductions (Airola and Buchholz 1984; Bagnall 1979; Davis and Glick 1978; Dzwonko and Loster 1988; Fugate 1994; Greller et al. 1990; Iida and Nakashizuka 1995; Kotz 1990; Pysèk and Pysèk 1990; Rao et al. 1990; Seidling 1990; Solinska-Górnicka and Symonides 1990) or increases in the species diversity of vascular plants (Dzwonko and Loster 1988, 1989; McBride and Jacobs 1986; Moran 1984). These seemingly contradictory reports may be explained by the "intermediate disturbance hypothesis". According to this hypothesis, moderate levels of disturbance frequently lead to increased species diversity due to increased heterogeneity of disturbed habitat versus nondisturbed habitat (Connell 1978; Huston 1979; Petraitis et al. 1989). However, as disturbance increases and the habitat becomes more homogenous, diversity begins to decrease again. This hypothesis has been supported by a number of investigators who have 
reported that plant species diversity initially increased and then decreased as disturbance intensified (Armesto and Pickett 1985; Hoehne 1981; Kowarik 1990).

In my research, causes of changes in species diversity may be complicated because Forest Park may function ecologically as a peninsula rather than an island. Many workers have observed that species diversity decreases toward the tip of a peninsula (Gilpin 1981; Milne and Forman 1986; Simpson 1964). However, in some studies, diversity of certain reptilian or mammalian groups did not seem to fit this model and were better explained by environmental gradients (Busack and Hedges 1984; Lawlor 1983; Seib 1980). Milne and Forman (1986) determined that plants along peninsulas in Maine supported the general hypothesis, but they determined that this finding was more closely related tc environmental heterogeneity than to any peninsular effect.

Not only does the number of species change, but scientists investigating the effects of urbanization on plant community structure have also reported wide varieties of changes in stand characteristics. The relative importance values (i.e., the relative contributions of species to the entire community calculated by summing the relative density, the relative frequency, and/or the relative coverage or basal area of trees (Brower et al. 1990)) of tree species have changed in the New York City Botanic Garden Forest over the past 48 years. Acer, Betula, and Prunus have gained strong footholds in the forest at the expense of two previously dominant trees -- Quercus and Tsuga. (Rudnicky and McDonnell 1989). Similar changes have also been observed in other urban woodland areas (Airola and Buchholz 1982; Yost et al. 1991; Zipperer and Zipperer 1992). Airola and Buchholz (1982) reported that tree 
species associated with human settlement have become more important than "normal" forest tree species as disturbance has increased.

The density of trees has been observed to decrease in forests in many urban areas (Airola and Buchholz 1982; McBride and Jacobs 1986; Rudnicky and McDonnell 1989), although the opposite has also been reported (Zipperer and Zipperer 1992). Rudnicky and McDonnell (1989) found that stem density was higher in the New York City Botanic Garden Forest than it had been 50 years earlier, although it was lower than that found in similar rural forests.

Scientists have also reported that the basal area and/or diameter at breast height (dbh) of trees is reduced in urban or disturbed forests (Airola and Buchholz 1984; James et al. 1979; and Rudnicky and McDonnell 1989). Rudnicky and McDonnell (1989) found that mortality of dominant tree species exceeded replacement in New York City. The overall effect of disturbance has been for forests to become denser, with smaller diameter trees representing earlier stages in succession. Causes that have been proposed by the researchers for the observed changes include trampling, fires, raking, predation, disease, and pollution (Airola and Buchholz 1984; James et al. 1979; Rudnicky and McDonnell 1989).

Besides altering characteristics of the tree community, disturbance also affects other aspects of the plant community. For example, the number of shrub species (richness) decreased (Dzwonko and Loster 1988; James et al. 1979; Levenson 1981; Rao et al. 1990), although shrub cover increased (Dzwonko and Loster 1988; Matlack 1994; Seidling 1990). Dzwonko and Loster (1988) found that altered 
distribution of shrubs was not related to the size of the woodland, but rather was correlated with increased anthropogenic pressures. Matlack (1994) reported that the increased density of shrubs in edge environments was caused by enhanced growth of previously existing shoots rather than an influx of new plants. James et al. (1979) observed that certain indigenous species of shrubs were very susceptible to anthropogenic pressures and that native shrubs decreased in frequency, often with a concomitant increase in exotic species. The increase in exotic species has been observed repeatedly (Beissinger and Osborne 1984; Cole and Landres 1996; Dzwonko and Loster 1988; Levenson 1981; Mills et al. 1989; 1991; Yost et al. 1991).

Disturbance has been reported to affect the herbaceous plant community as well. Native herbaceous species richness was higher in undisturbed areas than in disturbed areas (Bagnall 1979; Cole 1995; Cole and Landres 1996; Dzwonko and Loster 1988, 1990; Greller et al. 1990; Hoehne 1981; Kowarik 1990; Kubikova 1990; Seidling 1990; Yost et al. 1991). Areas subjected to large amounts of disturbance exhibited a loss of herbaceous cover (James et al. 1979), but increased disturbance also altered species composition of herbaceous vegetation, frequently resulting in a transition to more acidophilous plants (Greller et al. 1990) and/or to more non-native species (Bagnall 1979; Cole and Landres 1996; Greller et al. 1990; Hoehne 1981; James et al. 1979; Kowarik 1990; Mills et al. 1989, 1991; Seidling 1990; Yost et al. 1991). James et al. (1979) reported that herbaceous, dicotyledonous species of plants appeared to be more sensitive to anthropogenic disturbances than did woody species. 
This overview reveals that plant communities change along disturbance gradients as well as urbanization gradients. In many cases, urbanization is believed to cause, directly or indirectly, the observed effects, but this hypothesis remains largely unproved. In this study, I attempt to elucidate changes in a plant community in the Pacific Northwest and correlate those changes with increased urbanization. The study was not designed to investigate specific causes of change, only to determine what changes had occurred.

\section{METHODS FOR MEASURING THE PLANT COMMUNITY}

The density and total diameter of all tree, sapling, and shrub species were calculated based on measurements made at each transect. These data were used to calculate the importance value for each tree and shrub species. Abundance data were used to determine the species diversity index using the Shannon-Wiener formula $\left(\mathrm{H}^{\prime}=\right.$ $-\sum \mathrm{p}_{\mathrm{i}} \log _{\mathrm{e}} \mathrm{p}_{\mathrm{i}}$, where $\mathrm{p}_{\mathrm{i}}$ is the proportion of the "ith" species to all species present) (Brower et al. 1990). The percent of coniferous versus deciduous trees was also calculated for each quadrat, as was the total number of introduced tree species (e.g., mountain ash (Sorbus aucuparia L.), hawthorn (Crataegeus monogyna Jacq.)), and Port Orford cedar (Chamaecyparis lawsoniana Parl)) and the number of non-native shrub species (e.g., English holly, Himalayan blackberry (Rubus discolor Weihe and Nees), and laurel) as determined using Hitchcock and Cronquist (1974). I also calculated the abundance, density, diameter, and diversity for both shade-tolerant tree species (e.g., western hemlock, western red cedar, and Pacific yew), and shadeintolerant tree species (e.g., bigleaf maple, red alder, and Douglas-fir) (Franklin and Dyrness 1988). 
The percent cover for all tree and shrub species was measured along each transect by recording the presence and composition of overhead vegetation as the transect was traversed. Areas with no overhead vegetation were classified as sky.

The foliage height diversity (FHD) was determined at each transect in a manner similar to the procedure of MacArthur and MacArthur. The species present at each of eight different heights (ground level, $0.5,2,3,5,10,20$, and 50 meters) at five locations along each transect were recorded. The foliage height diversity was calculated as a Shannon-Wiener type of diversity index, $\mathrm{H}^{\prime}$ (MacArthur and MacArthur 1961).

The abundance of herbaceous plants along the transect was determined using the percent cover for each species on the transect. Plants covering less than five centimeters in any meter segment were recorded but not included in statistical analyses. Likewise, plants present at the site, but not on the transect or in the quadrat were recorded but not included in statistical analyses. Total cover and the ShannonWiener diversity index were calculated for herbaceous plants using the percent cover measurements (Brower et al. 1990). The number of species and the percent cover of non-native herbaceous plant species such as English ivy (Hedera helix L.), herb Robert (Geranium robertianum L.), lemon balm (Melissa officinalis L.), nipplewort (Lapsana communis L.), reed canarygrass (Phalaris arundinacea L.), vetch (Vicia hirsuta L.), wall lettuce (Lactuca muralis L.), and common groundsel (Senecio vulgaris L.) were determined for each transect (Hitchcock and Cronquist 1974). The number and percent cover of herbaceous species associated with old-growth and mature forests (e.g., vanilla leaf (Achlys triphylla Smith D.C.), Anemone deltoidea 
Hook, sandwort (Arenaria macrophylla Hook), coral root orchid (Corallorhiza sp. Chat), and foam flower (Tiarella trifoliata L) (Spies 1991)) were also used as dependent variables in statistical analyses.

\section{RESULTS}

\section{Data Analysis}

All dependent variables were analyzed using multiple regression and ANOVA as described in Chapter 4. I examined plant community variables relating to tree species density, richness, and diversity; tree diameter; tree importance; shrub species density, richness, and diversity; shrub height and basal area; herbaceous plant cover, richness, and diversity; and foliage height diversity (FHD). The results are reported in the following sections. Scientific and common names of all tree species present at sites in this study are reported in Appendix A; scientific and common names of all shrubs are reported in Appendix B; and scientific and common names of all herbaceous species are reported in Appendix C. Regression coefficients for plant variables are reported in Appendix D.

\section{Human Usage Gradients and Variables}

Each of the seven urbanization variables was examined using ANOVA and Bonferroni/Dunn to determine if there were significant differences among the different sections of the park. Each section was significantly different in terms of distance from downtown Portland (PDX) (Table 5-1). The distance from the nearest road (ROAD) was significantly lower for sites in the city section and the percent of surrounding forest (FOREST) was significantly lower in the old-growth stand. The 
Table 5-1. Mean values (standard deviation) of each of the urbanization variables per site for the different sections.

\begin{tabular}{lcccc} 
Urbanization variable & \multicolumn{1}{c}{ City } & Mid & Far & $O G$ \\
\cline { 2 - 5 } PDX & $2.8(0.6)^{\mathrm{a}}$ & $5.6(0.7)^{\mathrm{b}}$ & $8.2(0.8)^{\mathrm{c}}$ & $12.6(-)^{\mathrm{d}}$ \\
ROAD & $0.2(0.1)^{\mathrm{a}}$ & $0.5(0.1)^{\mathrm{b}}$ & $0.4(0.2)^{\mathrm{b}}$ & $0.3(-)^{\mathrm{ab}}$ \\
NWI & $0.6(0.2)^{\mathrm{a}}$ & $0.6(0.2)^{\mathrm{a}}$ & $0.6(0.2)^{\mathrm{a}}$ & $2.9(-)^{\mathrm{b}}$ \\
EDGE & $0.11(0.07)$ & $0.13(0.09)$ & $0.18(0.12)$ & $0.04(-)$ \\
FOREST & $0.8(0.1)^{\mathrm{a}}$ & $0.9(0.1)^{\mathrm{b}}$ & $0.9(0.2)^{\mathrm{b}}$ & $0.5(-)^{\mathrm{c}}$ \\
HOUSE & $51.3(63.8)^{\mathrm{a}}$ & $0.8(0.8)^{\mathrm{b}}$ & $12.5(19.5)^{\mathrm{b}}$ & $3.0(-)^{\mathrm{b}}$ \\
CENTER & $0.4(0.2)$ & $0.3(0.1)$ & $0.3(0.2))$ & $0.1(-)$ \\
& & & & 3 \\
$\mathrm{n}$ & 24 & 24 & 24 &
\end{tabular}

Results of Bonnferoni/Dunn testing is shown for each variable as superscripts for means that are significantly different from one another. For a given variable, means with different superscripts are significanty different from one another (e.g., for any given dependent variable, all means with a superscript of a are significantly different from those with a superscript of b). Significance was determined after the variables were transformed in the same manner as used in multiple regression testing (see Table 4-2) . 
distance from the Northwest industrial area was greatest for the old growth. There were significantly more houses in the city section of the park, however, there were no significant differences among sections for either distance from the nearest forest edge (EDGE) or distance from the center of the forest (CENTER).

I also analyzed the human usage variables using ANOVA and Bonferroni/Dunn. There was significantly higher human usage at sites in the city section as determined by the number of hikers and joggers, the number of dogs, and total human usage (Table 5-2).

\section{Multiple Regression Analysis of Plant Community Variables}

Several variables pertaining to trees correlated significantly with some of the urbanization variables as determined by multiple regression. Many tree variables, especially those related to coniferous or shade-tolerant species, as well as tree species diversity, correlated positively with the distance from downtown Portland (Table 53). Most of these same variables were also positively correlated with the number of surrounding houses and were negatively correlated with the distance from the nearest forest edge.

The total diameters (total $\mathrm{dbh}$ in $\mathrm{cm}$ ), the average diameters, and the importance values for some tree species were found to be significantly correlated with urbanization variables by multiple regression (Tables 5-4 and 5-5). Again, many variables that measured coniferous and/or shade-tolerant trees correlated positively with the distance from downtown Portland. The average diameters of both Douglasfir and cascara were correlated with several urbanization variables. Likewise, the 
Table 5-2. Human usage in the different study sections as measured by the mean number of hikers and joggers, the mean number of bicycles, the mean number of dogs, total human site usaget, the mean number of aircraft, and the mean background noise level per site (standard deviation) for the summer months.

\section{Human Usage Variable}

\author{
\# hikers, joggers $x$ \\ \# bicycles \\ \# dogs \\ \# aircraft \\ Total human site usage ${ }^{x \dagger}$ \\ Background noise
}

\begin{tabular}{llll} 
City & \multicolumn{1}{c}{ Mid } & \multicolumn{1}{c}{ Far } & OG \\
\hline $2.1(4.0)^{\mathrm{a}}$ & $0.4(1.5)^{\mathrm{b}}$ & $0.1(.5)^{\mathrm{b}}$ & $0.0(-)^{\mathrm{b}}$ \\
$0.2(0.8)$ & $0.0(0.2)$ & $0.0(0.2)$ & $0.0(-)$ \\
$0.7(1.3)^{\mathrm{a}}$ & $0.1(0.3)^{\mathrm{b}}$ & $0.1(0.3)^{\mathrm{b}}$ & $0.0(-)^{\mathrm{b}}$ \\
$6.5(2.5)^{\mathrm{a}}$ & $6.3(2.6)^{\mathrm{ab}}$ & $6.8(2.9)^{\mathrm{a}}$ & $4.5(1.7)^{\mathrm{b}}$ \\
$2.8(4.9)^{\mathrm{a}}$ & $0.5(1.5)^{\mathrm{b}}$ & $0.2(0.7)^{\mathrm{b}}$ & $0.0(-)^{\mathrm{b}}$ \\
$6.2(2.1)^{\mathrm{a}}$ & $4.7(2.2)^{\mathrm{b}}$ & $6.1(1.9)^{\mathrm{a}}$ & $0.3(0.5)^{\mathrm{c}}$
\end{tabular}

n

80

80

80

12

Results of Bonnferoni/Dunn testing is shown for each dependent variable as superscripts for means that are significantly different from one another. For a given variable, means with different superscripts are significantly different from one another (e.g., for any given dependent variable, all means with a superscript of a are significantly different from those with a superscript of $b$ ).

Variables were transformed in the same manner as in the multiple regression analyses to fulfill requirements of normality. A superscript of " $x$ " denotes that the square root of the variable was used in statistical analysis.

$\lceil$ Total human site usage $=$ the sum of the total number of people (joggers, hikers, and bicyclists) plus the number of dogs that passed by the site during the 10 minute data collection periods. 


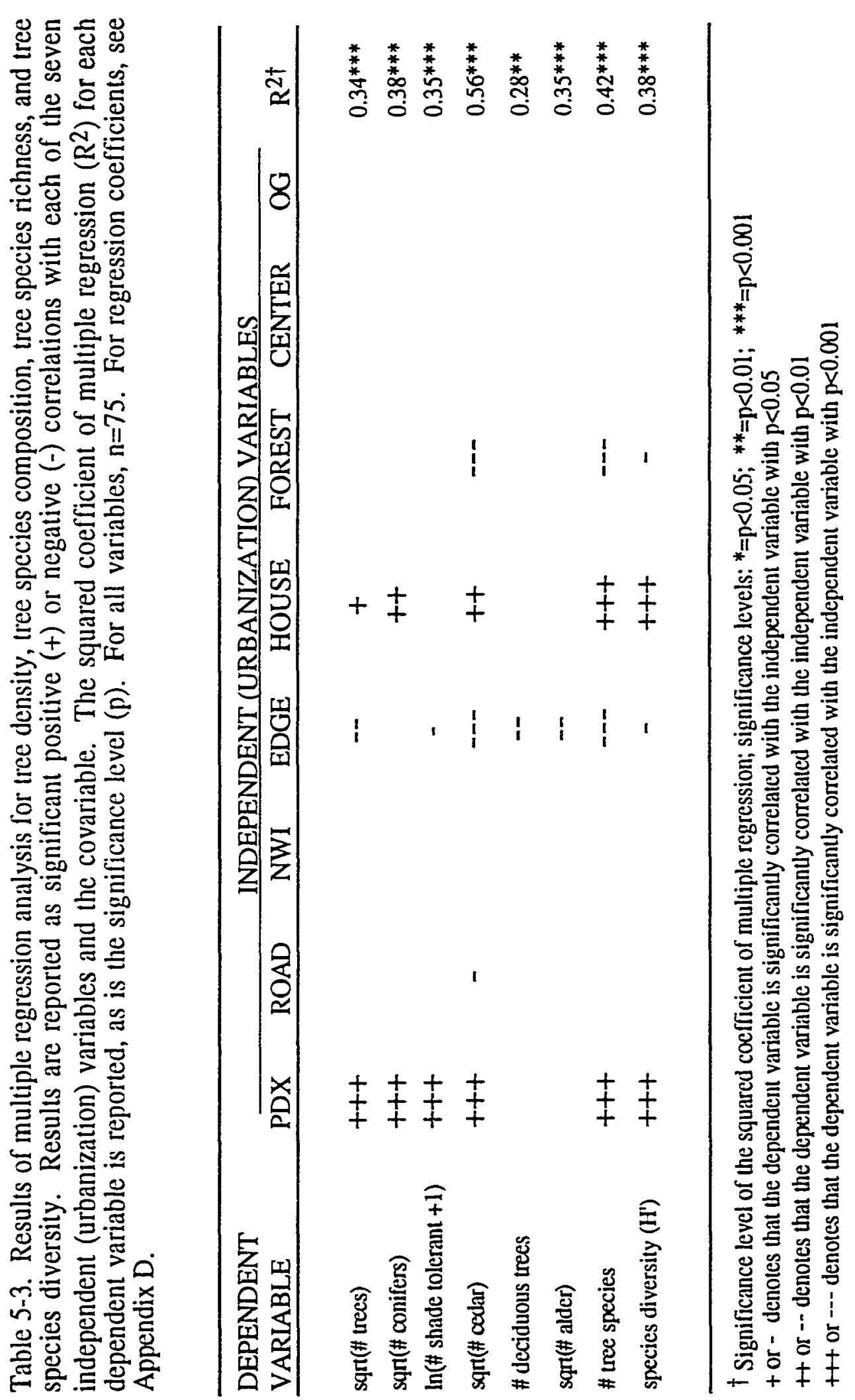




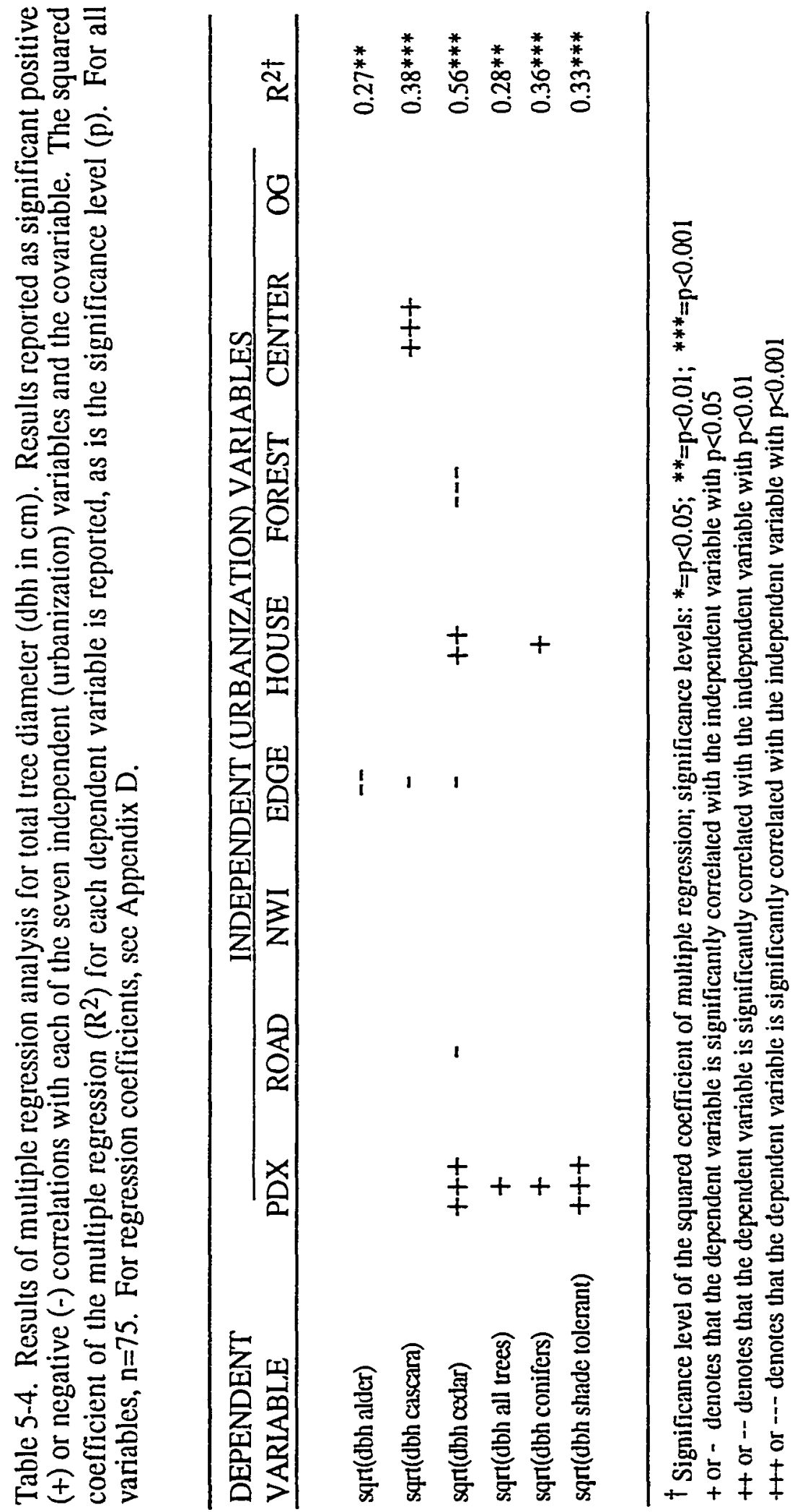




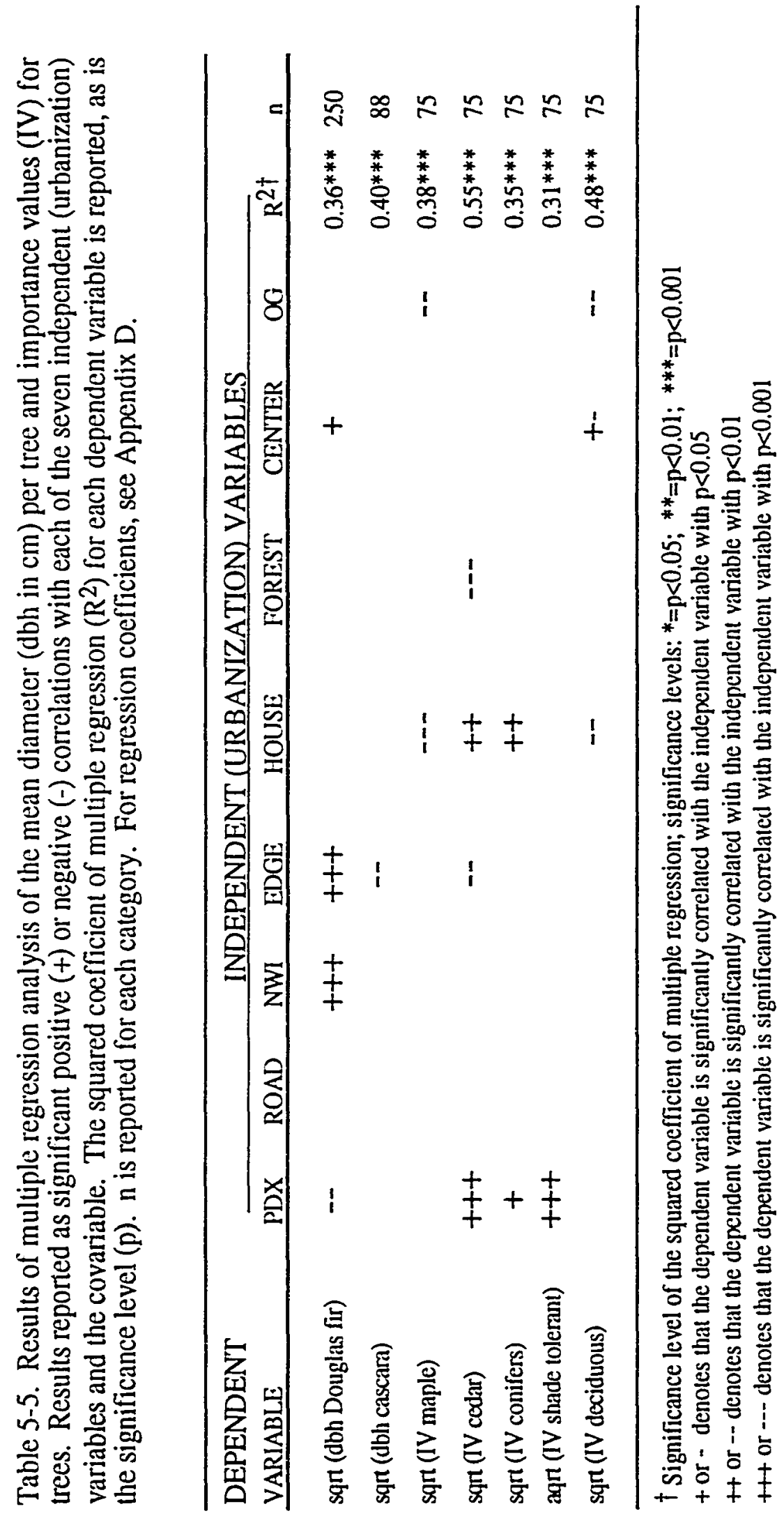


importance values of some coniferous species, as well as shade-tolerant trees, correlated positively with the distance from downtown Portland and the number of surrounding houses. The importance value of deciduous trees was negatively correlated with the old-growth stand.

While many tree variables were positively correlated with the distance from downtown Portland, many shrub variables correlated negatively with this urbanization variable (Table 5-6). Significant variables that were negatively correlated with many urbanization variables included shrub density, shrub species diversity, and many variables related to thimbleberry and red elderberry. Vine maple was the only shrub species to be positively correlated with many of the urbanization variables. Many herbaceous variables were also negatively correlated with the distance from downtown Portland (Table 5-7). Many of these same variables were positively correlated with the distance from the nearest road. Only the amount of bare ground (i.e., lack of herbaceous plant cover) showed opposite correlations.

To calculate foliage height diversity (FHD), I measured percent cover by various species at different heights. The percent cover of sky and the percent cover by cedar, as well as foliage height diversity at several heights were found to be significantly correlated to urbanization variables (Table 5-8). The distance from the nearest road and the distance from the nearest forest edge seemed to be the most important urbanization variables for cover and foliage diversity measurements. Total foliage height diversity was negatively correlated with the distance from the nearest forest edge. 


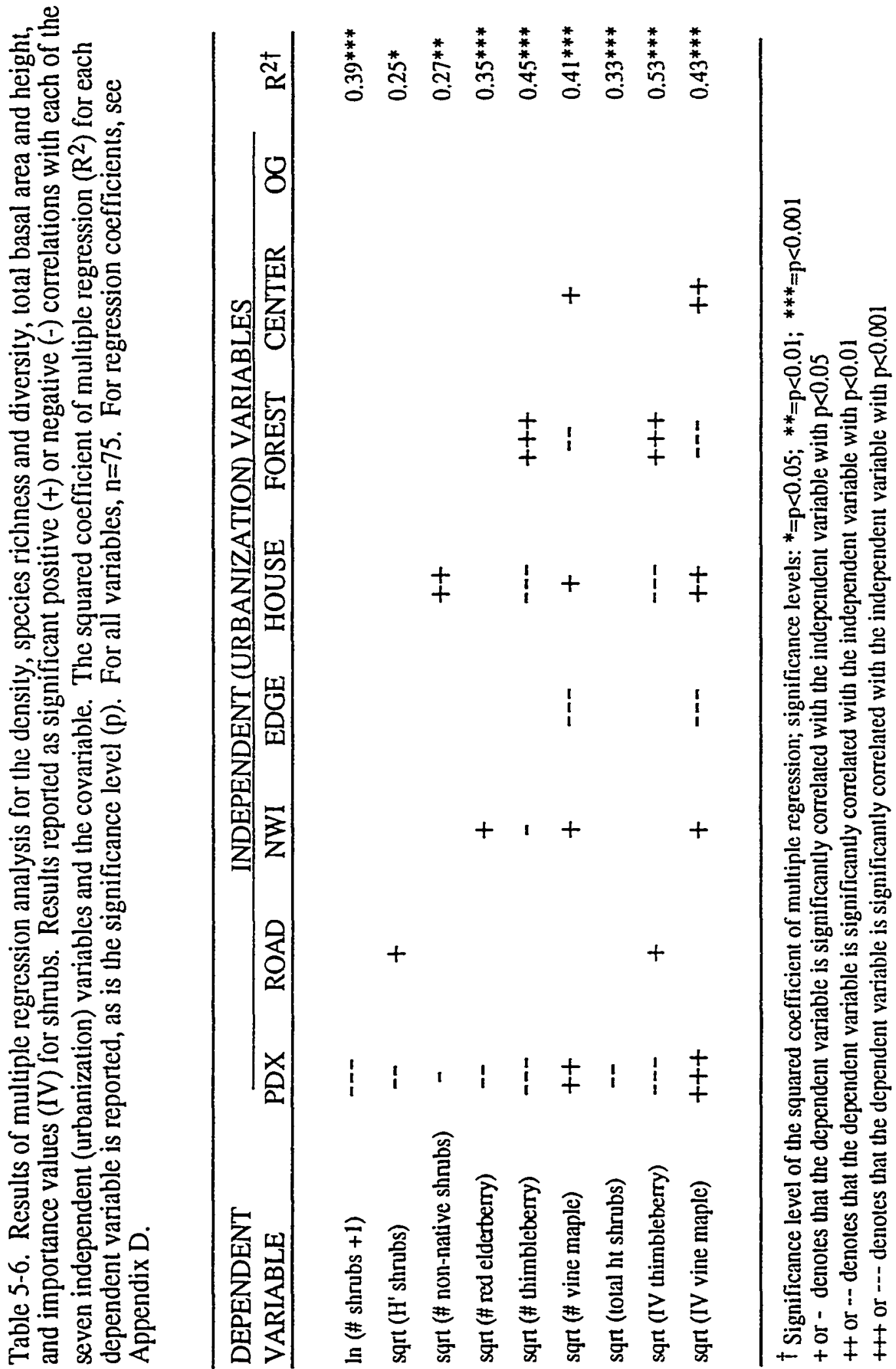




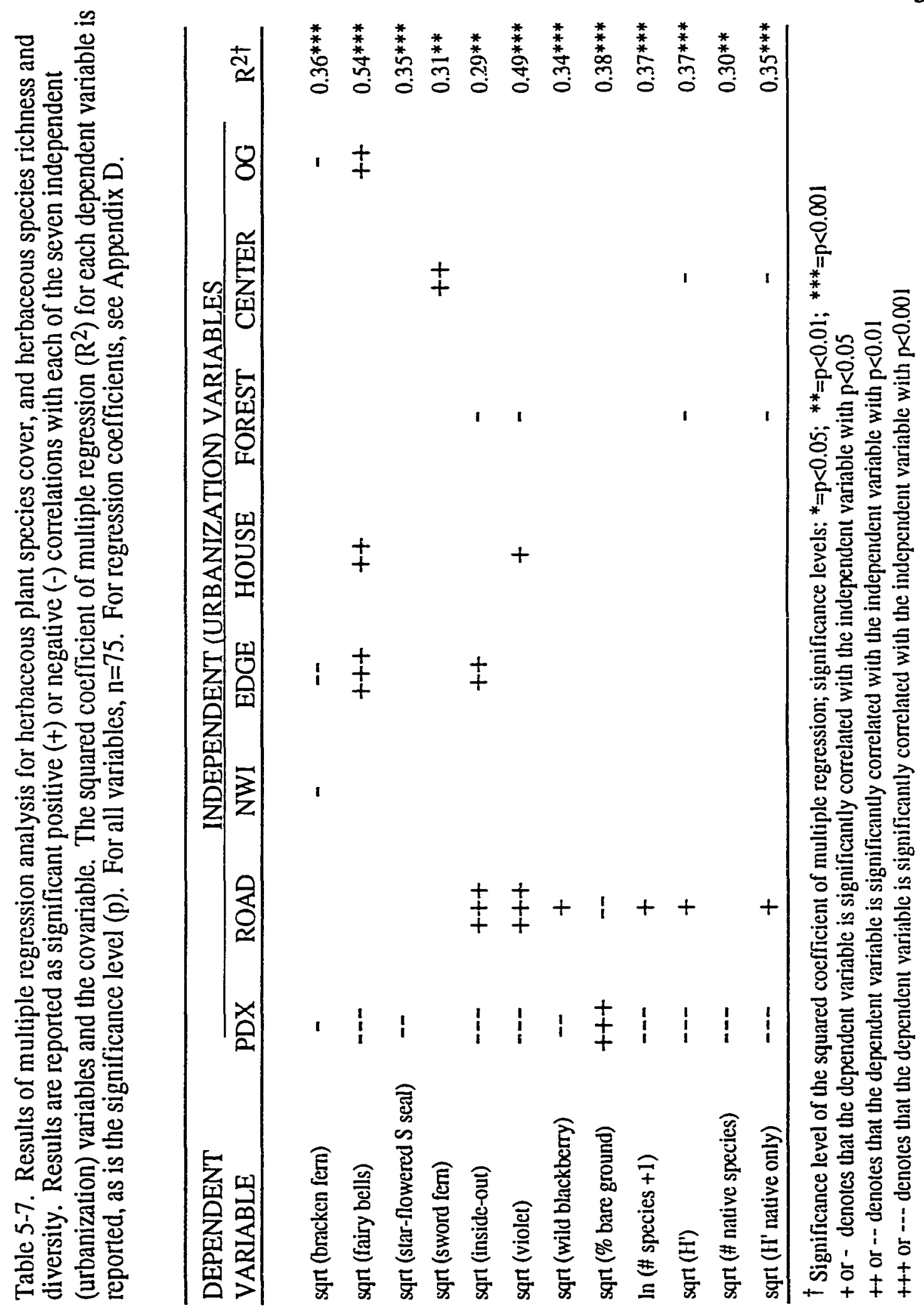




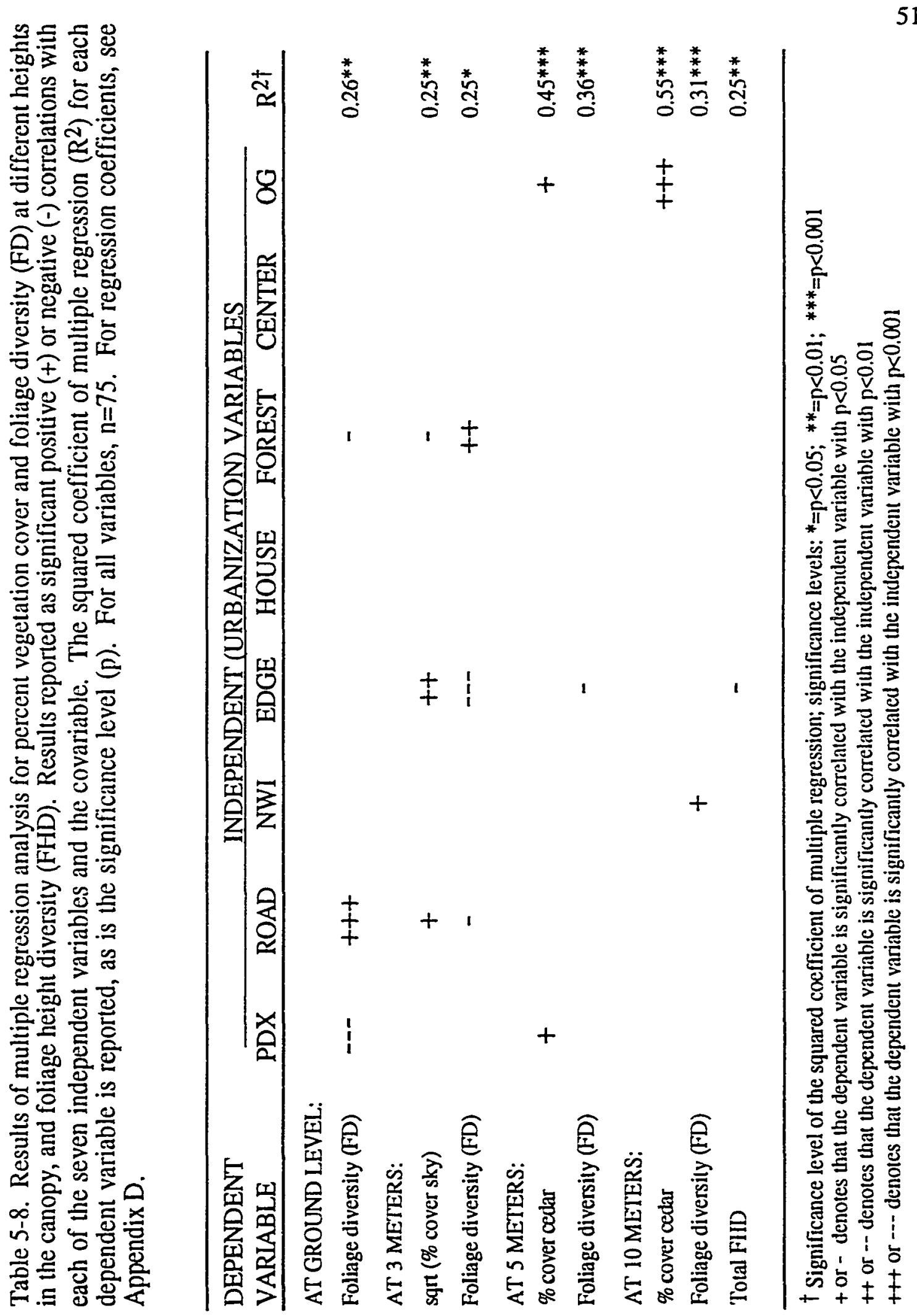




\section{Plant Community Structure -- Differences Between Sections}

Tree density, richness, and species diversity were greatest at sites in the far section of the park (Table 5-9). The far section and old-growth had significantly more shadetolerant species of trees and more conifers, including western red cedar. There were, however, more deciduous trees in Forest Park than in the old-growth stand, including significantly more red alder in the middle section of Forest Park.

The total diameter of trees was significantly greater at sites in the far section and the old-growth stand than at sites in the city or middle sections of the park (Table 5-10). Douglas-fir comprised a significantly greater amount of the total tree diameter in the old-growth stand. On the other hand, the total diameter of bigleaf maple was greater at all sites in Forest Park, and the total diameter of red alder was significantly greater in the middle section of the park. The average diameter of all trees significantly smaller in the far section (Table 5-11). In addition, there were significant differences in the average diameters for some tree species. Bigleaf maple, red alders, and western red cedar had significantly smaller diameters in the middle section of the park. Douglas-fir was significantly larger in the old-growth stand. Western red cedar was significantly larger in far section of the park and in the old-growth stand.

The importance value incorporates both tree density and tree diameter and varied among the different sections for some tree species (Table 5-12). The importance value of shade-tolerant trees was significantly higher in the far section of the park and the old-growth, as was the importance value of western red cedar. The importance 
Table 5-9. Mean tree density, tree species richness, and tree species diversity per $500 \mathrm{~m}^{2}$ (standard deviation) for the different sections of the study.

\begin{tabular}{|c|c|c|c|c|}
\hline Species & City & Mid & Far & OG \\
\hline $\begin{array}{l}\text { Abies grandis } \\
\text { Acer macrophyllum }\end{array}$ & $\begin{array}{r}2.4(6.9) \\
10.0(5.4)\end{array}$ & $\begin{array}{r}0.7(1.6) \\
11.6(5.7)\end{array}$ & $\begin{array}{r}1.1(2.3) \\
11.2(5.5)\end{array}$ & $\begin{array}{l}0.0(-) \\
3.0(2.0)\end{array}$ \\
\hline Alnus rubra & $2.3(3.3)^{\mathrm{a}}$ & $5.3(3.0)^{b}$ & $3.3(3.1)^{\mathrm{a}}$ & $0.0(-)^{c}$ \\
\hline Amelanchier alnifolia & $0.1(0.3)$ & $0.3(1.0)$ & $0.0(0.2)$ & $0.0(-)$ \\
\hline Chamaecyparis lawsoniana & $0.0(-)$ & $0.6(2.9)$ & $0.0(-)$ & $0.0(-)$ \\
\hline Cornus nuttallii & $0.4(0.8)$ & $0.3(1.0)$ & $0.0(0.2)$ & $1.7(2.1)$ \\
\hline Populus trichocarpa & $0.0(0.2)$ & $0.0(-)$ & $0.5(1.7)$ & $0.0(-)$ \\
\hline Prunus emarginata & $0.0(-)$ & $0.4(0.9)$ & $0.5(1.2)$ & $0.0(-)$ \\
\hline Pseudotsuga menziesii & $2.3(2.1)$ & $3.8(5.3)$ & $3.5(4.4)$ & $6.0(2.0)$ \\
\hline Rhamnus purshiana & $1.6(2.9)$ & $0.6(1.1)$ & $1.5(2.2)$ & $0.3(0.6)$ \\
\hline Sorbus aucuparia & $0.4(1.1)$ & $0.1(0.4)$ & $0.0(-)$ & $0.0(-)$ \\
\hline Taxus brevifolia & $0.0(-)$ & $0.1(0.3)$ & $0.2(0.4)$ & $0.0(-)$ \\
\hline Thuja plicata & $0.0(-)^{\mathrm{a}}$ & $1.4(2.5)^{\mathrm{a}}$ & $5.4(5.5)^{b}$ & $11.3(9.7)^{b}$ \\
\hline Tsuga heterophylla* & $1.9(3.7)^{\mathrm{a}}$ & $0.3(0.8)^{\mathrm{a}}$ & $3.5(4.4)^{b}$ & $12.7(4.0)^{c}$ \\
\hline Number trees of all species $x$ & $21.4(9.2)^{\mathrm{a}}$ & $25.5(12.0)^{\mathrm{ab}}$ & $30.8(9.7)^{b}$ & $35.0(5.3)^{\mathrm{ab}}$ \\
\hline \# shade-tolerant urees & $1.92(3.74)^{\mathrm{a}}$ & $1.75(3.07)^{\mathrm{a}}$ & $9.08(8.25)^{b}$ & $24.00(6.08)^{\mathrm{b}}$ \\
\hline \# conifers & $6.6(8.1)^{\mathrm{a}}$ & $6.8(6.9)^{\mathrm{a}}$ & $13.7(8.3)^{\mathrm{b}}$ & $30.0(4.4)^{b}$ \\
\hline \# deciduous trees & $14.8(6.5)^{\mathrm{a}}$ & $18.7(8.5)^{\mathrm{a}}$ & $17.1(6.5)^{\mathrm{a}}$ & $5.0(3.6)^{b}$ \\
\hline \# tree species & $4.0(1.2)^{\mathrm{a}}$ & $4.7(1.6)^{a b}$ & $5.6(1.3)^{b}$ & $6.0(-)^{\mathrm{ab}}$ \\
\hline $\mathrm{H}^{\prime}$ & $1.06(0.28)^{\mathrm{a}}$ & $1.15(0.26)^{\mathrm{ab}}$ & $1.34(0.23)^{b}$ & $1.29(0.11)^{\mathrm{ab}}$ \\
\hline Range species & $2-6$ & $2-8$ & $3-8$ & $5-5$ \\
\hline $\mathbf{n}$ & 24 & 24 & 24 & 3 \\
\hline
\end{tabular}

Results of Bonnferoni/Dunn testing is shown for each variable as superscripts for means that are significantly different from one another. For a given variable, means with different superscripts are significantly different from one another (e.g., for any given dependent variable, all means with a superscript of a are significandy different from those with a superscript of b). Significance was determined after the variables were transformed in the same manner as used in multiple regression testing.

A superscript of " $x$ " denotes that the square root of the variable was used in statistical analyses; a superscript of "*" denotes that the natural log of the variable +1 was used. 
Table 5-10. Mean total diameter ( $\mathrm{dbh}$ in $\mathrm{cm}$ ) of trees per $500 \mathrm{~m}^{2}$ (standard deviation) for the different sections. Only tree species present in at least two sections are reported.

\begin{tabular}{|c|c|c|c|c|}
\hline Species & City & Mid & Far & $O G$ \\
\hline Abies grandis & $18.2(50.8)$ & $10.2(39.3)$ & $8.7(18.5)$ & $0.0(-)$ \\
\hline Acer macrophyllum ${ }^{\mathrm{x}}$ & $309.7(159.2)^{\mathrm{a}}$ & $295.3(120.2)^{a}$ & $317.6(136.9)^{\mathrm{a}}$ & $64.4(36.6)^{b}$ \\
\hline Alnus rubrax & $80.4(112.3)^{\mathrm{ac}}$ & $150.0(67.8)^{b}$ & $104.8(103.7)^{\mathrm{a}}$ & $0.0(-) a^{c}$ \\
\hline Amelanchier alnifolia & $0.3(1.0)$ & $1.3(4.4)$ & $0.0(0.1)$ & $0.0(-)$ \\
\hline Chamaecyparis lawsoniana & $0.0(-)$ & $2.3(1.5)$ & $0.0(-)$ & $0.0(-)$ \\
\hline Cornus nuttalliix & $4.1(8.4)^{\mathrm{ab}}$ & $2.0(4.9)^{\mathrm{ab}}$ & $0.3(1.3)^{\mathrm{a}}$ & $12.5(12.6)^{\mathrm{b}}$ \\
\hline Populus trichocarpa & $1.9(9.3)$ & $0.0(-)$ & $13.7(46.6)$ & $0.0(-)$ \\
\hline Prunus emarginata & $0.0(-)$ & $5.8(14.8)$ & $6.9(15.9)$ & $0.0(-)$ \\
\hline Pseudotsuga menziesii $i^{\mathrm{x}}$ & $134.2(126.8)^{a}$ & $127.7(202.6)^{\mathbf{a}}$ & $120.3(131.0)^{\mathrm{a}}$ & $644.4(321.0)^{\mathrm{b}}$ \\
\hline Rhamnus purshiana & $2.9(7.2)$ & $0.9(2.0)$ & $1.2(1.7)$ & $0.2(0.3)$ \\
\hline Sorbus aucuparia & $1.5(6.6)$ & $0.1(0.7)$ & $0.0(-)$ & $0.0(-)$ \\
\hline Taxus brevifolia & $0.0(-)$ & $0.7(3.3)$ & $0.5(1.2)$ & $0.0(-)$ \\
\hline Thuja plicatax & $0.0(-)^{\mathrm{a}}$ & $8.8(14.7)^{\mathrm{a}}$ & $80.8(89.8)^{b}$ & $130.4(71.6)^{\mathrm{b}}$ \\
\hline Tsuga heterophyllax & $33.3(69.3)^{\mathrm{a}}$ & $6.7(27.6)^{a b}$ & $73.8(98.8)^{\mathrm{ac}}$ & $201.5(112.5)^{\mathrm{d}}$ \\
\hline dbh of all shade-tolerant trees $x$ & $33.3(69.3)^{\mathrm{a}}$ & $16.2(33.7)^{\mathrm{a}}$ & $155.0(167.8)^{b}$ & $331.9(66.3)^{b}$ \\
\hline dbh of all conifers ${ }^{x}$ & $185.7(169.1)^{\mathrm{a}}$ & $156.5(205.7)^{\mathrm{ab}}$ & $284.1(191.4)^{\mathrm{ac}}$ & $976.3(300.1)^{d}$ \\
\hline $\begin{array}{l}\text { Total dbh for all species } x \\
(320.3)^{\mathrm{b}}\end{array}$ & $586.6(171.7)^{\mathrm{a}}$ & $613.3(198.7)^{\mathrm{a}}$ & $728.8(204.1)^{\mathrm{b}}$ & 1053.4 \\
\hline & 24 & 24 & 24 & 3 \\
\hline
\end{tabular}

Results of Bonnferoni/Dunn testing is shown for each variable as superscripts for means that are significantly different from one another. For a given variable, means with different superscripts are significantly different from one another (e.g., for any given dependent variable, all means with a superscript of a are significantly different from those with a superscript of b). Significance was determined after the variables were transformed in the same manner as used in multiple regression testing.

A superscript of " $x$ " denotes that the square root of the variable was used in statistical analyses. 
Table 5-11. Mean tree diameter ( $\mathrm{dbh}$ in $\mathrm{cm}$ ) per $500 \mathrm{~m}^{2}$ (standard deviation) for the different sections. Only tree species that were present in at least two sections and/or had an abundance of greater than 12 trees total are reported.

\begin{tabular}{|c|c|c|c|c|}
\hline Species & City & Mid & Far & OG \\
\hline $\begin{array}{l}\text { Abies grandis } \\
\mathrm{n}\end{array}$ & $\begin{array}{c}8.0(5.7) \\
60\end{array}$ & $\begin{array}{c}15.3(16.6) \\
16\end{array}$ & $\begin{array}{l}9.3(7.1) \\
32\end{array}$ & $\begin{array}{c}0.0(-) \\
0\end{array}$ \\
\hline $\begin{array}{l}\text { Acer macrophyllum } \\
\mathrm{n}\end{array}$ & $\begin{array}{c}26.9(17.5)^{\mathrm{a}} \\
318\end{array}$ & $\begin{array}{c}21.7(17.1)^{\mathrm{b}} \\
364\end{array}$ & $\begin{array}{c}22.3(14.7)^{\mathrm{ab}} \\
415\end{array}$ & $\begin{array}{l}19.1(4.8)^{\mathrm{ab}} \\
11\end{array}$ \\
\hline $\begin{array}{l}\text { Alnus rubra } \\
\mathrm{n}\end{array}$ & $\begin{array}{l}35.1(7.5)^{\mathrm{a}} \\
\quad 61\end{array}$ & $\begin{array}{c}28.3(11.7)^{b} \\
164\end{array}$ & $\begin{array}{c}31.8(9.9)^{\mathrm{ab}} \\
91\end{array}$ & $\begin{array}{c}0.0(-)^{\mathrm{ab}} \\
0\end{array}$ \\
\hline $\begin{array}{l}\text { Cornus nuttallii } \\
\mathrm{n}\end{array}$ & $\begin{array}{c}8.6(4.3) \\
10\end{array}$ & $\begin{array}{c}6.0(4.1) \\
8\end{array}$ & $\begin{array}{l}5.2(1.9) \\
2\end{array}$ & $\begin{array}{c}7.5(3.1) \\
5\end{array}$ \\
\hline $\begin{array}{l}\text { Prunus emarginata } \\
\mathbf{n}\end{array}$ & $\begin{array}{c}16.2(6.8) \\
3\end{array}$ & $\begin{array}{c}13.9(7.7) \\
28\end{array}$ & $\begin{array}{c}17.0(6.7) \\
29\end{array}$ & $\begin{array}{c}0.0(-) \\
0\end{array}$ \\
\hline $\begin{array}{l}\text { Pseudotsuga menziesii } \\
\mathrm{n}\end{array}$ & $\begin{array}{l}55.8(31.3)^{\mathrm{a}} \\
64\end{array}$ & $\begin{array}{l}32.4(26.1)^{\mathrm{b}} \\
99\end{array}$ & $\begin{array}{c}29.6(23.2)^{b} \\
108\end{array}$ & $\begin{array}{l}80.7(61.1)^{c} \\
25\end{array}$ \\
\hline $\begin{array}{l}\text { Rhamnus purshiana } \\
\mathrm{n}\end{array}$ & $\begin{array}{l}2.1(1.4)^{\mathrm{a}} \\
39\end{array}$ & $\begin{array}{l}1.6(1.4) \\
15\end{array}$ & $\begin{array}{c}0.8(0.5)^{b} \\
40\end{array}$ & $0.5(-)$ \\
\hline $\begin{array}{l}\text { Thuja plicata } \\
\mathbf{n}\end{array}$ & $\begin{array}{c}0.0(-)^{\mathrm{ab}} \\
0\end{array}$ & $\begin{array}{l}7.3(11.2)^{\mathrm{a}} \\
35\end{array}$ & $\begin{array}{c}15.2(16.6)^{b} \\
155\end{array}$ & $\begin{array}{l}11.6(10.9)^{\mathrm{b}} \\
38\end{array}$ \\
\hline $\begin{array}{l}\text { Tsuga heterophylla } \\
\mathrm{n}\end{array}$ & $\begin{array}{c}16.2(18.9) \\
54\end{array}$ & $\begin{array}{c}26.9(25.9) \\
6\end{array}$ & $\begin{array}{c}18.2(17.0) \\
113\end{array}$ & $\begin{array}{l}14.2(15.6) \\
46\end{array}$ \\
\hline $\begin{array}{l}\text { dbh for shade-tolerant trees } \\
n \\
\text { dbh for conifers } \\
n \\
\text { dbh for deciduous trees } \\
n \\
\text { dbh for all trees/quadrat } \\
n\end{array}$ & $\begin{array}{c}17.4(20.3)^{\mathrm{a}} \\
46 \\
28.0(30.9) \\
159 \\
27.2(18.4)^{\mathrm{a}} \\
353 \\
27.4(22.9)^{\mathrm{a}} \\
514\end{array}$ & $\begin{array}{c}9.3(14.4)^{\mathrm{b}} \\
42 \\
22.8(24.9) \\
164 \\
24.5(16.4)^{\mathrm{ab}} \\
448 \\
24.1(19.0)^{\mathrm{ab}} \\
612\end{array}$ & $\begin{array}{l}17.3(17.9)^{\mathrm{a}} \\
218 \\
20.8(20.8) \\
329 \\
25.9(15.8)^{\mathrm{ab}} \\
411 \\
23.7(18.4)^{\mathrm{b}} \\
740\end{array}$ & $\begin{array}{l}13.8(14.5)^{\mathrm{a}} \\
72 \\
32.5(45.5) \\
90 \\
14.6(8.1)^{\mathrm{b}} \\
15 \\
29.9(42.7)^{\mathrm{ab}} \\
105\end{array}$ \\
\hline
\end{tabular}

Results of Bonnferoni/Dunn testing is shown for each variable as superscripts for means that are significantly different from one another. For a given variable, means with different superscripts are significantly different from one another (e.g., for any given dependent variable, all means with a superscript of a are significantly different from those with a superscript of b). Significance was determined after the variables were transformed in the same manner as used in multiple regression testing.

A superscript of " $x$ " denotes that the square root of the variable was used in statistical analyses; a superscript of "*" denotes that the natural log of the variable +1 was used. 
Table 5-12. Mean importance values (TV) of trees per $500 \mathrm{~m}^{2}$ (standard deviation) in the different sections of the park. Only tree species that were present in at least two sections were reported.

\begin{tabular}{|c|c|c|c|c|}
\hline Species & City & Mid & $\mathrm{Far}$ & $O G$ \\
\hline Abies grandis & $0.09(0.22)$ & $0.05(0.13)$ & $0.04(0.07)$ & $0.00(-)$ \\
\hline Acer macrophyllum ${ }^{\mathrm{x}}$ & $0.61(0.28)^{\mathrm{a}}$ & $0.75(0.18)^{\mathrm{a}}$ & $0.52(0.20)^{\mathrm{a}}$ & $0.08(0.05)^{b}$ \\
\hline Alnus rubrax & $0.26(0.36)^{\mathrm{a}}$ & $0.51(0.29)^{\mathrm{b}}$ & $0.26(0.25)^{\mathrm{a}}$ & $0.00(-)^{a}$ \\
\hline Amelanchier alnifolia & $0.01(0.02)$ & $0.01(0.03)$ & $0.00(0.01)$ & $0.00(-)$ \\
\hline Cornus nuttallii & $0.03(0.06)$ & $0.01(0.03)$ & $0.00(0.01)$ & $0.06(0.06)$ \\
\hline Populus trichocarpa & $0.01(0.04)$ & $0.00(-)$ & $0.03(0.10)$ & $0.00(-)$ \\
\hline Prunus emarginata & $0.00(-)$ & $0.03(0.07)$ & $0.03(0.08)$ & $0.00(-)$ \\
\hline Pseudotsuga menziesii & $0.37(0.37)$ & $0.30(0.37)$ & $0.28(0.32)$ & $0.76(0.17)$ \\
\hline Rhamnus purshiana & $0.09(0.12)$ & $0.02(0.03)$ & $0.06(0.10)$ & $0.01(0.02)$ \\
\hline Thuja plicata ${ }^{x}$ & $0.00(-)^{\mathrm{a}}$ & $0.06(0.10)^{\mathrm{a}}$ & $0.29(0.29)^{b}$ & $0.46(0.35)^{b}$ \\
\hline Tsuga heterophylla $\mathrm{x}$ & $0.13(0.25)^{\mathrm{a}}$ & $0.02(0.07)^{a}$ & $0.19(0.23)^{a b}$ & $0.56(0.19)^{\mathrm{b}}$ \\
\hline IV shade-tolerant ${ }^{x}$ & $0.13(0.25)^{\mathrm{a}}$ & $0.09(0.15)^{\mathrm{a}}$ & $0.48(0.43)^{\mathbf{b}}$ & $1.02(0.25)^{b}$ \\
\hline IV conifers $x$ & $0.59(0.46)^{\mathrm{a}}$ & $0.45(0.39)^{\mathrm{a}}$ & $0.80(0.38)^{a}$ & $1.79(0.12)^{b}$ \\
\hline IV deciduous ${ }^{x}$ & $1.03(0.53)^{\mathrm{a}}$ & $1.33(0.43)^{\mathrm{ab}}$ & $0.91(0.40)^{\mathrm{ac}}$ & $0.15(0.10)^{d}$ \\
\hline $\mathbf{n}$ & 24 & 24 & 24 & 3 \\
\hline
\end{tabular}

Results of Bonnferoni/Dunn testing is shown for each variable as superscripts for means that are significantly different from one another. For a given variable, means with different superscripts are significantly different from one another (e.g., for any given dependent variable, all means with a superscript of a are significantly different from those with a superscript of b). Significance was determined after the variables were transformed in the same manner as used in multiple regression testing.

A superscript of " $x$ " denotes that the square root of the variable was used in statistical analyses. 
value of conifers was significantly higher in the old-growth stand, as was the importance value of western hemlock. The importance value of deciduous trees, on the other hand, was greatest in the middle section of the park and lowest in the oldgrowth.

Shrub density, shrub species richness, shrub species diversity, and the total shrub basal area were all lowest at sites in the far section of the park (Table 5-13). Red elderberry, thimbleberry, and vine maple were the only shrub species to show significant differences among the sections. Red elderberry and thimbleberry were more abundant in the sections closer to the city, and vine maple was more abundant in the old growth stand. There were no significant differences in the distribution of species of non-native shrubs, but exotic shrub species were observed only at sites in the city and middle sections of the park.

Herbaceous species richness and diversity were greatest in the city section of the park (Table 5-14). Sites in the city section had significantly greater cover by species usually associated with shaded forest ecosystems such as fairy bells and starflowered Solomon's seal. The lack of herbaceous covering (i.e., bare ground) was significantly higher at sites in the far section and the old-growth stand. Most of my sites had been cleared of ivy by Park personnel and volunteers before I collected my plant data. This made it impossible to adequately assess the problems and effects of ivy at my sites. The percent cover of non-native herbaceous plant species such as ivy could not be individually analyzed statistically due to the low numbers of plants and/or their being present at too few sites. Therefore, I analyzed the number and 
Table 5-13. Mean shrub density, shrub species richness and diversity, and total shrub basal area $(\mathrm{cm})$ and height $(\mathrm{m})$ per $100 \mathrm{~m}^{2}$ (standard deviation) for the different sections of the park. For scientific names see Appendix C.

\begin{tabular}{|c|c|c|c|c|}
\hline Species & City & Mid & Far & $O G$ \\
\hline English laurel & $0.0(0.2)$ & $0.0(-)$ & $0.0(-)$ & $0.0(-)$ \\
\hline Filbert & $1.5(3.7)$ & 0.7 (1.3) & $0.0(-)$ & $0.0(-)$ \\
\hline Himalayan blackberry & $0.0(0.2)$ & $0.0(-)$ & $0.0(-)$ & $0.0(-)$ \\
\hline Holly & $0.8(1.9)$ & $0.3(1.0)$ & $0.0(-)$ & $0.0(-)$ \\
\hline Indian plum & $0.4(0.9)$ & $0.2(0.6)$ & $0.3(0.5)$ & $0.0(-)$ \\
\hline Mock orange & $0.0(0.2)$ & $0.0(-)$ & $0.0(-)$ & $0.0(-)$ \\
\hline Oceanspray & $0.2(0.7)$ & $0.8(1.3)$ & $0.2(0.4)$ & $0.3(0.6)$ \\
\hline Red elderberry $x$ & $3.4(3.9)^{\mathrm{a}}$ & $0.9(1.4)^{b}$ & $0.6(1.3)^{b}$ & $0.0(-)^{b}$ \\
\hline Red huckleberry & $2.4(2.5)$ & $2.0(2.4)$ & 1.4 (1.6) & $3.7(3.8)$ \\
\hline Salmonberry & $0.3(1.4)$ & $0.1(0.3$ & $0.3(1.1)$ & $0.0(-)$ \\
\hline Snowberry & $0.0(0.2)$ & $0.4(1.3)$ & $0.2(0.7)$ & $0.0(-)$ \\
\hline Thimbleberry $x$ & $1.4(2.0)^{\mathrm{a}}$ & $1.2(1.7)^{\mathrm{a}}$ & $0.1(0.3)^{b}$ & $0.0(-)^{a b}$ \\
\hline Vine maple ${ }^{x}$ & $0.8(2.3)^{\mathrm{a}}$ & $0.5(1.4)^{\mathrm{a}}$ & $0.8(2.5)^{a}$ & $7.0(10.4)^{b}$ \\
\hline Wild rose & $0.5(1.28)$ & $0.8(2.1)$ & $0.5(1.0)$ & $0.0(-)$ \\
\hline Total \# shrubs * & $11.9(6.3)^{\mathrm{a}}$ & $7.9(3.6)^{\mathrm{a}}$ & $4.3(4.0)^{\mathrm{b}}$ & $11.0(9.0)^{\mathrm{ab}}$ \\
\hline \# non-native shrubs $x$ & $0.9(2.0)$ & $0.3(1.0)$ & $0.0(-)$ & $0.0(-)$ \\
\hline \# shrub species $x$ & $3.2(1.7)^{\mathrm{a}}$ & $3.3(1.1)^{\mathrm{a}}$ & $2.0(1.3)^{b}$ & $2.0(1.0)^{\mathrm{ab}}$ \\
\hline Range of species per site & $2-8$ & $3-6$ & $2-7$ & NA \\
\hline $\mathrm{H}^{\prime} \mathrm{x}^{-}$ & $0.86(0.48)^{\mathrm{a}}$ & $0.98(0.33)^{\mathrm{a}}$ & $0.49(0.50)^{b}$ & $0.32(0.39)^{\mathrm{ab}}$ \\
\hline Total shrub basal area $(\mathrm{cm})^{x}$ & $91.6(63.1)^{\mathbf{a}}$ & $81.2(54.7)^{\mathrm{a}}$ & $42.4(51.7)^{b}$ & $20.1(15.6)^{a b}$ \\
\hline Total shrub ht (m) $x$ & $7.8(5.5)^{\mathrm{a}}$ & $4.9(2.1)^{\mathrm{a}}$ & $2.7(3.5)^{b}$ & $6.1(4.8)^{\mathrm{ab}}$ \\
\hline $\mathbf{n}$ & 24 & 24 & 24 & 3 \\
\hline
\end{tabular}

Results of Bonnferoni/Dunn testing is shown for each variable as superscripts for means that are significantly different from one another. For a given variable, means with different superscripts are significantly different from one another (e.g., for any given dependent variable, all means with a superscript of a are significantly different from those with a superscript of b). Significance was determined after the variables were transformed in the same manner as used in multiple regression testing.

A superscript of " $x$ " denotes that the square root of the variable was used in statistical analyses; a superscript of "*" denotes that the natural log of the variable +1 was used. 
Table 5-14. Mean percent cover by herbaceous species per 30 meter transect (standard deviation) for the different sections of the park. Only herbaceous species whose mean percent cover was greater than $1 \%(0.01)$ in at least one section were reported.

\begin{tabular}{|c|c|c|c|c|}
\hline Species & City & Mid & Far & QG \\
\hline Bedstraw & $0.03(0.04)$ & $0.02(0.03)$ & $0.02(0.04)$ & $0.00(0.00)$ \\
\hline Bracken fern $x$ & $0.02(0.03)^{\mathrm{a}}$ & $0.01(0.02)^{\mathrm{ab}}$ & $0.01(0.01)^{b}$ & $0.00(-)^{\mathrm{ab}}$ \\
\hline Candy flower & $0.05(0.06)$ & $0.03(0.03)$ & $0.03(0.08)$ & $0.00(-)$ \\
\hline Fairy bells $x$ & $0.05(0.05)^{a}$ & $0.01(0.01)^{b}$ & $0.01(0.01)^{\mathrm{b}}$ & $0.00(-)^{b}$ \\
\hline Fringe cup & $0.00(0.00)$ & $0.01(0.02)$ & $0.02(0.07)$ & $0.00(-)$ \\
\hline English ivy & $0.04(0.11)$ & $0.00(0.00)$ & $0.01(0.04)$ & $0.00(-)$ \\
\hline Lady fern & $0.01(0.02)$ & $0.01(0.02)$ & $0.02(0.06)$ & $0.00(-)$ \\
\hline Oregon grape & $0.11(0.14)$ & $0.12(0.17)$ & $0.10(0.15)$ & $0.23(0.09)$ \\
\hline Salal & $0.01(0.02)$ & $0.02(0.05)$ & $0.02(0.03)$ & $0.03(0.02)$ \\
\hline Star-flowered S. seal $x$ & $0.05(0.10)^{a}$ & $0.01(0.03)^{b}$ & $0.00(0.00)^{b}$ & $0.00(-)^{a b}$ \\
\hline Star flower & $0.00(0.00)$ & $0.00(0.00)$ & $0.00(0.00)$ & $0.02(0.03)$ \\
\hline Sword fem & $0.26(0.14)$ & $0.38(0.17)$ & $0.36(0.18)$ & $0.13(0.04)$ \\
\hline Trillium & $0.02(0.01)$ & $0.01(0.01)$ & $0.01(0.01)$ & $0.00(0.00)$ \\
\hline Inside-out flower & $0.04(0.08)^{\mathrm{ab}}$ & $0.06(0.08)^{a}$ & $0.01(0.02)^{\mathrm{b}}$ & $0.01(0.01)^{\mathrm{ab}}$ \\
\hline Yellow wood violet $x$ & $0.03(0.04)^{\mathrm{a}}$ & $0.01(0.01)^{\mathrm{ab}}$ & $0.01(0.01)^{b}$ & $0.00(-)^{a b}$ \\
\hline Water leaf & $0.02(0.03)$ & $0.02(0.04)$ & $0.03(0.03)$ & $0.00(-)$ \\
\hline Wild blackberry & $0.06(0.05)^{\mathrm{a}}$ & $0.12(0.10)^{b}$ & $0.02(0.03)^{\mathrm{a}}$ & $0.01(0.01)^{\mathrm{a}}$ \\
\hline Wild ginger & $0.02(0.02)$ & $0.01(0.01)$ & $0.00(0.01)$ & $0.00(-)$ \\
\hline Bare ground & $0.13(0.13)^{\mathrm{a}}$ & $0.11(0.05)^{\mathrm{a}}$ & $0.28(0.16)^{b}$ & $0.52(0.16)^{b}$ \\
\hline Cover by non-native species & $0.05(0.11)$ & $-0.01(0.01)$ & $0.01(0.04)$ & $0.00(0.00)$ \\
\hline$\#$ herbaceous species ${ }^{*}$ & $14.6(3.2)^{\mathrm{a}}$ & $12.3(2.8)^{\mathrm{ab}}$ & $10.3(3.6)^{\mathrm{b}}$ & $8.3(2.3)^{b}$ \\
\hline Range of species & $8-20$ & $5-20$ & $5-18$ & $7-11$ \\
\hline \# non-native species $x$ & $1.2(1.2)^{\mathrm{a}}$ & $0.7(0.9)^{\mathrm{ab}}$ & $0.3(0.6)^{b}$ & $0.7(0.6)^{\mathrm{ab}}$ \\
\hline \# native species $x$ & $13.4(3.6)^{\mathrm{a}}$ & $11.6(2.4)^{\mathrm{ab}}$ & $10.0(5.6)^{\mathrm{b}}$ & $7.7(2.1)^{\mathrm{b}}$ \\
\hline$H^{\prime}$ (all herb species) $x$ & $1.98(0.30)^{\mathrm{a}}$ & $1.77(0.32)^{\mathrm{ab}}$ & $1.53(0.38)^{\mathrm{b}}$ & $1.35(0.39)^{\mathrm{b}}$ \\
\hline $\begin{array}{l}H^{\prime} \text { (native herb species only) } \\
(0.38)^{\mathrm{ab}}\end{array}$ & $1.88(0.31)^{\mathrm{a}}$ & $1.73(0.31)^{\mathrm{ab}}$ & $1.49(0.38)^{\mathrm{b}}$ & 1.34 \\
\hline n & 24 & 24 & 24 & 3 \\
\hline
\end{tabular}

Results of Bonnferoni/Dunn testing is shown for each variable as superscripts for means that are significantly different from one another. For a given variable, means with different superscripts are significantly different from one another (e.g., for any given dependent variable, all means with a superscript of a are significantly different from those with a superscript of $b$ ). Significance was determined after the variables were transformed in the same manner as used in multiple regression testing.

A superscript of " $x$ " denotes that the square root of the variable was used in statistical analyses; a superscript of "*" denotes that the natural log of the variable +1 was used. 
percent of total non-native plants. I found significantly more non-native herbaceous plant species at sites in the city section.

There were some differences among the park sections regarding measurements associated with foliage height diversity (Table 5-15). There was significantly more vegetation (as measured by a reduced amount of sky) in the old-growth stand at two heights, and significantly less vegetation (more sky) in the middle section. There were also differences in the percent cover of certain tree species at different canopy heights, although these differences were often between the old growth stand and Forest Park.

Although there were no significant differences in the foliage height diversity (FHD) among the different park sections, there were differences with foliage diversity at different heights (Table 5-16). The old-growth stand had the greatest foliage diversity at heights of five, ten, and 50 meters, whereas the far section had the greatest foliage diversity at 20 meters, and the middle section had the greatest diversity at ground level.

\section{DISCUSSION}

Many plant community variables correlated strongly with one or more of the seven urbanization variables. I found significant differences in the density, richness, diversity, diameter, and importance values of trees, shrubs, and herbaceous plants in Forest Park and the old-growth stand along the defined urbanization gradient. 
Table 5-15. Mean vegetation cover (as a proportion) for different species at different heights in the canopy are reported per 30 meter transect (standard deviation) for the different sections. Only species present in at least two sections and/or with an abundance of greater than 10 percent $(0.10)$ in at least one park section are reported.

HEIGHT IN CANOPY

AT 0.5 METERS:

Sword fern

Sky (no vegetation)

AT 2 METERS:

Sky (no vegetation)

AT 3 MIETERS:

Western red cedar

Western hemlock

Sky (no vegetation)

AT 5 METERS:

Bigleaf maple

Western red cedar

Westem hemlock

Sky (no vegetation)

AT 10 METERS:

Red alder

Bigleaf maple

Western red cedar

Douglas-fir

Westem hemlock

Sky (no vegetation)

AT 20 METERS:

Red alder

Bigleaf maple

Douglas-fir

Western hemlock

Sky (no vegetation)

AT 50 METERS:

Douglas-fir $x$

Sky (no vegetation) $x$

n

\section{City}

$0.40(0.31)$

$0.35(0.32)$

$0.80(0.21)$

$0.00(-)^{\mathrm{a}}$

$0.73(0.21)$

$0.11(0.18)$

$0.00(-)^{\mathrm{a}}$

$0.04(0.10)$

$0.80(0.20)^{\mathrm{a}}$

$0.03(0.10)^{\mathrm{a}}$

$0.31(0.29)$

$0.00(-)^{\mathrm{a}}$

$0.05(0.08)^{\mathrm{ab}}$

$0.04(0.13)$

$0.56(0.32)^{\mathrm{ab}}$

$0.15(0.20)$
$0.60(0.30)^{\mathrm{a}}$
$0.22(0.29)^{\mathrm{a}}$
$0.01(0.04)^{\mathrm{a}}$
$0.01(0.04)^{\mathrm{a}}$

$0.25(0.27)^{\mathrm{ab}}$

$0.74(0.26)^{\mathrm{ab}}$

21
Mid

$0.56(0.26)$

$0.23(0.19)$

$0.73(0.16)$

$0.00(-)^{\mathrm{a}}$

$0.01(0.04)$

$0.79(0.19)$

$0.09(0.16)$

$0.00(-)^{\mathrm{a}}$

$0.03(0.09)$

$0.75(0.25)^{\mathrm{a}}$

$0.20(0.24)^{b}$

$0.30(0.22)$

$0.00(-)^{\mathrm{a}}$

$0.07(0.14)^{\mathrm{ab}}$

$0.02(0.08)$

$0.41(0.30)^{\mathrm{a}}$

$0.22(0.29)$
$0.40(0.34)^{\mathrm{ab}}$
$0.14(0.25)^{\mathrm{a}}$
$0.02(0.08)^{\mathrm{a}}$
$0.22(0.35)^{\mathrm{b}}$

$0.13(0.24)^{\mathrm{a}}$

$0.88(0.24)^{\mathrm{a}}$

21
Far

$0.54(0.33)$

$0.33(0.29)$

$0.81(0.22)$

$0.73(0.31)$

$0.08(0.14)^{\mathrm{b}}$

$0.07(0.13)$

$0.73(0.22)$

$0.17(0.29)^{\mathbf{b}}$

$0.20(0.35)$

$0.53(0.42)$

$0.07(0.11)$

$0.13(0.23)$

$0.06(0.14)^{\mathrm{a}}$

$0.11(0.19)$

$0.69(0.23)^{\mathrm{a}}$

$0.27(0.12)^{\mathrm{b}}$

$0.23(0.06)$

$0.13(0.23)^{\mathrm{b}}$

$0.01(0.04)^{\mathrm{a}} \quad 0.00(-)^{\mathrm{ab}}$

$0.19(0.21)$

$0.03(0.07)^{\mathrm{a}}$

$0.02(0.06)^{\mathrm{a}}$

$0.06(0.13)$

$0.68(0.28)^{b}$

$0.13(0.12)$

$0.20(0.00)^{\mathrm{b}}$

$0.20(0.20)^{\mathrm{b}}$

$0.13(0.12)$

$0.27(0.31)^{a b}$

$0.18(0.21) \quad 0.00(-)$

$0.53(0.24)^{\mathrm{a}} \quad 0.00(-)^{\mathrm{b}}$

$0.09(0.19)^{\mathrm{a}}$

$0.08(0.13)^{\mathrm{ab}}$

$0.05(0.14)^{\mathrm{ab}}$

$0.70(0.10)^{\mathrm{b}}$

$0.23(0.21)^{\mathrm{b}}$

$0.07(0.12)^{\mathrm{ab}}$

$0.17(0.29)^{\mathrm{ab}}$

$0.60(0.20)^{b}$

$0.79(0.31)^{\mathrm{a}}$

$0.33(0.12)^{\mathrm{b}}$

$2 I$
3

Results of Bonnferoni/Dunn testing is shown for each variable as superscripts for means that are significantly different from one another. For a given variable, means with different superscripts are significantly different from one another (e.g., for any given dependent variable, all means with a superscript of a are significantly different from those with a superscript of b). Significance was determined after the variables were transformed in the same manner as used in multiple regression testing.

A superscript of " $x$ " denotes that the square root of the variable was used in statistical analyses. 
Table 5-16. Mean foliage diversity (FD) for different species at different heights in the canopy, mean foliage height diversity (FHD), and mean foliage height diversity without the ground layer (FHD-ground) per 30 meter transect (standard deviation) for the different sections.

\begin{tabular}{lllll} 
Height in Canopy & City & Mid & Far & OG \\
\hline FD at ground level & $0.90(0.30)^{\mathrm{ab}}$ & $1.06(0.30)^{\mathrm{a}}$ & $0.74(0.42)^{\mathrm{b}}$ & $0.77(0.47)^{\mathrm{ab}}$ \\
FD at 0.5 meters & $0.53(0.34)$ & $0.58(0.38)$ & $0.38(0.34)$ & $0.29(0.10)$ \\
FD at 2 meters & $0.23(0.23)$ & $0.38(0.23)$ & $0.27(0.27)$ & $0.34(0.34)$ \\
FD at 3 meters & $0.37(0.29)$ & $0.31(0.27)$ & $0.32(0.24)$ & $0.34(0.36)$ \\
FD at 5 meters & $0.24(0.23)^{\mathrm{a}}$ & $0.31(0.30)^{\mathrm{a}}$ & $0.37(0.27)^{\mathrm{a}}$ & $1.10(0.21)^{\mathrm{b}}$ \\
FD at 10 meters & $0.37(0.22)^{\mathrm{a}}$ & $0.53(0.25)^{\mathrm{a}}$ & $0.38(0.31)^{\mathrm{a}}$ & $1.09(0.49)^{\mathrm{b}}$ \\
FD at 20 meters & $0.54(0.30)^{\mathrm{ab}}$ & $0.44(0.32)^{\mathrm{a}}$ & $0.68(0.29)^{\mathrm{b}}$ & $0.49(0.27)^{\mathrm{ab}}$ \\
FD at 50 meters & $0.20(0.16)^{\mathrm{ab}}$ & $0.08(0.15)^{\mathrm{a}}$ & $0.14(0.21)^{\mathrm{ab}}$ & $0.39(0.27)^{\mathrm{b}}$ \\
& & & & \\
& & & & \\
Total FHD & $3.37(0.98)$ & $3.28(1.09)$ & $3.69(0.98)$ & $4.80(1.10)$ \\
FHD - ground & $2.47(1.02)^{\mathrm{a}}$ & $2.54(0.97)^{\mathrm{a}}$ & $2.63(0.98)^{\mathrm{a}}$ & $4.03(1.15)^{\mathrm{b}}$
\end{tabular}

Results of Bonnferoni/Dunn testing is shown for each variable as superscripts for means that are significantly different from one another. For a given variable, means with different superscripts are significantly different from one another (e.g., for any given dependent variable, all means with a superscript of a are significantly different from those with a superscript of b). Significance was determined after the variables were transformed in the same manner as used in multiple regression testing. 
The distance from an urban center, probably the simplest method of describing an urbanization gradient, implies that sites nearer to the city are the most urbanized. Using this single measurement as a gradient, I found lower tree density, tree species richness, tree species diversity, and importance of shade-tolerant trees, as well as smaller total tree diameter (total $\mathrm{dbh}$ ) at more urban sites. Measurements involving shade-tolerant tree species were frequently negatively correlated with urbanization. I found lower densities and importances of shade-tolerant trees and conifers, as well as lower densities of such shade-tolerant coniferous species as western hemlock and western red cedar at more urban sites.

Many measures of shrubs were negatively correlated with the distance from Portland. I found decreased density and species diversity of shrubs, as well as lower total height of all shrub species with increased distance from Portland. Density and height of thimbleberry and red elderberry also decreased with distance from downtown. Vine maple was the only shrub species that was positively correlated with distance from Portland as evidenced by lower density, height, basal area, and importance at more urban sites.

Herbaceous cover generally decreased as distance from Portland increased. I found larger numbers of herbaceous species, both native and non-native, as well as greater species diversity for all herbaceous species and for native herbaceous species at more urban sites.

Although my contention is that urbanization in the Portland area is causing the measured effects on the plant community of Forest Park and the surrounding forested 
areas, it is also possible that there are other causes for the observed results. One possible explanation that excludes direct effects of humans is the peninsula effect. The peninsula effect predicts greater numbers of species in the old-growth (the "mainland" end), with decreasing numbers of species at sites closer to Portland. However, sites in the far section of Forest Park had more tree species and greater tree species diversity than the old-growth, sites in the city and middle sections had more shrub species and greater shrub species diversity than sites in the far section of Forest Park, and sites in the city section had more herbaceous species and higher herbaceous species diversity than sites in either the far section or the old-growth in contrast to what the peninsula effect would predict. My data are not consistent with a peninsula effect. It appears, rather, that environmental parameters (e.g., temperature or moisture at a site) or temporal factors (i.e., the length of time since the last major disturbance at a site) probably have greater roles in species distribution in Forest Park than does a peninsula effect. This conclusion is also supported by the findings of Milne and Forman (1986) who determined that environmental heterogeneity had a larger impact on species diversity than did a peninsula effect.

It is unlikely that "natural" environmental parameters are responsible for the observed results because Forest Park is relatively small, and environmental and edaphic factors are similar throughout the study area. In any case, variation due to such factors would be accounted for in the regression coefficients. It seems more likely that different sections of the park are in different stages of succession. In particular, changes in the distribution of shade-tolerant tree species (associated with later successional stages) relative to that of shade-intolerant species (associated with earlier successional stages) suggest that succession is very important in defining site 
characteristics. These changes indicate that continual and/or increased disturbance related to urbanization maintains more urbanized sites at earlier successional stages than at less urbanized sites.

My results suggest that the four sections studied (i.e., the three sections of Forest Park and the old-growth stand) are in different successional stages. The old-growth stand is significantly different from sites in Forest Park, probably because continual human disturbances are more prevalent in Forest Park than in the, until recently, relatively undisturbed old-growth stand. In the old-growth stand, I found greater abundance and dominance of shade-tolerant tree species, as well as trees of larger diameter than at any site in Forest Park. These observations confirm the idea that the old-growth stand is in a mature or later successional stage of forest development than any site in Forest Park. In addition, most measurements of canopy cover showed that the old-growth was significantly different from sites in Forest Park. Foliage height diversity was not significantly different for the different sections studied, although it was significantly higher in the old-growth when herbaceous ground cover was removed. This is in keeping with results found by Portland Parks and Recreation (1995) showing that the park in general has reduced vertical structure, a characteristic of earlier successional stages in forest development (Spies 1991; Wilson 1991).

Sites in the middle section were dominated by deciduous trees, particularly red alder. In addition, the trees in the middle section had smaller diameters than those in the other sections. Red alder is an early successional species in the Pacific Northwest (Franklin and Pechanec 1967; Houle 1996; Newton et al. 1967). Alders usually 
invade and dominate sites where soils have been deeply scarified to the exclusion of Douglas-fir (Franklin and Pechanec 1967; Newton et al. 1967). Available information confims that much of this section was burned in 1951 (Bill Keil, retired forester for Portland Parks and Recreation, personal communication, Dec. 1997). According to Keil, only two sites in this section (sites 18 and 32) were outside of the boundaries of that fire. Site 32 was similar in species composition to the other sites in the middle section, and there was evidence of fire at the site in the form of charred stumps. This site may have escaped the fire of 1951, but it had burned at some recent point in its history. If Keil is correct, it was probably logged and slash burned at some time prior to 1951 . Site 18 was very different from the other sites in the middle section. Site 18 had the most tree species (nine) of any site in that section of the park (mean number of species was 4.7). Among the species present was Pacific yew, a species associated with older successional forests (Spies 1991). Site 18 is the only site west of the area burned by the 1951 fire that is not in the far section. It appears to be in a successional stage that is more similar to sites in the far section than to sites in the middle section.

The far section of Forest Park, characterized by sites having increased dominance and importance of shade-tolerant tree species, seems to be in a later successional stage than other sections of the park. The distribution of Pacific yew supports this view, although Pacific yew was not present at enough sites or in sufficient numbers to analyze statistically. The species was found only at sites in the middle (site 18) and $\operatorname{far}$ (sites 6, 7, and 22) sections of the park. Although Pacific yews are most frequently found in older successional stands, their distribution is more influenced by past land use history and available seed sources than by seral stage (Busing et al. 
1995; Spies 1991). The increased abundance of shade-tolerant tree species also supports the contention that the far section is older than the middle or city sections.

The city section of Forest Park was difficult to place in a successional sequence relative to the far section. Sites in the city section had trees with larger diameters than did other sections of Forest Park (e.g., the city section had larger Douglas-firs, shade-tolerant trees, shade-intolerant trees, and deciduous trees than the middle section; it also had larger Douglas-firs and bigleaf maples than the far section). The increased diameter of trees relative to the middle section leads me to conclude that the city section is in a later seral stage than the middle section of the park. In addition, the fact that trees in general, and Douglas-firs in particular, were larger in the city section than in the far section suggests that perhaps sites in the city section are in the oldest successional stage in Forest Park. This interpretation is questionable, however, because of the increased dominance of shade-tolerant trees in the far section. The evidence suggests that some trees in the city section may be older than trees in the far section, but that factors not considered here may be causing aspects of the plant community in the city section to exhibit characteristics of an earlier successional stage.

There appears to be a successional gradient in Forest Park due to the effects of logging and/or fires. However, that successional gradient does not imply that there has been no additional human affect on the distribution of trees and other plant species in the park. It may be that human disturbance is altering the "normal" patterns of succession in the city section of Forest Park similar to what has occurred in other disturbed forests (Abrams and Nowacki 1992; Dale and Doyle 1987; Hong 
et al. 1995; Kowarik 1990; Matlack 1993b). As areas surrounding Forest Park have been developed, the park has become increasingly fragmented (Portland Parks and Recreation 1995). Such fragmentation results in an increased amount of edge habitat. In my results, a greater amount of edge habitat would be indicated by a dependent variable exhibiting negative correlations with the distance from the nearest forest edge, the distance from the nearest road, and the percent of surrounding forest, as well as positive correlations with the distance from the center of the forest and the number of surrounding houses. Tree species density, richness, and diversity, as well as density of conifers and shade-tolerant tree species, were positively correlated with edge habitat. The fact that most tree variables were associated with edge habitat lends credence to the theory that edge resulting from habitat fragmentation, a consequence of human disturbance, has had dramatic impacts on plant community structure in Forest Park just as has been reported for other areas (Airola and Buchholz 1984; Dzwonko and Loster 1988; Greller et al. 1990; Rudnicky and McDonnell 1989). Human disturbance frequently results in plant communities that exhibit characteristics of earlier seral stages (Abrams and Nowacki 1992; Dale and Doyle 1987; Hong et al. 1995; Kowarik 1990; Leak and Smith 1996; Matlack 1993b; Petraitis et al 1989; Swindel et al. 1986). The successional stages I have found indicate that humans have had and will probably continue to have a dramatic impact on the structure of Forest Park. As human disturbance, especially in the form of increased habitat fragmentation, increasingly affects Forest Park, it would be expected that plant community structure in Forest Park will continue to be affected.

Examination of the distribution of shrubs and herbaceous plants also supports the idea of a successional gradient influenced by humans. The old-growth stand had 
more vine maple than any site in Forest Park and, along with the far section, it had a higher percentage of bare ground. Spies (1991) found significantly more vine maple at older successional sites located along the Oregon coast. The increased occurrence of vine maple in the old-growth site supports the idea that this site is in a mature stage of forest succession. Spies and Franklin (1991) found that, in general, herbaceous cover increased with stand age class. However, they also pointed out that understory species varied widely depending on the overstory composition, site moisture, and site disturbance history. More than likely, decreased herbaceous cover in the far section of the park and the old-growth stand can be attributed to the increased density of trees and saplings, and to decreased soil moisture at the location of the transects since I noticed that lower, wetter sites had a higher coverage of herbaceous plants. In addition, the old-growth stand contained such old-growth associates as Corallorhiza sp. (coral-root orchid), Tiarella trifoliata (foam flower), and Linnaea borealis (twinflower) (Ruggiero et al. 1991; Spies 1991).

The city and middle sections had greater shrub species diversity and shrub species richness than did the far section. The city section also had a greater density of shrubs than the middle or far sections. The greater density of shrubs at more urban sites would be expected in earlier successional states, as well as in response to continual disturbance (Carey et al. 1991; Norse 1990). Fugate (1994) found positive correlations between shrub species richness and the distance from the edge of the forest. Although I did not find the same correlations in this study as Fugate, I did find positive correlations of other shrub variables with edge habitat. For example, the densities of non-native shrubs and vine maple plants were found to be related with edge habitat. The density of non-native shrubs correlated positively with the 
number of houses. Since many exotic species escape from gardens, the positive correlation with houses is not unexpected. Thus, in the shrub community, urbanization is correlated with an increased abundance of non-native species.

Whereas many shrub variables were associated with edge habitat, many herbaceous variables were associated with forest interior. Increased herbaceous species diversity and greater cover of several native herbaceous species were associated with forest interior habitat. The increase in herbaceous species near the city could be the consequence of historical usage because the city section appears to have been sheltered from fires and logging for longer than the other sections of the park. The city section has only experienced one small salvage logging job since 1951 that followed the Columbus Day storm in 1962 (Keil, W., retired forester for Portland Parks and Recreation, personal communication, Dec. 1997). Only one site (14) in the city section provided physical evidence of logging or fire, whereas six sites in the far section (all except site 7) provided evidence of such human disturbance (Table 517).

The distribution of non-native plant species followed a predictable pattern. Nonnative tree and shrub species were present only at sites in the city and middle sections of Forest Park. Non-native herbaceous plants were present at sites in all sections, but there were significantly more non-native herbaceous species present at sites in the city section than at sites in the far section. There were too few non-native trees to be statistically analyzed by either regression or ANOVA. However, increased density of non-native shrubs and increased cover by non-native herbaceous species were both associated with increased edge habitat. Since increased species richness and 
Table 5-17. Types of disturbance that have occurred in the past as determined by physical evidence of fire and/or logging activity observed at each site.

City Section:

Site \#

1
3
5
12
13
14
28
30

Middle Section:

Site \#

11

17

18

23

24

32

36

37
Evidence at Site

$-$

-

-

logged

-

Far Section:

Site \#

2

6

7

15

19

22

39

41

Evidence at Site

logged/fire

$-$

fire

logged/fire

logged/fire

\section{Evidence at Site fire \\ logged/fire \\ logged \\ logged/fire \\ fire \\ logged/fire \\ fire}

Old-growth:

Site \#

OG

Evidence at Site

fire 
species diversity with proximity to edge is well documented (Chen et al. 1992, 1995; Fugate 1994; Lehmkuhl and Ruggiero 1991; Levenson 1981; Matlack 1993a; Ranney et al. 1981), my results are not surprising.

Increased tree species richness and diversity were associated with edge habitat in this study, but both were significantly greater in the far section and the old-growth stand. These results suggest that although edge effect may be important to the distribution of trees in Forest Park, the past land use and history successional stage of the site is probably also very important. Increased species diversity of both shrubs and herbaceous plants was associated with forest interior habitat, although herbaceous species richness and diversity were significantly greater at sites in the city section. This result did not depend on including non-native species. Thus, the increase in species diversity was not merely the result of an influx of exotic species. The intermediate disturbance hypothesis may be the best explanation for the increased species diversity of herbaceous plants at the city end of the park. According to this hypothesis, moderate levels of disturbance lead to increased species diversity due to increased heterogeneity of disturbed habitat versus nondisturbed habitat (Connell 1978; Huston 1979; Petraitis et al. 1989). Disturbances can be described in terms of both severity and frequency. Intermediate levels of repeated disturbances help maintain the patchiness of a landscape, affording a greater variety of habitat types and allowing for a more heterogeneous distribution of species (Petraitis et al. 1989). A number of investigators have reported that plant species diversity initially increased and then decreased as disturbance intensified (Armesto and Pickett 1985; Hoehne 1981; Kowarik 1990), similar to the findings in this study. 
The level of disturbance in any forest should correlate with edge. The city section of Forest Park has significantly less area of forest interior habitat than other sections as a result of development and habitat fragmentation (Figure 5-1). Concomitantly, the city section has a greater amount of edge habitat (Figure 5-2). Increased edge habitat implies increased levels of disturbance. If this correlation is correct, the increased diversity at sites in the city section is to be expected. The diversity of all herbaceous species and many species of native herbaceous plants correlated positively with the distance from the nearest road suggesting that disturbance associated with roads may be causing the observed reduction in species diversity at sites near roads. This correlation could be due to the increased trampling (increased disturbance) near roads in the park, as roads provide access points for entry (Matlack 1993b). High levels of continual disturbance could lead to increased homogeneity and thereby to decreased species diversity at sites near roads, whereas areas further from roads would have less trampling and less disturbance even though they may still be more highly disturbed than other areas of the park. The city section of Forest Park has significantly higher usage by humans than other sections (Figure 5-3) due in part to a higher density of trails (Figure 5-4; adapted from data from Portland Parks and Recreation 1995) and probably more convenient access. The potential for physical disturbance and/or trampling of vegetation at a given site is therefore greater at more urban sites. The results may support the intermediate disturbance hypothesis where sites in the more highly utilized city section have increased species diversity due to moderate levels of disturbance, whereas areas nearer to roads have decreased species diversity as the result of higher and/or more continual levels of disturbance. 


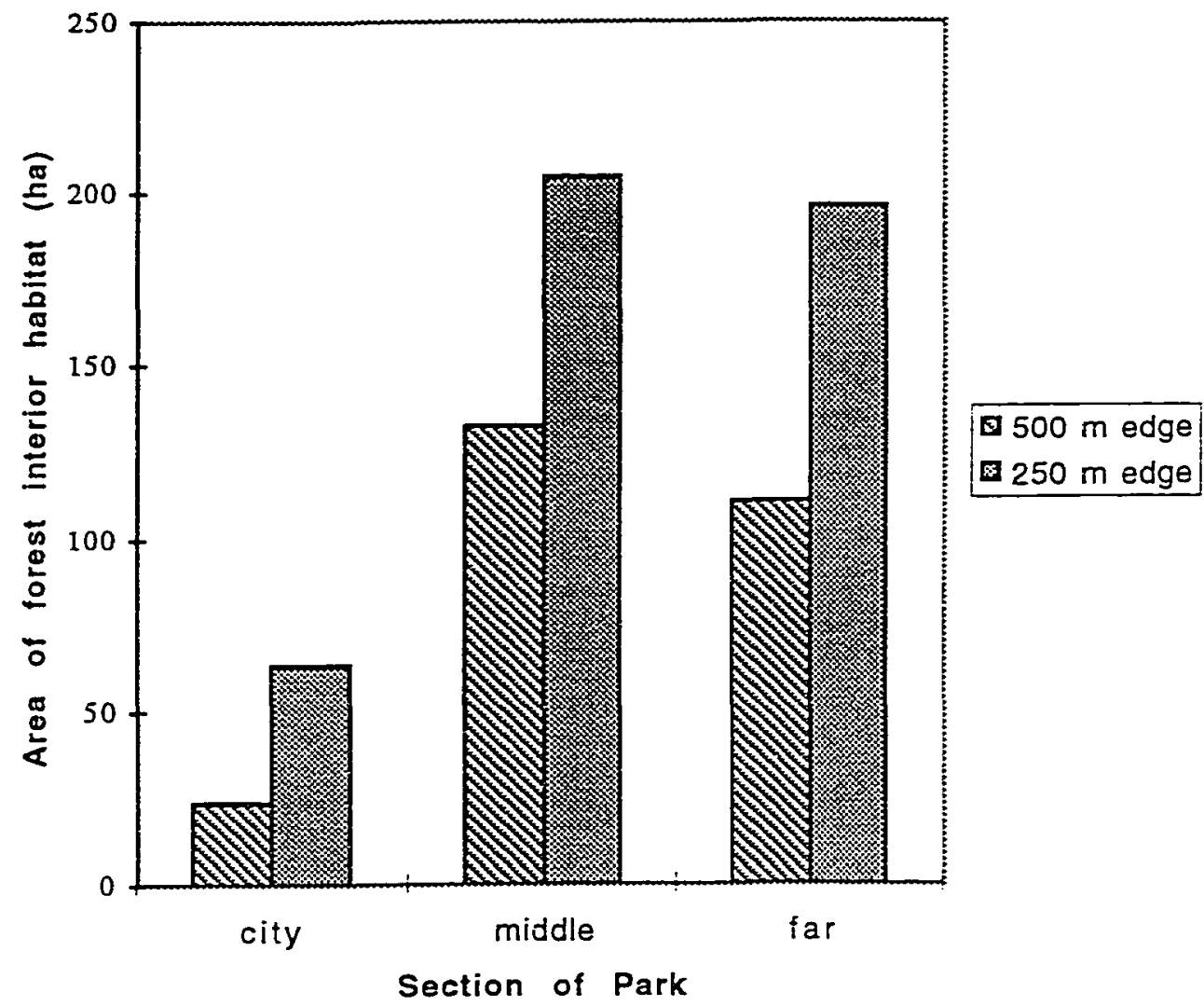

Figure 5-1. The area (ha.) of forest interior habitat in the different sections of the park assuming that edge extends 250 or 500 meters into the forest. 


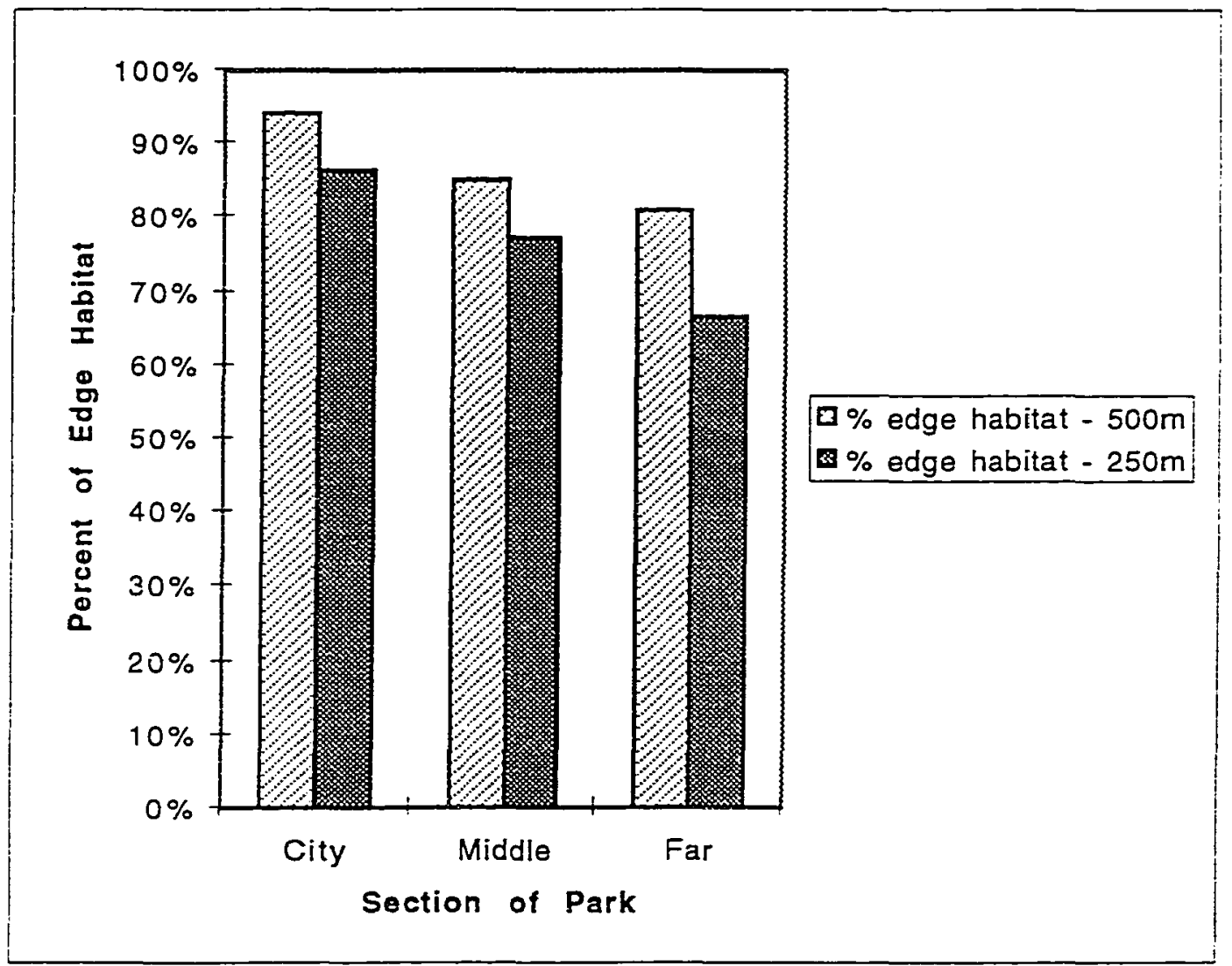

Figure 5-2. The percent of forest edge habitat in the different sections of Forest Park assuming that edge extends 250 or 500 meters into the forest. 


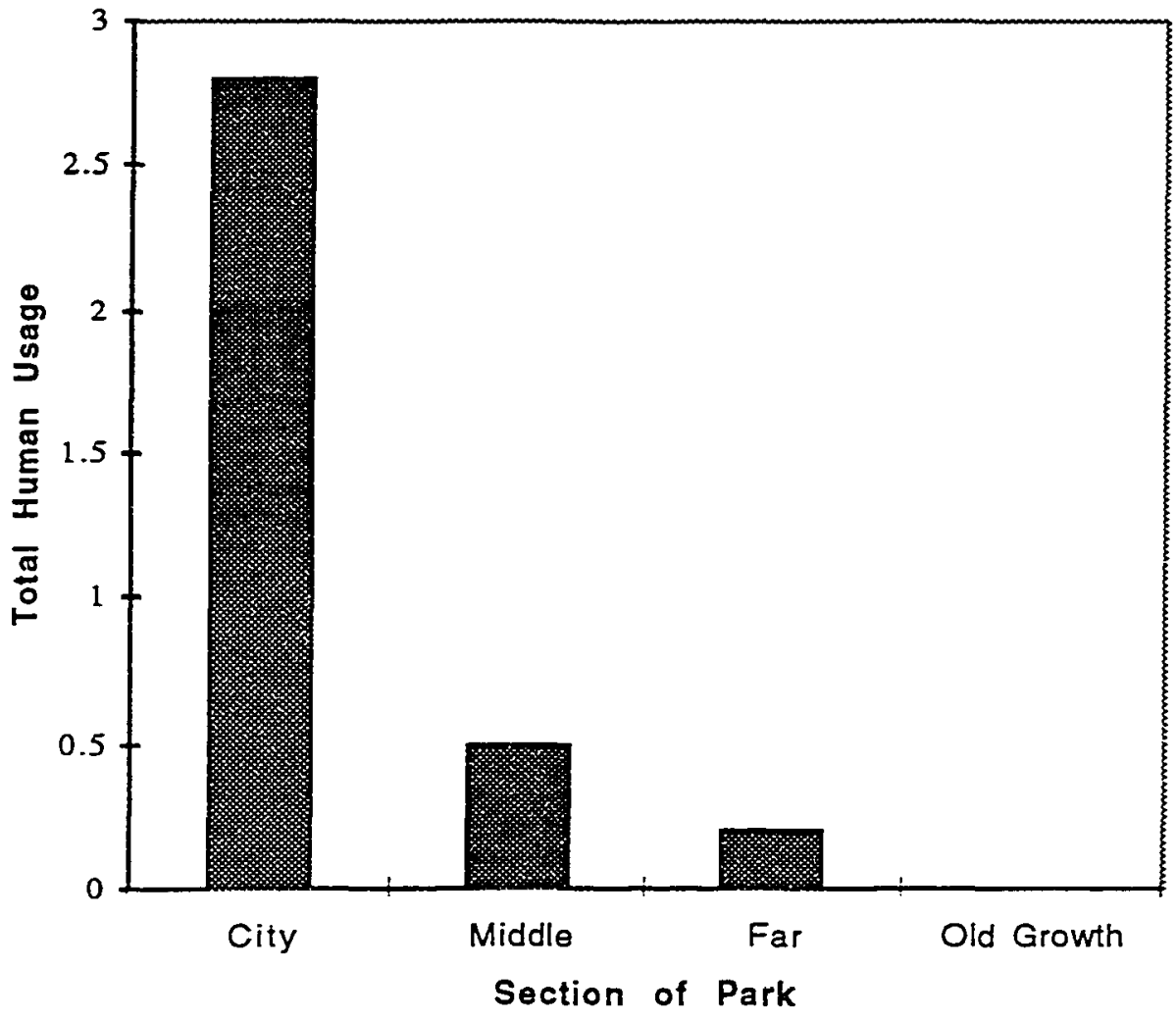

Figure 5-3. Mean site usage (total human usage) in different areas of the park. 


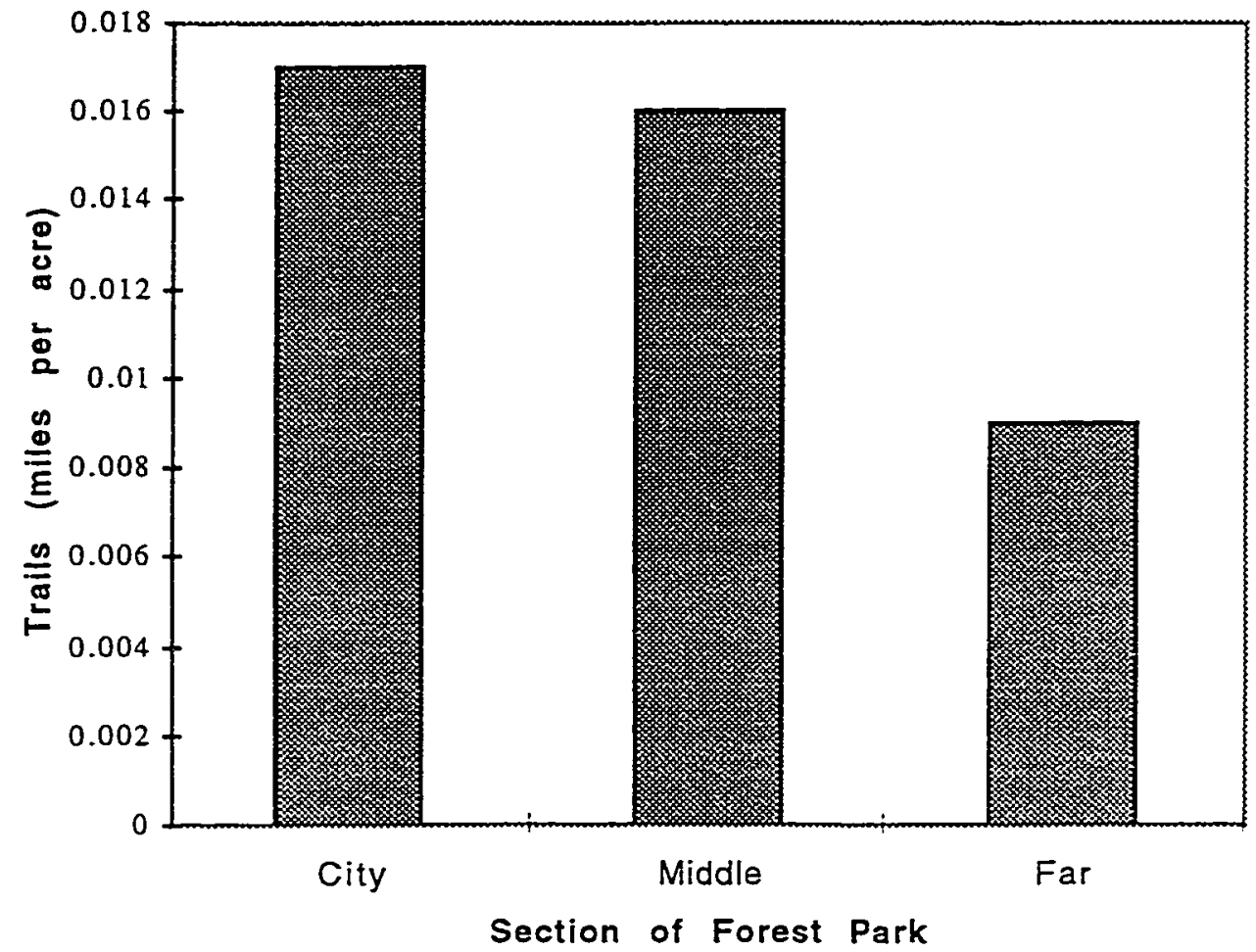

Figure 5-4. The density of trails (miles per acre) in the different sections of Forest Park. 
Assuming that the old-growth stand more closely resembles the original native forest than other younger forested lands, the forest that $I$ found growing in Forest Park was very different from the presettlement forest. I believe that this is the result of continual and dramatic disturbance events -- logging and forest fires -- that have resulted in a mosaic of landscapes. Many of my results can be explained by the observation that the different portions of the park are in different successional stages. However, humans appear to be a moderating influence on the rate of succession. Their effects are especially apparent in the city section of the park and may be retarding successional changes in the city section of Forest Park. 


\section{CHAPTER 6}

\section{THE EFFECTS OF HUMAN DISTURBANCE AND URBANIZATION ON THE POPULATION DYNAMICS AND VIGOR OF TREES IN THE FOREST}

Disturbance can cause shifts in the demographic structure of a forest, depending upon the degree and frequency of the disturbance (Harper 1977). Rao et al. (1990) reported that tree species in disturbed, subtropical forests in India exhibited reverse-J size distribution curves (i.e., an age structure showing large numbers of individuals in the smallest size class with a steep decline and flattening among larger size classes), whereas those in undisturbed forests exhibited either sigmoidal or bimodal curves. If urbanization increases the amount of disturbance in a system, then urbanization should have significant effects on the age structure of trees in a forest. Rudnicky and McDonnell (1989) are among the few researchers who have addressed the effects of urbanization on the demography of trees in a natural forest system. They found that the diameter size class distribution of trees in the New York City Botanic Garden Forest had changed over a 48-year period. Their research revealed a large increase in the number of smaller stems, especially for certain tree species. They also found a reverse- $J$ curve for the diameter size class distribution of all species of trees in New York City. However, the same reverse-J size distribution that indicates disturbance in some forests is reported to be normal for old-growth forests in the Pacific Northwest (Arsenault and Bradfield 1995; Franklin and Spies 1991b; Parker and Peet 1984). Urbanization, a type of disturbance, should affect the population dynamics of nearby forests. If older age classes are damaged or 
destroyed, the proportion of seedlings and saplings should increase, although if soil microenvironments in urban ecosystems are severely distupted by soil compaction or the effects of pollutants, there should be a decrease in the proportion of seedlings and saplings (Airola and Buchholz 1984; Greller et al. 1990; Kowarik 1990; Pouyat et al. 1994, 1995a, 1995b; Rogers and Rowntree 1988; Seidling 1990; Supuka 1994; Vanhala et al. 1996; White and McDonnell 1988; Yost et al. 1991).

Rudnicky and McDonnell (1989) found in their study an apparent lack of reproduction of certain native tree species in the New York City Botanic Garden Forest, especially for Tsuga canadensis and species of Quercus. Similar reproductive failures have also been reported at other disturbed locations (Airola and Buchholz 1984; Greller 1975; Hoehne 1981; Levenson 1981; McBride and Jacobs 1986; Yost et al. 1991). James et al. (1979) found a reduction in the abundance of tree seedlings in campgrounds in Ontario. Airola and Buchholz (1984) found decreased reproduction by shade-tolerant tree species (e.g., Acer rubrum and Quercus alba), but increased reproduction by early seral ("weedy") tree species (e.g., Ailanthus altissima and Prunus serotina) in more disturbed areas. Yost et al. (1991) noticed a reduction in the abundance of tree seedlings as the percentage of non-native herbaceous species increased. Proposed causes for the observed decline in tree reproduction include the effects of trampling and arson, increased browsing by small mammals such as squirrels, competition by non-native plants, and the effects of pollution. Many scientists have reported reductions in the abundance of seedlings of native, dominant tree species in areas with high concentrations of atmospheric pollutants (Greller et al. 1990; Klein and Perkins 1988; Kozlowski et al. 1991; Rudnicky and McDonnell 1989; Woodward 1992). 
Abiotic factors related to urbanization, such as increased amounts of air pollution or soil compaction, could be expected to cause reduced tree vigor and/or increased mortality (Airola and Buchholz 1984; Greller et al. 1990; James et al. 1979; Klein and Perkins 1988; Kowarik 1990; Pouyat et al. 1994, 1995a, 1995b; Rogers and Rowntree 1988; Rudnicky and McDonnell 1989; Seidling 1990; Supuka 1994; Vanhala et al. 1996; White and McDonnell 1988; Yost et al. 1991). Tree vigor relates to the overall health of the tree and is usually measured as diameter increment growth (Ashby and Fritts 1972; Fitzgerald and Raynal 1991; James et al. 1979; Jones et al. 1994; McBride and Jacobs 1986; McLaughlin et al. 1983; Nash et al. 1975; Rudnicky and McDonnell 1989; Thompson 1981). However, other criteria such as crown fullness, amount of twig dieback, needle loss (Fitzgerald and Raynal 1991), and the degree of regeneration (Jones, et al. 1994; McBride and Jacobs 1986) are also employed. James et al. (1979) found reductions in both annual increment growth and needle length in areas of heavy human disturbance. Several researchers found reductions in the size of annual rings in areas with moderate to high levels of air pollution (Ashby and Fritts 1972; McLaughlin et al. 1983; Nash et al. 1975; Thompson 1981). Continued reductions in tree vigor could be expected to be correlated with increased tree mortality. McBride and Jacobs (1986) found reduced radial increment growth along with increased tree mortality in some California urban areas. Urbanization has also been reported to cause increases in the mortality rates of certain tree species (Levenson 1981, McBride and Jacobs 1986, Rudnicky and McDonnell 1989). Increased concentrations of heavy metals, such as lead, that accumulate in urban soils have been correlated with increased tree mortality rates (Airola and Buchholz 1984; Pouyat et al. 1994; Pouyat et al. 1995a, 1995b; Supuka 
1994; White and McDonnell 1988; Yost et al. 1991). If mortality is random, there should be no species or age-specific differences in the death pattern, and there will be no apparent effect on the age structure of the forest. If, however, mortality is more common in certain species or if it is more prevalent at a specific portion of the age structure (i.e., very old or very young trees), the structure of the forest will change.

Many investigators have argued that changes occur in the age structure of a forest along an urbanization gradient (Airola and Buchholz 1984; Greller 1975; Hoehne 1981; Levenson 1981; McBride and Jacobs 1986; Rudnicky and McDonnell 1989; Yost et al. 1991). These changes are often manifested by differential rates of either regeneration or mortality or both. In addition, the health or vigor of trees also seems to be affected by the processes of urbanization (Airola and Buchholz 1984; Greller et al. 1990; Klein and Perkins 1988; Kowarik 1990; Pouyat et al. 1994, 1995a, 1995b; Rogers and Rowntree 1988; Rudnicky and McDonnell 1989; Seidling 1990; Supuka 1994; Vanhala et al. 1996; White and McDonnell 1988; Yost et al. 1991). In this study, I have tried to determine if changes are occurring in the age structure of trees in Forest Park along an urbanization gradient and I have examined tree regeneration, tree mortality, and the vigor of trees as determined by increment growth.

\section{METHODS FOR POPULATION DYNAMICS}

The diameters at breast height (dbh) of all living trees and saplings in each 500 square meter quadrat were measured using a diameter tape. Each tree or sapling was placed into a size class based upon its dbh. There were two classes of saplings: saplings $0-4.9 \mathrm{~cm} \mathrm{dbh}$ and saplings $5.0-9.9 \mathrm{~cm} \mathrm{dbh}$. There were four categories 
of trees: trees with dbh $10.0-19.9 \mathrm{~cm} ; 20.0-39.9 \mathrm{~cm}, 40.0-59.9 \mathrm{~cm}$, and greater than $60.0 \mathrm{~cm}$.

Randomly selected trees at each site were cored at a height of approximately one meter. This height was chosen because it was lower to the ground than breast height, and hence would provide more accurate tree ages, while still allowing for the leverage necessary to core a hardwood tree. Sites with many trees were sampled by randomly selecting trees from several size classes for all species present. The cores were sanded and stained using phloroglucinol. The number of rings was counted under a dissecting microscope to estimate the age of the tree. To determine the ages of trees too small to core ( $<5 \mathrm{~cm} \mathrm{dbh}$ ), randomly selected saplings were harvested, a stem disk was taken from near-ground levels, and the rings counted on the round obtained.

The increment cores were also used to determine whether the tree's vigor, as revealed by growth rate, had changed over time or along a spatial urbanization gradient over the last 70 years. Growth rates were measured as the average width of annual rings measured in decade intervals. Decade intervals were used to minimize annual climatic fluctuations. This analysis was done for seven consecutive decades on all cores where it was possible and for as many decades as possible on trees with fewer than 70 annual rings. In addition, the live crown ratio (the ratio of the height of the lowest living branch to the height of the tree) was used as another means to compare the vigor of trees among sites. 
Regeneration and mortality of trees were determined at each site. Regeneration was measured by counting the number of living seedlings of each tree species located along each transect and by counting the number of living saplings in each quadrat. All dead trees located in each quadrat were counted, their height and dbh were measured, and the trees were identified to species when possible. These mortality measurements were reported for both standing and recently fallen trees. Sites were visited for four consecutive years (1993 through 1996), tree mortality was recorded annually, and a rate of mortality was calculated for each location.

\section{RESULTS}

\section{Data Analysis}

The dependent variables that were related to tree demographics were divided into related groups: tree regeneration, age structure, tree mortality, and tree growth rates. As before, all dependent variables were analyzed using multiple regression and ANOVA. Each dependent variable was analyzed by multiple regression using the seven independent urbanization variables and the covariable as discussed previously. Each significant dependent variable was further examined using ANOVA, and the various sections of the park were compared using Bonferroni/Dunn analysis to detect significant differences. Regression coefficients are located in Appendix E.

\section{Multiple Regression Analysis of Tree Demographics -- Age Structure, Recruitment, Mortality, and Growth Rates}

Several dependent variables associated with the demographics of trees and saplings at sites in Forest Park and the old-growth stand were found to be correlated with at least one urbanization variable by multiple regression (Table 6-1). Variables that were 


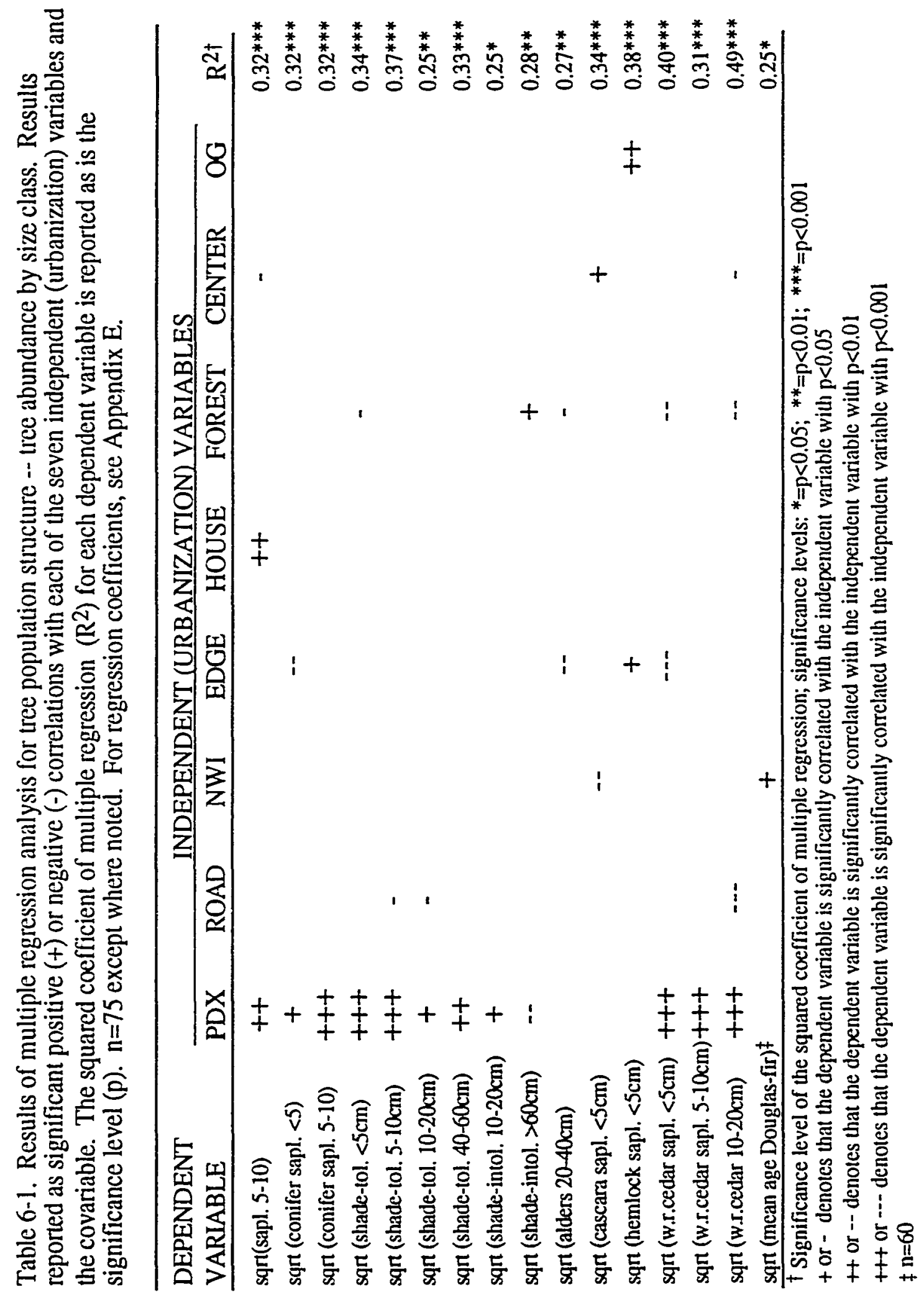


positively correlated with the distance from downtown Portland included the density of larger (5-9.9 $\mathrm{cm} \mathrm{dbh)} \mathrm{saplings,} \mathrm{and} \mathrm{the} \mathrm{densities} \mathrm{of} \mathrm{shade-tolerant} \mathrm{trees} \mathrm{and}$ coniferous trees. The only variable that was negatively correlated with this urbanization variable was the density of larger shade-intolerant trees. Other urbanization variables that were correlated with tree population structure included the distance from the nearest road (negatively), the distance from the nearest edge (mostly negatively), and the percent of surrounding forest (mostly negatively).

Several independent variables that measured tree mortality were also positively correlated with the distance from downtown Portland (Table 6-2). The numbers of dead western hemlocks, dead western red cedars, dead conifers, dead shade-tolerant trees, and dead trees of all species were each positively correlated with the distance from downtown Portland, as was the percentage of trees on a site that were dead in 1996. Three of these same variables were also positively correlated with the distance from the nearest forest edge.

Tree increment growth rates (GR) were found to be correlated with urbanization variables for several species (Table 6-3). Growth rates of coniferous species such as western red cedar, grand fir, and western hemlock for the last 4 decades were often positively correlated with the distance from the nearest road. The number of surrounding houses, the distance from the nearest forest edge and the percent of surrounding forest were also significant in many cases. Douglas-fir growth rates for earlier decades were negatively correlated with the distance from the nearest forest edge and positively correlated with the percent of surrounding forest. 


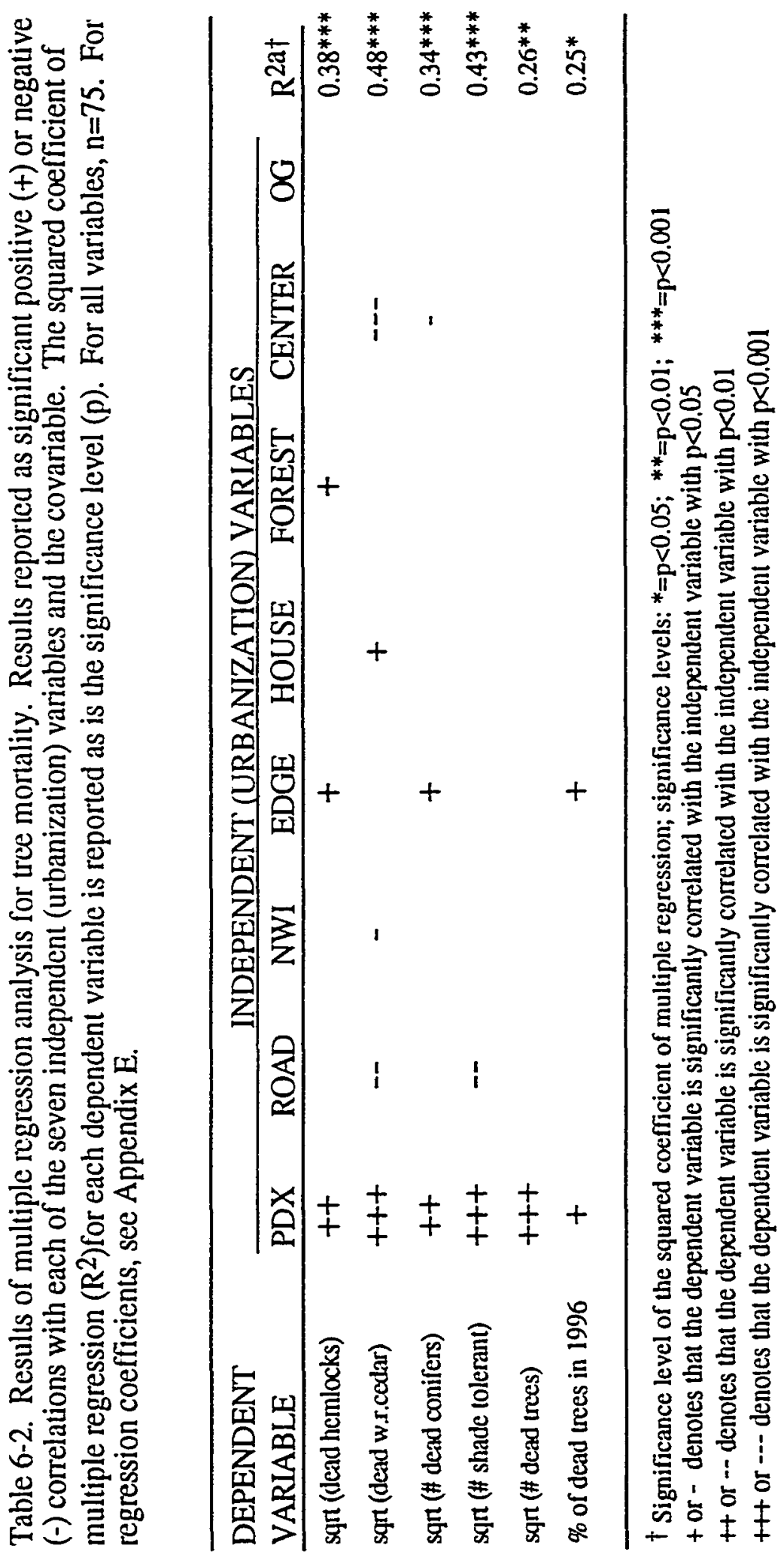




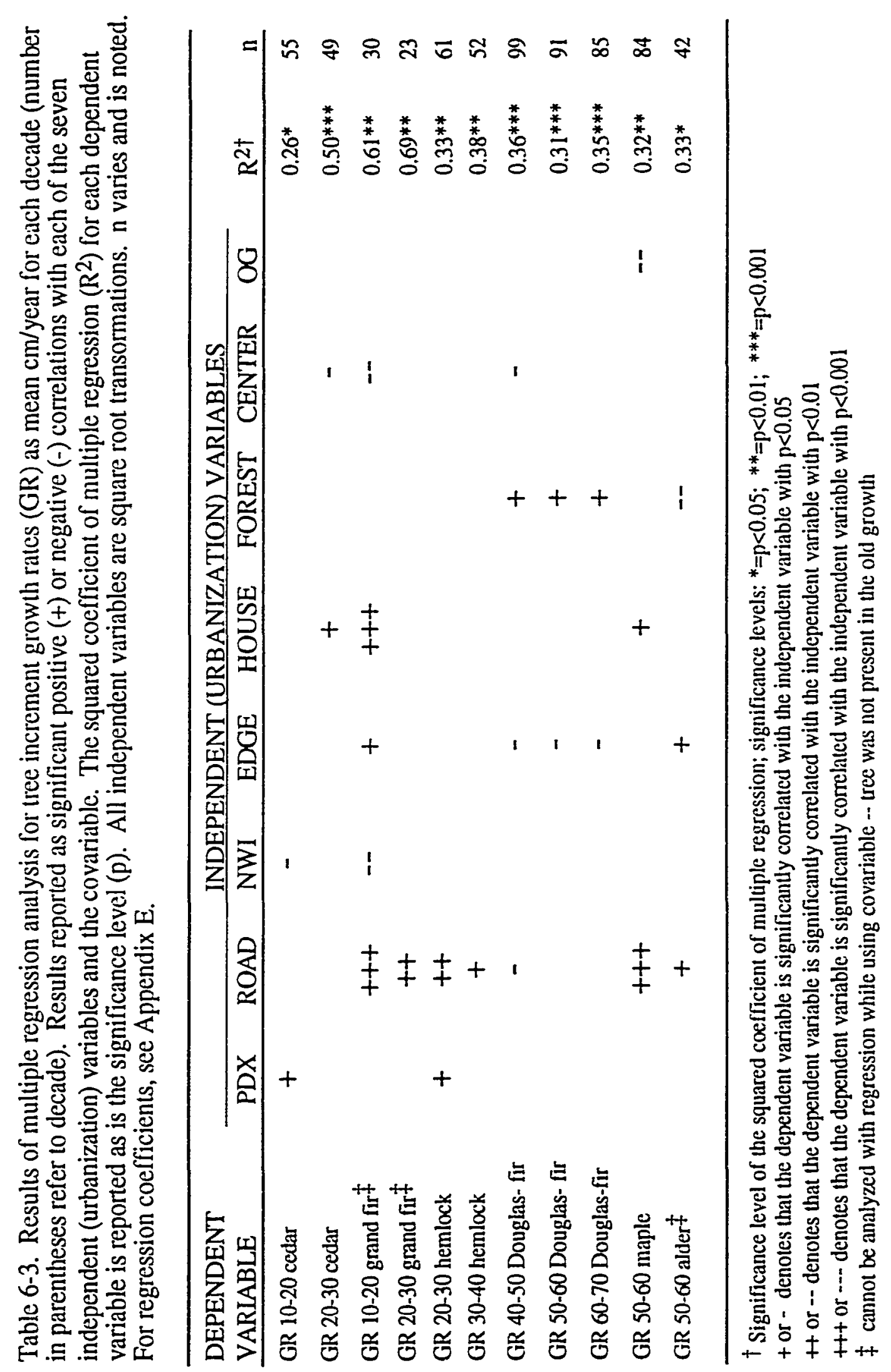


The live crown ratio (LCR) was only significant for four dependent variables (Table 6-4). Generally, the live crown ratio was negatively correlated with the distance from downtown Portland and the distance from the nearest forest edge, and positively correlated with the distance from the nearest road.

\section{Tree Demographics -- Age Structure, Recruitment, Mortality, and Growth Rates -- Differences Between Sections}

\section{Age Structure}

There were no differences observed in the distribution of seedlings as evaluated by either regression or ANOVA. Indeed, there were relatively few seedlings measured at any site (Table 6-5). There were no significant differences in the numbers of seedlings among the different sections, and although the middle section had 82 bigleaf maple seedlings, all but four were counted on one transect. Observations later the same year found that none of these seedlings had survived. The far section was the only area where seedlings of any coniferous species (western red cedar) were counted.

Sites in the city and middle sections had significantly fewer shade-tolerant saplings and trees of all sizes than sites in the far section or the old-growth (Figure 6-1). There were significantly more shade-intolerant small saplings $(<5 \mathrm{~cm} \mathrm{dbh})$ in the middle section than the other sections. There were also significantly more shadeintolerant trees in the $10-20 \mathrm{~cm}$ size class in the middle and far sections of the park. There were significantly more very large $(>60 \mathrm{~cm} \mathrm{dbh})$ trees in the old-growth. For ANOVA and Bonnferoni/Dunn analysis results, see Appendix F. 


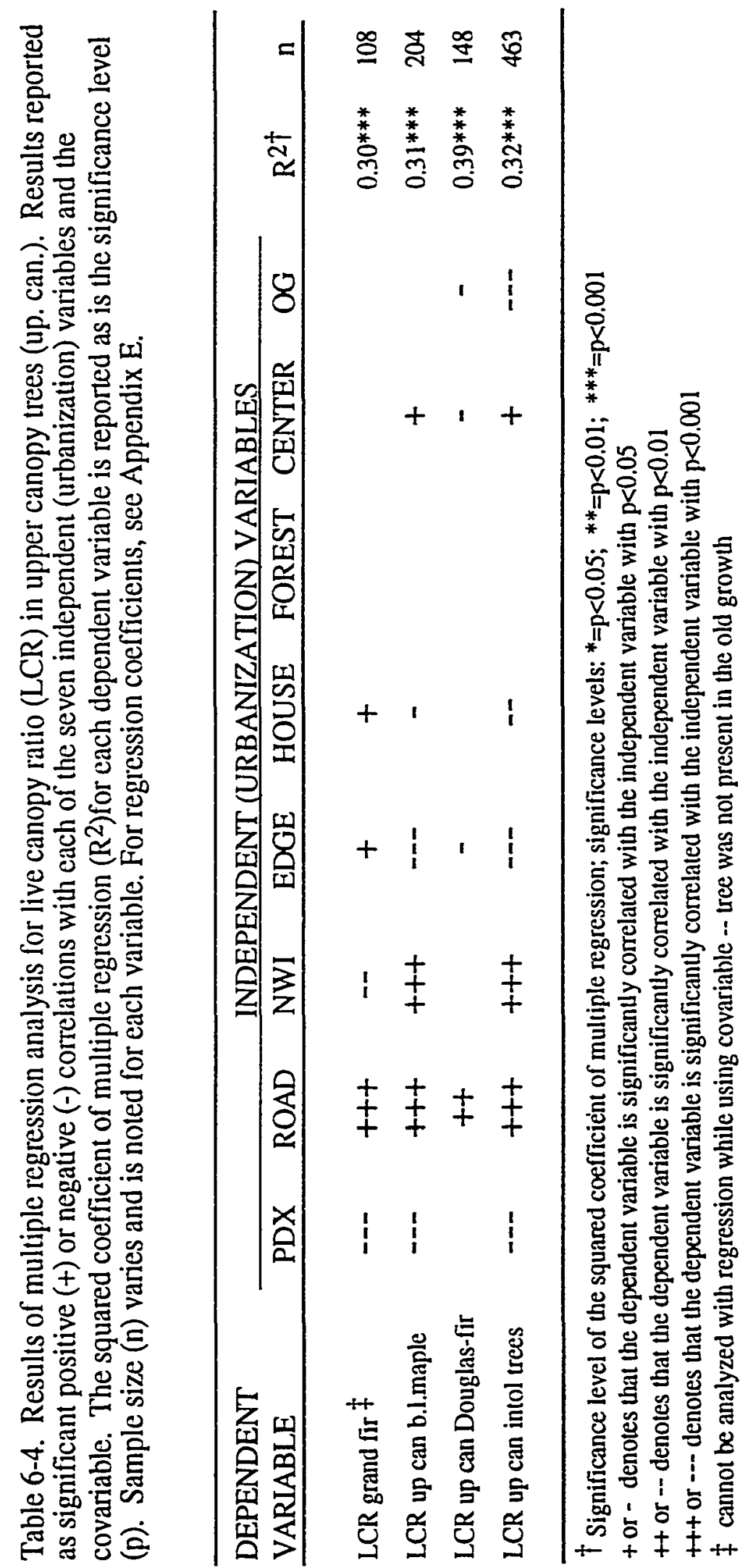


Table 6-5. Total number by species of seedlings found in the different sections of the park.

$\begin{array}{lcccc}\text { Species } & \text { City } & \text { Middle } & \text { Far } & \text { OG } \\ \text { Acer macrophyllum } & 0 & 82^{\dagger} & 2 & 0 \\ \text { Rhamnus purshiana } & 8 & 0 & 3 & 1 \\ \text { Thuja plicata } & 0 & 0 & 4 & 0 \\ \text { Prunus emarginata } & 0 & 0 & 2 & 0 \\ & & & & \\ \text { Total \# seedlings } & 8 & 82^{*} & 11 & 1 \\ \text { Mean \# seedlings (standard } & & & & 0.3(0.6) \\ \text { deviation) } & 0.3(0.9) & 3.4(15.9) & 0.5(1.0) & 1\end{array}$

$\dagger$ Seedlings on one transect at this site were counted in June 1995. All other transects were counted between July 1 and August 31, 1994. Observations later in the summer of 1995 revealed no living seedlings on this transect. 


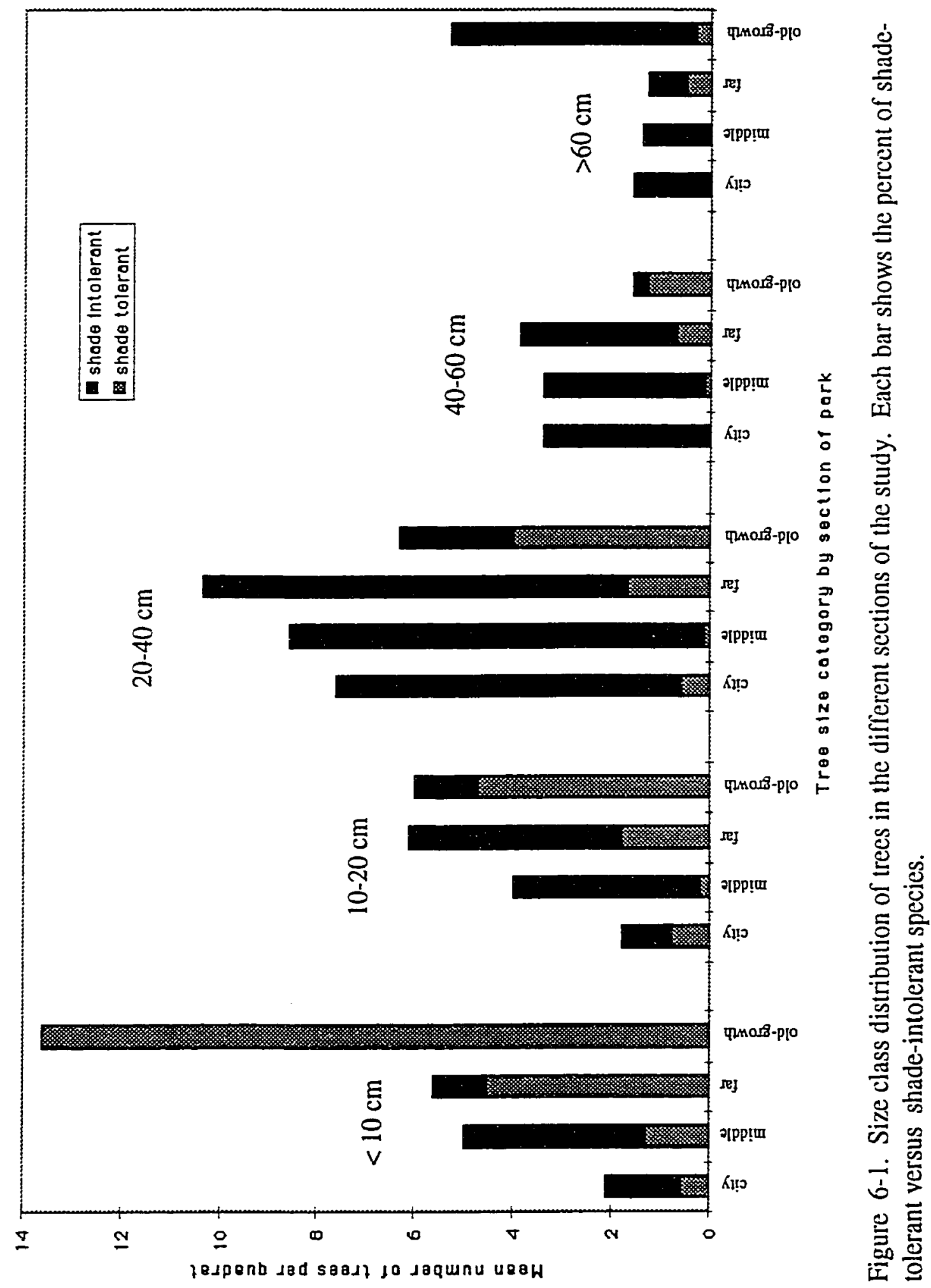


The mean age of all trees whose cores I could age (i.e., generally trees less than 50 $\mathrm{cm} \mathrm{dbh}$ ) was greatest for the site in the old-growth (62 years), followed by the city section (51.5 years), the far section (43.7 years), and then the middle section ( 38.8 years) (Table 6-6). Trees, on average, were significantly older at sites in the oldgrowth and the city section than at sites in the middle and far sections of Forest Park. Bigleaf maples were significantly older in the city than in the middle or far sections, and alders and Douglas-firs were older in the city than in the middle section.

\section{Mortality}

There were significantly more dead trees in the far section than in either the city or middle section of Forest Park (Table 6-7). There were more dead conifers and shade-tolerant trees in the far section and the old-growth. There was significantly more dead bigleaf maple in the far section, more dead red alder in the middle section, and more dead western hemlock and western red cedar in both the far section and the old-growth.

\section{Increment Growth Rate and Live Crown Ratio}

For all decades examined, the average increment growth rates (cm/year) for both Douglas-firs and bigleaf maples were lowest in the old-growth stand (Figure 6-2). Growth rates for trees in Forest Park had a unimodal pattern where rate of growth had peaked between 30 and 50 years ago with slower rates before and after that time. The growth rates for the two most recent decades (0-10 and 10-20 years ago) tended to be significantly lower than the other decades for all sections of the park. The oldgrowth (outside of the park) had a very different pattern with no significant pattern 
Table 6-6. Mean age of trees that were small enough to be aged by coring (standard deviation) for the different sections. Tree species that were present in less than two sections were omitted from the table. Reported results are for only trees for which complete core samples were available (generally $<50 \mathrm{~cm} \mathrm{dbh}$ ). $\mathrm{n}$ varies by section and species and is reported for each variable.

City Mid Far OG

\begin{tabular}{|c|c|c|c|c|}
\hline Bigleaf maple & $\begin{array}{c}57.4(28.4)^{\mathrm{a}} \\
50\end{array}$ & $\begin{array}{c}43.1(15.1)^{b} \\
59\end{array}$ & $\begin{array}{c}44.0(13.2)^{\mathbf{b}} \\
49\end{array}$ & $\begin{array}{c}62.2(16.8)^{\mathrm{ab}} \\
5\end{array}$ \\
\hline Red alder $x$ & $\begin{array}{c}66.2(25.8)^{\mathrm{a}} \\
22\end{array}$ & $\begin{array}{c}48.2(14.0)^{\mathrm{b}} \\
38\end{array}$ & $\begin{array}{c}53.7(17.5)^{\mathrm{ab}} \\
26\end{array}$ & - \\
\hline Cherry & $\overline{0}$ & $\begin{array}{c}34.0(2.8) \\
2\end{array}$ & $\begin{array}{c}69.0(-) \\
1\end{array}$ & - \\
\hline Dogwood & $\begin{array}{c}31.0(7.0) \\
3\end{array}$ & $\begin{array}{c}33.5(0.7) \\
2\end{array}$ & - & $\begin{array}{l}59.0(-) \\
1\end{array}$ \\
\hline Douglas-fir ${ }^{x}$ & $\begin{array}{c}68.9(36.0)^{\mathrm{a}} \\
14\end{array}$ & $\begin{array}{c}42.9(22.9)^{\mathrm{b}} \\
15\end{array}$ & $\begin{array}{c}62.4(36.1)^{\mathrm{ab}} \\
21\end{array}$ & - \\
\hline Western hemlock & $\begin{array}{c}57.6(18.7) \\
19\end{array}$ & $\begin{array}{c}39.0(9.5) \\
3\end{array}$ & $\begin{array}{c}57.9(39.8) \\
17\end{array}$ & $\begin{array}{c}65.6(30.5) \\
8\end{array}$ \\
\hline Western red cedar & - & $\begin{array}{c}39.5(14.0) \\
6\end{array}$ & $\begin{array}{c}42.9(23.7) \\
25\end{array}$ & $\begin{array}{c}59.5(15.2) \\
6\end{array}$ \\
\hline Grand fir & $\begin{array}{c}38.4(14.3) \\
14\end{array}$ & $\begin{array}{c}37.9(11.0) \\
7\end{array}$ & $\begin{array}{c}41.4(6.8) \\
5\end{array}$ & - \\
\hline All trees ${ }^{x}$ & $\begin{array}{c}51.5(28.9)^{\mathrm{a}} \\
151\end{array}$ & $\begin{array}{c}38.8(17.8)^{b} \\
174\end{array}$ & $\begin{array}{c}43.7(25.4)^{b} \\
203\end{array}$ & $\begin{array}{c}62.0(21.3)^{\mathrm{a}} \\
21\end{array}$ \\
\hline Conifers $x$ & $\begin{array}{c}52.1(27.7)^{\mathrm{a}} \\
52\end{array}$ & $\begin{array}{c}36.7(19.0)^{b} \\
46\end{array}$ & $\begin{array}{c}46.1(30.0)^{\mathrm{ab}} \\
99\end{array}$ & $\begin{array}{c}62.1(23.8)^{\mathrm{a}} \\
16\end{array}$ \\
\hline Deciduous trees & $\begin{array}{c}51.1\left(29.6^{\mathrm{a}}\right. \\
99\end{array}$ & $\begin{array}{c}39.5(17.4)^{b} \\
128\end{array}$ & $\begin{array}{c}41.4(20.1)^{b} \\
104\end{array}$ & $\begin{array}{c}61.7(15.1)^{\mathrm{ab}} \\
6\end{array}$ \\
\hline Shade tolerant $x$ & $\begin{array}{c}51.3(23.7)^{\mathrm{ab}} \\
22\end{array}$ & $\begin{array}{c}37.1(19.2)^{\mathrm{a}} \\
14\end{array}$ & $\begin{array}{c}42.2(28.1)^{\mathrm{a}} \\
64\end{array}$ & $\begin{array}{c}62.1(23.8)^{b} \\
15\end{array}$ \\
\hline Shade intolerant & $\begin{array}{c}57.9(29.6)^{\mathrm{a}} \\
100\end{array}$ & $\begin{array}{c}41.0(17.6)^{b} \\
134\end{array}$ & $\begin{array}{c}47.9(23.1)^{b} \\
112\end{array}$ & $\begin{array}{c}62.2(16.8)^{a b} \\
5\end{array}$ \\
\hline
\end{tabular}

Results of Bonnferoni/Dunn testing is shown for each variable as superscripts for means that are significantly different from one another. For a given variable, means with different superscripts are significantly different from one another (e.g., for any given dependent variable, all means with a superscript of a are significantly different from those with a superscript of b). Significance was determined after the variables were transformed in the same manner as used in multiple regression testing.

A superscript of " $x$ " denotes that the square root of the variable was used in statistical analyses. 
Table 6-7. Mean number of dead trees (all results from 1996) of different species (standard deviation) for the different sections Tree species that were present in less than two sections were considered rare and omitted.

City Mid Far OG

Bigleaf maple*

Red alder ${ }^{\mathrm{x}}$

Chenry

Cascara

Dogwood

Douglas-fir

Westem hemlock $x$

Western red cedar ${ }^{x}$

Grand fir

$\begin{array}{ll}4.4(3.3)^{\mathrm{ab}} & 4.5(4.6)^{\mathrm{ab}} \\ 0.4(0.8)^{\mathrm{b}} & 2.0(2.1)^{\mathrm{a}} \\ 0.1(0.3) & 1.0(2.0) \\ 0.5(1.3) & 0.2(0.4) \\ 0.1(0.4) & 0.0(0.2) \\ 0.4(0.8) & 0.6(1.2) \\ 0.3(0.9)^{\mathrm{a}} & 0.3(1.2)^{\mathrm{a}} \\ 0.0(-)^{\mathrm{a}} & 0.0(0.2)^{\mathrm{a}} \\ 0.3(1.0) & 0.0(0.2)\end{array}$

$6.8(3.6)^{\mathrm{a}}$

$1.0(1.3)^{\mathrm{a}}$

$5.5(3.1)^{\mathrm{ab}}$

$0.3(0.9)^{\mathrm{a}}$

$5.2(3.1)$

7.1 (6.2)

$24(10)^{\mathrm{a}}$

1.9 (1.6)

$9.1(6.5)^{\mathrm{a}}$
$1.1(2.1)^{\mathrm{a}}$
$7.8(6.1)^{\mathrm{ab}}$
$0.3(1.3)^{\mathrm{a}}$
$7.1(5.6)$
$6.2(5.5)$
$25(11)^{\mathrm{ab}}$
$2.3(2.0)$

24

$7.3(5.4)^{\mathrm{a}}$
$0.8(1.0)^{\mathrm{b}}$
$1.0(2.0)$
$0.3(0.5)$
$0.0(0.2)$
$1.3(2.1)$
$1.6(2.2)^{\mathrm{b}}$
$1.4(1.8)^{\mathrm{b}}$
$0.4(1.3)$

$0.7(0.6)^{b}$

$0.0(0.1)^{\mathrm{b}}$

-

$0.3(0.6)$

2.3 (1.5)

$3.7(1.5)^{\mathrm{b}}$

$2.7(3.1)^{\mathrm{b}}$

$14.5(7.9)^{\mathrm{b}}$
$4.7(4.7)^{\mathrm{b}}$
$9.5(5.7)^{\mathrm{a}}$
$3.1(3.0)^{\mathrm{b}}$
$9.4(5.9)$
$8.5(6.3)$
$34(13)^{\mathrm{b}}$
$3.4(2.1)$

$9.7(2.3)^{\mathrm{ab}}$

$8.7(2.3)^{\mathrm{b}}$

$1.0(0.0)^{\mathrm{b}}$

$6.3(1.5)^{\mathrm{b}}$

$3.0(2.0)$

$6.9(5.7)$

$24(7)^{a b}$

$3.0(2.6)$

$\mathbf{n}$

24

24

3

Results of Bonnferoni/Dunn testing is shown for each variable as superscripts for means that are significantly different from one another. For a given variable, means with different superscripts are significantly different from one another (e.g., for any given dependent variable, all means with a superscript of a are significantly different from those with a superscript of b). Significance was determined after the variables were transformed in the same manner as used in multiple regression testing.

A superscript of " $x$ " denotes that the square root of the variable was used in statistical analyses; a superscript of "*" denotes that the natural $\log$ of the variable +1 was used. 


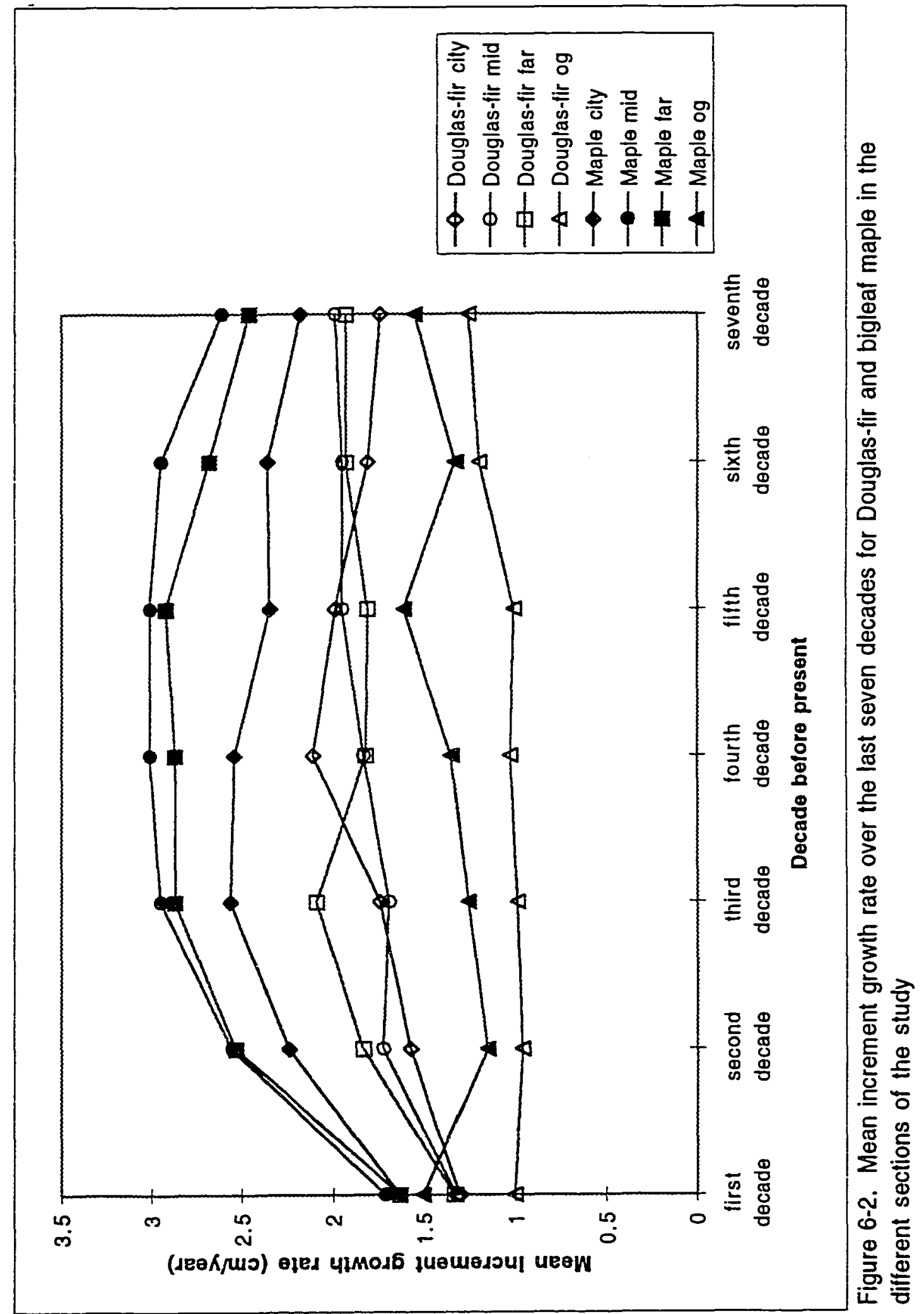


over the years in the growth rates. For results from ANOVA and Bonnferoni/Dunn analysis, see Appendix G.

The live crown ratio (LCR) for all trees was significantly greater in the old-growth and city sections than in the far section (Table 6-8). Bigleaf maples had a greater live crown ratio in the city and middle sections, and Douglas-firs, western red cedars, and grand firs were highest in the middle section. When the live crown ratio of only upper canopy trees was examined, it was greatest for bigleaf maples in the city section and for Douglas-firs in the middle and far sections.

\section{DISCUSSION}

Many of the variables related to tree demographics and vigor were correlated with one or more of the urbanization variables. My results showed a dearth of recent tree regeneration as measured by the number of seedlings at my sites. Most sites did not have any seedlings, and those sites that did have seedlings had a preponderance of early seral species. Only one site (site 7 in the far section) had any seedlings (four) of a climax species -- western red cedar. The distribution of seedlings was not correlated with any measure of urbanization. The low numbers of seedlings could have been a function of weather or other environmental factors. It could also have been an artifact of my sampling procedure, although I did not observe many seedlings at any location in the park.

Although seedlings were scarce, I found saplings at most sites indicating that some regeneration of trees has occurred. The density and composition of saplings showed correlations with urbanization. The densities of larger saplings of all tree species, 
Table 6-8. Live crown ratio (LCR) for trees of different species (standard deviation) for the different sections. Tree species that were present in less than two sections or for which the total $\mathrm{n}$ was less than 12 were considered infrequent or rare species and were omitted. $\mathrm{n}$ is reported for each variable.

\begin{tabular}{|c|c|c|c|c|}
\hline Species & City & Mid & Far & OG \\
\hline Bigleaf maple & $\begin{array}{c}0.42(0.30)^{\mathrm{a}} \\
318\end{array}$ & $\begin{array}{c}0.42(0.30)^{\mathrm{a}} \\
364\end{array}$ & $\begin{array}{c}0.29(0.26)^{b} \\
416\end{array}$ & $\begin{array}{c}0.49(0.28)^{\mathrm{ab}} \\
11\end{array}$ \\
\hline Red alder & $\begin{array}{c}0.32(0.16) \\
61\end{array}$ & $\begin{array}{c}0.31(0.23) \\
164\end{array}$ & $\begin{array}{c}0.31(0.18) \\
91\end{array}$ & - \\
\hline Cherry & $\begin{array}{r}0.00(-) \\
3\end{array}$ & $\begin{array}{c}0.10(0.17) \\
28\end{array}$ & $\begin{array}{c}0.16(0.26) \\
29\end{array}$ & - \\
\hline Dogwood & $\begin{array}{c}0.43(0.19) \\
10\end{array}$ & $\begin{array}{c}0.49(0.16) \\
8\end{array}$ & $\begin{array}{c}0.13(0.18) \\
2\end{array}$ & $\begin{array}{c}0.30(0.19) \\
5\end{array}$ \\
\hline Douglas-fir & $\begin{array}{c}0.50(0.24)^{\mathrm{ab}} \\
64\end{array}$ & $\begin{array}{c}0.55(0.25)^{\mathrm{a}} \\
99\end{array}$ & $\begin{array}{c}0.43(0.28)^{b} \\
108\end{array}$ & $\begin{array}{c}0.36(0.27)^{b} \\
25\end{array}$ \\
\hline Western bemlock & $\begin{array}{c}0.60(0.28) \\
54\end{array}$ & $\begin{array}{c}0.74(0.13) \\
6\end{array}$ & $\begin{array}{c}0.52(0.35) \\
113\end{array}$ & $\begin{array}{c}0.45(0.29) \\
46\end{array}$ \\
\hline Westem red cedar & - & $\begin{array}{c}0.84(0.18)^{\mathrm{a}} \\
35\end{array}$ & $\begin{array}{c}0.63(0.32)^{b} \\
155\end{array}$ & $\begin{array}{c}0.57(0.26)^{b} \\
38\end{array}$ \\
\hline Grand fir & $\begin{array}{c}0.41(0.19)^{\mathrm{a}} \\
60\end{array}$ & $\begin{array}{c}0.57(0.18)^{b} \\
16\end{array}$ & $\begin{array}{c}0.28(0.23)^{c} \\
32\end{array}$ & - \\
\hline All trees & $\begin{array}{c}0.44(0.28)^{a} \\
633\end{array}$ & $\begin{array}{c}0.43(0.30)^{a b} \\
768\end{array}$ & $\begin{array}{c}0.40(0.31)^{b} \\
1012\end{array}$ & $\begin{array}{c}0.47(0.29)^{\mathrm{a}} \\
126\end{array}$ \\
\hline Upper canopy maple & $\begin{array}{c}0.58(0.14)^{\mathrm{a}} \\
45\end{array}$ & $\begin{array}{c}0.54(0.23)^{\mathrm{a}} \\
80\end{array}$ & $\begin{array}{c}0.46(0.12)^{\mathrm{b}} \\
79\end{array}$ & - \\
\hline Upper canopy Douglas- fir & $\begin{array}{c}0.59(0.13)^{\mathrm{a}} \\
43\end{array}$ & $\begin{array}{c}0.69(0.15)^{\mathrm{b}} \\
40\end{array}$ & $\begin{array}{c}0.64(0.09)^{\mathrm{ab}} \\
46\end{array}$ & $\begin{array}{c}0.50(0.16)^{c} \\
18\end{array}$ \\
\hline Upper canopy alder & $\begin{array}{c}0.33(0.12) \\
22\end{array}$ & $\begin{array}{c}0.38(0.14) \\
45\end{array}$ & $\begin{array}{c}0.35(0.11) \\
45\end{array}$ & - \\
\hline Upper canopy all species & $\begin{array}{c}0.54(0.17) \\
114\end{array}$ & $\begin{array}{c}0.54(0.22) \\
171\end{array}$ & $\begin{array}{c}0.52(0.18) \\
205\end{array}$ & $\begin{array}{c}0.54(0.18) \\
22\end{array}$ \\
\hline Upper canopy shade intolerant & $\begin{array}{c}0.53(0.16) \\
110\end{array}$ & $\begin{array}{c}0.53(0.22) \\
165\end{array}$ & $\begin{array}{c}0.48(0.15) \\
170\end{array}$ & $\begin{array}{c}0.50(0.16) \\
18\end{array}$ \\
\hline
\end{tabular}

Results of Bonnferoni/Dunn testing is shown for each variable as superscripts for means that are significantly different from one another. For a given variable, means with different superscripts are significantly different from one another (e.g., for any given dependent variable, all means with a superscript of a are significantly different from those with a superscript of b). Significance was determined after the variables were transformed in the same manner as used in multiple regression testing. 
and of both sizes of red cedar saplings, coniferous saplings, and shade-tolerant saplings were lower at more urban sites as indicated by the distance from downtown Portland. The results suggest that urbanization may suppress the recruitment of trees, especially shade tolerant species, in Forest Park. This assertion is supported by the results of multiple regression that revealed that the densities of large saplings, small cedar saplings, small coniferous saplings, and shade tolerant saplings were all associated with edge habitat as indicated by correlations with the urbanization variables. An increase in density of saplings and small trees is a documented edge effect (Chen et al 1992; Chen et al 1995; Matlack 1993a). Since the city section of the park had more edge (Figure 5-2, page 75), one could reasonably expect more saplings in the city section of Forest Park due to the edge effect, but, the opposite was found. The decreased density of saplings at more urban sites could be the result of a lack of seed source or higher rates of seed or seedling predation in the city section of the park, or it may be due to the effects of pollution or human foot traffic that would be greater in more urban areas. The consequences of such human disturbances appear to be overriding any potential edge effects that may be resulting from fragmentation. The apparent reduction in tree regeneration is in agreement with the findings of Rudnicky and McDonnell (1989) and Airola and Buchholz (1984), although I did not find a concomitant increase in the number of saplings of "weedy" tree species. This lower density of saplings in the city section, especially of shadetolerant species, should be investigated further.

Statistical examination of the species composition in each age class also revealed correlations with urbanization. I found decreased densities of several sizes of trees including smaller (10-20 cm dbh) western red cedars and both smaller shade-tolerant 
and shade-intolerant trees at more urban sites. Variables associated with edge habitat in this study included $10-20 \mathrm{~cm}$ sized western red cedars and shade-tolerant trees, and $20-40 \mathrm{~cm}$ sized red alders. I found the same reduction in the density of smaller sized trees in the city section that I noted for saplings. The decreased density of smaller trees in the city section may be the result of long term suppression of regeneration as suggested by the results for saplings. If this is the case, it means that some aspect or aspects of urbanization may have been suppressing tree recruitment for a longer period of time.

The negative correlation between the distance from downtown Portland and the density of small trees suggests that small trees are more affected by urbanization than are larger (older) trees. This result also suggests that some aspect of urbanization other than habitat fragmentation is important in the distribution of small trees. The fact that I found more small dead trees in the far section than the city suggests that increased mortality is not the reason for having fewer young trees in the city section. However, the lower density of saplings and smaller trees at sites near the city may indicate that urbanization is suppressing tree recruitment in the more urban parts of Forest Park. The causes for this finding should be investigated further in another study.

Distribution of the trees into various size classes revealed that the old-growth stand exhibited a more or less reverse-J shaped curve, whereas the trees in the other areas of Forest Park (city section is shown, but middle and far section graphs appear similar) exhibited a uni- or bi-modal shaped curve (Figure 6-3). In addition, the old- 


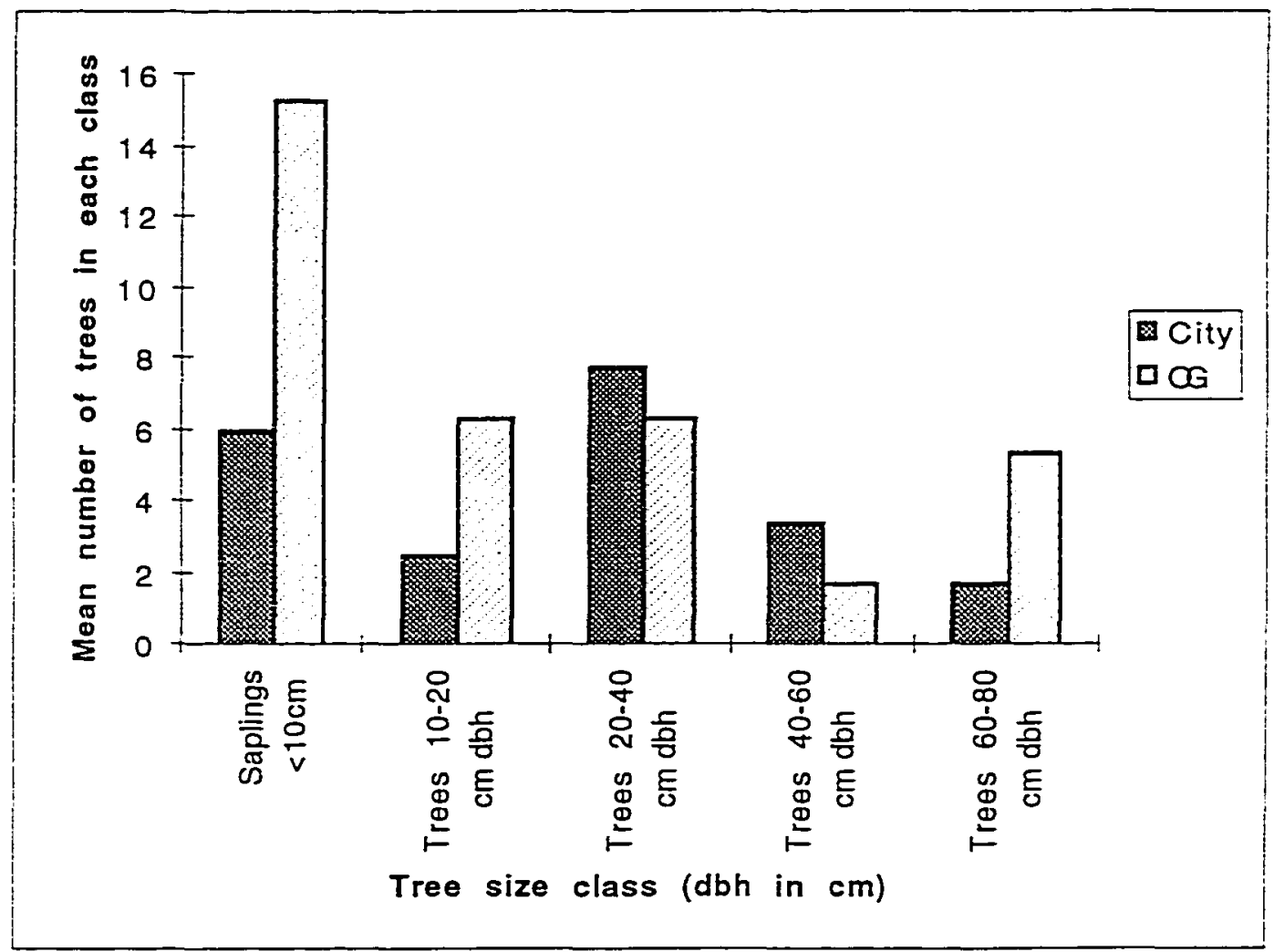

Figure 6-3. Size class distribution of trees in the city section of Forest Park and in the old-growth stand. 
growth stand is dominated by coniferous trees, whereas Forest Park is dominated by deciduous trees.

Closer examination of the distribution of tree species in the various size classes also revealed that different seral stages were present at my sites, although all were in a closed canopy stage (Franklin and Dymess 1988; Houle 1996). To examine this idea more closely, I composed five different successional stages (seres), ranging from sites dominated by shade-intolerant species to mature forest and spanning the successional gradient present at my sites. The earliest seral stage was represented by sites having canopies dominated by shade-intolerant species such as bigleaf maple, Douglas-fir, and/or red alder with few to no shade-tolerant understory trees. The second seral stage was also dominated by bigleaf maple, Douglas-fir, and/or red alder, but small shade-tolerant trees were relatively common in the understory. The third seral stage was represented by sites that still had many bigleaf maple, Douglasfir, and/or red alder in the canopy, but which also had sizable shade-tolerant trees in the understory and at the mid-canopy level of the forest. The second and third stages show understory re-initiation. The fourth stage was dominated by large bigleaf maple, western hemlock, and western red cedar, the last two being shade-tolerant species of trees. The fifth seral stage -- mature forest -- was dominated by very large, old Douglas-firs and large western hemlocks, with a multilayered understory of variously sized western hemlocks and western red cedars. This stage was found only at the old-growth stand. I classified each site into one of the five seres on the basis of the species distribution and relative age structure found at each location (Table 6-9). Sites in the city section had an average seral stage of 1.8; sites in the 
Table 6-9. Distribution of sites into different seral stage categories as determined in this study.

\begin{tabular}{ccccc} 
Seral Stage & \multicolumn{4}{c}{ Site Numbers in the Following Sections } \\
\cline { 2 - 5 } 1 & City & Mid & Far & OG \\
2 & $3,5,12,14$ & $11,32,37$ & 41 & - \\
3 & 1,13 & 23 & $2,6,7,7$ & - \\
4 & 28,30 & $17,18,24,36$ & - & - \\
5 & - & - & $22,19,39$ & - \\
& - & - & - & og
\end{tabular}


middle section had 2.0; sites in the far section averaged 2.1; and the old-growth stand was 5.0 (Table 6-10), showing, that in general, the successional status of sites increasedwith distance from Portland, although these were not significant differences.

The age structures of trees at each site revealed that the majority of sites were in the first two (earlier) stages of succession (Tables 6-9 and 6-10), as is much of Forest Park (Portland Parks and Recreation 1995). These two stages are characterized by having minimal understory development and, at least in Forest Park, most likely result from a history of punctuated disturbances such as logging, wood cutting, and/or fires. Logging and woodcutting are obviously human disturbances. In Forest Park, recent major fires were caused by human activity. For example, the last major fire in 1951 was caused by an escaped campfire (Robinson 1978). Major disturbances such as fire and logging produced the mosaic-like pattern of successional stages seen in the forest, but they are not the whole story. The dominance of much of the park by red alder and bigleaf maple has probably been caused by the history of continual disturbance of the land. Normally, after a disturbance in the Pacific Northwest, Douglas-fir would be the major early seral tree species to invade an upland site. However, severe and/or continual disturbance leads to the depletion of soil nutrition (especially nitrogen), and frequently results in hardwoods replacing softwood coniferous species (Franklin and Pechanec 1967; Houle 1996; Newton et al. 1967). The complete dominance of hardwoods in the park has precluded the invasion of most sites by Douglas-fir, a shade-intolerant species. Instead, if a seed source is available, shade-tolerant species eventually begin to invade, as is seen at many sites with young understory trees. As the hardwoods 
Table 6-10. Total number of sites in each seral stage in each section as well as the mean seral stage (standard deviation) found in each section.

Seral Stage

1

2

3

4

5
Total Number of Sites in the Following Sections

City

2

2

0

0
Mid

3

1

4

0

0
Far

1

6

0

1

0

1
$1.8(0.9)^{\mathrm{a}}$
8
$2.0(0.9)^{\mathrm{a}}$
8
Mean seral stage
$2.1(0.8)^{\mathrm{a}}$
$5.0(-)^{b}$
n

8
8

Results of Bonnferoni/Dunn testing is shown for mean seral stage as superscripts for means that are significantly different from one another. Means with different superscripts are significantly different from one another (e.g., for any given dependent variable, all means with a superscript of a are significantly different from those with a superscript of b). 
age and begin to fall due to disease and old age, the corresponding openings in the canopy release those understory trees, allowing them to overtop the remaining hardwoods and eventually become dominant (Franklin and Pechanec 1967; Houle 1996; Newton et al. 1967). I expect that Forest Park, if undisturbed, will circumvent much of the Douglas-fir stage, and instead succeed directly to a climax forest dominated by shade-tolerant species such as western hemlock and western red cedar. These two trees are present in the understory at many sites. However, sites that are dominated by extensive stands of pure hardwoods may lack appropriate sources of shade-tolerant seeds, and may need to have young trees planted since the Forest Park master plan advocates for the eventual successional culmination to a mature or oldgrowth coniferous forest (Portland Parks and Recreation 1995).

To determine the date of the last major disturbance at each site (i.e., fire or logging), I assumed that the date of such a disturbance corresponded to the average age of shade-intolerant trees on the site. The old-growth stand showed evidence of fire (a major disturbance). Assuming that the bigleaf maples at this site began their growth after that event and since the mean age of the bigleaf maples was 62 years, I estimated that a fire had swept through the old-growth in the early 1930s even though the largest Douglas-firs at the site were estimated to be approximately 425 years old.

My data revealed that study sites in Forest Park were younger than the old-growth stand with no site having any trees approaching the size and/or estimated age of the large Douglas-firs in the old-growth stand. Most sites in Forest Park appeared to have experienced the last major disturbance (logging and/or fire) between 38 and 57 years ago. Sites in the city section experienced their last major disturbance on 
average about 52 years ago. The tree ages support the hypothesis that the city section is in an older successional stage than is the far section of the park since the far section averaged only 44 years since the last major disturbance. Trees at sites in the city section were significantly older than trees at sites in either the middle or far sections of Forest Park. A map at Portland Parks and Recreation showed that the far section had more areas of recent logging and/or fire than the city section. The average age of trees at sites in the middle section (39 years) coincided with the date of the big fire of 1951, although sites 18 and 32 lay outside of the boundary of that fire and had older trees. Another piece of evidence regarding the disturbance history of the middle section of the park was imparted by bigleaf maple. Bigleaf maple frequently responds to fire or cutting by suckering (sending up shoots from the existing roots). Often, more than one shoot sprouts from the existing root, frequently leading to trees with multiple trunks. ANOVA demonstrates there are significantly more bigleaf maples with multiple trunks in the middle section (Figure 6-4). This, along with a greater abundance of red alders, suggests that the middle section has experienced a major disturbance.

Most likely, the successional status at each site (Table 6-9) is related to the past land use history of Forest Park. However, when the successional status at each site is compared to the relative ages of the dominant trees in each section, the city section appears to be at an earlier successional stage than would be expected based on the length of time since the last major disturbance. If suppression of shade-tolerant saplings had occurred at more urban sites, sites in the city section would have less understory development. The lack of understory development would make it difficult to ascertain the relative time since the last major disturbance for sites in that 


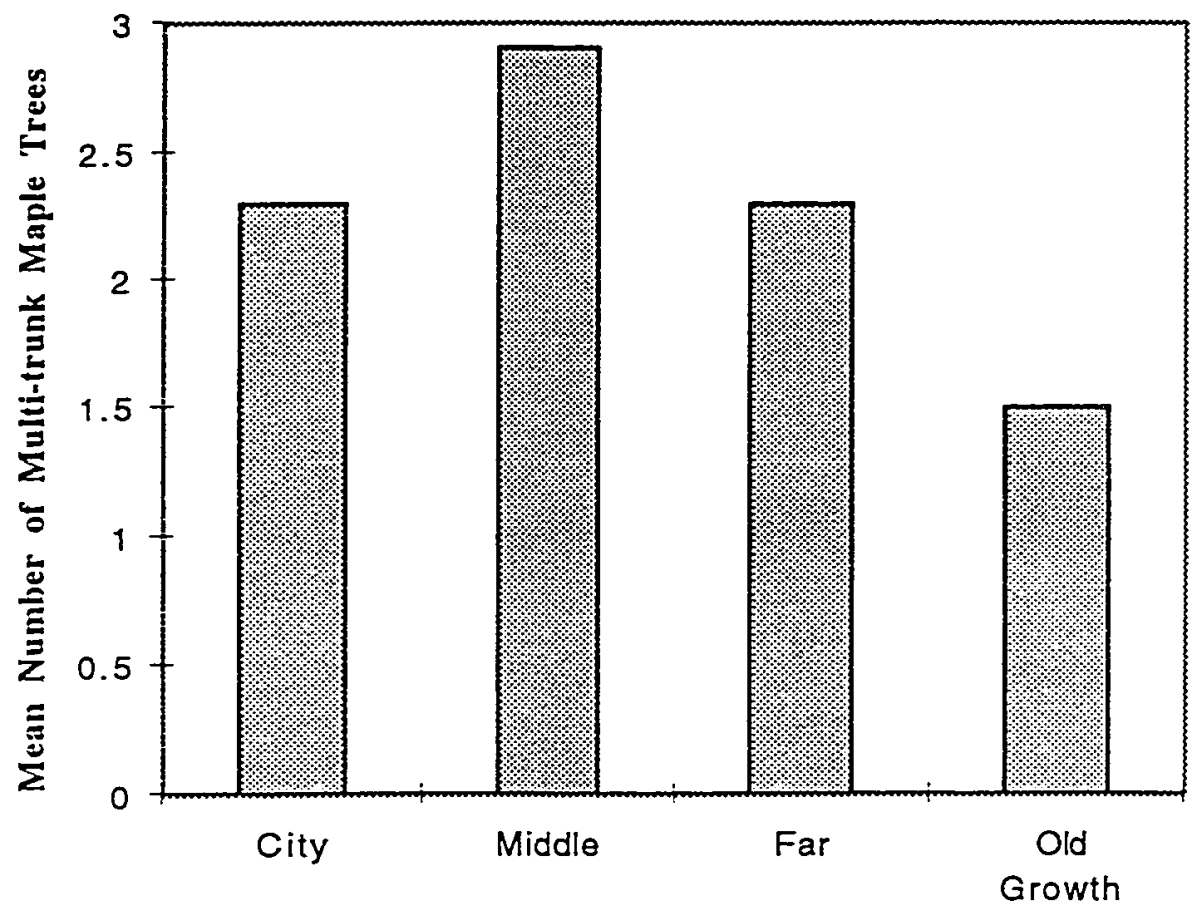

Section of Park

Figure 6-4. The mean number of multi-trunk bigleaf maples in the different sections of Forest Park and the old-growth stand. 
section of the park from stand structure alone. In a closed canopy forest, most seedlings and saplings should be shade-tolerant species. If suppression of small trees occurred for several decades, the population age curve could become skewed. A reduction in the establishment of shade-tolerant trees in urban areas of the forest would disrupt normal successional processes of stand re-initiation at more urban sites. Such a mechanism would explain how the city section could be older than the far section of Forest Park, even though there was a paucity of shade-tolerant trees in more urban areas. The scarcity of shade-tolerant trees in the forest understory poses questions as to the future of much of Forest Park as the shade-intolerant species reach the end of their normal life spans and die. Many of the red alders in the park are approaching that age now and many have rotten cores that may contribute to their demise in future wind and ice storms. The death of such trees opens the canopy and normally allows release of shade-tolerant understory trees. Sites without an understory of shade-tolerant species may remain dominated by hardwood species, or perhaps they will shift to a Douglas-fir forest if the appropriate seed source is available.

The mortality of trees is another major component of succession in the forest. Tree mortality was greater at sites further from Portland and increased with distance from the city for western hemlock, western red cedar, conifers, and shade-tolerant species. In addition, increased numbers of dead western hemlocks and dead conifers were associated with forest interior habitat. The likeliest explanation for this increased mortality is self-thinning or stem exclusion. As overstory trees become more dominant during succession and eventually reach the closed canopy stage, their canopies become denser, leading to the suppression and frequently the mortality of 
understory trees, especially those of shade-intolerant species (Franklin and Dymess 1988). This argument is supported by the fact that most dead trees in Forest Park are shade-intolerant species. Only in the old-growth stand did I find more dead trees of shade-tolerant species. The death of trees in 1996 is positively correlated to the density of trees in that same year by a second order polynomial regression (Figure 65). The normal successional processes of self-thinning appear to be overriding any effects of urbanization as a factor in tree mortality in the park. As self-thinning occurs understory trees are released from suppression and can grow to overtop the present canopy of shade-intolerant tree species such as red alder and bigleaf maple. The far section, with more shade-tolerant saplings in the understory, appears to be on a normal successional pathway.

The only measures of tree vigor (examined as increment growth rate) that were associated with urbanization (as measured by the distance from downtown Portland) were the increment growth rates of western red cedars 10-20 years ago and western hemlocks 20 to 30 years ago. The increment growth rate for western red cedar and western hemlock during these time periods was lower at sites nearer the city. The finding of depressed growth in western red cedar 10-20 years ago and western hemlock 20 to 30 years ago at more urban sites may be an indication of the effects of urbanization upon tree growth and health. However, more data are needed to substantiate this finding before such conclusions can be reached since depressed growth rate could also be the result of earlier canopy closure in the "older" city section of the park. 


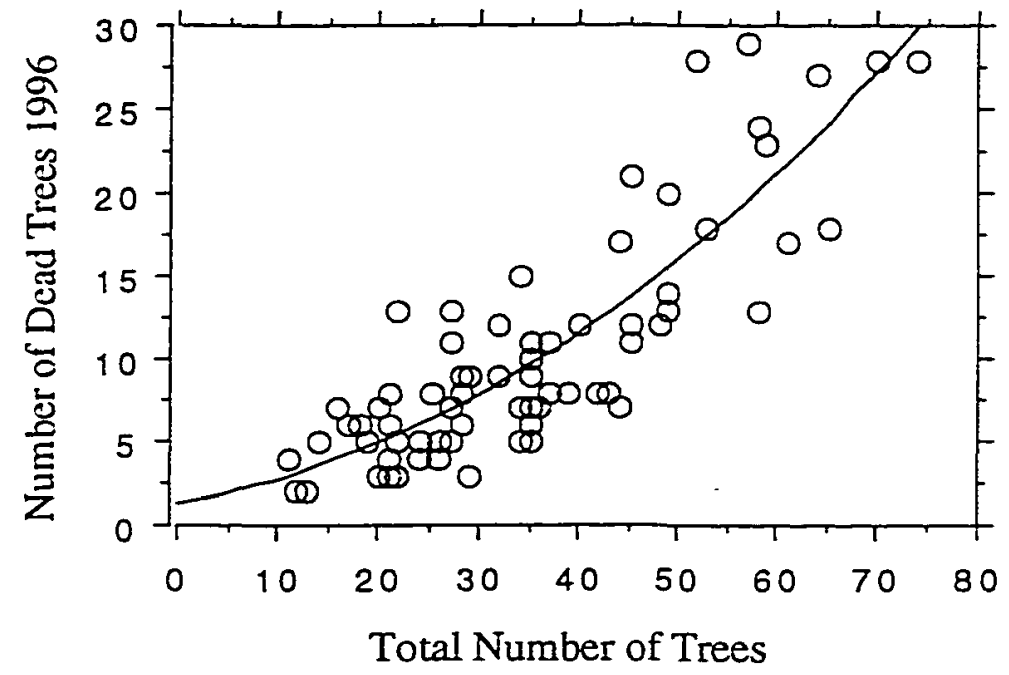

Figure 6-5. Graph of tree mortality (number of dead trees in 1996) versus the total number of trees at sites in 1996 . The second order polynomial regression formula was $\mathrm{y}=1.28 \mathrm{x}+0.10 \mathrm{x}+0.004 \mathrm{x}^{2} ; \mathrm{R}^{2}=0.75 ; \mathrm{p}<0.0001$ 
The growth rate time series (Figure 6-2, page 96) was indicative of the fact that increment growth rates had been greatest about 40 to 50 years ago, probably due to the release of trees after fire and/or logging. For all sections of Forest Park, the rate has declined each subsequent decade as the canopy has closed. Only the old-growth stand remained more or less consistent (and low) over the years. Since large Douglas-fir trees are less susceptible to fire than are many other species, and since these trees dominate the canopy in the old-growth stand, it is likely that the old growth did not experience substantial canopy opening after the fire.

The other indicator of vigor that I calculated was the live crown ratio. The live crown for upper canopy trees was reduced at sites nearer to Portland. This may be another indication that trees at sites closer to downtown Portland have lower vigor than trees at more rural sites. The decreased live crown ratio may be due to canopy closure at the "older", more urban sites as a normal consequence of succession. However, the reduced live crown ratios and the reduced increment growth rates at more urban sites may also be the result of some factor of urbanization. Pollution, especially by heavy metals associated with automobile exhaust, has been demonstrated to result in reductions of tree health (Airola and Buchholz 1984; Ashby and Fritts 1972; McLaughlin et al. 1983; Nash et al. 1975; Pouyat et al. 1994; Pouyat et al. 1995a, 1995b; Supuka 1994; Thompson 1981; White and McDonnell 1988; Yost et al. 1991). My findings could be an indication of the effects of pollution on tree health in the more urban areas of Portland that could possibly cause reductions in increment growth and live crown canopy. Such effects could also account for the suppression 
of tree recruitment in the city section of the park. However, research on this specific topic would be needed to determine whether such an effect exists. 


\section{CHAPTER 7}

\section{THE EFFECTS OF HUMAN DISTURBANCE AND URBANIZATION UPON THE RICHNESS, ABUNDANCE, AND SPECIES DIVERSITY OF BIRDS}

Extensive research has been published on the effects of human disturbance upon bird communities. Much of the interest, which began in the 1970 's, grew out of concern for the seeming decline of certain neotropical migratory bird species throughout the eastern and midwestern regions of the United States (Askins and Philbrick 1987; Galli et al. 1976; Terborgh 1989; Whitcomb et al. 1981; Wilcove 1985). This concern led to research into the reasons for the decline (Aldrich and Coffin 1980; Askins 1994; Askins 1995; Askins and Philbrick 1987; Beissinger and Osborne 1984; Blake et al. 1994; Blake and Karr 1987; Bollinger and Linder 1994; Brown and Robinson 1996; Donovan et al. 1995a, 1995b; Edgar and Kershaw 1994; Friesen et al. 1995; Graber and Graber 1983; Hagan et al. 1996; Herkert 1995; Kroodsma 1984; Lent and Capen 1995; Levenson 1981; Lynch and Whigham 1984; Martin et al. 1996; Mauer and Heywood 1993; McIntyre 1995; Peterjohn and Sauer 1994; Rappole and McDonald 1994; Rich et al. 1994; Robinson and Holmes 1984; Robinson et al. 1995; Stouffer and Bierregaard 1995; Taper et al. 1995; Temple 1986; Temple and Wilcox 1986; Terborgh 1980; Terborgh 1989; Terborgh 1992; Verner 1986; Wilcove 1985; Yahner and Mahan 1996). Much of the research has centered on the effects of habitat fragmentation on bird species richness, abundance, and diversity. The research has focused attention on several factors that are believed to have played a role in the decline of migratory songbirds. 
Many scientists have sought to determine whether the theory of island biogeography explains observed reductions in avian species diversity in forest remnants. According to this theory, larger islands will support more species at equilibrium than similarly situated smaller islands, and islands closer to the mainland should support more species than similarly sized islands further from the mainland (MacArthur 1972; MacArthur and Wilson 1967). Even though forest remnants are often referred to as "islands", the theory of island biogeography has proved inadequate to explain many of the observed changes. In part, this is believed to be because the matrix separating the "islands" is, unlike water, capable of supporting terrestrial life. Most researchers have found greater diversity in larger forests (Askins 1994, 1995; Blake 1983; Blake and Karr 1987; DeGraaf 1991, 1995; Donovan et al. 1995b; Gavareski 1976; Hoover et al. 1995; Lent and Capen 1995; Lynch and Whigham 1984; McIntyre 1995; McLellan et al. 1986; Robinson et al. 1995; Rosenberg and Raphael 1986; Temple 1986; Tilghman 1987; Verner 1986; Wiens 1994; Wilcove 1985), although neither area (size) nor distance from the nearest large forest ("the mainland") have been shown adequately to predict the number of species a forest of a given size can support (Blake 1983; Blake and Karr 1987; Blondel 1985; Davis and Glick 1978; Dzwonko and Loster 1988, 1989; Gavareski 1979; Haila 1986; Levenson 1981; Lovejoy and Oren 1981; McLellan et al. 1986; Rowntree 1986; Tilghman 1987; Tramer and Subrweir 1975; Weaver and Kellman 1981; Whitcomb et al. 1981; Zacharias and Brandes 1990). There does, however, seem to be a minimum critical size that a forest remnant must be in order to support a near normal avian biodiversity (Blake 1983; Dzwonko and Loster 1989; Gotfryd and Hansell 1986; Johnson et al. 1981; Ranney et al. 1981; Rosenberg and Raphael 1986; Temple 1986; Tilghman 
1987; Whitcomb et al. 1981). For example, a Douglas-fir forest of approximately square or circular shape should be a minimum of 64 hectares (Chen et al. 1995; Franklin and Forman 1987). But as described earlier, the minimum area is as much a function of shape as it is of size. Forests with small area to edge ratios function as edge communities (Blake 1983; Gotfryd and Hansell 1986; Harris 1984; Johnson et al. 1981; Ranney et al. 1981; Rosenberg and Raphael 1986; Temple 1986; Tilghman 1987; Whitcomb et al. 1981). As forest land continues to be cleared, the effects of habitat fragmentation and the increasing amounts of edge habitat are believed to affect adversely many species of birds through a variety of mechanisms.

One consequence of forest fragmentation is increased predation on nests, particularly those of ground nesting birds. Many predators, such as raccoons, opossums, crows, and jays, are edge associated species. Most of these species are present in higher densities in smaller forest fragments and have been shown to significantly decrease ground nesting success (Angelstam and Andren 1988; Askins 1994; Askins 1995; Blake 1983; Bollinger and Linder 1994; Brown and Robinson 1996; Craig 1997; DeGraaf 1995; Diehl 1986; Donovan et al. 1995a; Hagan et al. 1996; Hoover et al. 1995; Lehmkuhl and Ruggiero 1991; Leimgruber et al. 1994; Linder and Bollinger 1995; Martin and Clobert 1996; Martin et al. 1996; McLellan et al. 1986; Rich et al. 1994; Robinson et al. 1995; Rosenberg et al. 1987; Terborgh 1989; Whitcomb et al. 1981; Wiens 1994; Wilcove 1985; Yahner and Mahan 1996). Wilcove (1985) demonstrated experimentally that in small forest fragments (less than 10 hectares), predation rates on ground nesting birds could reach 100 percent. 
Another major consequence of forest fragmentation is increased rates of brood parasitism by brown-headed cowbirds. Brown-headed cowbirds lay their eggs in the nests of other bird species to the detriment of the host species' young. Although the range of the brown-headed cowbird was once limited to the Great Plains, it has expanded dramatically throughout the last century to its present range covering most of North America, an expansion that followed the advancement of European settlement. It has been reported that brown-headed cowbirds have successfully parasitized 144 species of birds and have been observed to lay eggs in over 200 different species' nests (Ehrlich et al. 1988; Robbins et al. 1983; Terborgh 1989). Female brown-headed cowbirds lay their eggs in the nests of forest species, but forage in open areas such as roadside strips, yards, pastures, and grassy corridors and so need access to forest edge. As forest area decreases, the ability of brownheaded cowbirds to invade and parasitize nests increases. They are nearly ubiquitous in forested areas of all sizes except for very large expanses of contiguous forest (Askins 1995; Brittingham and Temple 1983; Coker and Capen 1995; Terborgh 1989; Wilcove 1985). Research in many areas of the country has demonstrated that brown-headed cowbirds are more numerous in smaller fragments where they significantly reduce the breeding success of native birds (Askins 1995; Bollinger and Linder 1994; Brown and Robinson 1996; Coker and Capen 1995; Ehrlich et al. 1988; Gustafson and Crow 1994; Hoover et al. 1995; Linder and Bollinger 1995; Rich et al. 1994; Robinson et al. 1995; Terborgh 1989; Wilcove 1985). They have already been implicated in the near-extinction of bird species such as Kirtland's warbler (Mayfield 1977) and the least Bell's vireo (Goldwasser et al. 1980), and are expected to impact seriously many other woodland species (Askins 1995; Bollinger and Linder 1994; Brown and Robinson 1996; Coker and Capen 1995; Ehrlich et al. 
1988; Gustafson and Crow 1994; Hoover et al. 1995; Linder and Bollinger 1995; Rich et al. 1994; Robinson et al. 1995; Terborgh 1989; Wilcove 1985).

Not only has habitat fragmentation of forests in North America been blamed for bird species reductions, but loss and fragmentation of habitat in neotropical regions has also been implicated in the decline of certain bird species. As neotropical land is cleared of native vegetation, neotropical migratory species of birds lose wintering habitat. Loss of wintering habitat may cause reductions in bird species population numbers (Conway et al. 1995; Hutto 1980; Karr and Roth 1971; Mauer and Heywood 1993; Rappole and McDonald 1994; Terborgh 1980; Terborgh 1989; Wilcove 1985; Willson et al. 1994). It is widely believed that loss of winter habitat is the major cause of the probable extinction of Bachman's warbler, a neotropical migrant that over-wintered primarily in forests in Cuba before they were cleared for sugar plantations (Terborgh 1989). Further evidence supporting tropical deforestation as being important is that many neotropical migratory birds are experiencing population declines, whereas populations of many permanent resident species and short-distance migrant species are remaining stable or even increasing (Conway et al. 1995; Karr and Roth 1971; Terborgh 1989; Wilcove 1985; Willson et al. 1994).

Whereas global land use patterns are cited as a probable cause for the decline of many species, increased local disturbances, many of which are amplified by the process of urbanization, are also believed to have an impact upon bird abundance (density), bird species richness (the number of species), and bird species diversity $\left(\mathrm{H}^{\prime}\right)$. Bird abundance has been reported to increase with disturbance (Askins and Philbrick 
1987; Davis and Glick 1978; DeGraaf 1991; Lehmkuhl et al. 1991; Mills et al. 1989, 1991; Rosenberg et al. 1987). Bird species diversity (BSD) has been found either to increase with disturbance (Aldrich and Coffin 1980; Blake 1983; Huff and Raley 1991; Lehmkuhl et al. 1991), or decrease (Davis and Glick 1978; Edgar and Kershaw 1994; Gavareski 1979; Lancaster and Rees 1979; McIntyre 1995; Mills et al. 1989; Tilghman 1987). The intermediate disturbance hypothesis may explain these findings as the highest diversity is often reached at intermediate levels of disturbance or development (Blair 1996; Lent and Capen 1995). In a similar fashion, bird species richness has been reported either to increase (Gotfryd and Hansell 1986; Lehmkuhl et al. 1991; Tilghman, 1987) or decrease (Beissinger and Osborne 1984; Blake 1983; Davis and Glick 1978; DeGraaf 1991; Fugate 1994; Johnson et al. 1981; Levenson 1981; Rowntree 1986; Stouffer and Bierregaard 1995; Verner 1986; Wentworth and Telfer 1993) with disturbance. The changes in abundance, BSD, and richness are often attributed to an influx of "edge" and non-native species (Aldrich and Coffin 1980; Askins and Philbrick 1987; Beissinger and Osborne 1984; Blair 1996; Davis and Glick 1978; DeGraaf and Wentworth 1986; Gavareski 1976; Harris 1984; Kroodsma 1984; Lancaster and Rees 1979; Lehmkuhl and Ruggiero 1991; Lent and Capen 1995; McIntyre 1995; McLellan et al. 1986; Mills et al. 1989,1991; Rich et al. 1994; Rosenberg and Raphael 1986; Rosenberg et al. 1987; Terborgh 1989; Whitcomb et al. 1981; Wilcove 1985), often with a concomitant loss of forest species (Aldrich and Coffin 1980; Askins 1995; Askins and Philbrick 1987; Blair 1996; Blake et al. 1994; Bollinger and Linder 1994; Donovan et al. 1995a; Hoover et al. 1995; Keller and Anderson 1992; Kroodsma 1984; Lehmkuhl and Ruggiero 1991; Lent and Capen 1995; McIntyre 1995; McLellan et al. 1986; 
Rosenberg and Raphael 1986; Stouffer and Bierregaard 1995; Temple and Wilcox 1986; Terborgh 1989; Wilcove 1985).

Analysis of avian community structure across urban land use gradients -- usually industrial and commercial property, residential areas of various densities and ages, and/or open spaces such as golf courses or parks -- has revealed shifts in bird abundance, richness, and species diversity. Most researchers have reported increased bird density and decreased bird species diversity with increasing urbanization (Beissinger and Osborne 1984; Blair 1996; Davis and Glick 1978; DeGraaf 1991; DeGraaf and Wentworth 1986; Edgar and Kershaw 1994; Gavareski 1976; Kubantsev and Kolyakin 1995; Lancaster and Rees 1979; Mills et al. 1989. 1991; Reijnen et al. 1995; Rosenberg et al. 1987). Most frequently, there is a loss of native, forest interior species (e.g., western wood-peewee and Hutton's vireo (Blair 1996); black and white warbler and ovenbirds (DeGraaf and Wentworth 1986)), accompanied by a gain in non-native, omnivorous species such as house sparrows, European starlings, and rock doves. As urbanization increases, the abundance of a single species may reach 100 percent (Askins and Philbrick 1987; Beissinger and Osborne 1984; DeGraaf 1991; Edgar and Kershaw 1994; Gavareski 1976; Lancaster and Rees 1979; Mills et al. 1989; Rosenberg et al. 1987). Blair (1996) recently compared bird species richness, density, and diversity along an urbanization gradient from relatively pristine forest to highly urban habitat. He found that moderate development increased avian species diversity by increasing the number of "widely distributed species" such as mourning doves and house finches at the expense of native habitat specialists. As urbanization increased, both total and native specialist species diversity decreased (Blair 1996). Friesen et al. (1995) compared the avian 
communities in woodlots of differing sizes that were surrounded by various degrees of urbanization. They found that regardless of the size of the woodlot, diversity and abundance of neotropical migratory bird species was negatively correlated with the number of surrounding houses. The authors speculated that forest interior birds were lost, not only because of the effects of fragmentation, but due to other unidentifiable "negative effects" associated with nearby urban habitat (Friesen et al. 1995).

Many of the previous studies examined changes in the avian community in terms of guild structure. A guild is a functional group of species that have similar habitat and resource use. Most often, bird species are placed into guilds on the basis of the food eaten, the portion of the ecosystem where the food is gathered, and/or food gathering behavior (DeGraaf and Wentworth 1986; Ehrlich et al. 1988). Although a bird's guild often changes with the seasons, the guild occupied during the breeding season is the one usually examined (Abrams 1991; Beissinger and Osborne 1984; DeGraaf 1991; DeGraaf et al. 1991; DeGraaf and Wentworth 1986; Huff et al. 1991; Huff and Raley 1991; Lewke 1982; Manuwal 1991; Manuwal and Huff 1987; Willson 1970, 1974). Bird guilds in urban or disturbed areas become increasingly dominated by omnivores and ground-gleaning species at the expense of more specialized foliage, bark, and/or aerial gleaners (Aldrich and Coffin 1980; Beissinger and Osborne 1984; Blake 1983; Block et al. 1986; Carey et al. 1991; Davis and Glick 1978; DeGraaf 1991; DeGraaf and Wentworth 1986; Lancaster and Rees 1979; Lent and Capen 1995; Manuwal 1991; Manuwal and Huff 1987; Rosenberg et al. 1987). 
Avian communities are also commonly examined in terms of the migratory status of bird species. This has become increasingly important because of evidence that tropical deforestation may have detrimental effects on neotropical migratory bird species diversity and abundance (Conway et al. 1995; Hutto 1980; Karr and Roth 1971; Mauer and Heywood 1993; Rappole and McDonald 1994; Terborgh 1980; Terborgh 1989; Wilcove 1985; Willson et al. 1994). The observed decline in neotropical migratory species diversity and abundance has been documented in the eastern and central portions of the United States. In these areas, neotropical species account for 70 to 75 percent of the breeding bird population. In the westem United States, however, the percent of neotropical bird species is lower. In old-growth Douglas-fir forests, 60 to 100 percent of breeding season birds are members of resident bird species (Carey et al. 1991; Harris 1984; Huff and Raley 1991; Manuwal 1991; Manuwal and Huff 1987; Morse 1980). In addition, the neotropical species that summer in the western United States coniferous forests commonly winter in Mexico rather than Central or South America where disturbances have been greater (Hutto 1980; Manuwal 1991; Terborgh 1980). However, as all tropical areas become increasingly altered by human disturbance, there are potential implications for reductions in neotropical bird abundance and diversity in the Pacific Northwest.

Many researchers have also attempted to correlate bird species richness, abundance, and diversity with plant community structure. For example, BSD has been correlated with foliage height diversity (FHD) (Bersier and Meyer 1994; Karr and Roth 1971; Lancaster and Rees 1979; MacArthur and MacArthur 1961; Mills et al 1989, 1991; Willson 1974), plant species richness and diversity (Dobkin and Wilcox 1986), and canopy cover or foliage volume (Beissinger and Osborne 1984; Ito and Fujimaki 
1990; O'Brien 1990; Rowntree 1986; Tilghman 1987; Willson 1974). Some scientists have attempted to correlate bird density or abundance with total vegetation volume (TVV) (Mills et al 1989, 1991; Willson 1974), the percent of coniferous or deciduous forest (Carey et al 1991; Clark et al 1983; Goldstein et al 1986; James and Wamer 1982; MacArthur and MacArthur 1961; Tilghman 1987), tree height (Aldrich and Coffin 1980; Mills et al 1989, 1991; O'Brien 1990; Tilghman 1987; Wentworth and Telfer 1993), canopy height or the amount of foliage cover (Clark et al 1983; Sedgwick 1987), and the amount of non-native vegetation (Beissinger and Osborne 1984; DeGraaf 1991; DeGraaf and Wentworth 1986; Gravareski 1976; Mills et al 1989, 1991). Results from these studies have been inconclusive. In this study, such comparison may be important to help elucidate whether observed changes in avian distribution are due to community succession (and the changing plant characteristics that accompany that succession) or if urbanization is playing a role.

\section{METHODS}

Bird species richness and abundance were measured using the fixed-radius point method (Manuwal and Carey 1991). Although many biologists prefer Emlen's spot count method (Emlen 1977), scientists in Pacific Northwest forests have found it difficult to walk along a transect over the rough terrain and through thick vegetation while accurately detecting birds. Spot counts and line transect methods have been reported to undercount birds by as much as 40 percent (Manuwal and Carey 1991). In addition, since each of my sites covered a limited area, it was impossible to use the transect method without leaving the site. 
For each count, all birds were counted that were seen and/or heard within a 10 minute time period and that were estimated to be within a 50 meter radius extending from the center of the site (Hutto et al. 1986; Manuwal and Carey 1991; Verner 1985). These measurements were taken after waiting silently and unmoving for 5 minutes to ensure that birds were accustomed to the observer's presence. Bird counts were not done during periods of moderate to heavy rain or during episodes of strong winds or heavy fog. Assumptions of the procedure were that all birds were accurately identified, all birds in the circle were counted, the limits of the circle were recognizable, all bird species were equally detectable, and all recorded birds were counted only once per census (Manuwal and Carey 1991). All bird counts were conducted by the same observer.

Birds were counted during the breeding season (May to June) and in the winter (December to February). All breeding season bird counts were conducted between sunrise and 11:00 a.m. During the spring, each site was visited a total of three times each year, with counts at each individual site being conducted at least one week apart. The counts were repeated for three consecutive seasons (1993 - 1995). During spring of 1993, bird counts were conducted between May 8 and June 30; during the spring of 1994, bird counts were conducted between May 14 and June 28; and during the spring of 1995, bird counts were conducted between May 30 and June 30 .

All winter bird counts were conducted between sunrise and 3 p.m. because birds are active throughout the daylight hours during the winter season. Only one count per site was done during the 1994 and 1995 seasons, but three counts per site were conducted during the 1996 season. The counts at a given site in 1996 were made at 
least one week apart. Counts were conducted between January 10 and January 19 in 1994; between January 4 and January 20 in 1995; and between January 3 and February 20 in 1996. The much longer time period for 1996 was due to the triplicate sampling and to the severe winter storms that delayed field work.

Bird abundance, richness, and diversity were examined using the same statistical analyses as previously discussed -- multiple regression using the same seven independent variables of urbanization plus the covariable and ANOVA using section of the park as the independent variable. Counts during the breeding season were statistically analyzed for total birds counted per year since annual fluctuations were not important to this study. Winter counts, however, were statistically analyzed for mean birds per year because I did not have triplicate samples for the first two seasons.

Bird richness and abundance were also examined for certain "indicator" species. Eight bird species were assigned to each habitat type -- urban, edge, or forest (Table 7-1). Bird species that prefer paved and open lawn areas were considered indicative of cities or urban areas. Such bird species are commonly present in urban settings. The eight bird species that were selected to represent this category were rock doves, house sparrows, European starlings, American robins, house finches, American crows, brown headed cowbirds, and scrub jays. Three of the selected species are exotic, and a fourth, the brown-headed cowbird, is not native to western Oregon, although it is native to North America (Gilligan et al. 1994). These species are referred to in this study as "urban birds". Edge habitats are usually characterized by 
Table 7-1. Bird species used as indicator species for the three habitat types: urban, edge, and forest interior. Abbreviations used for the birds are given after each species.

HABITAT TYPE

Urban

Edge

Forest Interior

* non-native species

\section{BIRD INDICATOR SPECIES}

rock dove* (RODO), house sparrow* (HOSP), European starling* (EUST), American robin (AMRO), house finch (HOFI), American crow (AMCR), brown-headed cowbird (BHCO), scrub jay (SCJA)

spotted towhee (SPTO), olive-sided flycatcher (OSFL), Bewick's wren (BEWR), mourning dove (MODO), northern flicker (NOFL), yellowrumped warbler (YRWA), purple finch (PUFI), and song sparrow (SOSP)

band-tailed pigeon (BTPI), hairy woodpecker (HAWO), pileated woodpecker (PIWO), Pacificslope flycatcher (PSFL), western wood-peewee (WWPE), brown creeper (BRCR), Swainson's thrush (SWTH), black-throated gray warbler (BTWA) 
thick brushy areas. Bird species associated with such habitats were chosen as "edge" species. The bird species that were selected to represent edge environments were spotted towhees, olive-sided flycatchers, Bewick's wrens, mourning doves, northern flickers, yellow-rumped warblers, purple finches, and song sparrows. These eight species are referred to in this study as "edge birds". Forest interior bird species are those species rarely found outside of forested environments. The species selected as indicative of forest interior habitat were band-tailed pigeons, hairy woodpeckers, pileated woodpeckers, Pacific-slope flycatchers, western woodpeewees, brown creepers, Swainson's thrushes, and black-throated gray warblers. These bird species are referred to as "forest birds". Although each of the 24 species chosen was used to indicate a certain habitat type, many of the other bird species observed during this study have also been associated with urban, edge, and/or forest habitat by other authors (Blair 1996; Carey et al. 1991; Gilbert and Allwine 1991; Huff and Raley 1991; Lundquist and Mariani 1991; Manuwal 1991; Ruggiero et al. 1991; Whitcomb et al. 1981).

I also analyzed bird abundance by guild organization and migratory status. I categorized birds into guilds based on food gathering behavior (Ehrlich et al. 1988). The following guilds were used: foliage gleaners (take food items from vegetation), ground gleaners (pick food items from the surface of the ground), bark gleaners (remove invertebrates from bark; includes birds that excavate and drill into bark), aerial gleaners (take food while in flight), and predatory birds (eat other vertebrates). Aerial gleaners includes the categories of gleaning while hovering (e.g., hummingbirds), short flights to catch prey (e.g., Pacific-slope flycatcher), and capturing prey while in continuous flight (e.g., violet-green swallow). Predatory 
birds include birds that hunt using either aerial pursuit (chasing and catching birds in the air or on their perch, such as a Cooper's hawk), or swoop (snatching prey off of the ground using talons, such as a northern pygmy-owl) (Ehrlich et al. 1988). A list of birds and their foraging guilds can be found in Appendix $\mathrm{H}$.

Since tropical deforestation is believed to have a major impact on neotropical bird species richness and abundance, I examined migratory status to see whether or not there were any short-term changes observable in Forest Park's avian community and/or if there were any changes correlated with urbanization variables. The migratory status of a bird indicates whether or not, and how far, that species migrates annually. Bird species are often described as being residents, short distance (local) migrants, or neotropical (long distance) migrants (Askins 1995, Askins and Philbrick 1987, Blake et al. 1994, DeGraaf 1991, Ehrlich et al. 1988; Lynch and Whigham 1984). Residents are birds that remain in the same general location throughout the year. Examples of resident bird species in the Portland area include the black-capped chickadee and dark-eyed junco. Short-distance migrants, or local migrants, are bird species that travel a short distance in terms of either latitude or elevation, but do not enter tropical areas. These bird species are present during the winter months in the Portland area, having come from further north or higher elevations. Examples of local migratory species include the American robin and white-crowned sparrow. Neotropical (long-distance) migratory species are those that annually fly to Mexico, Central America, and/or South America. Members of this group will only rarely be seen in the Portland area during winter. Examples include the Swainson's thrush and Wilson's warbler (Ehrlich et al. 1988; Gilligan et al. 1994; Hutto 1980). The migratory status of birds counted in this study is listed in Appendix $\mathrm{H}$. 
I analyzed avian species abundance, richness, and diversity, as well as species abundance, richness, and diversity as categorized by both migratory status and guild membership. I analyzed breeding season birds and winter birds. Avian species that were counted less than 30 times total and/or present in less than two sections of the park were considered rare and were not analyzed. All dependent variables were analyzed using multiple regression and ANOVA as described previously. The common and scientific names of all bird species counted in this study, as well as abbreviations used, are listed in Appendix I.

I also compared avian community variables (dependent variables) with a select group of plant community variables (independent variables) using multiple regression. Plant community variables were selected that had been significantly correlated with urbanization in the previous chapters, and that were indicative of successional stage and/or increased numbers of exotic plant species. I tried to select variables that encompassed all plant layers (e.g., I selected variables that measured different characteristics of trees, shrubs, and herbs), as well as foliage height diversity (FHD). Using a correlation matrix, I reduced the number of useful vegetation variables to eight by selecting variables that had less than 60 percent collinearity and that met the requirements of representing different sections of the plant community. The eight plant community variables that were chosen functioned as the independent variables in multiple regression analyses that compared plant community structure with avian distribution. The eight independent variables were: the number of trees (TREE), the number of bigleaf maples (MAPLE), the number of small $(10-20 \mathrm{~cm} \mathrm{dbh})$ western red cedar trees (CEDAR), the number of shrubs (SHRUB), the total basal area of 
thimbleberry (THIMB), the species diversity for the herb layer (HERB), the percent cover by exotic herbs (EXOTIC), and the foliage height diversity (FHD). To meet the assumptions of normality, some of the independent variables were transformed using the same method described earlier (Table 7-2) (Draper and Smith 1966; Jongman et al. 1995; Sokal and Rohlf 1969; Steel and Torrie 1960; Tabachnick and Fidell 1996). These transformations were used consistently in all data analyses where vegetation parameters were compared to avian variables. Dependent variables (avian) that were not normally distributed were also transformed (Draper and Smith 1966; Jongman et al. 1995; Sokal and Rohlf 1969; Steel and Torrie 1960; Tabachnick and Fidell 1996). The transformations are reported in the tables. Regression coefficients comparing urbanization variables with breeding and winter bird variables are reported in Appendix J; regression coefficients comparing avian and vegetative variables are reported in Appendix $\mathrm{K}$.

\section{RESULTS}

\section{Breeding Birds (Spring Counts)}

Fifty-six species of birds were observed at my sites during the breeding season over the three year period of data collection (Table 7-3). During that time, 6062 individual birds were counted. I counted 1948 birds in the city section, 1915 in the middle section, 1866 in the far section, and 333 in the old-growth.

Several variables relating to breeding season birds were correlated with one or more of the urbanization variables by multiple regression (Table 7-4). The abundances of 
Table 7-2. Independent variables of vegetation parameters, their abbreviations as utilized in the paper, and the transformations done to meet assumptions of normality. These transformations were used in all statistical analyses pertaining the vegetation variables.

Vegetation Variable (Abbreviation)

Density of trees (TREE)

Density of bigleaf maples (MAPLE)

Density of w. red cedar 10-20 cm dbh (CEDAR)

Density of shrubs (SHRUB)

Total basal area thimbleberry (THIMB)

Herbaceous species diversity (HERB)

Percent exotic herbaceous species (EXOTIC)

Foliage Height Diversity (FHD)
Transformation

square root (TREE)

none

square root (CEDAR)

In (SHRUB + 1)

square root (THIMB)

square root (HERB)

square root (EXOTIC)

none 
Table 7-3. Total avian abundance and species richness during the breeding season as counted in the different sections of Forest Park and the old-growth stand in the different years of the study.

$\begin{array}{llllll}\text { Category and Year } & \text { City } & \text { Mid } & \text { Far } & \mathrm{OG}^{\dagger} & \text { Total }\end{array}$

Avian Abundance

$\begin{array}{crrrrr}1993 & 578 & 570 & 540 & 92 & 1780 \\ 1994 & 687 & 678 & 638 & 116 & 2119 \\ 1995 & 683 & 667 & 688 & 125 & 2163 \\ & & & & & \\ \text { Total number of birds } & 1948 & 1915 & 1866 & 333 & 6062\end{array}$

Avian Species Richness

$\begin{array}{clllll}1993 & 43 & 37 & 38 & 21 & 52 \\ 1994 & 43 & 38 & 36 & 19 & 48 \\ 1994 & 38 & 37 & 39 & 22 & 43 \\ \text { Total number of species } & 52 & 44 & 46 & 30 & 56\end{array}$

$\lceil$ Numbers for the old growth section are for one site whereas numbers for all other sections are for eight sites per section. 


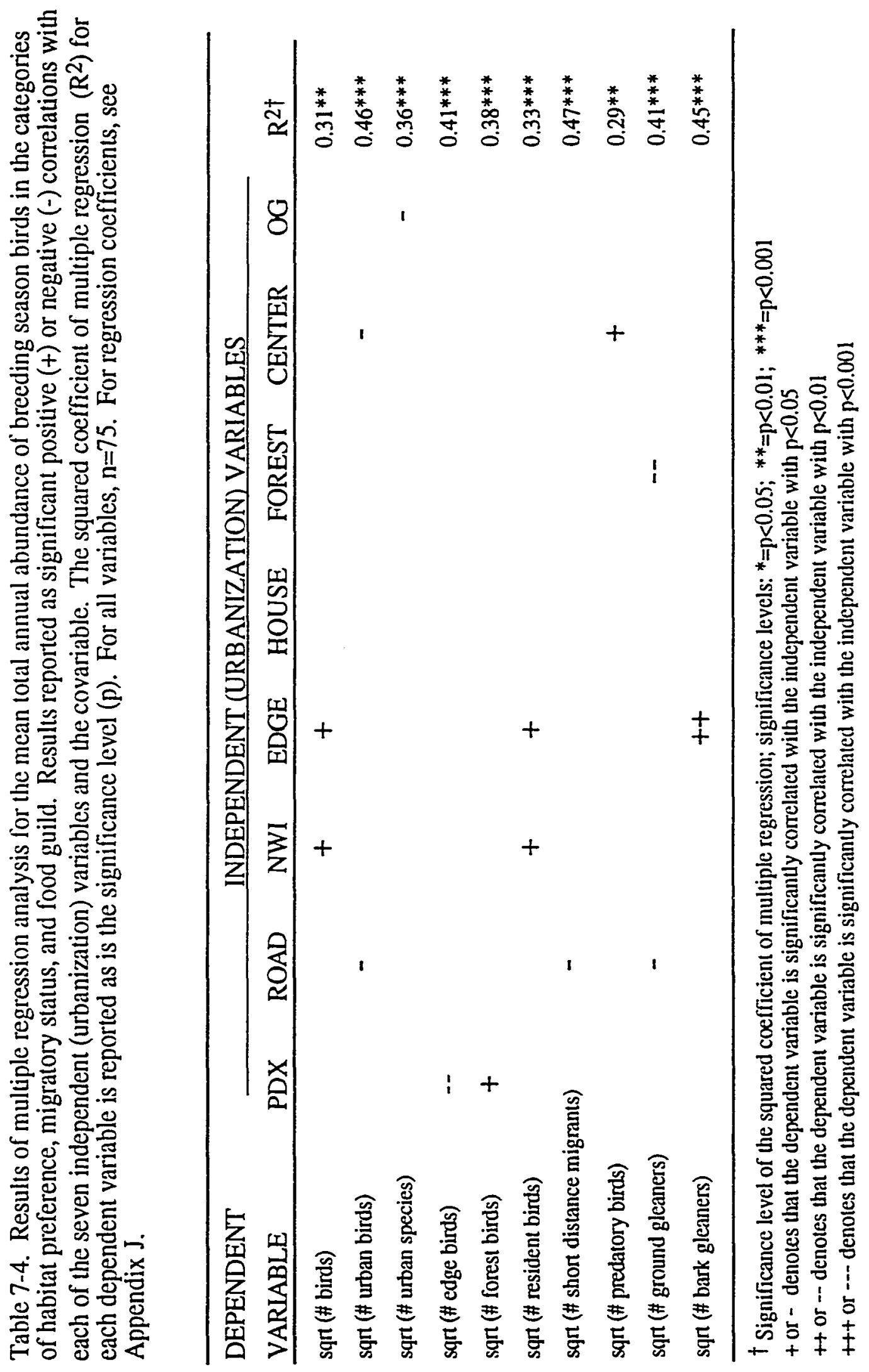


birds, resident birds, and bark gleaners were positively correlated with the distance from the nearest forest edge, whereas the abundances of urban birds, shortdistance migratory birds and ground gleaners were negatively correlated with the distance from the nearest road.

The abundances of several species of birds also correlated with one or more of the urbanization variables (Table 7-5). The abundance of house finches, categorized in this study as urban birds, was positively correlated with the number of surrounding houses. The abundances of spotted towhees and song sparrows, considered to be edge species in this study, correlated negatively with the distance from downtown Portland. The abundance of winter wrens, a species usually associated with forests (although not classified into the forest interior bird category in this study) were positively correlated with the distance from the nearest forest edge.

The old-growth stand had significantly more hawks (includes Cooper's, sharpshinned, and red-tailed hawks), Steller's jays, red-breasted nuthatches, brown creepers, Swainson's thrushes, and Hutton's vireos (Table 7-6). Many of these bird species are classified as forest birds here and elsewhere. Sites in more urban sections of Forest Park (i.e., the city and middle sections) had significantly more American robins, spotted towhees, and song sparrows (all categorized as either urban or edge species in this study), and significantly fewer Pacific-slope flycatchers (classified as a forest interior species in this study).

There were significantly more birds in the old-growth stand than at any site in Forest Park (Table 7-7). There were also more urban birds, edge birds, and short distance 


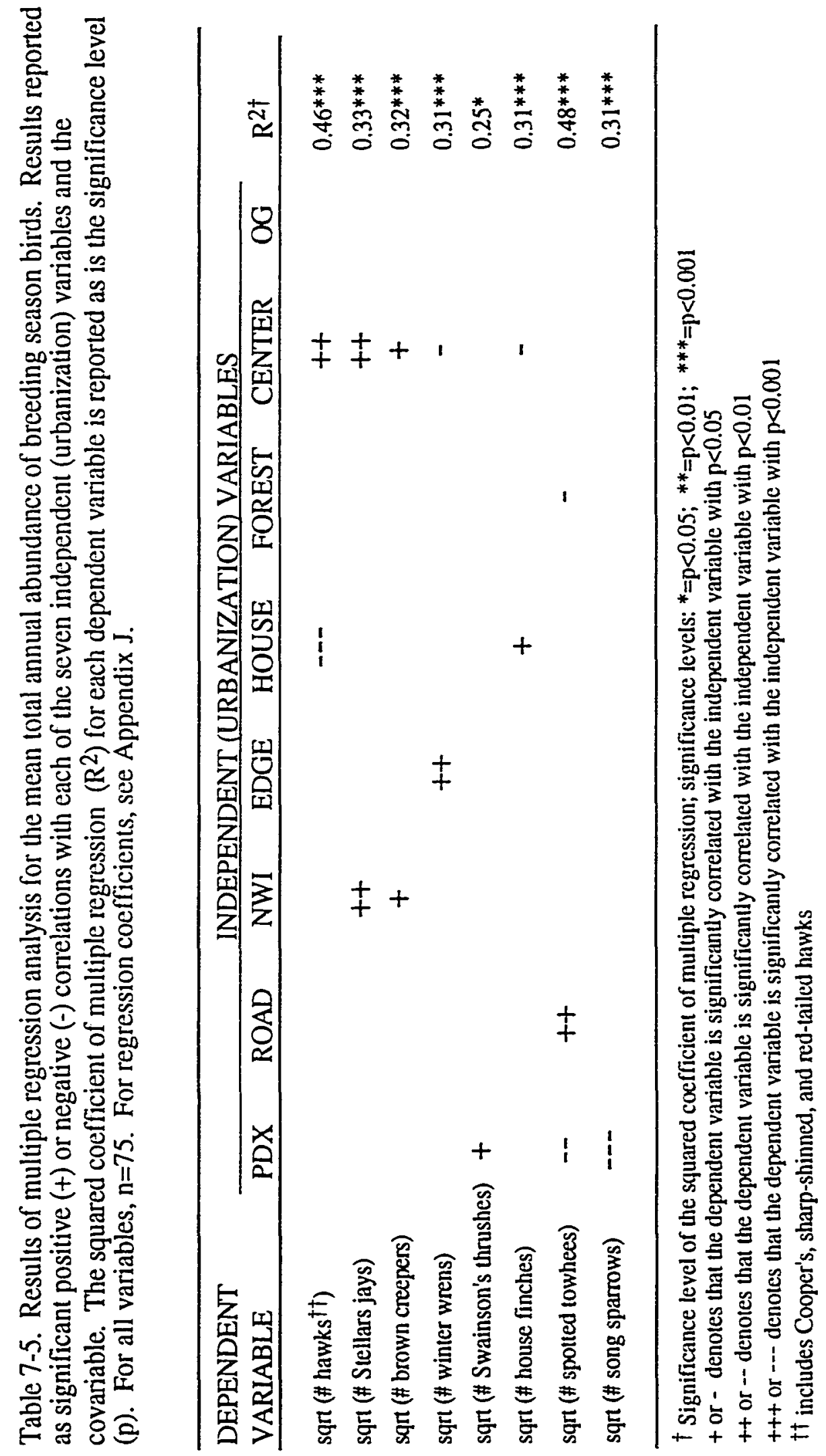


Table 7-6. Mean number of breeding season birds (standard deviation) for each section. Bird species that were present in less than two sections or were counted fewer than 30 times over the three year period were considered infrequent or rare species and were omitted from the analyses. $\mathrm{n}$ is reported for each section.

\begin{tabular}{|c|c|c|c|c|}
\hline Bird Species & City & Mid & Far & $\underline{O G}$ \\
\hline Hawkst† & $0.5(1.0)^{\mathrm{a}}$ & $0.3(0.6)^{\mathrm{a}}$ & $0.5(0.7)^{\mathrm{a}}$ & $3.0(2.6)^{b}$ \\
\hline Mourning doves & $0.6(0.8)$ & $0.2(0.5)$ & $0.3(0.6)$ & $0.7(0.6)$ \\
\hline Hairy woodpeckers & $0.1(0.3)$ & $0.5(1.0)$ & $0.6(1.0)$ & $1.0(1.0)$ \\
\hline Downy woodpeckers & $0.5(0.8)$ & $0.3(0.6)$ & $0.5(1.0)$ & $0.7(1.2)$ \\
\hline Pileated woodpeckers & $0.6(0.8)$ & $0.8(1.0)$ & $0.9(1.0)$ & $1.7(1.5)$ \\
\hline Olive-sided flycatchers & $0.7(1.4)$ & 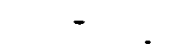 & $0.3(0.6)$ & $0.7(0.6)$ \\
\hline Pacific-slope flycatchers & $4.1(1.9)^{\mathrm{a}}$ & $5.9(1.8)^{b}$ & $6.3(2.0)^{\mathrm{b}}$ & $7.7(0.6)^{\mathrm{b}}$ \\
\hline Steller's jays $x$ & $1.3(1.5)^{\mathrm{a}}$ & $1.5(1.6)^{\mathrm{a}}$ & $1.5(1.4)^{\mathrm{a}}$ & $8.3(3.2)^{b}$ \\
\hline Black-capped chickadees & $7.7(7.7)$ & $9.8(7.2)$ & $6.8(5.8)$ & $19.7(14.5)$ \\
\hline Chestnut-backed chickadees & $1.0(1.9)$ & $2.7(3.9)$ & $0.7(1.3)$ & $1.0(1.7)$ \\
\hline Bush tits & $1.4(3.0)$ & $1.0(2.2)$ & $0.6(2.3)$ & - \\
\hline Red-breasted nuthatches & $3.1(2.2)^{\mathrm{a}}$ & $2.4(2.1)^{\mathrm{a}}$ & $3.6(2.1)^{\mathrm{ab}}$ & $7.0(3.5)^{b}$ \\
\hline Brown creepers ${ }^{x}$ & $3.2(2.0)^{\mathrm{a}}$ & $3.3(1.9)^{\mathrm{a}}$ & $3.6(1.9)^{\mathrm{a}}$ & $10.7(4.6)^{\mathrm{b}}$ \\
\hline Bewick's wrens & $0.5(0.9)$ & $0.1(0.3)$ & $0.4(0.8)$ & - \\
\hline Winter wrens & $7.3(2.5)^{\mathrm{ab}}$ & $6.4(2.4)^{\mathrm{a}}$ & $8.6(2.0)^{\mathrm{b}}$ & $10.3(2.1)^{b}$ \\
\hline American robins ${ }^{x}$ & $7.3(3.2)^{\mathrm{a}}$ & $4.3(2.3)^{b}$ & $5.3(2.9)^{\mathrm{ab}}$ & $1.3(1.5)^{c}$ \\
\hline Swainson's thrushes $\mathrm{x}$ & $2.7(1.9)^{\mathrm{a}}$ & $3.3(2.1)^{\mathrm{a}}$ & $3.9(2.1)^{\mathrm{ab}}$ & $8.3(5.0)^{\mathrm{b}}$ \\
\hline Golden-crowned kinglets & $0.5(0.9)$ & $0.7(2.4)$ & $1.1(1.8)$ & $3.7(4.0)$ \\
\hline Solitary vireos & $0.8(1.1)$ & $0.6(1.1)$ & $0.4(0.6)$ & $1.0(1.7)$ \\
\hline Hutton's vireos $\mathrm{x}$ & $0.7(1.6)^{\mathrm{a}}$ & $0.3(0.6)^{\mathrm{a}}$ & $0.3(0.6)^{\mathrm{a}}$ & $3.3(1.5)^{b}$ \\
\hline Orange-crowned warblers & $4.4(2.5)$ & $4.6(2.1)$ & $3.5(2.7)$ & $1.3(0.6)$ \\
\hline Yellow-rumped warblers & $1.5(5.3)$ & $0.3(1.1)$ & $0.1(0.2)$ & - \\
\hline Black-throated gray warbler & $1.9(2.1)$ & $4.0(3.5)$ & $3.4(2.4)$ & $2.0(2.6)$ \\
\hline Wilson's warblers & $5.8(2.3)$ & $6.2(2.7)$ & $6.3(2.7)$ & $5.0(1.7)$ \\
\hline Brown-headed cowbirds & $0.2(0.6)$ & - & $0.2(0.6)$ & \\
\hline Western tanagers & $1.3(1.6)$ & $1.8(1.9)$ & $2.7(1.9)$ & $4.3(2.3)$ \\
\hline Black-headed grosbeaks & $1.5(1.8)$ & $1.3(1.5)$ & $1.9(1.4)$ & $0.3(0.6)$ \\
\hline Purple finches & $1.9(2.7)$ & $0.9(0.9)$ & $1.3(1.5)$ & - \\
\hline House finches $x$ & $1.0(2.1)^{\mathrm{a}}$ & $0.1(0.2)^{\mathrm{b}}$ & $0.1(0.4)^{\mathrm{ab}}$ & - \\
\hline Pine siskins & $0.6(1.0)$ & $0.4(0.7)$ & $0.1(0.2)$ & - \\
\hline Spotted towhees & $5.8(2.1)^{\mathrm{a}}$ & $4.9(2.4)^{\mathrm{a}}$ & $3.7(2.2)^{b}$ & $0.7(1.2)^{b}$ \\
\hline Dark-eyed juncos ${ }^{x}$ & $3.4(2.1)^{\mathrm{ab}}$ & $4.3(2.3)^{\mathrm{a}}$ & $3.8(1.9)^{\mathrm{ab}}$ & $1.3(1.2)^{\mathrm{b}}$ \\
\hline Song sparrows ${ }^{x}$ & $4.0(2.2)^{\mathrm{a}}$ & $3.9(2.5)^{\mathrm{a}}$ & $1.7(2.2)^{b}$ & $0.0(0.1)^{b}$ \\
\hline $\mathrm{n}$ & 24 & 24 & 24 & 3 \\
\hline
\end{tabular}

Results of Bonnferoni/Dumn testing is shown for each variable as superscripts for means that are significantly different from one another. For a given variable, means with different superscripts are significantly different from one another (e.g., for any given dependent variable, all means with a superscript of a are significantly different from those with a superscript of b). Significance was determined after the variables were transformed in the same manner as used in multiple regression testing.

A superscript of " $x$ " denotes that the square root of the variable was used in statistical analyses. it includes Cooper's, sharp-shinned, and red-tailed hawks 
Table 7-7. Mean abundance of total breeding season birds by categories of habitat preference, migratory status, and food guild (standard deviation) per year for each section.

\begin{tabular}{|c|c|c|c|c|}
\hline Category & City & Mid & Far & OG \\
\hline \# urban birds $x$ & $8.6(4.1)^{\mathrm{a}}$ & $4.4(2.2)^{b c}$ & $5.7(3.4)^{\mathrm{b}}$ & $1.3(1.5)^{c}$ \\
\hline \# urban species $x$ & $1.6(0.8)^{a}$ & $1.1(0.4)^{\mathrm{ab}}$ & $1.3(0.5)^{\mathrm{ab}}$ & $0.7(0.6)^{b}$ \\
\hline \# edge birds $x$ & $15.1(6.7)^{\mathrm{a}}$ & $10.5(4.4)^{\mathrm{b}}$ & $7.7(3.9)^{\mathrm{b}}$ & $2.3(2.1)^{c}$ \\
\hline \# edge species $x$ & $3.8(1.2)^{\mathrm{a}}$ & $3.0(0.9)^{\mathrm{ab}}$ & $2.9(1.3)^{\mathrm{ab}}$ & $2.0(1.7)^{\mathrm{b}}$ \\
\hline \# forest birds $x$ & $13.2(4.5)^{\mathrm{a}}$ & $18.0(4.7)^{\mathrm{b}}$ & $18.8(5.6)^{\mathrm{b}}$ & $31.3(9.8)^{c}$ \\
\hline \# forest species & $4.4(0.9)$ & $4.7(1.0)$ & $5.0(0.6)$ & $5.0(1.0)$ \\
\hline \# resident birds & $41.8(16.2)^{\mathrm{a}}$ & $41.4(13.7)^{\mathrm{a}}$ & $39.8(11.3)^{\mathrm{a}}$ & $74.0(23.6)^{b}$ \\
\hline \# neotropical birds & $25.5(7.2)$ & $28.6(5.5)$ & $28.9(5.7)$ & $31.7(8.5)$ \\
\hline$\#$ short distance migrants $x$ & $20.2(6.7)^{\mathrm{a}}$ & $12.9(5.3)^{\mathrm{ab}}$ & $13.5(7.0)^{\mathrm{ab}}$ & $4.0(2.6)^{c}$ \\
\hline \# predatory birds $x$ & $0.5(1.0)^{\mathrm{a}}$ & $0.5(0.7)^{\mathrm{a}}$ & $0.8(0.9)^{\mathrm{ab}}$ & $3.0(2.6)^{\mathrm{b}}$ \\
\hline \# ground gleaners $x$ & $33.5(7.2)^{\mathrm{a}}$ & $26.9(5.5)^{\mathrm{b}}$ & $27.3(5.8)^{\mathrm{b}}$ & $24.3(3.2)^{\mathrm{ab}}$ \\
\hline \# foliage gleaners $x$ & $33.0(10.3)^{\mathrm{a}}$ & $37.9(10.8)^{\mathrm{ab}}$ & $32.5(8.8)^{\mathrm{a}}$ & $51.7(11.0)^{\mathrm{b}}$ \\
\hline $\begin{array}{l}\text { \# bark gleaners }{ }^{x} \\
\text { \# aerial gleaners }\end{array}$ & $\begin{array}{l}8.0(3.7)^{\mathrm{a}} \\
5.4(2.2)\end{array}$ & $\begin{array}{l}7.5(4.0)^{\mathrm{a}} \\
6.0(1.8)\end{array}$ & $\begin{array}{l}9.6(3.6)^{\mathrm{a}} \\
6.7(2.1)\end{array}$ & $\begin{array}{c}21.0(6.6)^{b} \\
8.3(1.2)\end{array}$ \\
\hline$\#$ birds $x$ & $81.2(15.9)^{\mathrm{a}}$ & $79.8(15.0)^{\mathrm{a}}$ & $77.8(12.0)^{\mathrm{a}}$ & $111.0(17.1)^{b}$ \\
\hline \# species & $21.2(3.6)$ & $20.6(2.9)$ & $20.6(1.9)$ & $21.3(1.2)$ \\
\hline range species per site & $14-28$ & $16-26$ & $17-24$ & $20-22$ \\
\hline $\mathrm{H}^{\prime}$ & $2.76(0.17)$ & $2.74(0.13)$ & $2.77(0.11)$ & $2.70(0.18)$ \\
\hline $\mathrm{n}$ & 24 & 24 & 24 & 3 \\
\hline
\end{tabular}

Results of Bonnferoni/Dunn testing is shown for each variable as superscripts for means that are significantly different from one another. For a given variable, means with different superscripts are significantly different from one another (e.g., for any given dependent variable, all means with a superscript of a are significantly different from those with a superscript of b). Significance was determined after the variables were transformed in the same manner as used in multiple regression testing.

A superscript of " $x$ " denotes that the square root of the variable was used in statistical analyses. 
migratory birds at sites in the city, whereas there were more forest birds and resident birds in the old-growth. I did not find any significant differences among the sections regarding neotropical species of birds. The old-growth stand, however, had significantly more predatory birds, foliage gleaners, and bark gleaners, whereas the city section had significantly more ground gleaners.

\section{Winter Birds}

I observed 2230 individual birds from 35 species during the three winter seasons (Table 7-8). Total bird abundance, abundances of resident birds, and abundances of foliage gleaners were all positively correlated with the old-growth stand (Table 7-9). Several avian variables were also positively correlated with the distance from the center of the forest. Abundances of only two bird species -- brown creepers and golden-crowned kinglets -- were correlated with urbanization variables. The abundance of brown creepers, classified as forest interior species in this study, was positively correlated with the distance from the center of the forest, whereas the abundance of golden-crowned kinglets, classified as forest birds by others, was positively correlated with the old-growth stand.

The abundances of all bird species that were significant (i.e., black-capped chickadees, red-breasted nuthatches, brown creepers, and golden-crowned kinglets) were greater in the old-growth stand (Table 7-10). There were also significantly more forest birds, resident birds, foliage gleaners, and bark gleaners in the oldgrowth stand than in any section of Forest Park. 
Table 7-8. Total avian abundance and species richness as counted in the winter months in the different sections of Forest Park and the old-growth stand during the three years of the study.

$\begin{array}{llllll}\text { Category and Year } & \text { City } & \text { Mid } & \text { Far } & \mathrm{OG}^{\dagger} & \text { Total }\end{array}$

\section{Avian Abundance}

$\begin{array}{lrrrrr}1994 & 138 & 86 & 94 & 66 & 384 \\ 1995 & 96 & 110 & 187 & 110 & 503 \\ 1996^{\ddagger} & 415 & 352 & 328 & 248 & 1343 \\ \text { Total number of birds } & 649 & 548 & 609 & 424 & 2230\end{array}$

Avian Species Richness

$\begin{array}{lrrrrr}1994 & 11 & 8 & 9 & 6 & 17 \\ 1995 & 10 & 8 & 13 & 8 & 18 \\ 1996^{\ddagger} & 20 & 18 & 20 & 8 & 29 \\ \text { Total number of species } & 26 & 18 & 25 & 11 & 36\end{array}$

Numbers for the old growth section are for one site whereas numbers for all other sections are for eight sites per section.

$\doteqdot$ Abundances and richness for 1996 sample represent the total of triplicate sampling whereas only one sample per year was taken for 1994 and 1995. 


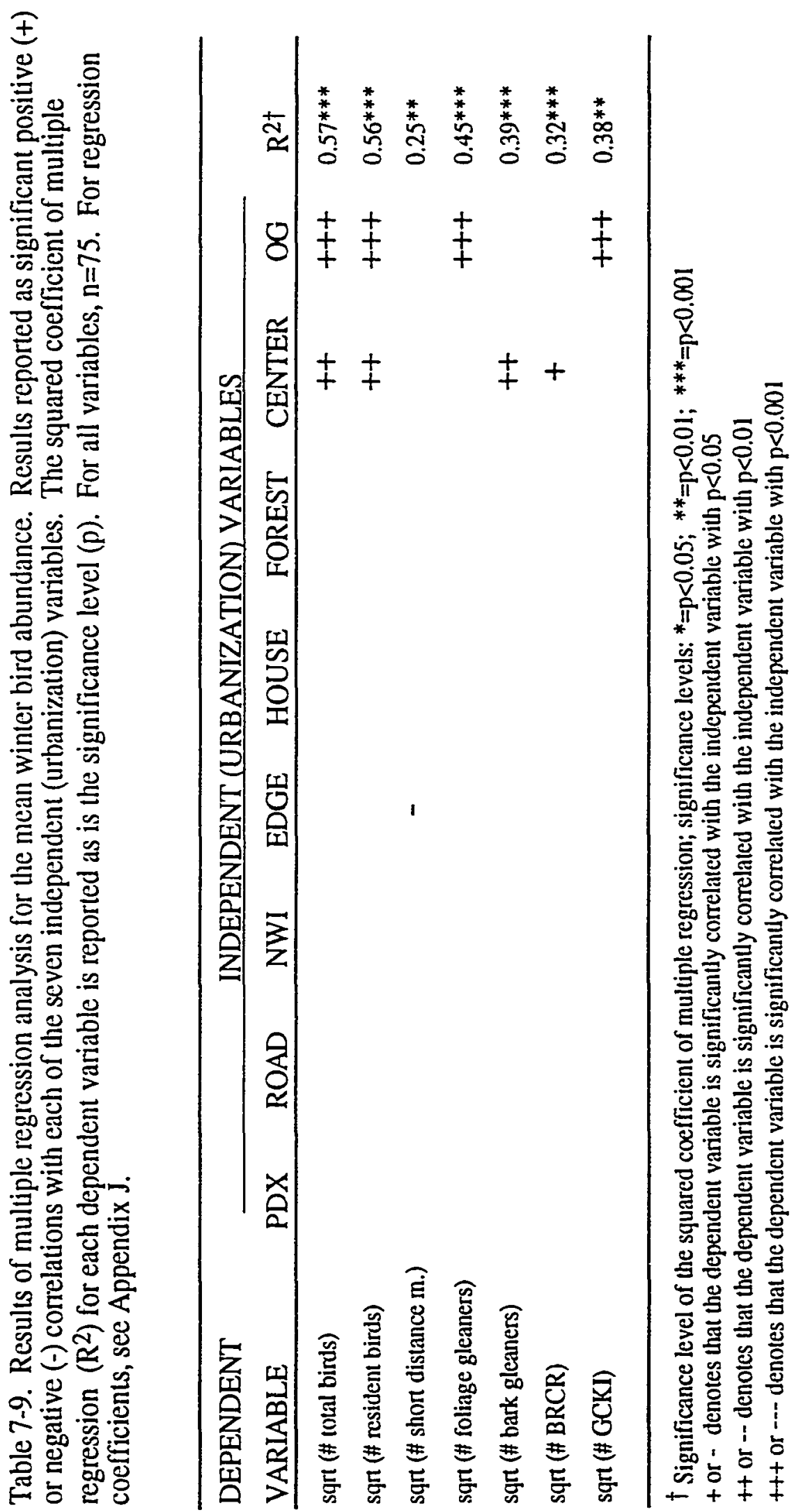


Table 7-10. Mean abundance of winter birds (standard deviation) for each section. Bird species that were present in less than two sections or were counted fewer than 40 times over the three year period were considered infrequent or rare species and were omitted from the analyses.

\begin{tabular}{|c|c|c|c|c|}
\hline & City & Mid & Far & OG \\
\hline All woodpeckers & $0.1(0.3)$ & $0.2(0.5)$ & $0.2(0.5)$ & $0.2(0.4)$ \\
\hline American crows & $0.1(0.3)$ & $0.5(1.4)$ & $0.1(0.3)$ & - \\
\hline Black-capped chickadees ${ }^{x}$ & $4.3(2.5)^{\mathrm{a}}$ & $3.5(3.0)^{\mathrm{a}}$ & $4.1(4.2)^{\mathrm{a}}$ & $23.3(14.7)^{b}$ \\
\hline Red-breasted nuthatches $x$ & $0.6(0.7)^{\mathrm{a}}$ & $0.4(0.6)^{a}$ & $0.9(0.7)^{\mathrm{ab}}$ & $2.7(0.6)^{b}$ \\
\hline Brown creepers ${ }^{x}$ & $1.1(1.1)^{\mathrm{a}}$ & $1.2(1.0)^{\mathrm{a}}$ & $1.0(0.8)^{\mathrm{a}}$ & $7.0(5.0)^{b}$ \\
\hline Winter wrens & $1.6(1.3)$ & $1.8(1.3)$ & $2.2(1.3)$ & $4.4(0.5)$ \\
\hline Golden-crowned kinglets $x$ & $5.0(6.2)^{\mathrm{a}}$ & $3.9(3.3)^{\mathrm{a}}$ & $5.8(8.5)^{\mathrm{a}}$ & $39.7(5.5)^{b}$ \\
\hline Dark-eyed juncos & $0.8(1.2)$ & $0.5(0.8)$ & $0.5(0.9)$ & $0.7(1.2)$ \\
\hline$\#$ birds $x$ & $14.8(7.4)^{\mathrm{a}}$ & $12.0(6.3)^{\mathrm{a}}$ & $15.9(13.4)^{\mathrm{a}}$ & $81.3(25.1)^{\mathrm{a}}$ \\
\hline \# species & $6.2(2.8)$ & $5.6(2.7)$ & $6.4(2.7)$ & $8.0(1.0)$ \\
\hline range species per site & $6-14$ & $6-11$ & $6-13$ & $7-9$ \\
\hline $\mathrm{H}^{\prime}$ & $1.42(0.39)$ & $1.40(0.44)$ & $1.47(0.37)$ & $1.45(0.21)$ \\
\hline \# urban birds & $0.1(0.4)$ & $0.0(0.1)$ & $0.0(0.2)$ & - \\
\hline \# edge birds & $0.2(0.6)$ & $0.1(0.1)$ & $0.1(0.2)$ & - \\
\hline \# forest birds $x$ & $1.4(1.2)^{\mathrm{a}}$ & $1.5(1.5)^{\mathrm{a}}$ & $1.3(0.9)^{\mathrm{a}}$ & $7.2(5.0)^{b}$ \\
\hline \# resident birds ${ }^{x}$ & $14.7(7.4)^{\mathrm{a}}$ & $12.5(6.4)^{\mathrm{a}}$ & $15.7(13.5)^{\mathrm{a}}$ & $81.3(25.1)^{\mathbf{b}}$ \\
\hline \# short distance birds & $0.4(0.8)$ & $0.1(0.2)$ & $0.2(0.5)$ & - \\
\hline \# ground gleaners & $3.2(2.2)$ & $3.0(2.2)$ & $3.3(1.6)$ & $5.7(1.5)$ \\
\hline \# foliage gleaners ${ }^{x}$ & $9.9(6.9)^{\mathrm{a}}$ & $7.7(5.9)^{\mathrm{a}}$ & $10.3(12.4)^{\mathrm{a}}$ & $65.3(18.8)^{b}$ \\
\hline \# bark gleaners ${ }^{x}$ & $1.8(1.3)^{\mathrm{a}}$ & $1.8(1.3)^{\mathrm{a}}$ & $2.2(1.4)^{\mathrm{a}}$ & $10.0(5.0)^{b}$ \\
\hline & 24 & 24 & 24 & 3 \\
\hline
\end{tabular}

Results of Bonnferoni/Dunn testing is shown for each variable as superscripts for means that are significantly different from one another. For a given variable, means with different superscripts are significantly different from one another (e.g., for any given dependent variable, all means with a superscript of a are significantly different from those with a superscript of b). Significance was determined after the variables were transformed in the same manner as used in multiple regression testing.

A superscript of " $x$ " denotes that the square root of the variable was used in statistical analyses. 
In all three years, I observed significantly higher bird abundances at the old-growth stand than at any site in Forest Park (Figure 7-1), although species richness and diversity were similar among the different sections. The increased avian abundances seemed to be positively correlated with snow level in the nearby mountain ranges (i.e., Cascades and Coast Range). To test this hypothesis, I compared the number of birds counted in the old-growth with the snow level at Government Camp (a small town at an elevation of 1190 meters on the south shoulder of nearby Mount Hood) four days earlier using simple regression analysis. Comparing the depth of snow at Government Camp on the same day that the birds were counted would not allow time for the birds to move from higher elevation to the old-growth stand after a substantial snowfall. The iegression (Figure 7-2) revealed a significant positive correlation between snow in nearby mountains and bird abundance in the old-growth stand four days later.

\section{Plant Community Structure and Avian Distribution}

Several measurements of bird abundance were found to be significantly correlated with some of the plant community variables (Table 7-11). For breeding season birds, the abundances of birds and bark gleaners were negatively correlated with the number of bigleaf maples. The densities of urban birds and short distance migrants, as well as edge species richness, were all negatively correlated with the foliage height diversity (FHD). The abundances of urban birds and short distance migratory species were positively correlated with the basal area of thimbleberry and the percent of exotic species. The abundances of Pileated woodpeckers and Swainson's thrushes (forest species) were both negatively correlated with the density of trees and positively correlated with the foliage height diversity (FHD) (Table 7-12). 


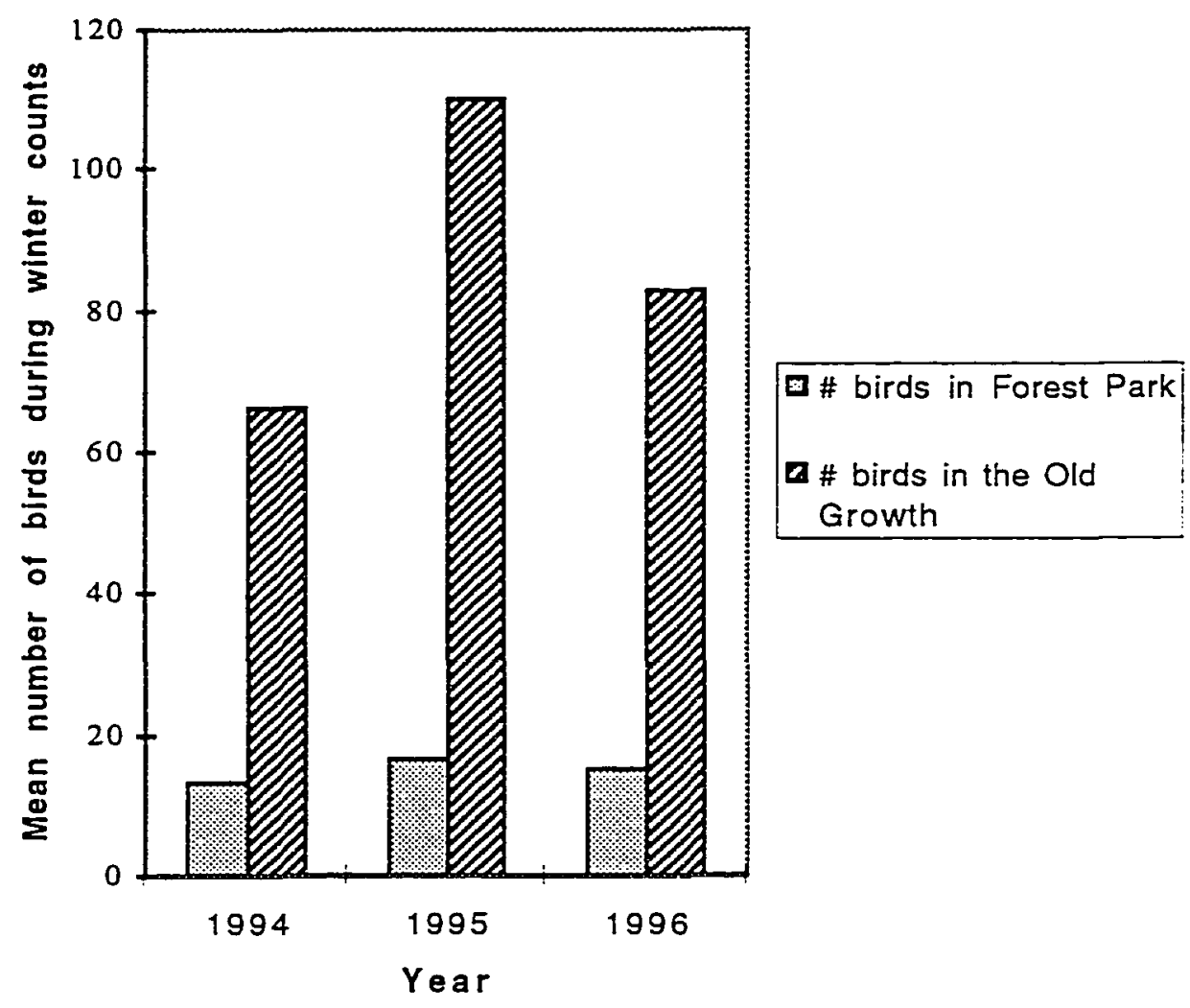

Figure 7-1. The mean number of winter birds in Forest Park versus in the oldgrowth stand for each year of the study. 


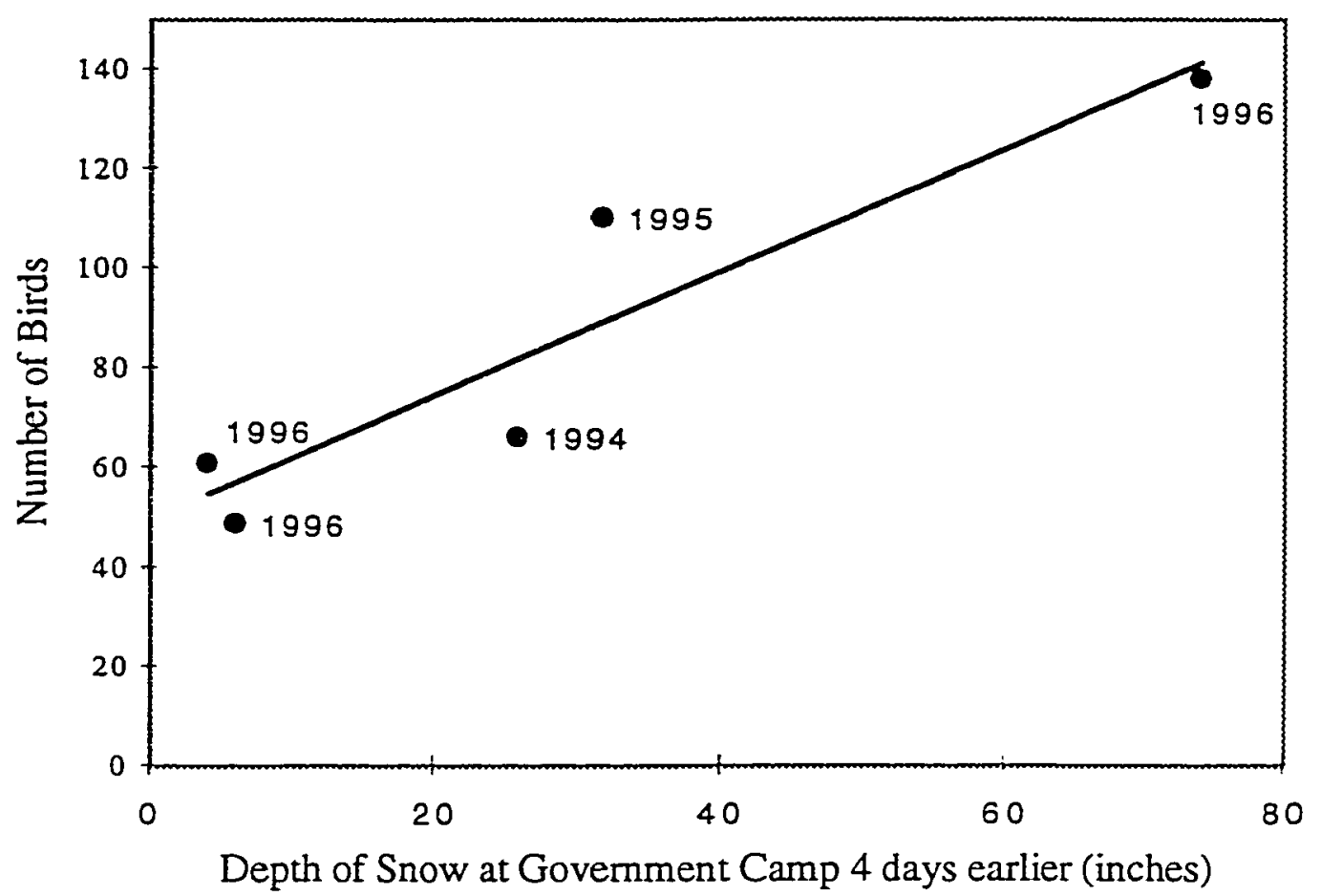

Figure 7-2. The number of birds in the old growth stand versus snow depth (inches) at Government Camp four days prior to the day that the bird count was conducted. The regression equation is $\mathrm{y}=1.23 \mathrm{x}+49.7 ; \mathrm{R}^{2}=0.86 ; \mathrm{p}=0.02$. 


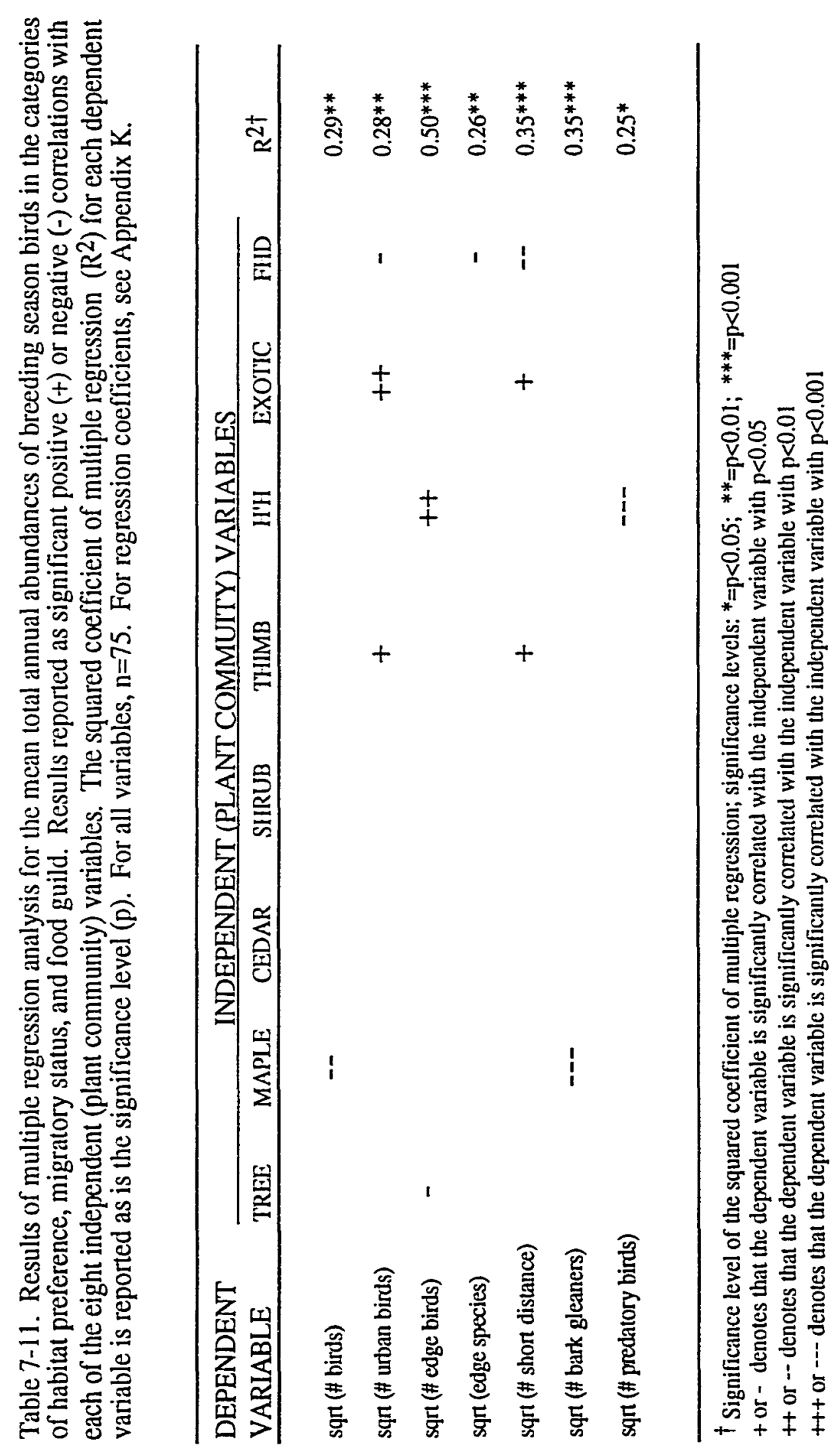




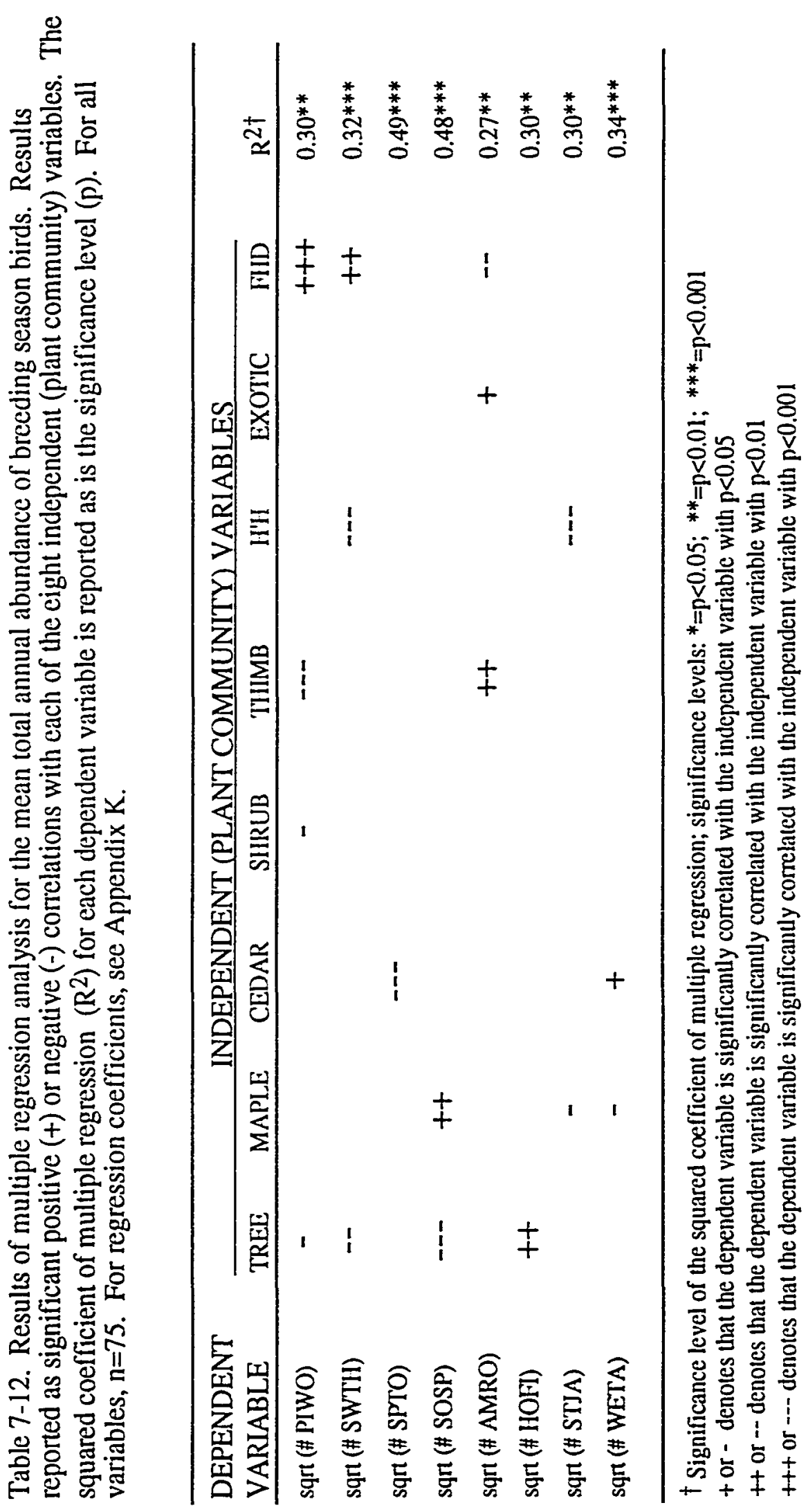


Significant correlations with vegetative parameters were different during the winter season than during the breeding season (Table 7-13). The abundances of birds, urban birds, forest birds, resident birds, foliage gleaners, bark gleaners, brown creepers, and golden-crowned kinglets were all negatively correlated with the density of bigleaf maples (a deciduous species), and except for the abundance of urban birds, all the previously listed bird categories were also negatively correlated with the species diversity of the herbaceous layer. In addition, the abundances of urban birds, resident birds, foliage gleaners, and black-capped chickadees were all positively correlated with the density of shrubs.

\section{DISCUSSION}

\section{Breeding Bird Community}

Several breeding season bird variables correlated with urbanization. Using the distance from downtown Portland as a simple urbanization gradient as described in chapters 5 and 6 , I found greater richness and density of birds categorized as edge species, as well as greater density and richness of individual edge species such as spotted towhees and song sparrows at more urban sites. Concomitant with the greater numbers of edge birds, there were fewer forest birds and fewer forest bird species such as winter wrens and Swainson's thrushes. These results are consistent with those from other studies (Askins 1995; Askins and Philbrick 1987; Blair 1996; Blake et al. 1994; Bollinger and Linder 1994; Donovan et al. 1995a; Hoover et al. 1995; Keller and Anderson 1992; Kroodsma 1984; Lent and Capen 1995; McIntyre 1995; McLellan et al. 1986; Stouffer and Bierregaard 1995; Temple and Wilcox 


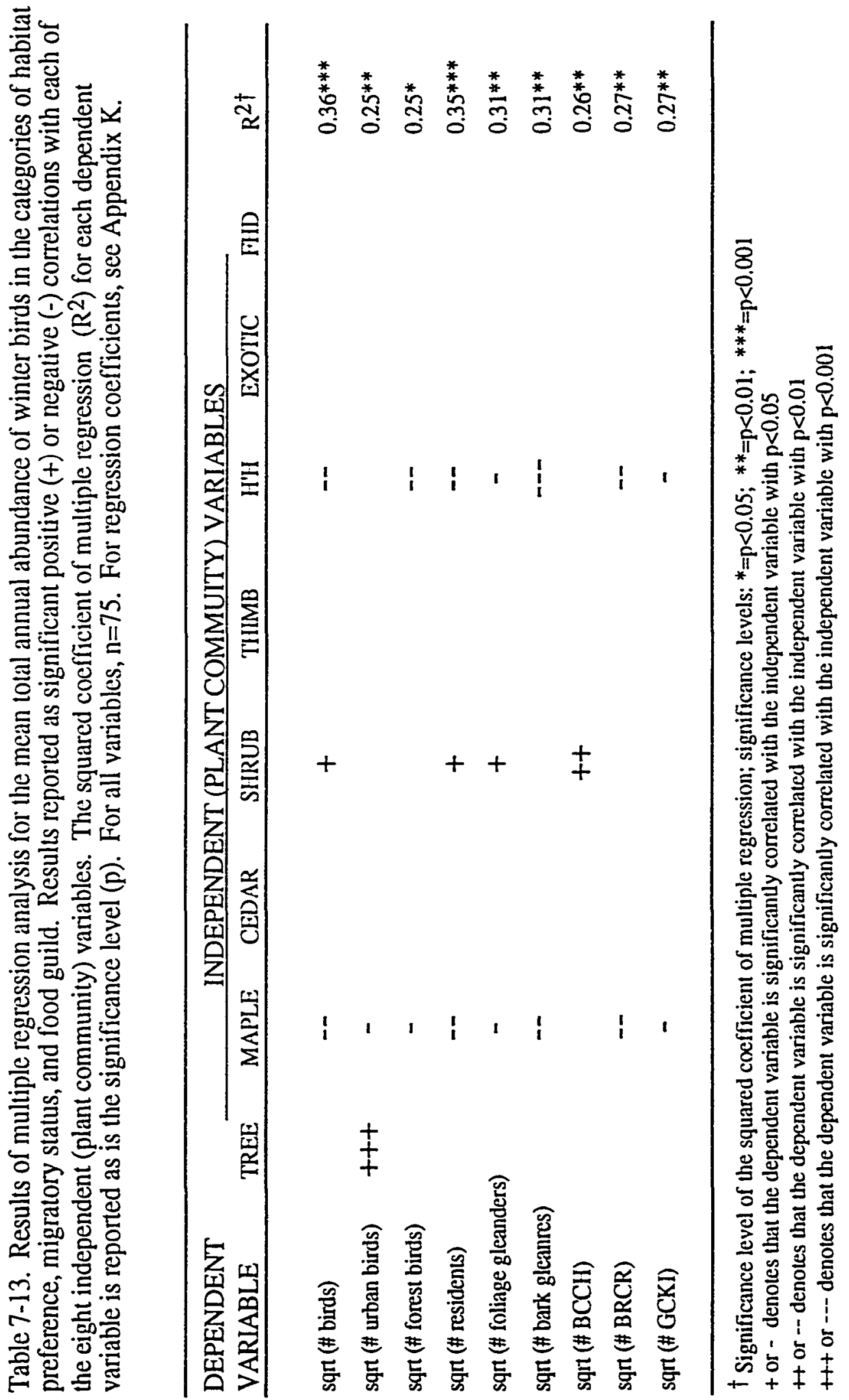


1986; Terborgh 1989; Wilcove 1985). However, unlike the previous studies where forested areas were adjacent to developed areas of differing land uses, my findings were confined to a forested area contiguous with a city. The city section of Forest Park has a greater density of edge habitat birds than did the other areas sampled which is consistent with more edge habitat in the city section of the park (see Figure $5-2$, page 75$)$.

Many species of birds, the edge species, respond more favorably to increased edge habitat that results from forest fragmentation. Forest bird species, on the other hand, frequently have specialized habitat requirements and are more sensitive to habitat fragmentation (Lent and Capen 1995; Lynch and Whigham 1984; Whitcomb et al. 1981; Wilcove 1985). I found that the richness and abundance of both edge birds and urban birds were greater in edge habitats. Species such as song sparrows, spotted towhees, American robins, and house finches have been associated with edge or suburban areas by others (Blair 1996; Whitcomb et al. 1981) and were also found to be associated with edge habitat in this study. In addition, I found that species classified by others as preferring forest interior habitat such as Cooper's and sharpshinned hawks, brown creepers, winter wrens, and Hutton's vireos were all associated with forest interior habitat in this study. These results demonstrate that increased development around Forest Park is producing more edge habitat and that the avian community is responding to the changes.

My results show that habitat fragmentation in Forest Park is correlated with changes in the abundance and diversity of birds. But, are these results the consequence of habitat fragmentation or can the observed differences be attributed to different past 
land usage patterns in Forest Park? Since forest fires and logging produce a fragmented landscape similar to the effects of development, it may be hard to distinguish between the effects of urban development and other human effects. To investigate the relationships between birds and past land use, I compared the distribution of individual bird species in different sections of the park.

I found significantly more forest birds in the old-growth stand, including Cooper's , sharp-shinned, and red-tailed hawks (nested in the stand), Swainson's thrushes, Steller's jays, red-breasted nuthatches, brown creepers, Hutton's vireos, and winter wrens. Of these species, brown creepers, red-breasted nuthatches, Hutton's vireos, Steller's jays, and winter wrens have all been found to be associated with old-growth and mature forests in the Pacific Northwest in spring (Carey et al. 1991; Gilbert and Allwine 1991; Huff and Raley 1991; Lundquist and Mariani 1991; Manuwal 1991; Ruggiero et al. 1991). While all of these old-growth associated avian species were also found at sites in Forest Park, they were present in reduced abundances as compared to those in the old-growth. I also found significantly more bark gleaners, foliage gleaners, and predatory birds in the old-growth. There have been reports of increased abundance of bark gleaners in old-growth Douglas-fir forests (Carey et al. 1991; Huff and Raley 1991; Lundquist and Mariani 1991). Larger numbers of predatory birds (e.g., Cooper's hawks and Northern pygmy-owls) have been reported in old-growth forests; but due to the large ranges and relative scarcity of the birds, most of these examples have not been statistically significant (Carey et al. 1991, Huff and Raley 1991; Ruggiero et al. 1991). Avian evidence is consistent with the observation that the old-growth stand is significantly different from Forest Park. However, I found significantly reduced density and richness of edge birds in 
the old-growth even though the old-growth stand is essentially all edge as a result of the surrounding clear cuts. This finding supports the idea that successional stage, not fragmentation, is the most important factor in avian distribution at this study site. Nevertheless, the increased abundance of all birds may be related to the increased amount of edge habitat surrounding the stand.

The only bird species whose abundances were greatest in the far section were the winter wren and Pacific-slope flycatcher (Table 7-6). Both bird species are typically found in older seral stage forests (Carey et al. 1991; Gilbert and Allwine 1991; Huff and Raley 1991; Manuwal 1991; Ruggiero et al. 1991). I found more forest birds and fewer urban and edge birds at sites in the far section as compared to the city section of Forest Park. In most cases, however, avian abundances in the far and middle sections were not significantly different from one another. Those differences that were observed were most likely the result of the degree of vegetation homogeneity in the different sections. Trees have a more heterogeneous distribution in the far section of Forest Park that is most likely attributable to the more patchy nature of past disturbances (i.e., small scale logging and slash burns in the far section versus a widespread, devastating fire in the middle section). At this time, with the minimal differences in avian distribution between these two sections of Forest Park, it is hard to determine whether fragmentation is playing role in the distribution of birds in either of these two sections.

Avian distribution in the city section was different from that in the other areas. I found greater abundances of both urban and edge birds than in the other sections. I also found greater abundances of such urban-adapted species as American robins and 
house finches, as well as more ground gleaners, similar to the findings of others Aldrich and Coffin 1980; Beissinger and Osborne 1984; Blake 1983; Block et al. 1986; Carey et al. 1991; Davis and Glick 1978; DeGraaf 1991; DeGraaf and Wentworth 1986; Lancaster and Rees 1979; Lent and Capen 1995). In addition, there were increased abundances of such edge-adapted species as spotted towhees and song sparrows. These species have been categorized as edge-adapted species in other studies (Askins and Philbrick 1987; Blair 1996; DeGraaf and Wentworth 1986; Lent and Capen 1995; Levenson 1981; McIntyre 1995; McLellan et al. 1986; Rich et al. 1994; Rosenberg and Raphael 1986; Wiicove 1985). The city section also had significantly fewer forest interior birds, as well as fewer forest associated species such as Pacific-slope flycatchers. The decreased abundance of forest associated species of birds, as well as the increased abundance of urban and edge associated species of birds in the city section supports the conclusion that habitat fragmentation is important in avian patterns of distribution in the city section of the park. In terms of the avian community, the city section of Forest Park appear to be functioning as edge habitat due to the higher degree of habitat fragmentation. In addition, its close proximity to the urban environment appears to be attracting such urban adapted species as house finches.

The increased disturbance regime in and around the city section is likely increasing the patchiness of the landscape, increasing the amount of edge habitat, and providing edge and urban associated bird species a niche that would not normally be present in an older seral forest. It is also possible that not only is the amount of edge important, but so is the matrix or habitat surrounding the forest. Several recent studies have shown that the surrounding habitat and/or land use is more important to the 
distribution of birds in a patch than is the size of the patch itself (Friesen et al. 1995; Sisk et al. 1997). The distribution of birds in the old-growth lends some support to this hypothesis as the increased amount of edge habitat surrounding the old-growth stand has not resulted in an increased amount of edge birds, nor a decreased amount of forest birds. Other studies have shown that close proximity to highly traveled roads may result in changes in avian distribution (Reijnen and Foppen 1995). It may be that different land uses surrounding Forest Park, as well as the extensive network of roads in the area, contribute to the effects of edge, especiaily in the city section of the park where development has, up until the recent past, been far less dramatic.

My avian findings are also supported by correlations with the vegetation parameters. The densities of edge birds were found to be correlated with plant variables in the same manner that the plant variables had been previously correlated with edge habitat. These findings support the contention that the effects of habitat fragmentation are influencing the avian community through vegetative community structure. The effects of habitat fragmentation on the plant community are correspondingly affecting the avian community.

Because neotropical migratory species seem to be especially affected by habitat fragmentation (Friesen et al. 1995; Lynch and Whigham 1984; Sauer et al. 1997; Whitcomb et al. 1981), I expected to see fewer such birds at more urban sites. I found that the abundance of resident bird species declined with urbanization and the abundance of short-distance migratory species increased, similar to the findings of others (Blair 1996; Lent and Capen 1995; Lynch and Whigham 1984; Wilcove 1985). Huff and Raley (1991) reported greater abundance of resident birds in 
Douglas-fir old-growth forests as compared to younger seral forests. Although I did find significantly more resident birds in the old-growth, I did not find any significant differences in the distribution of neotropical migratory species. Long-term analyses of results from the Breeding Bird Survey show no significant reduction in the abundance of neotropical migratory birds in the western portions of the United States, in spite of extensive forest fragmentation (Herkert 1995; Peterjohn and Sauer 1994; Sauer et al. 1997). This may be because neotropical migratory birds comprise a smaller percentage of the avifauna in Pacific Northwest forests than they do in eastern forests where most studies have been conducted (Manuwal 1991) or it may be due to other unknown factors.

My results suggest that birds are responding to the successional stage of the forest, but that increased habitat fragmentation also accounts for changes in the avian community near Portland. I found more edge and urban adapted species at sites nearer to the city. Many edge and city adapted species are what Lent and Capen (1995) refer to as "fugitive species". "Fugitive species" are adapted to an everchanging landscape and are opportunists in nesting and surviving in the everchanging mosaic of habitats (Lent and Capen 1995). Many Pacific Northwest forest bird species, being generalists, inhabit seral communities from early successional to old-growth forests and lead such a "fugitive" life style. Since "normal" forest structure in the Pacific Northwest is a mosaic of landscapes caused by natural disturbances such as fires and wind storms, it follows that many of the avian species in this area would be well suited to the ever-changing landscape and could exist in a wide range of habitats. 
It is possible that certain human disturbances (e.g., logging) mimic certain natural disturbances and have little detrimental effect on the distribution of most Pacific Northwest bird species at the landscape level (McGarigal and McComb 1995; Peart et al. 1992; Raphael and Barrett 1983). However, at some point, urbanization will probably affect the avian community in more insidious ways than through simple habitat fragmentation. I am unaware of any such effects in this study, however one possible example is presence of the brown-headed cowbird in Forest Park. Breeding activity west of the Cascades was first reported in the early 1950s (Gilligan et al. 1994). Although their numbers have grown, an increase in abundance of the species has never been reported in forest fragments generated through logging activity. (Carey et al. 1991; Gilbert and Allwine 1991; Gilligan et al. 1994; Huff and Raley 1991; Lundquist and Mariani 1991; Manuwal 1991; Ruggiero et al. 1991). Because brown-headed cowbirds prefer sites with chronic disturbance and/or pasture-like (i.e., lawn) habitat (Coker and Capen 1995) and because logged lands are usually reforested, their absence from forest "islands" surrounded by logged land is not surprising. Whereas the species was present too infrequently in this study to analyze statistically, it is interesting to note that it was only recorded at sites in the city and far sections of the park -- areas that have large amounts of edge associated with either urban or agricultural development and hence have a greater amount of pasture and lawn (Figure 7-3). Brown-headed cowbirds preferentially parasitize many neotropical bird species (Askins 1995; Rich et al. 1994; Robinson et al. 1995; Whitcomb et al. 1981; Wilcove 1985). Therefore, a decrease in neotropical migratory species at sites near the city could be expected to occur if the abundance of brown-headed cowbirds increases in the Portland area. Concomitantly, the extent of 


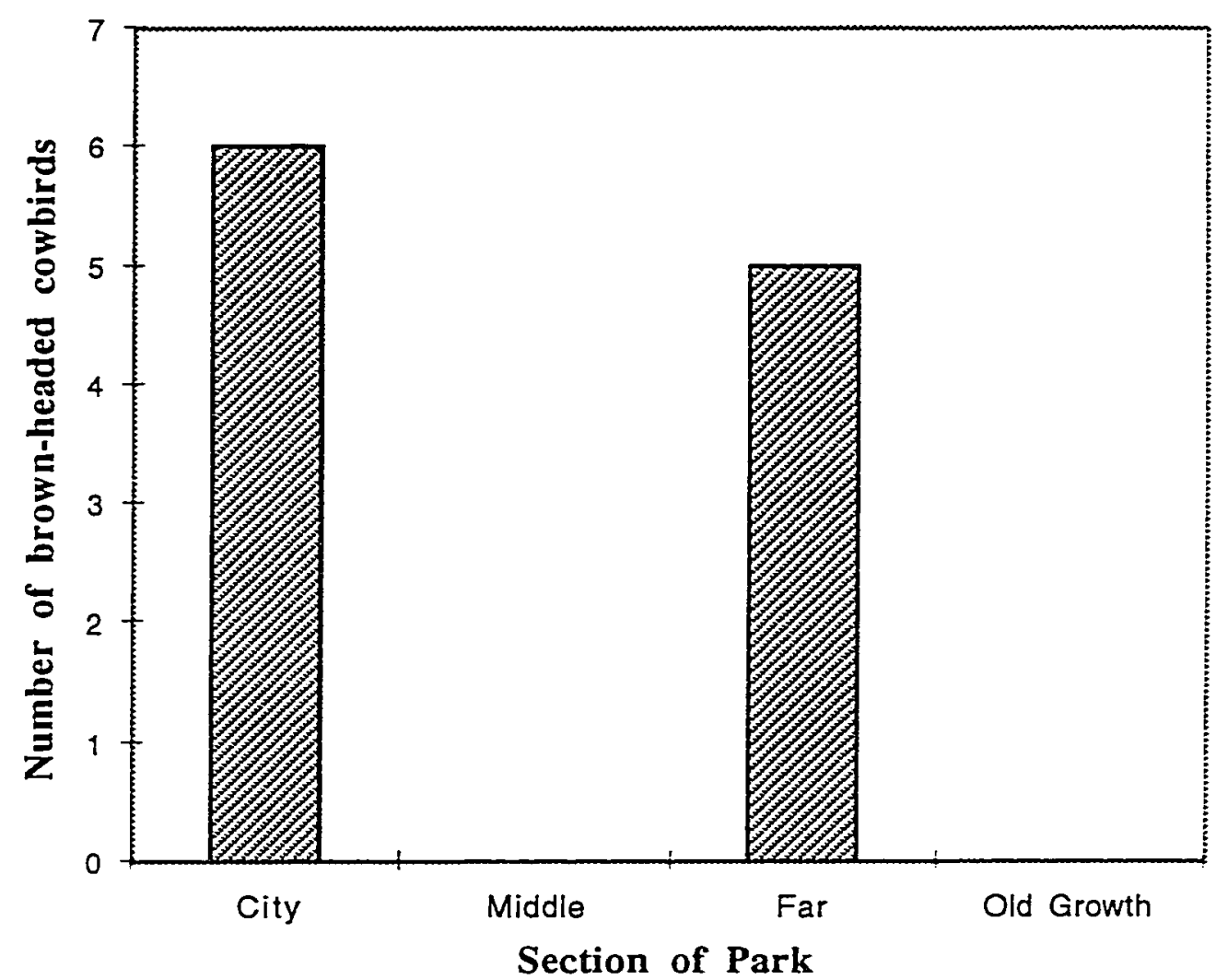

Figure 7-3. Distribution of brown-headed cowbirds in the study. 
predation by both avian (e.g., crows and jays) and mammalian (e.g., raccoons, cats and dogs) predators has also been shown to increase with continued fragmentation and urbanization (Askins 1995; DeGraaf 1995; Hoover et al. 1995; Martin et al. 1996; Rich et al. 1994; Robinson et al. 1995; Wilcove 1985; Yahner and Mahan 1996). Many predators of birds have been shown to prefer neotropical bird species, usually because of their habit of nesting near or on the ground (Bollinger and Linder 1994; Linder and Bollinger 1994; Rich et al. 1994; Wilcove 1985). I did not monitor predation so I cannot determine the effects of predation on avian species in Forest Park. I believe that the increased abundances of certain bird species (e.g., house finches and brown-headed cowbirds) are indicative of the early effects of urbanization and habitat fragmentation on the avian community in Forest Park. However, it is difficult to determine if the bird community is changing, and if so, how it is changing, without detailed temporal studies. Long-term monitoring should be initiated to elucidate any changes that may occur as fragmentation and increased urbanization.

\section{Winter Bird Community}

The major difference I found between summer and winter patterns of bird distribution was the greater abundance of birds in the old-growth stand during the winter. I counted significantly more birds, forest birds, black-capped chickadees, red-breasted nuthatches, golden-crowned kinglets, and brown creepers in the oldgrowth stand than at any site in Forest Park. There were also more bark gleaners, foliage gleaners, and resident birds in the old-growth. 
For three consecutive winters (the duration of this study), the old-growth site had far greater abundance of winter resident birds than any of the sites in Forest Park (Figure 7-1). Mean bird abundance at sites in Forest Park ranged from 13.3 to 16.4 birds, whereas the site in the old-growth stand ranged from 66 to 110 birds. For three consecutive years, the old-growth site supported at least five times more birds than any site in Forest Park which suggests that resident birds aggregate in old-growth forests during the winter, particularly in lower elevation old-growth. The data also show that birds in the Pacific Northwest seem to prefer more mature forest in the winter. Morse (1985) reported that although most researchers investigate breeding birds to ascertain the health of avian populations, winter may be the more critical time of the year for the birds, especially for winter residents. Birds that survive the winter go on to breed the following year. The more birds that survive the winter, the better are the chances for increasing population numbers for that species the following breeding season (Graber and Graber 1983; Huff et al. 1991; Manuwal 1991; Mariani 1987; Morse 1985). McIntyre (1995) found increased bird abundance in winter with increased size of unfragmented coniferous habitat in Georgia. Wentworth and Telfer (1993) found increased bird abundance in winter in more mature aspen forests in Alberta. Researchers west of the Cascades have found greater numbers of winter resident birds in old-growth coniferous forests (Huff et al. 1991; Manuwal 1991; Manuwal and Huff 1987, Raphael and Barrett 1983). Old-growth forests exhibit increased structural complexity that is believed to offer superior habitat to wildlife during the winter (Huff et al. 1991; Manuwal 1991; Manuwal and Huff 1987; Mariani 1987; Norse 1990). Old-growth forests have, on average, a much more highly stratified canopy structure than do earlier seral stage forests (Franklin and Spies 1991a; Franklin and Spies 1991b; Spies and Franklin 1991). In this study, the 
old-growth stand had a significantly greater foliage height diversity than any site in Forest Park when the ground layer component was not included in the calculation. The increased height and stratification affords animals greater protection from severe climatic conditions and provides more area to forage. These features may be especially important in winter when food supplies are in shorter supply than they are in summer. In addition, old-growth forests west of the Cascades are known to provide a more reliable food source because western hemlocks, on average, produce more cones annually than Douglas-firs (Huff et al. 1991; Manuwal 1991; Manuwal and Huff 1987).

Lower elevation old-growth became increasingly important to birds as snowfall increased in the nearby mountains. Although it is likely that freezing level (or the altitude at which snow accumulation begins) is a more important variable to birds than snow depth at any one location, freezing level is not recorded in the weather archives (George Taylor, Oregon State Climatologist, personal communication) and so could not be studied. More research is needed to clarify the relationship among snowfall, bird abundance, and low elevation old-growth forests. 


\section{CHAPTER 8 \\ CONCLUSIONS, FURTHER RESEARCH, AND SUGGESTIONS FOR MANAGEMENT}

Generally, the plant and avian communities at my sites are those that would be expected based upon the successional status and past land use history of Forest Park and the old-growth stand. The city section of Forest Park is an exception to this statement. In the city section, there were fewer shade-tolerant trees (many of which are also climax species) than expected given the length of time since the last major disturbance. I found lower densities of saplings of coniferous and shade-tolerant species of trees in the city section than in the other areas of the park. This suggests that the city section appears to be successionally younger than would be expected based on time since the last major disturbance. Urbanization appears to have interfered with normal successional progression in the city section of Forest Park to the extent that the city section seems to be in an earlier successional stage than would be expected based upon its age. It appears that the normal successional sequence has been retarded or modified in the this section of the park. This finding is similar to the work of others who have shown that one effect of human disturbance is to "set back" the successional clock (Abrams and Nowacki 1992; Dale and Doyle 1987; Hong et al. 1995; Kowarik 1990; Leak and Smith 1996; Matlack 1993b; Petraitis et al. 1989; Swindel et al. 1986). In the absence of sufficient numbers of young shade-tolerant trees, there will be either continued dominance by hardwoods such as bigleaf maple and/or red alder or, if a potential seed source is available, Douglas-fir could enter and 
dominate the forest. Whether the specific causal factors for the shortage of trees are a lack of seed source due to logging and/or large fires or whether they are the result of other human activities will require further study.

The city section was also notable for increased abundances of introduced plant species such as mountain ash, holly and English ivy, as well as greater densities of shrubs, and greater cover by such herbaceous species as bracken fern. The findings are probably the result of the greater levels of edge habitat in the city section of the park. The increase in non-native plant species is an expected consequence of proximity to human development.

Similarly, there was an increase in the abundance of human associated bird species such as house finches and brown-headed cowbirds. Brown-headed cowbirds have been shown to cause significant reductions in the nesting success of many avian species, especially those that nest on or near the ground (Bollinger and Linder 1994; DeGraaf 1995; Leimgruber et al. 1994; Linder and Bollinger 1995; Robinson et al. 1995; Terborgh 1989; Wilcove 1985; Yahner and Mahan 1996). The status of brown-headed cowbirds in Forest Park should be closely monitored in the future. The city section also had increased abundances of urban birds, edge birds, ground gleaning birds, short-distance migrants, American robins, spotted towhees, and song sparrows. In addition, it had lower abundances of forest birds, including Pacificslope flycatchers and winter wrens. These variations in avian abundance seem to be responses to increasing amounts of edge habitat as indicated by statistical correlations with edge variables and/or levels of disturbance. 
I also found that old-growth or mature coniferous forests are important to birds during the winter. The increase in winter bird abundance in the old-growth stand suggests that winter resident species rely upon mature forests during severe weather. Although my sample size was low $(n=5)$, there was a very strong positive correlation between avian abundance in the old-growth stand and severe weather in the surrounding mountain ranges. This finding may be cause for grave concern, considering that very few lower elevation old-growth stands remain, and begs for the preservation of what little is left since we have incomplete understanding of the implications.

\section{FUTURE RESEARCH}

My study was exploratory in nature. I was interested in what, if anything, correlated with urbanization in Forest Park. The fact that the city section appears to have been affected by some factor(s) that I believe to be related to urbanization raises the need for further research to identify the causal agent(s). Regular re-examination of my sites may reveal whether or not the observed differences are stable or transient. Possible future research encompasses studying the reasons for the lack of shadetolerant saplings in the city sections of the park, the introduction and spread of exotic species, the effects of soil compaction in the different sections of the park, the effects of pollutants and/or heavy metals on park populations, and the effects of urbanization upon the soil microfauna in the different sections of the park.

Long term studies that monitor the health and survivorship of trees in the forest will also be important. Such studies will help elucidate whether the differences among sites that I observed are a reflection of increasing urbanization or past land use. Many 
upper canopy (dominant) trees in Forest Park are nearing the ends of their life expectancies. Perhaps an opportunity to study age structure and successional progression in Forest Park is available. Such studies will help elucidate successional progression of forested sites that are chronically disturbed by humans.

In terms of avian research, continued monitoring of bird species populations is needed. Long term studies will be critical to understanding the effects of human development on the forest and the associated avifauna. Research could also be conducted on the effects of different levels of disturbance, including that of hikers or bicyclists, on reproductive success by nesting birds. Although I did find some differences in avian abundance, avian abundance is not always a good indication of reproductive success. It appears that small forest remnants in the Eastern and Midwestern sections of the country act as avian sinks by drawing in birds from larger forested tracts to reproduce, although these birds produce few offspring (Brown and Robinson 1996; Donovan et al. 1995; Hoover et al. 1995; Robinson et al. 1995). Research should be done to determine whether and/or to what extent Forest Park is acting as an avian sink. To help accomplish this, work needs to be done on the effects of predation and parasitism on nesting birds in Forest Park, as well as measurements of reproductive success and avian return rates.

\section{SUGGESTIONS FOR MANAGEMENT}

Given the management objective that Forest Park proceed along a normal successional sequence to an "old-growth forest", I have the following suggestions. First, the reduced abundance of shade-tolerant saplings implies that the city section will not proceed along a traditional successional pathway without intervention. I 
recommend planting native shade-tolerant tree saplings in the city section. Subsequently, the saplings should be monitored for survivorship. If the reduction in shade-tolerant saplings is the result of decreased recruitment or a lack of shadetolerant tree seed sources, merely planting the trees will eventually allow for overstory development of climax species. However, if the reduction is caused by some other factor of urbanization (e.g., increased herbivore pressure, or increased mortality of seedlings and saplings due to pollutants, trampling, soil compaction, etc.), more intensive intervention may be required, or acceptance of a modified seral state must be considered.

It is also important for the city to fight the further introduction and spread of nonnative plant species as much as possible. Forest Park's "No Ivy League" already is making great strides against ivy in the park, although the work needs to continue. Removing ivy is a continual battle that can not be won as long as so much land surrounding the park (much of it in private ownership) is covered by ivy. However, continued vigilance can help reduce the spread of ivy into the forest interior. Removal of exotic species, however, should not stop with English ivy, but should be expanded to include many other introduced species that appear to be spreading throughout the park such as holly, honesty (Lunaria annua L.), Himalayan blackberry, and nipplewort. In addition, the city should continue to work with neighboring developments and neighborhood associations to educate people about the problems of certain invasive plant species and encourage the use of native plants for landscaping. 
The spread of the brown-headed cowbird into the park should be closely monitored. Although their numbers are very small at present, it may, at some point in the future, become necessary to take steps to limit encroachment by this species. Other avian species also need to be monitored. Human adapted species, such as house finches, that are known to reside inside the park, may outcompete forest interior species and adversely affect native population numbers. Other human adapted and exotic species (e.g., rock doves, house sparrows and European starlings) were not recorded inside of the park by this study. Since many of these species are associated with edge and human development, perhaps the single most important control would be to limit the creation of additional edge and large open expanses (e.g., lawns) near the park.

It is very important for Portland Parks and Recreation to protect forest interior habitat. Both the middle and far sections of Forest Park contain significant amounts of forest interior habitat (figure 5-1, page 73). The Natural Resources Management Plan (Portland Parks and Recreation 1995) stressed the need to protect wildlife habitat in the park, especially in the far (north unit) and middle (central unit) sections of the park. The city section has the greatest human usage at present, although usage has increased dramatically in the middle section in the last decade or so (Portland Parks and Recreation 1995). I encourage the city to continue to plan for better access in the city section, but to limit access points into the middle and far sections. My results indicate that urbanization and development are "retarding" normal successional processes in the city section of the park. As development encroaches on all sides of the park, the surrounding lands will become more fragmented. The middle and far sections, although having more forest interior habitat, already have a high percentage of edge habitat (figure 5-2, page 74). Further fragmentation of lands 
surrounding the park could alter the normal successional processes in these sections, too. Tc minimize this problem, land surrounding the park, especially around the middle and far sections, should be purchased when possible so that it can be preserved rather than developed. Continued development, especially along the southwest boundary of the park, will cause increased habitat fragmentation and degradation of wildlife habitat. There will also be changes as lands to the northwest continue to be cleared and developed. Metro has purchased some of the clearcut land in this area for preservation. However, continued loss of lands to development could isolate Forest Park which would ultimately impact wildlife populations and probably eliminate wide ranging species such as bear, mountain lion, and elk. Long term monitoring of the plant and animal communities in and around the park will be important.

The future of the old-growth stand is also of concern. As the site is developed and a hiking trail is constructing up to and into the area of oldest trees (i.e., the forest interior), the integrity of the forest will be compromised. The Ancient Forest Preserve Master Plan is set up so that the interior trail is limited in scope and much of the forest will not be involved (Ancient Forest Preserve Master Plan 1996). However, only continual monitoring will reveal whether and how much the forest is altered as the usage by humans increases. In this regard, baseline data are urgently needed. Of special importance is the refuge that the old-growth forest system provides birds during winter. As such, avian use in winter, particularly after storms, should be monitored. It may be necessary to limit human access to the site in winter months to avoid disturbing the avifauna. Because human usage will most likely be lower in the winter months, such restrictions may be unnecessary. Of added interest 
is the fact that a pair of bald eagles was observed roosting at the site last spring (Lee Kellogg, Friends of Forest Park, personal communication, March 1998). The usage of the site by bald eagles, a threatened species, could require specific restrictions.

Most of the land around the old growth stand is zoned commercial forest or rural residential and several properties have conservation easements. The Ancient Forest Preserve Master Plan (1996) determines to work with adjacent property owners to establish a buffer around the site to minimize the edge effect. However, as land becomes increasing scarce in the Portland area, pressures to develop some of the surrounding property may increase. To maintain the integrity of the forest, as much of the land as possible surrounding the forest stand should be purchased and preserved.

My research has revealed some effects of urbanization and human development upon forested lands surrounding Portland, Oregon. Overall, the minimization of edge habitat is a key to maintaining a "healthy" forest system. Long term monitoring will help elucidate whether my observations are stable or transient, as well as provide information as to changes that occur with increasing human disturbance. Regardless, this study has provided valuable baseline data to which future data can be compared. 


\section{LITERATURE CITED}

Abacus Concepts. 1992. Statview. Version 4.5. Abacus Concepts, Inc., Berkeley, $\mathrm{Ca}$.

Abrams, Marc D. and Gregory J. Nowacki. 1992. Historical variation in fire, oak recruitment, and post-logging accelerated succession in central Pennsylvania. Bulletin of the Torrey Botanical Club 119: 19-28.

Abrams, Peter A. 1991. Life history and the relationship between food availability and foraging effort. Ecology 72: 1242-1252.

Agee, James K. 1991. Fire history of Douglas-fir forests in the Pacific Northwest. pages 25-33. In Ruggiero, Leonard F., Keith B. Aubry, Andrew B. Carey and Mark H. Huff (Editors). Wildlife and Vegetation of Unmanaged Douglasfir forests. U.S Department of Agriculture Forest Service Pacific Northwest Research Station General Technical Report PNW-GTR-285. May 1981. 533 pages.

Airola, Teuvo M. and Kenneth Buchholz. 1984. Species structure and soil characteristics of five urban forest sites along the New Jersey Palisades. Urban Ecology 8: 149-164. 
Aldrich, John W. and R. Winthrop Coffin. 1980. Breeding bird populations from forest to suburbia after thirty-seven years. American Birds 34: 3-7.

Angelstam, Per and Henrik Andren. 1988. Elevated predation rates as an edge effect in habitat islands: experimental evidence. Ecology 69: 544-547.

Anonymous. 1997a. Oregon Climate Zone Summary: Zone 2 -- the Willamette Valley. Oregon Climate Service. http://www.ocs.orst.edu/pub_ftp/reports/ zone/Zone_2_narrative.html.

Anonymous. 1997b. Monthly means and extremes, Portland KGW-TV, Oregon. Oregon Climate Service. http://www.ocs.orst.edu/pub_ftp/climate_data/hmn/ mme6749.html.

Anonymous. 1997c. Oregon's historical wind storms. http://nimbo.wrh.noaa.gov/ Portland/windstorm.html.

Armesto, J.J. and S.T.A. Pickett. 1985. Experiments on disturbance in old-field plant communities: Impact on species richness and abundance. Ecology 66: 230-240.

Arsenault, Andre and Gary E. Bradfield. 1995. Structural-compositional variation in three age-classes of temperate rainforests in southern coastal British Columbia. Canadian Journal of Botany 73: 54-64. 
Ashby, W.C. and H.C. Fritts. 1972. Tree growth, air pollution and climate near Laporte, Indiana. Bull. Am Meteorol. Soc. 53: 246-251.

Askins, Robert A. 1994. Open corridors in a heavily forested landscape: impact on shrubland and forest interior birds. Wildlife Society Bulletin 22: 339-347.

Askins, Robert A. 1995. Hostile landscapes and the decline of migrating songbirds. Science 267: 1956-1957.

Askins, Robert A. and Margarett J. Philbrick. 1987. Effect of changes in regional forest abundance on the decline and recovery of a forest bird community. Wilson Bulletin 99: 7-21.

Bagnall, R.G. 1979. A study of human impact on an urban forest remnant: Redwood Bush, Tawa, near Wellington, New Zealand. New Zealand Journal of Botany 17: 117-126.

Bailey, Liberty Hyde and Ethel Zoe Bailey (original compilers), revised and expanded by the Staff of the Liberty Hyde Bailey Herbarium. 1976. Hortus Third: A Concise Dictionary of Plants Cultivated in the United States and Canada. MacMillan Publishing Company. New York, NY. 1290 pages.

Becher, Ruth and Dietmar Brandes. 1985. Vergleichende Untersuchungen an städtischen and stadtnahren Gehölzbeständen am Beispiel von Braunschweig (Comparative investigations of urban forests demonstrated by the example of 
Brunswick (Lower Saxony)). Braunschweiger Naturkundliche Schriften 2: 309-339.

Beissinger, Steven R. and David R. Osborne. 1984. Effects of urbanization on avian community organization. Condor $84: 75-83$.

Bersier, Louis-Felix and Dietrich R. Meyer. 1994. Bird assemblages in mosaic forests: The relative importance of vegetation structure and floristic composition along the successional gradient. Acta Oecologia 19: 561-576.

Blanco, Guillermo and Tomas Velásco. 1996. Bird-habitat relationships in an urban park during winter. Folia Zoologica 45: 35-42.

Blair, Robert B. 1996. Land use and avian species diversity along an urban gradient. Ecological Applications 6: 506-519.

Blake, John G. 1983. Trophic structure of bird communities in forest patches in east-central nlinois. Wilson Bulletin 95: 416-430.

Blake, John G., Joann M. Hanowski, Gerald J. Niemi, and Patrick T. Collins. 1994. Annual variations in birds populations of mixed conifer-northern hardwood forests. The Condor 96: 381-399.

Blake, John G. and James R. Karr. 1987. Breeding birds of isolated woodlots: area and habitat relationship. Ecology 68: 1724-1734. 
Block, William M., Leonard A Brennan and R.J. Gutiérrez. 1986. Chapter 18. The use of guilds and guild-indicator species for assessing habitat suitability. Pages 109-113. In Verner, Jared, Michael L. Morrison and C. John Ralph (Editors). Wildlife 2000: Modeling Habitat Relationships of Terrestrial Vertebrates. The University of Wisconsin Press. Madison, Wisconsin. 470 pages.

Blondel, Jacques. 1985. Chapter 17. Habitat selection in island versus mainland birds. Pages 477-516. In Cody, Martin L. (Editor). Habitat Selection in Birds. Academic Press, Inc. Orlando, Florida. 558 pages.

Bollinger, Erik K. and Eric T. Linder. 1994. Reproductive success of neotropical migrants in a fragmented Ilinois forest. Wilson Bulletin 106: 46-54.

Brittingham, M.C. and S.A. Temple. 1983. Have cowbirds caused forest songbirds to decline? Bioscience 33: 31-35.

Brower, James E., Herrold H. Zar. and Carl N. von Ende. 1990. Field Laboratory Methods for General Ecology. Third Edition. William C. Brown, Publishers. Dubuque, Iowa. 237pages.

Brown, Jeffrey D. and Scott K. Robinson. 1996. Source-sink population dynamics may complicate the interpretation of long-term census data. Ecology 77:3-12. 
Bureau of Planning. March 1992. Northwest Hills Natural Areas Protection Plan. Portland, Oregon. 258 pages.

Burns, W. J. and B. K. Fiedorowicz. 1997. Landslide inventory and slope susceptibility of Forest Park, Portland, Oregon. Proceedings of Oregon Academy of Science 33: 35 .

Busack, Stephen D. and S. Blair Hedges. 1984. Is the peninsular effect a red herring? The American Naturalist 12: 266-275.

Busing, Richard T., Charles B. Halpern, and Thomas A. Spies. 1995. Ecology of Pacific yew (Taxus brevifolia) in Western Oregon and Washington. Conservation Biology 9: 1199-1207.

Carey, Andrew B, Mary Mae Hardt, Scott P. Horton and Brian L. Biswell. 1991. Spring bird communities in the Oregon Coast range. pages 123-142. In Ruggiero, L. F., K.B. Aubry, A.B. Carey and M.H. Huff (Editors). Wildlife and Vegetation of Unmanaged Douglas-fir forests. USDA Forest Service Pacific Northwest Research Station General Technical Report PNW-GTR-285. May 1991.

Chen, Jiquan, Jerry F. Franklin, and Thomas A. Spies. 1992. Vegetation responses to edge environments in old-growth Douglas-fir forests. Ecological Applications 2: 387-396. 
Chen, Jiquan, Jerry F. Franklin, and Thomas A. Spies. 1995. Growing-season microclimate gradients from clearcut edges into old-growth Douglas-fir forests. Ecological Applications 5: 74-86.

Clark, Karen, David Euler and Edward Armstrong. 1983. Habitat associations of breeding birds in cottage and natural areas of central Ontario. Wilson Bulletin 95: 77-96.

Coker, Daniel R. and David E. Capen. 1995. Landscape-level habitat use by brown-headed cowbirds in Vermont. Journal of Wildlife Management 59: 631637.

Cole, David N. 1995. Experimental trampling of vegetation. I. Relationship between trampling intensity and vegetation response. Journal of Applied Ecology 32: 203-214.

Cole, David N. and Peter B. Landres. 1996. Threats to wilderness ecosystems: Impacts and research needs. Ecological Applications 6: 168-184.

Connell, J.H. 1978. Diversity in tropical rain forests and coral reefs. Science 199: $1302-1310$.

Conway, Courtney J., George V.N. Powell, and James D. Nichols. 1995. Overwintering survival of neotropical migratory birds in early-successional and mature tropical forests. Conservation Biology 9: 855-864. 
Craig, David. 1997. Corvid densities and nest predation in rural versus wild forests. Paper presented at the 24th Annual Natural Areas Association Conference. Portland, Oregon. August 27-30, 1997.

Dale, Virginia H. and Thomas W. Doyle. 1987. The role of stand history in assessing forest impacts. Environmental Management 11: 351-357.

Davis, Anthony M. and Thomas F. Glick. 1978. Urban ecosystems and island biogeography. Environmental conservation 5: 299-304.

DeGraaf, Richard M. 1991. Winter foraging guild structure and habitat associations in suburban bird communities. Landscape and Urban Planning 21: 173-180.

DeGraaf, Richard M. 1995. Nest predation in managed and reserved extensive northern hardwood forests. Forest Ecology and Management 79: 227-234.

DeGraaf, Richard M., Aelred D. Geis, and Patricia A. Healy. 1991. Bird population and habitat surveys in urban areas. Landscape and Urban Planning 21: 181-188.

DeGraaf, Richard M. and James M. Wentworth. 1986. Avian guild structure and habitat associations in suburban bird communities. Urban Ecology 9: 399-412. 
DeVoto, Bernard (Editor). 1953. The Journals of Lewis and Clark. Houghton Mifflin Co. 504 pages.

Diehl, Barbara. 1986. Factors confounding predictions of bird abundance from habitat data. pages 229-233. In Verner, Jared, Michael L. Morrison and C. John Ralph (Editors). Wildlife 2000: Modeling Habitat Relationships of Terrestrial Vertebrates. The University of Wisconsin Press. Madison, Wisconsin. 470 pages.

Dobkin, David S. and Bruce A. Wilcox. 1986. Chapter 42. Analysis of natural forest fragments: Riparian birds in the Toyabe Mountains, Nevada. Pages 293-299. In Verner, Jared, Michael L. Morrison and C. John Ralph (Editors). Wildlife 2000: Modeling Habitat Relationships of Terrestrial Vertebrates. The University of Wisconsin Press. Madison, Wisconsin. 470 pages.

Donovan, Therese M., Roland H. Lamberson, Allison Kimber, Frank R. Thompson III, and John Faaborg. 1995a. Modeling the effects of habitat fragmentation on source and sink demography of neotropical migrant birds. Conservation Biology 9: 1396-1407.

Donovan, Therese M., Frank R. Thompson III, John Faaborg, and John R. Probst. 1995b. Reproductive success of migratory birds in habitat sources and sinks. Conservation Biology 9: 1380-1395. 
Draper, N.R. and H. Smith. 1966. Applied Regression Analysis. John Wiley and Sons, Inc., New York, NY. 407 pages.

Dzwonko, Zbigniew and Stefania Loster. 1988. Species richness of small woodlands on the westem Carpathian foothills. Vegetatio 76: 15-27.

Dzwonko, Zbigniew and Stefania Loster. 1989. Distribution of vascular plant species in small woodlands on the western Carpathian foothills. Oikos 56: 7786.

Edgar, D.R. and G.P. Kershaw. 1994. The density and diversity of the bird populations in three residential communities in Edmonton, Alberta. The Canadian Field-Naturalist 108: 156-161.

Ehrlich, Paul R., David S. Dobkin, and Darryl Wheye. 1988. The Birder's Handbook: A Field Guide to the Natural History of North American Birds. Simon \& Schuster, Inc. New York, New York. 785 pages.

Emlen, John T. 1977. Estimating breeding season bird densities from transect counts. The Auk 94: 455-468.

Fain, Jay J, Timothy A. Volk and Timothy J. Fahey. 1994. Fifty years of change in an upland forest in south-central New York: General patterns. Bulletin of the Torrey Botanical Club 121: 130-139. 
Fitzgerald, Brian T. and Dudley J. Raynal. 1991. Population dynamics and growth of balsam fir on Whiteface Mountain, New York. Bulletin of the Torrey Botanical Club 11: 255-264.

Foppen, Ruud and Rien Reijnen. 1994. The effects of car traffic on breeding bird populations in woodland. II. Breeding dispersal of male willow warblers (Phylloscopus trochilus) in relation to the proximity of a highway. Journal of Applied Ecology 31: 95-101.

Fralish, James S., Fred B. Crooks and Jim L. Chambers. 1991. Comparison of presettlement, second-growth and old-growth forest on six site types in the Illinois Shawnee Hills. American Midland Naturalist 125: 294-309.

Franklin, Jerry F. and C.T. Dyrness. 1988. Natural Vegetation of Oregon and Washington. Oregon State University Press. Corvallis, Oregon. 452 pages.

Franklin, Jerry F. and R.T.T. Forman. 1987. Creating landscape patterns by forest cutting: ecological consequences and principles. Landscape Ecology 1: 5-18.

Franklin, Jerry F. and Anna A. Pechanec. 1967. Comparison of vegetation in adjacent alder, conifer, and mixed alder-conifer communities. I. Understory vegetation and stand structure. pages 37-43. In Trappe, J. M., J.F. Franklin, R.F. Tarrant, and G.M. Hansen (Editors). Biology of Alders. Pacific Northwest Forest and Range Experiment Station. Forest Service. Department of Agriculture. Portland, Oregon. 
Franklin, Jerry F. and Thomas A. Spies. 1991a. Ecological definitions of oldgrowth Douglas-fir forests. pages 61-69. In Ruggiero, L.F., K.B. Aubry, A.B. Carey, and M.H. Huff (Editors). Wildlife and Vegetation of Unmanaged Douglas-fir forests. USDA, Forest Service Pacific Northwest Research Station, General Technical Report PNW-GTR-285. May 1991.

Franklin, Jerry F. and Thomas A. Spies. 1991b. Composition, function, and structure of old-growth Douglas-fir forests. pages 71-80. In Ruggiero, L.F., K.B. Aubry, A.B. Carey, and M.H. Huff (Editors). Wildlife and Vegetation of Unmanaged Douglas-fir forests. USDA, Forest Service Pacific Northwest Research Station, General Technical Report PNW-GTR-285. May 1991.

Friesen, Lyle, E., Paul F. J. Eagles, and R. J. Mackay. 1995. Effects of residential development on forest dwelling neotropical migrant songbirds. Conservation Biology 9: 1408-1414.

Fugate, Jerry S. 1994. Relationships between avian diversity and vegetational parameters in forested patches of the Tualatin Mountains, Oregon. Masters Thesis. Portland State University. Portland, Oregon. 24 pages.

Galli, A.E., C.F. Leck, and R.T. Forman. 1976. Avian distribution patterns in forest islands of different sizes in central New Jersey. Auk 93: 356-365. 
Gavareski, Carol A. 1976. Relation of park size and vegetation to urban bird populations in Seattle, Washington. The Condor 78: 375-382.

Gilbert, Frederick F. and Rochelle Allwine. 1991. Spring bird communities in the Oregon Cascade range. Pages 145-158. In Ruggiero, L. F., K.B. Aubry, A.B. Carey, and M.H. Huff (Editors). Wildlife and Vegetation of Unmanaged Douglas-fir forests. USDA Forest Service Pacific Northwest Research Station General Technical Report PNW-GTR-285. May 1991.

Gilligan, Jeff, Mark Smith, Dennis Rogers, and Alan Contreras (Eds). 1994. Birds of Oregon: Status and Distribution. Cinclus Publications, McMinnville, Oregon. 330 pages.

Gilpin, M. 1981. Peninsula diversity patterns. American Naturalist 118: 291-296.

Glitzenstein, Jeff S., Charles D. Canham, Mark J. McDonnell and Donna R. Streng. 1990. Effects of environment and land-use history on upland forests of the Cary Arboretum, Hudson Valley, New York. Bulletin of the Torrey Botanical Club 117: 106-122.

Goldstein, Edward L., Meir Gross, and Richard W. DeGraaf. 1986. Breeding birds and vegetation: a quantitative assessment. Urban Ecology 9: 377-385.

Goldwasser, S., D. Goines, and S.R. Wilbur. 1980. The least Bell's vireo in California: A de facto endangered race. American Birds 34: 742-745. 
Gotfryd, Arnie and Roger I.C. Hansell. 1986. Chapter 46. Prediction of birdcommunity metrics in urban woodlots. Pages 321-326. In Verner, Jared, Michael L. Morrison and C. John Ralph (Editors). Wildlife 2000: Modeling Habitat Relationships of Terrestrial Vertebrates. The University of Wisconsin Press. Madison, Wisconsin. 470 pages.

Graber, Jean W. and Richard R. Graber. 1983. Expected decline of forest bird populations in severe and mild winters. Wilson Bulletin 95: 682-690.

Green, George L. 1983. Soil Survey of Multnomah County, Oregon. U.S. Department of Agriculture. Soil Conservation Service and Forest Service. 225 pages.

Greller, Andrew M. 1975. Persisting natural vegetation in Northern Queens County, New York, with proposals for its conservation. Environmental Conservation 2: 61-69.

Greller, Andrew M., David C. Locke, Victoria Kilanowski and G. Elizabeth Lotowycz. 1990. Changes in vegetation composition and soil acidity between 1922 and 1985 at a site on the North Shore of Long Island, New York. Bulletin of the Torrey Botanical Club 117: 450-458.

Gutte, Peter. 1990. Der Florenwandel im Stadtgebiet von Leipzig. (Changes in the flora of urban Leipzig). Tuexenia 10: 57-65. 
Gustafson, Eric J. and Thomas R. Crow. 1994. Modeling the effects of forest harvesting on landscape structure and the spatial distribution of cowbird brood parasitism. Landscape Ecology 9: 237-248.

Hagan, John M., W. Matthew Vander Haegen, and Peter S. McKinley. 1996. The early development of forest fragmentation effects on birds. Conservation Biology 10: 188-202.

Haila, Yrjö. 1986. Chapter 45. North European land birds in forest fragments: Evidence for area effects? Pages 315-319. In Verner, Jared, Michael L. Morrison and C. John Ralph (Editors). Wildlife 2000: Modeling Habitat Relationships of Terrestrial Vertebrates. The University of Wisconsin Press. Madison, Wisconsin. 470 pages.

Harper, John L. 1977. Population Biology of Plants. Academic Press. New York, NY. 892 pages.

Harris, Larry D. 1984. The Fragmented Forest. Island Biogeography Theory and the Preservation of Biotic Diversity. The University of Chicago Press, Chicago, II. 211 pages.

Herkert, James R. 1995. An analysis of midwestern breeding bird population trends: 1966-1993. American Midland Naturalist 134: 41-50. 
Hitchcock, C Leo and Arthur Cronquist. 1974. Flora of the Pacific Northwest. University of Washington Press, Seattle, Wa. 730 pages.

Hoehne, Linda M. 1981. Chapter 4. The groundlayer vegetation of forest islands in an urban-suburban matrix. Pages 41 - 54. In Burgess, Robert L., and David M. Sharpe (Editors). Ecological Studies 41. Forest Island Dynamics in Man-Dominated Landscapes. Springer-Verlag. New York. 310 pages.

Hong, Sun-Kee, Nobudazu Nakagoshi and Mahito Kamada. 1995. Human impacts on pine-dominated vegetation in rural landscapes in Korea and western Japan. Vegetatio 116: 161-172.

Hoover, Jeffrey P., Margaret C. Brittingham, and Laurie J. Goodrich. 1995. Effects of forest patch size on nesting success of wood thrushes. The Auk 112: 146-155.

Houle, Marcy C. 1996. One City's Wilderness: Portland's Forest Park. The Oregon Historical Society. Portland, Oregon. 151 pages.

Huff, Mark H. and Catherine M. Raley. 1991. Regional patterns of diurnal breeding bird communities in Oregon and Washington. pages 177-205. In Ruggiero, L. F., K.B. Aubry, A.B. Carey, and M.H. Huff (Editors). Wildlife and Vegetation of Unmanaged Douglas-fir forests. USDA. Forest Service Pacific Northwest Research Station General Technical Report PNW-GTR-285. May 1991. 
Huff, Mark H, David A. Manuwal and Judy A. Putera. 1991. Winter bird communities in the southern Washington Cascade range. pages 207-218. In Ruggiero, L. F., K.B. Aubry, A.B. Carey, and M.H. Huff (Editors). Wildlife and Vegetation of Unmanaged Douglas-fir forests. USDA Forest Service Pacific Northwest Research Station General Technical Report PNW-GTR-285. May 1991.

Hutto, Richard L. 1980. Winter habitat distribution of migratory land birds in Western Mexico, with special reference to small foliage-gleaning insectivores. pages 181-203. In: Keast, Allen and Eugene S. Morton (Editors). Migrant Birds in the Neotropics: Ecology, Behavior, Distribution, and conservation. A Symposium held at the Conservation and Research Center, National Zoological Park, Smithsonian Institution October 27-29, 1977. Smithsonian Institution Press, Washington D.C.

Hutto, R.L., S.M. Pletche, and P. Hendricks. 1986. A fixed-radius point count method for nonbreeding and breeding season use. Auk 103: 593-602.

Huston, Michael. 1979. A general hypothesis of species diversity. The American Naturalist 113: 81-101.

Iida, Shigeo and Tohru Nakashizuka. 1995. Forest fragmentation and its effects on species diversity in sub-urban coppice forests in Japan. Forest Ecology and Management 73: 197-210. 
Ito, Ikuko and Jogo Fujomaki. 1990. Birds of parks in Obihiro City, western Kokkaide (Japan). Japanese Journal of Ornithology. 38: 119-130.

James, Frances C. and Noel O. Wamer. 1982. Relationships between temperate forest bird communities and vegetation structure. Ecology 63: 159-i71.

James, J.D.W., D.W. Smith, E.E. Mackintosh, M.K. Hoffman and P. Monti. 1979. Effects of camping recreation on soil, Jack pine, and understory vegetation in a northwestern Ontario Park. Forest Science 25: 333-349.

Johnson, W. Carter, David M. Sharpe, Donald L. DeAngelis, David E. Fields and Richard J. Olson. 1981. Chapter 10. Modeling seed dispersal and forest island dynamics. Pages 215-239. In Burgess, Robert L. and David M. Sharpe (Editors). Ecological Studies 41. Forest Island Dynamics in ManDominated Landscapes. Springer-Verlag. New York. 310 pages.

Johnson, Richard A. and Dean W. Wichern. 1982. Applied Multivariate Statistical Analysis. Prentice-Hall, Inc. Englewood Cliffs, NJ. 594 pages.

Jones, Robert H., Rebecca R. Sharitz, Susanne M. Jones, and Philip M. Dixon. 1994. Tree population dynamics in seven South Carolina mixed-species forests. Bulletin of the Torrey Botanical Club 121:360-368. 
Jongman, R.H.G., D.J.F. Ter Braak and O.F.R. Van Tongeren, Editors. 1995. Data Analysis in Community and Landscape Ecology. Cambridge University Press. 299 pages.

Karr, James R. and Roland R. Roth. 1971. Vegetation structure and avian diversity in several new world areas. The American Naturalist 105: 423-435.

Keller, Mary E. and Stanley H. Anderson. 1992. Avian use of habitat configurations created by forest cutting in southeastern Wyoming. The Condor 94: 55-65.

Klein, Richard M. and Timothy D. Perkins. 1988. Primary and secondary causes and consequences of contemporary forest decline. The Botanical Review 54: $1-43$

Kotz, Stefan. 1990 Species/area and species/inhabitant relations in European cities. in Sukopp , H. and S. Henjy (Editors). Urban Ecology. Plants and Plant Communities in Urban Environments. The Hague. The Netherlands. 282 pages.

Kowarik, Ingo. 1990. Some responses of flora and vegetation to urbanization in Central Europe. pages 45-74. In Sukopp , H. and S. Hejny (Editors). Urban Ecology. Plants and Plant Communities in Urban Environments. SPB Academic Publ, The Hague, The Netherlands. 282 pages. 
Kozlowski, Theodore T., Paul J. Kramer and Stephen G. Pallardy. 1991. The Physiological Ecology of Woody Plants. Academic Press. San Diego, Ca. 657 pages.

Kroodsma, Roger L. 1984. Effect of edge on breeding forest bird species. Wilson Bulletin 96: 426-436.

Kubantsev, B.S. and N.N. Kolyakin. 1995. Spatial differentiation of the animal component in industrial urban ecosystems. Russian Journal of Ecology 26: 121-125.

Kubikova, Jamila. 1990 Natural and semi-natural plant communities of the City of Prague. Pages 131-139. In Sukopp, H. and S. Hejny (Editors). Urban Ecology. Plants and Plant Communities in Urban Environments. SPB Academic Publ, The Hague, The Netherlands. 282 pages.

Lancaster, Richard K. and William E. Rees. 1979. Bird communities and the structure of urban habitats. Canadian Journal of Zoology 57: 2358-2368.

Lawlor, T. E. 1983. The peninsular effect on mammalian species diversity in Baja California. American Naturalist 121: 432-439.

Leak, William B. and Marie-Louise Smith. 1996. Sixty years of management and disturbance in a New England forested landscape. Forest Ecology and Management 81: 63-73. 
Lehmkuhl, John F. and Leonard F. Ruggiero. 1991. Forest fragmentation in the Pacific Northwest and its potential effects on wildlife. In Ruggiero, L. F., K.B. Aubry, A.B. Carey and M.H. Huff (Editors). Wildlife and Vegetation of Unmanaged Douglas-fir forests. USDA Forest Service Pacific Northwest Research Station General Technical Report PNW-GTR-285. May 1991.

Lehmkuhl, John F., Leonard F. Ruggiero and Patricia A. Hall. 1991. Landscapescale patterns of forest fragmentation and wildlife richness and abundance in the Southern Washington Cascade Range. pages 425-442. In L. F. Ruggiero, K.B. Aubry, A.B. Carey and M.H. Huff (Editors). Wildlife and Vegetation of Unmanaged Douglas-fir forests. USDA Forest Service Pacific Northwest Research Station General Technical Report PNW-GTR-285. May 1991.

Leimgruber, Peter, William J. McShea, and John H. Rappole. 1994. Predation of artificial nests in large forest blocks. Journal of Wildlife Management 58: 254260 .

Lent, Richard A. and David E. Capen. 1995. Effects of small-scale habitat disturbance on the ecology of breeding birds in a Vermont (USA) hardwood forest. Ecography 18: 97-108.

Levenson, James B. 1981. Chapter 3. Woodlots as biogeographic islands in southeastern Wisconsin. Pages 13-39. In Robert L. Burgess and David M. 
Sharpe (Editors). Ecological Studies 41. Forest Island Dynamics in ManDominated Landscapes. Springer-Verlag. New York. 310 pages.

Lewke, Robert E. 1982. A comparison of foraging behavior among permanent, summer, and winter resident bird groups. The Condor 84: 84-90.

Liebhold, Andrew M, William L. MacDonald, Dale Bergdahl and Victor C. Mastro. 1995. Invasion by exotic forest pests: A threat to forest ecosystems. Forest Science Monograph 30: 1-49.

Linder, Eric T. and Erik K. Bollinger. 1995. Depredation of artificial Ovenbird nests in a forested patch. Wilson Bulletin 107: 169-174.

Lovejoy, Thomas E. and David C. Oren. 1981. Chapter 2. The minimum critical size of ecosystems. Pages 7-12. In Burgess, Robert L. and David M. Sharpe (Editors). Ecological Studies 41. Forest Island Dynamics in Man-Dominated Landscapes. Springer-Verlag. New York. 310 pages.

Ludwig, David F. 1989. Anthropic ecosystems. Bulletin of the Ecological Society of America 70: 12-14.

Lundquist, Richard W. and Jina M. Mariani. 1991. Nesting habitat and abundance of snag-dependent birds in the southern Washington Cascade range. Pages 221-240. In Ruggiero, L. F., K.B. Aubry, A.B. Carey and M.H. Huff (Editors). Wildlife and Vegetation of Unmanaged Douglas-fir forests. USDA 
Forest Service Pacific Northwest Research Station General Technical Report PNW-GTR-285. May 1991.

Lynch, James F. and Dennis F. Whigham. 1984. Effects of forest fragmentation on breeding bird communities in Maryland, U.S.A. Biological Conservation 28: 287-324.

MacArthur, Robert H. 1972. Geographical Ecology. Patterns in the Distribution of Species. Harper and Row, Publishers, New York, New York.

MacArthur, Robert H. and John W. MacArthur. 1961. On bird species diversity. Ecology 42: 594-598.

MacArthur, Robert H. and Edmund O. Wilson. 1967. The Theory of Island Biogeography. Princeton University Press, Princeton, N.J.

Manuwal, David A. 1991. Spring bird communities in the southern Washington Cascade range. pages 161-174. In Ruggiero, L. F., K.B. Aubry, A.B. Carey and M.H. Huff (Editors). Wildlife and Vegetation of Unmanaged Douglas-fir forests. USDA Forest Service Pacific Northwest Research Station General Technical Report PNW-GTR-285. May 1991.

Manuwal, David A. and Andrew B. Carey. 1991. Methods for measuring populations of small, diurnal forest birds. Portland, Oregon. United States 
Department of Agriculture, Forest Service, Pacific Northwest Research Station, General Technical Report PNW-GTR-278. November 1991. 23 pages.

Manuwal, David A. and Mark H. Huff. 1987. Spring and winter bird populations in a Douglas-fir forest sere. Journal of Wildlife Management 51: 586-595.

Marcot, Bruce G., Richard S. Holthausen, Johy Teply, and W. Dean Carrier. 1991. Old-growth inventories: Status, definitions, and visions for the future. pages 47- 60. In Ruggiero, L.F., K.B. Aubry, A.B. Carey, and M.H. Huff (Editors). Wildlife and Vegetation of Unmanaged Douglas-fir forests. Portland, Oregon. U.S. Department of Agriculture, Forest Service, Pacific Northwest Research Station, General Technical Report PNW-GTR-285. May 1991.

Mariani, Jina Marie. 1987. Brown creeper (Certhia americana) abundance patterns and habitat use in the southern Washington Cascades. Master's Thesis, University of Washington, Seattle, Wa.

Martin, Thomas E. and Jean Clobert. 1996. Nest predation and avian life-history evolution in Europe versus North America: A possible role of humans? The American Naturalist 147: 1028-1046.

Martin, Thomas E., I.J. Ball, and J. Tewksbury. 1996. Environmental perturbations and rates of nest predation in birds. Transactions of the 61st North American Wildlife and Natural Resources Conference. pages 43-49. 
Matlack, Glenn R. 1993a. Microenvironmental variation within and among forest edge sites in the eastern United States. Biological Conservation 66: 185-194.

Matlack, Glenn R. 1993b. Sociological edge effects: Spatial distribution of human impact in suburban forest fragments. Environmental Management 17: 829835.

Matlack, Glenn R. 1994. Vegetation dynamics of the forest edge -- trends in space and successional time. Journal of Ecology 82: 113-123.

Mauer, Brian A. and S. Greg Heywood. 1993. Geographic range fragmentation and abundance in Neotropical migratory birds. Conservation Biology 7: 501509.

Mayfield, H. 1977. Brown-headed cowbird: Agent of extermination? American Birds 31: 107-113.

McBride, Joe R. and Diana F. Jacobs. 1986. Presettlement forest structure as a factor in urban forest development. Urban Ecology 9: 245-266.

McDonnell, Mark J. and Steward T.A. Pickett. 1990. Ecosystem structure and function along urban-rural gradients: An unexploited opportunity for Ecology. Ecology 71: 1232-1237. 
McDonnell, Mark J., Steward T.A. Pickett, and Richard V. Pouyat. 1993. Chapter 15. The Application of the Ecological Gradient Paradigm to the Study of Urban Effects. pages 175-189. In McDonnell, M.J. and S.T.A. Pickett (Editors). Humans as Components of Ecosystems: The Ecology of Subtle Human Effects and Populated Areas. Springer-Verlag.

McGarigal, Kevin and William C. McComb. 1995. Relationships between landscape structure and breeding birds in the Oregon coast range. Ecological Monographs 65: 235-260.

McIntyre, Nancy E. 1995. Effects of forest patch size on avian diversity. Landscape Ecology 10: 85-99.

McLaughlin, S.B., I.J. Blasing, L.K. Mann and D.N. Duvick. 1983. Effects of acid rain and gaseous pollutants on forest productivity: a regional approach. J. Air Pollut. Control Assoc. 33: 1042-1049.

McLellan, Charles H., Andrew P. Dobson, David S. Wilcove and James F. Lynch. 1986. Chapter 44. Effects of forest fragmentation on new- and old-world bird communities: Empirical observations and theoretical implications. Pages 305313. In Verner, J., M. L. Morrison and C. J. Ralph (Editors). Wildlife 2000: Modeling Habitat Relationships of Terrestrial Vertebrates. The University of Wisconsin Press. Madison, Wisconsin. 
Metro Regional Parks and Greenspaces. 1996. Ancient Forest Preserve Master Plan. Metro Regional Parks and Greenspaces, Portland, Oregon.

Mills, G. Scott, John B. Dunning, Jr. and John M. Bates. 1989. Effects of urbanization on breeding bird community structure in southwestern desert habitats. The Condor 91: 416-428.

Mills, G. Scott, John B. Dunning, Jr. and John M. Bates. 1991. The relationship between breeding bird density and vegetation volume. Wilson Bulletin 103: 468-479.

Milne, Bruce T. and Richard T. T. Forman. 1986. Peninsulas in Maine: Woody plant diversity, distance, and environmental patterns. Ecology 67: 967-974.

Monkkonen, Mikko and Daniel A. Welsh. 1994. A biogeographical hypothesis on the effects of human caused landscape changes on the forest bird communities of Europe and North America. Annales Zoologici Fennici 31: 61-70.

Moran, Mary Ann. 1984. Influence of adjacent land use on understory vegetation of New York forests. Urban Ecology 8: 329-340.

Morrison, Donald F. 1976. Multivariate Statistical Methods, 2nd edition. McGrawHill Book Company. New York, NY. 415 pages. 
Morse, Douglass H. 1980. Population limitation: breeding or wintering grounds? pages 505-516. In: Keast, Allen and Eugene S. Morton (Editors). Migrant Birds in the Neotropics: Ecology, Behavior, Distribution, and conservation. A Symposium held at the Conservation and Research Center, National Zoological Park, Smithsonian Institution October 27-29, 1977. Smithsonian Institution Press, Washington D.C.

Munger, Thornton T. 1960. History of Portland's Forest-Park. Published by the Forest-Park Committee of Fifty. Portland, Oregon. Feb. 4, 1960. 36 pages.

Nash, T.H., H.C. Fritts and M.A. Stokes. 1975. A technique for examining nonclimatic variation in widths of annual tree rings with special reference to air pollution. Tree-Ring Bull. 35: 15-24.

Natuhara, Yoshiro and Chobei Imai. 1996. Spatial structure of avifauna along urban-rural gradients. Ecological Research 11: 1-9.

Newton, Michael, B.A. El Hassan, and Jaroslav Zavitkovski. 1967. Role of red alder in western Oregon succession. pages 73-84. In Trappe, J. M., J.F. Franklin, R.F. Tarrant, and G.M. Hansen (Editors). Biology of Alders. Pacific Northwest Forest and Range Experiment Station. Forest Service. U.S. Department of Agriculture. Portland, Oregon.

Norse, Elliott A. 1990 Ancient Forests of the Pacific Northwest. Island Press, Washington, D.C. 327 pages. 
Nowacki, Gregory J. and Marc D. Abrams. 1992. Community, edaphic and historical analysis of mixed oak forests of the Ridge and Valley Province in central Pennsylvania. Canadian Journal of Forest Research 22: 790-800.

Nuorteva, Pekka. 1971. The synanthropy of birds as an expression of the ecological cycle disorder caused by urbanization. Annales Zoologici Fennici 8: 547-553.

O'Brien, Renee A. 1990. Assessment of nongame bird habitat using forest survey data. United States Department of Agricuiture. Forest Service Intermountain Research Station Research Paper INT-431. October 1990. 8 pages.

Oregon Bird Records Committee. 1998. Official Checklist of Oregon Birds. http:// www.cyber-dyne.com/ -lb/obrcchecklist.htm.

Old-Growth Definition Task Group. 1986. Research Notes PNW-447. Portland, Oregon: U.S. Department of Agriculture, Forest Service, Pacific Northwest Research Station. 7 pages.

Palik, Brian J. and Kurt S. Pregitzer. 1992. A comparison of presettlement and present-day forests on two bigtooth aspen-dominated landscapes in Northern Lower Michigan. American Midland Naturalist 12: 327-338. 
Parker, Albert J. and Robert K. Peet. 1984. Size and age structure of conifer forests. Ecology 65: 1685-1689.

Peart, David R., Charles V. Cogbill and Peter A. Palmiotto. 1992. Effects of logging history and hurricane damage on canopy structure in a northern hardwoods forest. Bulletin of the Torrey Botanical Club 119:29-38.

Peck, Morton E. 1941. A Manual of the Higher Plants of Oregon. Binfords and Mort, Publ. Portland, Oregon. 866 pages.

Peterjohn, Bruce G. and John R. Sauer. 1994. Population trends of woodland birds from the North-American breeding bird survey. Wildlife Society Bulletin 22: $155-164$.

Peterken, G.F. and M. Game. 1984. Historical factors affecting the number and distribution of vascular plant species in the woodlands of central Lincolnshire. Journal of Ecology 72: 155-182.

Peterken, G.F. and E.W. Jones. 1989. Forty years of change in Lady Park Wood: The young-growth stands. Journal of Ecology 77: 401-429.

Petraitis, Peter S., Roger E. Latham, and Richard A. Niesenbaum. 1989. The maintenance of species diversity by disturbance. The Quarterly Review of Biology 64: 393- 418 
Pimentel, Richard A. 1979. Morphometrics. The Multivariate Analysis of Biological Data. Kendall/Hunt Publishing Company. Dubuque, Iowa. 276 pages.

Portland Parks and Recreation. February 1995. Forest Park Natural Resources Management Plan.. Portland Parks and Recreation. Portland, Oregon. 224 pages.

Pouyat, Richard V. and Wayne C. Zipperer. 1991. The uses and management of urban woodlands. pages 26-29. In The American Forestry Association. The Proceedings of the Fifth National Urban Forestry Conference. Los Angeles California. November 15-19, 1991.

Pouyat, R.V., R.W. Parmelee and M.M. Carreiro. 1994. Environmental effects of forest soil-invertebrates and fungal densities in oak stands along an urban-rural land use gradient. Pedobiologia 38: 385-399.

Pouyat, RV, M.M. Carreiro, M.J. McDonnell, S.T.A. Pickett, P.M. Parmelee, K.E. Medley, and W.C. Zipperer. 1995a. Carbon and nitrogen dynamics in oak stands along an urban-rural gradient. Pages 569-587. In McFee, W.W. and J.M. Kelly (Editors). Carbon Forms and Functions in Forest Soils. The 8th Annual North American Forest Soils Conference. May 1993. Soil Science of America. Madison, Wi. 
Pouyat, Richard V., Mark J. McDonnell, and S.T.A. Pickett. 1995b. Soil characteristics of oak stands along an urban-rural land-use gradient. Journal of Environmental Quality 24: 516-526.

Pysèk, Petr. 1989. On the richness of Central European urban flora. Preslia, Praha 61: 329-334.

Pysèk, Petr and Antonin Pysèk. 1990. Comparison of the vegetation and flora of the West Bohemia villages and towns. In Sukopp, H.and S Hejny (Editors). Urban Ecology. Plants and Plant Communities in Urban Environments. SPB Academic Publ., The Hague. The Netherlands.

Ranney, J.W., M.C. Bruner and James B. Levenson. 1981. Chapter 6. The importance of edge in the structure and dynamics of forest islands. Pages 6795. In Burgess, R. L. and D. M. Sharpe (Editors). Ecological Studies 41. Forest Island Dynamics in Man-Dominated Landscapes. Springer-Verlag. New York. 310 pages.

Rao, P., S.K. Barik, H.N. Pandey and R.S. Tripathi. 1990. Community composition and tree population structure in a sub-tropical broad-leaved forest along a disturbance gradient. Vegetatio 88: 151-162.

Raphael, Martin G. and Reginald H. Barrett. 1983. Diversity and abundance of wildlife in late successional Douglas-fir forests. Pages 352-360. In. New 
Forests for a Changing World. Proceedings of the 1983 SAF National Convention. Portland, Oregon. October 16-20.

Rappole, John H. and Mary Victoria McDonald. 1994. Cause and effect in population declines of migratory birds. The Auk 111: 652-660.

Reijnen, Rien and Ruud Foppen. 1994. The effects of car traffic on breeding bird populations in woodland. I. Evidence of reduced habitat quality for willow warblers (Phylloscopus trochilus) breeding close to a highway. Journal of Applied Ecology 31: 85-94.

Reijnen, Rien, Ruud Foppen, Cajo Ter Braak and Johan Thissen. 1995. The effects of car traffic on breeding bird populations in woodland. III. Reduction of density in relation to proximity of main roads. Journal of Applied Ecology 32: 187-202.

Reijnen, Rien and Ruud Foppen. 1995. The effects of car traffic on breeding bird populations in woodland. IV. Influences of population size on the reduction of density close to a highway. Joumal of Applied Ecology 32: 481-491.

Rich, Adam C., David S. Dobkin and Lawrence J. Niles. 1994. Defining forest fragmentation by corridor width: The influence of narrow forest-dividing corridors on forest-nesting birds in Southern New Jersey. Conservation Biology 8: 1109-1121. 
Robbins, Chandler S., Bertel Bruun, and Herbert S. Zim. 1983 A Guide to Field Identification Birds of North America. Golden Press. New York, New York. 360 pages.

Robinson, Peggy. 1978. The Portland Walkbook. Far West Book Service. Portland, Oregon. 168 pages.

Robinson, Scott K. and Richard T. Holmes. 1984. Effects of plant species and foliage structure on the foraging behavior of forest birds. The Auk 10: 672684.

Robinson, Scott K., Frank R. Thompson III, Therese M. Donovan, Donald R. Whitehead and John Faabord. 1995. Regional forest fragmentation and the nesting success of migratory birds. Science 267: 1987-1990.

Rogers, Garry F. and Rowan A. Rowntree. 1988. Intensive surveys of structure and change in urban natural areas. Landscape and Urban Planning 15: 59-78.

Rosenberg, Kenneth V. and Martin G. Raphael. 1986. Chapter 38. Effects of forest fragmentation on vertebrates in Douglas-fir forests. Pages 263-272. In Verner, J., M.L. Morrison and C. J. Ralph (Editors). Wildlife 2000: Modeling Habitat Relationships of Terrestrial Vertebrates. The University of Wisconsin Press. Madison, Wisconsin. 
Rosenberg, Kenneth V., Scott B. Terrill and Gary H. Rosenberg. 1987. Value of suburban habitats to desert riparian birds. Wilson Bulletin 99: 642-654.

Rowntree, Rowan A. 1986. Ecology of the urban forest -- Introduction to Part II. Urban Ecology 9: 229-243.

Rudnicky, James L. and Mark J. McDonnell. 1989. Forty-eight years of canopy change in a hardwood-hemlock forest in New York City. Bulletin of the Torrey Botanical Club 116: 52-64.

Ruggiero, Leonard F., Lawrence L.C. Jones, and Keith B. Aubry. 1991. Plant and animal habitat associations in Douglas-fir forests of the Pacific Northwest: an overview. pages 447-462. In Ruggiero, L. F., K.B. Aubry, A.B. Carey and M.H. Huff (Editors). Wildlife and Vegetation of Unmanaged Douglas-fir forests. USDA Forest Service Pacific Northwest Research Station General Technical Report PNW-GTR-285. May 1991.

Sachse, Urike, Uwe Starfinger, and Ingo Kowarik. 1990. Synanthropic woody species in the urban area of Berlin (west). pages 233-243. In Sukopp, H. and S. Hejny (Editors). Urban Ecology. Plants and Plant Communities in Urban Environments. SPB Academic Publications. The Hague. The Netherlands. 282 pages.

Sauer, J.R., J.E. Hines, G. Gough, I. Thomas, and B.G. Peterjohn. 1997. The North American Breeding Bird Survey Results and Analysis. Version 96.4. 
Patuxent Wildlife Research Center, Laurel, Md. http://www.mbr-pwrc. usgs.gov/bbs/bbs.html

Sedgwick, James A. 1987. Avian habitat relationships in Pinyon-Juniper woodland. Wilson Bulletin 99: 413-431.

Seib, R. L. 1980. Baja California: A peninsula for rodents but not for reptiles. The American Naturalist 11: 613-620.

Seidling, Walter. 1990 Recent changes in forest vegetation in an area on the outskirts of Berlin. Pages 223-232. In Sukopp, H. and S. Hejny (Editors). Urban Ecology. Plants and Plant Communities in Urban Environments. SPB Academic Publications. The Hague. The Netherlands. 282 pages.

Sharpe, David M., Forest Stearns, Lawrence A. Leitner and John R. Dorney. 1986. Fate of natural vegetation during urban development of rural landscapes in southeastern Wisconsin. Urban Ecology 9: 267-287.

Simpson, George G. 1964. Species density of North American Recent mammals. Systematic Zoology 13: 57-73.

Sisk, Thomas, Nick M. Haddad, and Paul R. Ehrlich. 1997. Bird assemblages in patchy woodlands: modeling the effects of edge and matrix habitats. Ecological Applications 7: 1170-1180. 
Smith, Robert Leo. 1996. Ecology and Field Biology. Fifth Edition. Harper Collins College Publishers. New York NY. 749 pages.

Sokal, Robert R. and F. James Rohlf. 1969. Biometry. W.H. Freeman and Company. San Francisco, CA. 776 pages.

Solinska-Górnicka, Barbara and Ewa Symonides. 1990. Effect of a large city on the structure of coenoelements in a natural woodland in Warsaw. Vegetatio 88: 163-176.

Spies, Thomas A. 1991. Plant species diversity and occurrence in young, mature, and old-growth Douglas-fir stands in western Oregon and Washington. pages 111-121. In Ruggiero, L.F., K.B. Aubry, A.B. Carey, and M.H. Huff (Editors). Wildlife and Vegetation of Unmanaged Douglas-fir forests. USDA, Forest Service Pacific Northwest Research Station, General Technical Report PNW-GTR-285. May 1991.

Spies, Thomas and Jerry F Franklin. 1991. The structure of natural young, mature, and old-growth Douglas-fir forests in Oregon and Washington. pages 91-109. In Ruggiero, L.F., K.B. Aubry, A.B. Carey, and M.H. Huff (Editors). Wildlife and Vegetation of Unmanaged Douglas-fir forests. USDA, Forest Service Pacific Northwest Research Station, General Technical Report PNWGTR-285. May 1991. 
Steel, Robert G.D. and James H. Torrie. 1960. Principles and Procedures of Statistics with Special Reference to the Biological Sciences. McGraw-Hill Book Co, Inc. New York, NY. 481 pages.

Stouffer, Philip C. and Richard O. Bierregaard, Jr. 1995. Use of Amazonian forest fragments by understory insectivorous birds. Ecology 76: 2429-2445.

Sukopp, Herbert. 1972. Wandel von Flora und Vegetation in Mitteleuropa unter dem Einfluß des Menschen. (Changes in vegetation in middle Europe as influenced by mankind) Ber. Ldw. 50: 112-139.

Sukopp, H. 1990. Urban ecology and its application in Europe. pages 1-22. In Sukopp , H. and S. Hejny (Editors). Urban Ecology. Plants and Plant Communities in Urban Environments. SPB Academic Publ. The Hague. The Netherlands.

Supuka, Jan. 1994. Conditions and growth limit values for selected woody plants in an urban environment. Ekologia Bratislava. 13: 425-441.

Swindel, Benee F., Louise R. Conde, and Joel E. Smith. 1986. Successional changes in Pinus elliotti plantations following two generation treatments. Canadian Journal of Forest Research 16: 630-636.

Tabachnick, Barbara G. and Linda S. Fidell. 1996. Using Multivariate Statistics. Harper Collins College Publications. 880 pages. 
Taper, Mark L., Katrin Bohning-Gaeses and James H. Brown. 1995. Individualistic responses of bird species to environmental change. Oecologia 10: $478-486$.

Taylor, George. 1995. The big storm -- December 12, 1995. http://www.ocs.orst. edu/reports/Dec95_wind.html

Taylor, George. 1996. The great flood of 1996. http://www.ocs.orst.edu/ reports/flood96/flood $2 . h t m l$

Temple, Stanley A. 1986. Chapter 43. Predicting impacts of habitat fragmentation on forest birds: A comparison of two models. Pages 301-304. In Verner, Jared, Michael L. Morrison and C. J. Ralph (Editors). Wildlife 2000: Modeling Habitat Relationships of Terrestrial Vertebrates. The University of Wisconsin Press. Madison, Wisconsin.

Temple, Stanley A. and Bruce A. Wilcox. 1986. Introduction: Predicting effects of habitat patchiness and fragmentation. In Verner, Jared, Michael L. Morrison, and C. John Ralph (Editors). Wildlife 2000: Modeling Habitat Relationships of Terrestrial Vertebrates. The University of Wisconsin Press. Madison, Wisconsin.

Terborgh, John W. 1980. The conservation status of Neotropical migrants: Present and future. pages 21-30. In: Keast, Allen and Eugene S. Morton (Editors). 
Migrant Birds in the Neotropics: Ecology, Behavior, Distribution, and conservation. A Symposium held at the Conservation and Research Center, National Zoological Park, Smithsonian Institution October 27-29, 1977. Smithsonian Institution Press, Washington D.C.

Terborgh, John W. 1989. Where Have All the Birds Gone? Princeton University Press. Princeton, New Jersey. 207 pages.

Terborgh, John W. 1992. Why American songbirds are vanishing. Scientific American 92: 98-104.

Thompson, M.A. 1981. Tree rings and air pollution. A case study of Pinus monophylla growing in east-central Nevada. Environ. Pollut., Ser A 26: 251-266.

Tilghman, Nancy G. 1987. Characteristics of urban woodlands affecting breeding bird diversity and abundance. Landscape and Urban Planning 14: 481-495.

Tramer, Elliot J. and David E. Subrweir. 1975. Farm woodlots as biogeographic islands: Regulation of tree species richness. Bulletin of the Ecological Society 56: 53.

Vanhala, Pekka, Oili Kiikkilä, and Hanna Fritze. 1996. Microbial responses of forest soil to moderate anthropogenic air pollution. Water, Air and Soil Pollution 86: 173-186. 
Verner, Jared. 1985. Assessment of counting techniques. Current Ornithology 2: 247-302.

Verner, Jared. 1986. Summary: predicting effects of habitat patchiness and fragmentation - the researcher's viewpoint. pages 327-333. In Verner, Jared, Michael L. Morrison and C. John Ralph (Editors). Wildlife 2000: Modeling Habitat Relationships of Terrestrial Vertebrates. University of Wisconsin Press, Madison, Wisconsin. 470 pages.

Waitt, Jr., R. B. 1985. Case for periodic Jökulhlaups from Pleistocene Lake Missoula. Geological Society of America Bulletin 96(10): 1271-1286.

Weaver, J. and D. Dale. 1978. Trampling effects of hikers, motorcycles and horses in meadows and forests. Journal of Applied Ecology 15: 451-457.

Weaver, Marcia and Martin Kellman. 1981. The effects of forest fragmentation on woodlot tree biotas in southern Ontario. Journal of Biogeography 8: 199-210.

Wentworth, D.A. and E.S. Telfer. 1993. Summer and winter bird populations associated with five age-classes of aspen forest in Alberta, Canada. Canadian Journal of Forest Research 23: 1830-1836.

Whitcomb, R.F., C.S. Robbins, J.F. Lynch, B.L. Whitcomb, M.K. Klimkiewicz and D. Bystrak. 1981. Chapter 8. Effects of forest fragmentation on avifauna 
of the eastern deciduous forest. Pages 125-205. In Burgess, R.L. and D.M. Sharpe (Editors). Ecological Studies 41. Forest Island Dynamics in Mandominated Landscapes. Springer-Verlag. New York.

White, Caarleston S. and Mark J. McDonnell. 1988. Nitrogen cycling processes and soil characteristics in an urban versus rural forest. Biogeochemistry 5: 243-262.

White, Douglas W., Wade Worthen and Edmund W. Stiles. 1990. Woodlands in post-agricultural landscape in New Jersey. Bulletin of the Torrey Botanical Club 117: 256-265.

White, P.S., and S.T.A. Pickett. 1985. Natural disturbance and patch dynamics: an introduction. pages 279-338. In Pickett, S.T.A. and P.S. White (Editors), The Ecology of Natural Disturbance and Patch Dynamics. Academic Press, Orlando.

Whitney, Gordon G. 1986. Relation of Michigan's presettlement pine forests to substrate and disturbance history. Ecology 67: 1548-1559.

Whittaker, R. L. 1967. Gradient analysis of vegetation. Biological Review 42: 207-264.

Wiens, John A. 1994. Habitat fragmentation: island versus landscape perspectives on bird conservation. Ibis 137: S97-S104. 
Wilcove, David S. 1985. Ph.D. Thesis: Forest fragmentation and the decline of migratory songbirds. Princeton University. 124 pages.

Wilson, Mark V. 1991. Age structure patterns in Abies amabilis stands of the Cascade Mountains. American Midland Naturalist 12:331-339.

Willson, Mary F. 1970. Foraging behavior of some winter birds of deciduous woods. The Condor 72: 169-174.

Willson, Mary F. 1974. Avian community organization and habitat structure. Ecology 55: 1017-1029.

Willson, Mary F., Toni L. DeSanto, Carlos Sabag, and Juan J. Armesto. 1994. Avian communities of fragmented south-temperate rainforests in Chile. Conservation Biology 8: 508-520.

Wilson, Scott D. and Paul A. Keddy. 1986. Species competitive ability and position along a natural stress/disturbance gradient. Ecology 67: 1236-1242.

Woodward, F.I. 1992. Tansley review no. 41. Predicting plant responses to global environmental change. New Phytologist 122: 239-251.

Yahner, Richard H. and Carolyn G. Mahan. 1996. Effects of egg type on depredation of artificial groundnests. Wilson Bulletin 10: 129-136. 
Yost, Susan E., Susan Antenen and Gregg Hartvigsen. 1991. The vegetation of the Wave Hill natural area, Bronx, New York. The Bulletin of the Torrey Botanical Club 118: 312-325.

Zacharias, Dietmar and Dietmar Brandes. 1990. Species area-relationships and frequency - Floristical data analysis of 44 isolated woods in northwestern Germany. Vegetatio 88: 21-29.

Zipperer, Wayne C., Robert L. Burgess and Ralph D. Nyland. 1990. Patterns of deforestation and reforestation in different landscape types in central New York. Forest Ecology and Management 36: 103-117.

Zipperer, Wayne C. and Constance E. Zipperer. 1992. Vegetation responses to changes in design and management of an urban park. Landscape and Urban Planning 22: 1-10.

Zipperer, Wayne C. 1993. Deforestation patterns and their effects on forest patches. Landscape Ecology 8: 177-184. 
APPENDIX A

SCIENTIFIC AND COMMON NAMES OF SPECIES OF TREES OBSERVED IN FOREST PARK AND THE OLD-GROWTH STAND 


\title{
SCIENTIFIC AND COMMON NAMES OF SPECIES OF TREES OBSERVED IN FOREST PARK AND THE OLD-GROWTH STAND
}

$$
\text { (* }=\text { non-native })
$$

\author{
SCIENTIFIC NAME (AUTHORITY) \\ Abies grandis (Douglas) \\ Acer macrophyllum (Pursh) \\ Alnus rubra (Bong) \\ Amelanchier alnifolia (Nuttall) \\ Arbutus menziesii (Pursh) \\ Chamaecyparis lawsoniana (Parl) \\ Cornus nuttallii (Aud) \\ Crataegus monogyna (Jacq) \\ Euonymous occidentalis (Nuttall) \\ Populus trichocarpa ( $\mathrm{T}$ and $\mathrm{G}$ ) \\ Prunus emarginata (Douglas Walp) \\ Pseudotsuga mensiezii (Mirbel Franco) \\ Rhamnus purshiana (DC) \\ Sorbus aucuparia (Linneaus) \\ Taxus brevifolia (Nuttall) \\ Thuja plicata (Donn.) \\ Tsuga heterophylla (Raf Sarg)
}

\section{COMMON NAME}

Grand fir

Bigleaf maple

Red alder

Serviceberry

Pacific madrone

Port Orford cedar*

Pacific dogwood

Hawthorn*

Westem wahoo

Black cottonwood

Bitter cherry

Douglas-fir

Cascara

Mountain ash*

Pacific yew

Western red cedar

Western hemlock

Nomenclature from Hitchcock and Cronquist 1974 except for Chamaecyparis Lawsoniana which came from Peck 1941 
APPENDIX B

\section{SCIENTIFIC AND COMMON NAMES OF SPECIES OF SHRUBS OBSERVED} IN FOREST PARK AND THE OLD-GROWTH STAND 


\section{SCIENTIFIC AND COMMON NAMES OF SPECIES OF SHRUBS OBSERVED IN FOREST PARK AND THE OLD-GROWTH STAND}

$$
\text { (* = non-native) }
$$

SCIENTIFIC NAME (AUTHORITY)

Acer circinatum (Pursh)

Corylus cormuta (Marsh)

Holodiscus discolor (Pursh Maxim)

Ilex aquifolium (Linneaus)

Oemleria cerasiformis ( $T$ and $\mathrm{G}$. Greene)

Philadelphus lewisii (Pursh)

Rosa gymnocarpa (Nuttall)

Rubus discolor (Weihe and Nees)

Rubus parviflorus (Nuttall)

Rubus spectabilis (Pursh)

Sambucus racemosa (Linneaus)

Symphoricarpos albus (L. Blake)

Vaccinium parvifolium (Smith)

Prunus laurocerasus (Linneaus)

\section{COMMON NAME}

Vine maple

Filbert

Oceanspray

English holly*

Indian plum

Mock orange

Little wood rose

Himalayan blackberry*

Thimbleberry

Salmonberry

Red elderberry

Snowberry

Red huckleberry

English laurel*

Nomenclature from Hitchcock and Cronquist 1974 except for Ilex aquifolium and Prunus Laurocerasus which are from Bailey and Bailey 1976. 


\section{APPENDIX C}

SCIENTIFIC AND COMMON NAMES OF SPECIES OF HERBACEOUS PLANTS OBSERVED IN FOREST PARK AND THE OLD-GROWTH STAND 


\section{SCIENTIFIC AND COMMON NAMES OF SPECIES OF HERBACEOUS PLANTS OBSERVED IN FOREST PARK AND THE OLD-GROWTH STAND}

$$
\text { (* = non-native; } * \text { ? = questionable origin) }
$$

SCIENTIFIC NAME (AUTHORITY)

Achlys triphylla (Smith D.C.)

Actaea rubra (Ait)

Adenocaulon bicolor (Hook)

Adiantum pedatum (Linneaus)

Anemone deltoidea (Hook)

Arenaria macrophylla (Hook)

Asarum caudatum (Lindl)

Athyrium filix-femina (Linneaus, Roth)

Berberis nervosa (Pursh)

Campanula scouleri (Hook)

Cimicifuga elata (Nutt)

Circaea alpina (Linneaus)

Clematis ligusticifolia (Nutt)

Corallorhiza sp. (Chat)

Disporum hookeri (Torr. Nicholson)

Dryopteris austriaca (Jacq Woynar)

Epilobium minutum (Lindl)

Galium aparine (Linneaus)

Gaultheria shallon (Pursh)

Geranium robertianum (Linneaus)

Hedera helix (Linneaus)

Heuchera micrantha (Douglas)

Hydrophyllum tenuipes (Heller)

Lactuca muralis (L. Fresen)

Lapsana communis (Linneaus)

Lonicera ciliosa (Pursh)

Melica bulbosa (Geyer)

Melissa officinalis (Linneaus)

Montia sibirica (L. Howell)

Nemophila parviflora (Douglas)

Osmorhiza chilensis ( $\mathrm{H}$. and $\mathrm{A})$

Oxalis corniculata (Linneaus)

Petasites frigidus (Linneaus Fires)

Phalaris arundinaceae (Linneaus)

Polypodium glycyrrhiza (D.C. Eat)

Polystichum lonchitis (L. Roth)

Polystichum munitum (Kaulf Presl)

Pteridium aquilinum ( $L$ Kuhn)

Rubus leucodermis (Douglas)

Rubus ursinus (Cham. and Schlecht.)
COMMON NAME

Vanilla leaf

Baneberry

Pathfinder

Maidenhair fern

Western anemone

Bigleaf sandwort

Wild ginger

Lady fern

Oregon grape

Bellflower

Bugbane

Enchanter's nightshade

Western clematis*?

Coral-root orchid

Fairy-bells

Wood fern

Willow weed

Bedstraw, velcro plant

Salal

Herb Robert*

English ivy*

Smallflower alumroot

Pacific waterleaf

Wall lettuce*

Nipplewort*

Orange honeysuckle

Oniongrass

Lemon balm*

Candy flower

Small-flowered nemophila

Sweet-cicely

Yellow oxalis*

Coltsfoot

Reed canarygrass*?

Licorice ferm

Christmas fern*

Sword fern

Bracken fern

Blackcap

Wild blackberry 
SCIENTIFIC NAME (AUTHORITY)

Senecio vulgaris (Linneaus)

Smilacina racemosa (L. Desf)

Smilacina stellata (L Desf.)

Stachys cooleyae (Heller)

Stellaria crispa (Cham \& Schlecht)

Streptopus amplexifolius (Linneaus)

Tellima grandiflorum (Pursh Dougl)

Tiarella trifoliata (Linneaus)

Trientalis latifolia (Hook)

Trillium ovatum (Pursh)

Vancouveria hexandra (Hook; Morr and Dec)

Vicia hirsuta (L. SF Gray)

Viola glabella (Nutt)

\section{PRESENT AT SITES -- NOT ON TRANSECTS}

SCIENTIFIC NAME (AUTHORITY)

Aquilegia formosa (Fisch)

Disporum smithii (Hook Piper)

Geum macrophyllum (Willd)

Lilium columbianum (Hanson)

Linnaea borealis (Linneaus)

Montia perfoliata (Donn, Howell)

Monotropa unifora (Linneaus)

Prunella vulgaris (Linneaus)

Rumex crispus (Linneaus)

Tolmiea menziesii (Pursh; $\mathrm{T}$ and $\mathrm{G}$ )
COMMON NAME

Common groundsel*

False Soloman's seal

Star-flowered Soloman's seal

Cooley's hedge-nettle

Starwort

Twisted stalk

Fringecup

Foamflower

Starflower

Trillium

Inside-out-flower, duckfoot

Hairy vetch*

Yellow wood violet
COMMON NAME

Red columbine

Fairy lanterns

Large-leaved avens

Tiger lily

Twin flower

Miner's lettuce

Indian pipe

Self heal

Curly dock

Pig-a-back plant

Nomenclature from Hitchcock and Cronquist 1974 except Polystichum lonchitis which is from Bailey and Bailey 1976. 


\section{APPENDIX D}

REGRESSION COEFFICIENTS FOR PLANT COMMUNITY CHARACTERISTICS 


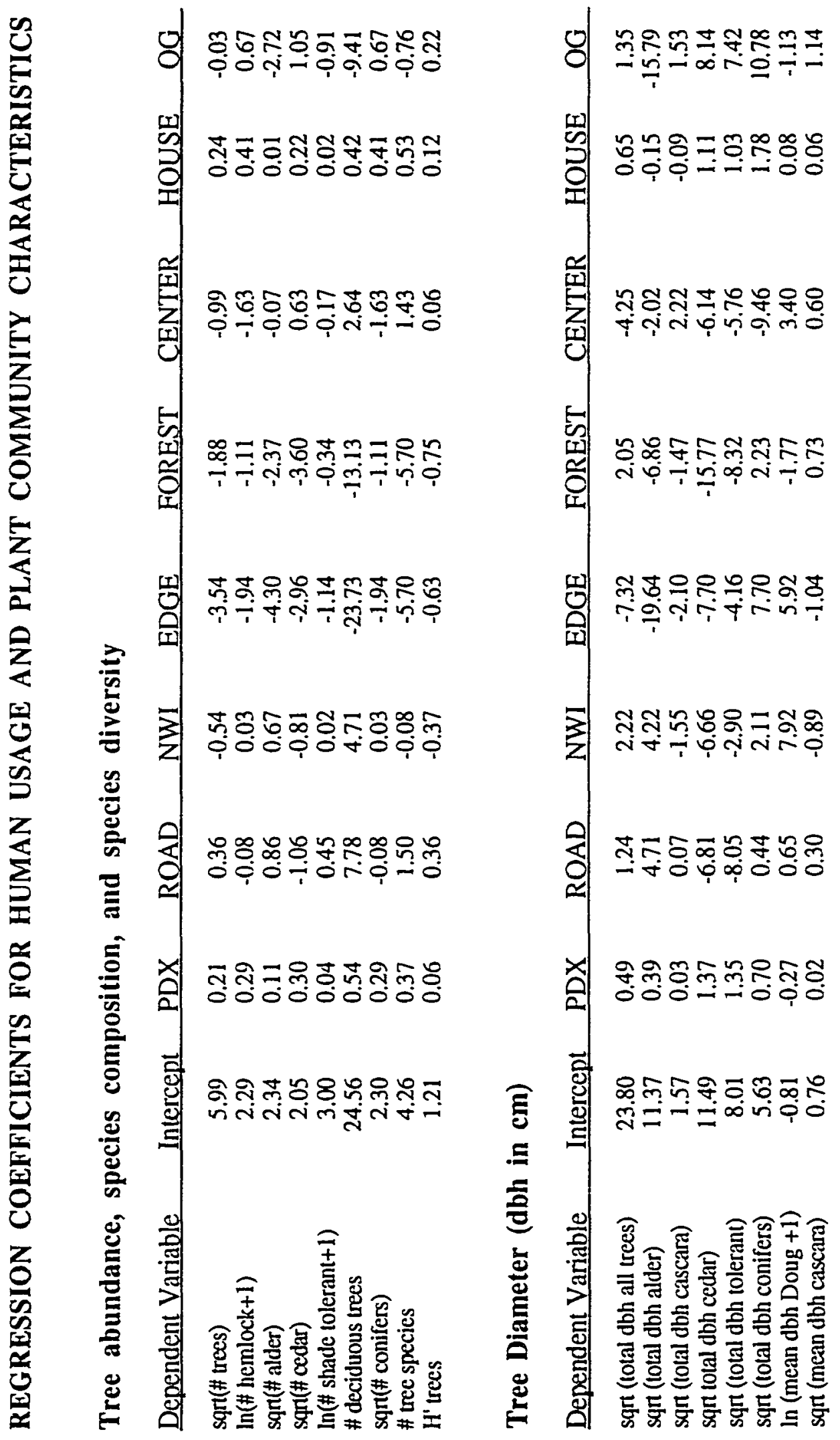




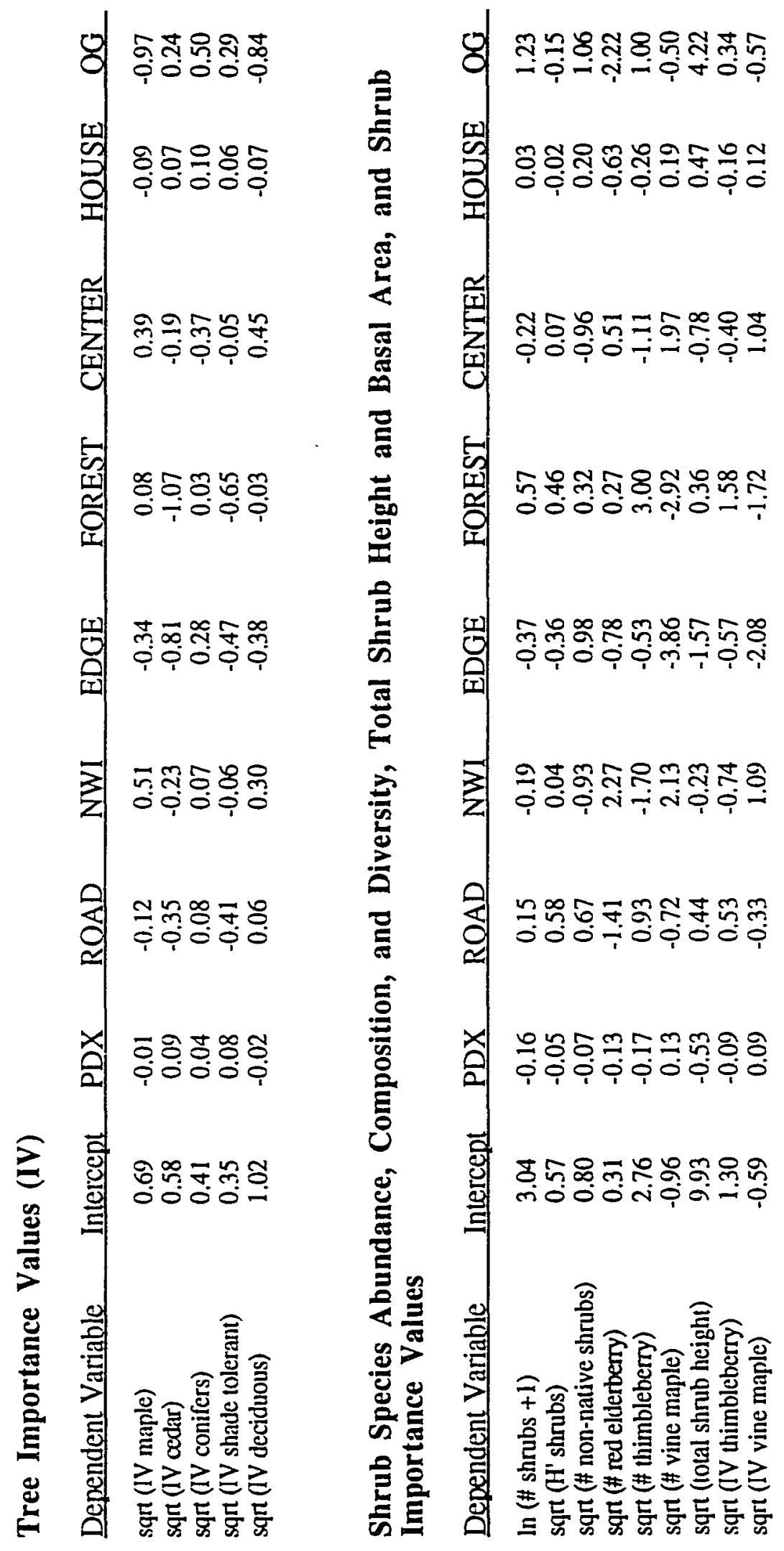




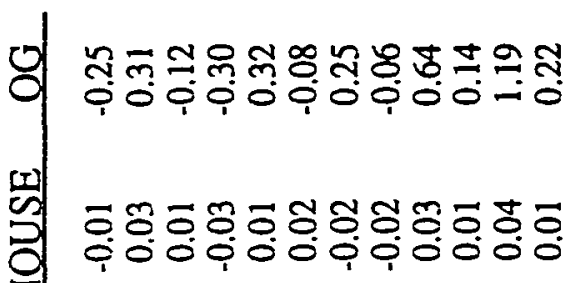

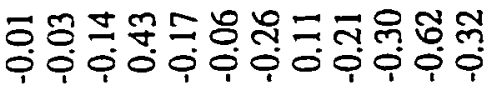

๙

过他

디

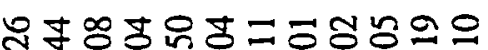

仓ั0

กิษ

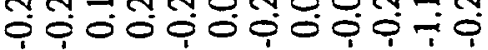

$\S$

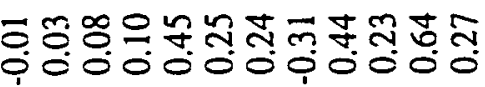

Qิ

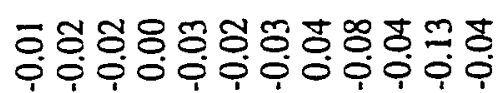

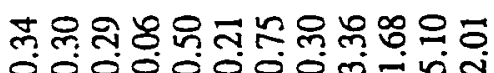
00000000

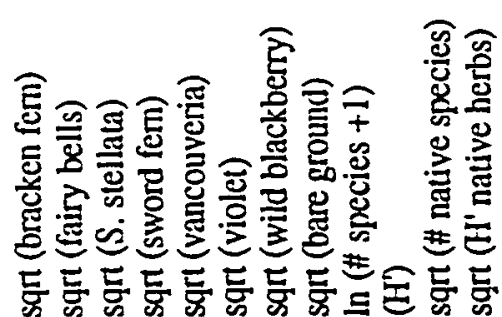

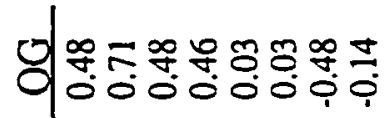

됙

영ㅇㅇㅇㅇㅇㅇㅇㅇㅇㅇㅇㅇㅇㅇㅇㅇㅇㅇ

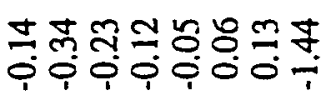

고

武

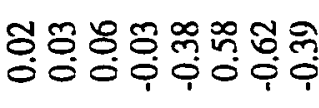

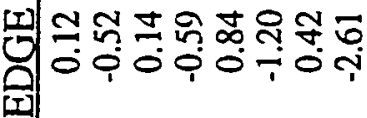

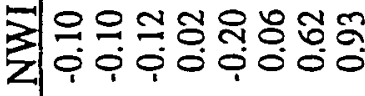

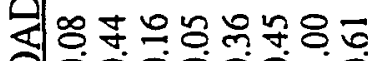

iói

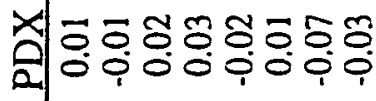

อ

강

웅응ㅇㅇㅇำ

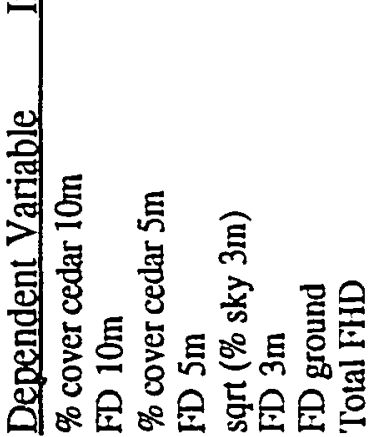




\section{APPENDIX E}

REGRESSION COEFFICIENTS FOR TREE POPULATION DEMOGRAPHICS RECRUTTMENT, SIZE CLASS STRUCTURE, MORTALITY, GROWTH RATE, AND LIVE CROWN RATIO (LCR) 


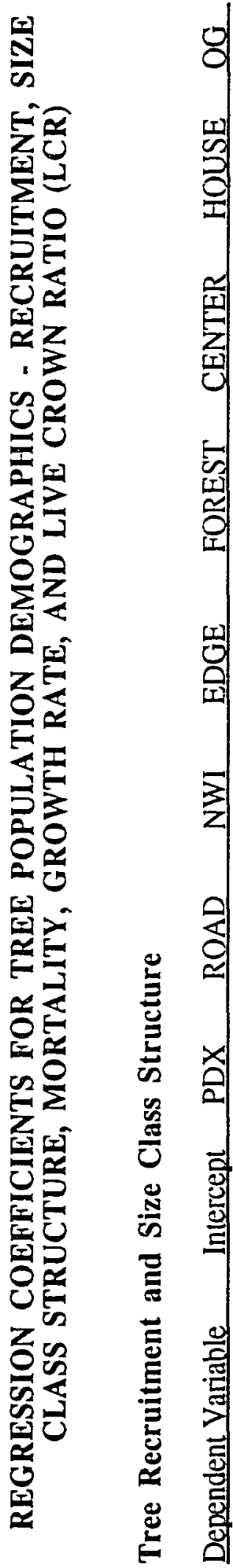

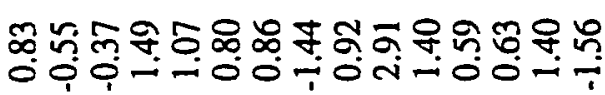

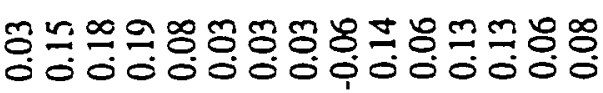

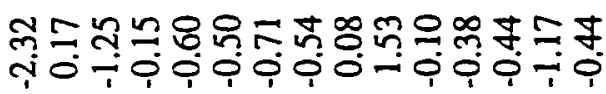

สุ\&

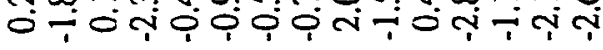

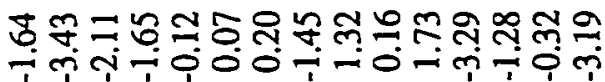

으느유윻중 तíonio

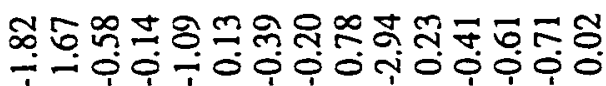

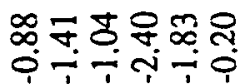

응유

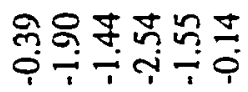

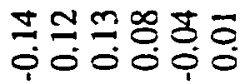

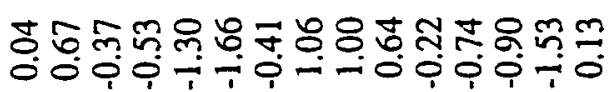

웡

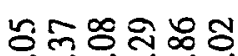

$\div \div \div \div \div$

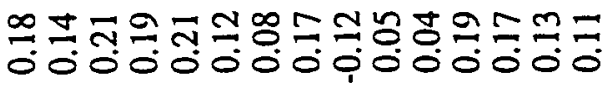

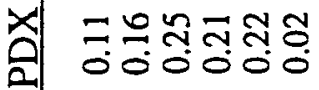

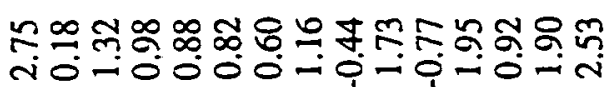

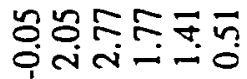

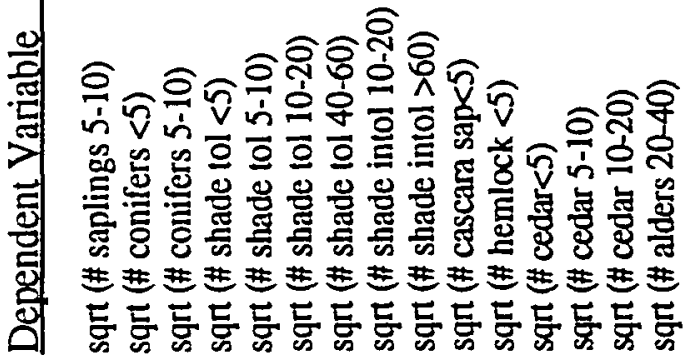

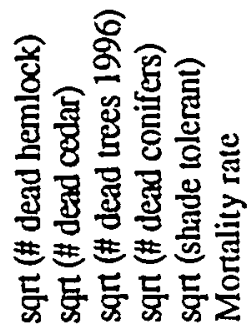



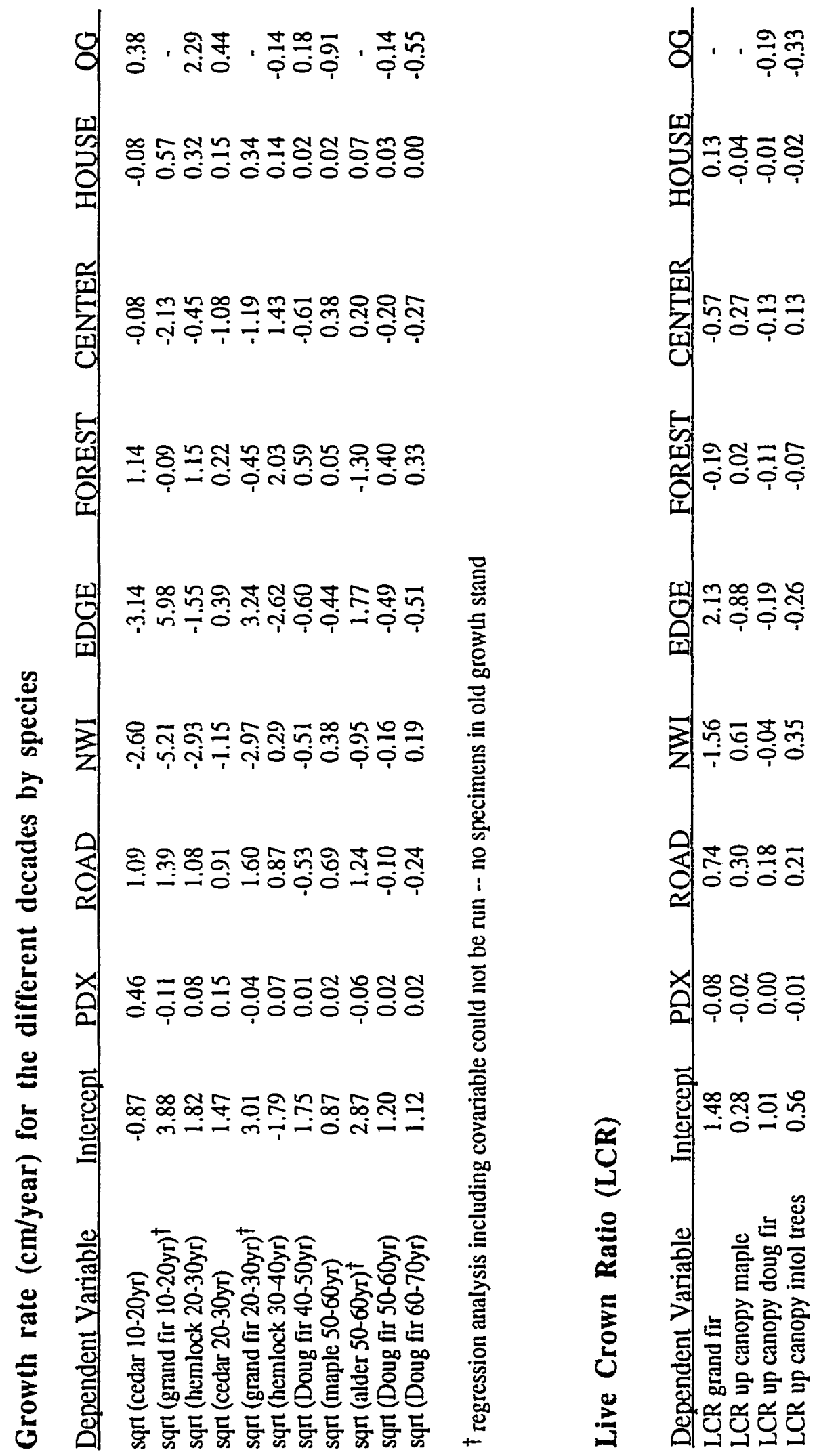


\section{APPENDIX F}

THE MEAN NUMBER OF SAPLINGS AND TREES BY SIZE CLASS CATEGORY IN THE DIFFERENT SECTIONS 
THE MEAN NUMBER OF SAPLINGS AND TREES (Standard Deviation) BY SIZE CLASS CATEGORY IN THE DIFFERENT SECTIONS

Size Categories/Species
City

Saplings < $5 \mathrm{~cm} \mathrm{dbh}$ :
Mid

Far

OG

BL maple saplings $<5 \mathrm{~cm} d \mathrm{bh}^{x}$

Cascara saplings $<5 \mathrm{~cm} d \mathrm{bh}$

W.Hemlock saplings $<5 \mathrm{~cm} \mathrm{dbh}^{\mathrm{x}}$

WRCedar saplings $<5 \mathrm{~cm} d \mathrm{bh}^{\mathrm{x}}$

Grand fir $<5 \mathrm{~cm}$ dbh

Saplings all species $<5 \mathrm{~cm} d b h$

Conifer saplings $<5 \mathrm{~cm} \mathrm{dbh}$

Deciduous saplings $<5 \mathrm{~cm} d \mathrm{bh}$

Shade tolerant $<5 \mathrm{~cm} \mathrm{dbh}^{x}$

Shade intolerant $<5 \mathrm{~cm} \mathrm{dbh}^{x}$ $1.3(2.0)^{a b}$

$1.5(2.9)$

$0.5(1.1)^{\mathrm{a}}$

$0.0(-)^{2}$

$0.7(2.3)$

$4.3(4.0)$

$1.2(2.4)^{\mathrm{a}}$

$3.1(3.8)$

$0.5(1.1)^{\mathrm{a}}$

$1.3(2.0)^{\mathrm{ab}}$

$$
\begin{array}{r}
1.9(3.3)^{\mathrm{a}} \\
0.6(1.1) \\
0.0(0.2)^{\mathrm{ac}} \\
1.0(2.2)^{\mathrm{ab}} \\
0.3(0.9) \\
\\
5.4(6.2) \\
2.4(3.2)^{\mathrm{ac}} \\
3.1(4.6) \\
1.1(2.3)^{\mathrm{a}} \\
2.6(3.9)^{\mathrm{a}}
\end{array}
$$

$$
\begin{array}{r}
0.2(0.6)^{\mathrm{b}} \\
1.5(2.2) \\
0.8(1.2)^{\mathrm{ad}} \\
1.5(1.7)^{\mathrm{b}} \\
0.3(1.0) \\
\\
5.0(2.7) \\
2.8(2.6)^{\mathrm{bc}} \\
2.2(2.6) \\
2.5(2.2)^{\mathrm{bc}} \\
0.3(0.6)^{\mathrm{b}}
\end{array}
$$

$0.4(1.1)$

$0.6(1.0)^{\mathrm{b}}$

$1.3(2.8)^{\mathrm{b}}$

$0.3(1.1)$

0.5 (1.2)

$3.3(3.6)$

$2.8(3.0)^{\mathrm{b}}$

$0.5(1.1)$

$2.0(2.8)^{\mathrm{b}}$

$0.8(1.5)$

$0.2(0.6)^{2}$

$1.1(1.6)$

Shade tolerant $5-10 \mathrm{~cm} \mathrm{dbh}^{\mathrm{x}}$

Shade intolerant $5-10 \mathrm{~cm} \mathrm{dbh}$

\section{Trees $10-20 \mathrm{~cm}$ dbh:}

BL maple trees $10-20 \mathrm{~cm} \mathrm{dbh}^{x}$

RAlder trees $10-20 \mathrm{~cm}$ dbh

WHemlock trees $10-20 \mathrm{~cm}$ dbh

WRCedar trees $10-20 \mathrm{~cm} \mathrm{dbh}^{x}$

Douglas-fir $10-20 \mathrm{~cm}$ dbh

Grand fir $10-20 \mathrm{~cm}$ dbh

Trees all species $10-20 \mathrm{~cm}$ dbh

Conifer trees $10-20 \mathrm{~cm}$ dbh

Deciduous trees $10-20 \mathrm{~cm} \mathrm{dbh}^{x}$

Shade tolerant $10-20 \mathrm{~cm} \mathrm{dbh}^{\mathrm{x}}$

Shade intolerant $10-20 \mathrm{~cm} \mathrm{dbh}^{x}$ $0.9(1.3)^{\mathrm{a}}$

$0.0(0.2)^{\mathrm{a}}$

$0.8(1.5)$

$0.0(-)^{\mathrm{a}}$

$0.1(0.3)$

$0.5(1.6)$

$2.5(2.5)^{\mathrm{a}}$

$1.4(2.2)^{\mathrm{a}}$

$1.1(1.5)^{\mathrm{a}}$

$0.8(1.5)^{\mathrm{a}}$

$1.0(1.4)^{\mathrm{a}}$

$$
\begin{gathered}
2.4(2.8)^{\mathrm{ab}} \\
1.0(1.6)^{\mathrm{b}} \\
0.0(0.2) \\
0.1(0.3)^{\mathrm{a}} \\
0.4(1.1) \\
0.2(0.5)
\end{gathered}
$$

$4.5(3.3)^{\mathrm{ab}}$
$0.8(1.5)^{\mathrm{a}}$
$3.7(3.2)^{\mathrm{b}}$
$0.2(0.5)^{\mathrm{a}}$
$3.8(3.6)^{\mathrm{b}}$ $3.1(3.4)^{\mathrm{b}}$

$0.3(0.5)^{\mathrm{ab}}$

$0.7(1.3)$

$1.2(1.8)^{\mathrm{b}}$

$1.0(1.8)$

$0.3(0.7)$

$6.5(4.6)^{\mathrm{b}}$

$3.0(2.7)^{\mathrm{b}}$

$3.4(3.6)^{\mathrm{b}}$

$1.8(2.4)^{\mathrm{b}}$

$4.3(4.2)^{b}$
$0.0(-)^{2}$

$0.3(0.6)$

$4.7(2.5)^{b}$

$3.7(3.5)^{\mathrm{b}}$

$0.0(-)$

$9.0(2.6)$

$8.3(3.2)^{b}$

$.7(0.6)$

$8.3(3.2)^{\text {bd }}$

$0.0(-)^{\mathrm{ab}}$

$0.0(-)$
$2.0(3.5)^{\mathrm{ab}}$
$3.3(4.9)^{\mathrm{b}}$
$0.0(-)$
$0.0(-)$

$6.3(5.5)$

$5.3(4.7)^{\mathrm{ab}}$

$1.0(1.7)$

$5.3(4.7)^{\mathrm{b}}$

$0.0(-)$

$1.3(1.5)^{\mathrm{ab}}$

$0.0(-)^{\mathrm{ab}}$

$1.7(1.5)$

$3.0(2.6)^{\mathrm{b}}$

$0.0(-)$

$0.0(-)$

$6.3(3.2)^{\mathrm{ab}}$

$4.7(3.1)^{b}$

$1.7(1.5)^{\mathrm{ab}}$

$4.7(3.1)^{b}$

$1.3(1.5)^{\mathrm{ab}}$ 
APPENDDX G

MEAN INCREMENT GROWTH RATE (CM/YEAR) BY DECADE FOR THE PREVIOUS TEN DECADES BY TREE SPECIES 
MEAN INCREMENT GROWTH RATE (CM/YEAR) BY DECADE FOR THE PREVIOUS TEN DECADES BY TREE SPECIES

FIRST DECADE (0-10 Years Ago)

$\begin{array}{ccccc}\text { Tree Species } & \text { City } & \text { Mid } & \text { Far } & \text { OG } \\ \text { Bigleaf Maple } & 1.63(0.53) & 1.71(0.56) & 1.63(0.56) & 1.50(0.69) \\ \text { n } & 95 & 93 & 79 & 5 \\ \text { Red Alder } & 1.65(0.61) & 1.69(0.51) & 1.54(0.41) & 0.0(-) \\ \text { n } & 33 & 57 & 38 & 0 \\ \text { Cherry } & 0.0(-) & 1.68(0.19) & 1.27(0.40) & 0.0(-) \\ \text { n } & 0 & 5 & 7 & 0 \\ \text { Dogwood } & 1.43(0.43) & 1.43(0.39) & 0.0(-) & 1.60(-) \\ \text { n } & 4 & 2 & 0 & 1 \\ \text { Douglas-fir } & 1.30(0.62) & 1.32(0.48) & 1.33(0.43) & 1.00(0.41) \\ \text { n } & 43 & 40 & 40 & 12 \\ \text { Western Hemlock } & 1.22(0.59) & 1.42(0.56) & 1.27(0.53) & 1.05(0.29) \\ \text { n } & 21 & 5 & 32 & 11 \\ \text { Western Red cedar } & 0.0(-) & 1.07(0.33) & 1.22(0.43) & 0.96(0.22) \\ \text { n } & 0 & 7 & 40 & 8 \\ \text { Grand fir } & 1.22(0.34) & 1.37(0.46) & 1.24(0.91) & 0.0(-) \\ \text { n } & 15 & 9 & 7 & 0 \\ \text { All trees } & & & & \\ \text { n } & 1.48(0.58)^{\mathrm{a}} & 1.59(0.54)^{\mathrm{ac}} & 1.43(0.52)^{\mathrm{ad}} & 1.09(0.42)^{\mathrm{b}} \\ & 214 & 223 & 247 & 37\end{array}$

SECOND DECADE (10-20 Years Ago)

$\begin{array}{ccccc}\text { Tree Species } & \text { City } & \text { Mid } & \text { Far } & \text { OG } \\ \text { Bigleaf Maplex } & & & & \\ \text { n } & 2.24(0.69)^{\mathrm{a}} & 2.55(0.77)^{\mathrm{b}} & 2.53(0.88)^{\mathrm{ab}} & 1.15(0.40)^{\mathrm{c}} \\ \text { Red Alder } & 94 & 90 & 79 & 5 \\ \text { n } & 2.17(0.97) & 2.37(0.57) & 2.40(0.67) & 0.0(-) \\ \text { Douglas-fir } & 33 & 57 & 38 & 0 \\ \text { n } & 1.57(0.68)^{\mathrm{a}} & 1.72(0.59)^{\mathrm{a}} & 1.83(0.71)^{\mathrm{a}} & 0.96(0.37)^{\mathrm{b}} \\ \text { Western Hemlock } & 43 & 40 & 40 & 12 \\ \text { n } & 1.46(0.71) & 1.72(0.59) & 1.63(0.78) & 1.17(0.49) \\ \text { Westem Red cedar } & 21 & 5 & 32 & 11 \\ \text { n } & 0.0(-)^{\mathrm{ab}} & 0.81(0.31)^{\mathrm{a}} & 1.50(.72)^{\mathrm{b}} & 1.22(0.51)^{\mathrm{ab}} \\ \text { Grand fir } & 0 & 7 & 40 & 8 \\ \text { n } & 1.71(0.57) & 1.69(0.64) & 2.26(2.04) & 0.0(-) \\ & 14 & 9 & 7 & 0 \\ \text { All trees } & & & & 2.04 \\ \text { n } & 1.95(0.80)^{\mathrm{a}} & 2.20(0.80)^{\mathrm{b}} & 2.09(0.92)^{\mathrm{ab}} & 1.13(0.45)^{\mathrm{c}} \\ & 212 & 219 & 247 & 37\end{array}$




$\begin{array}{lcccc}\text { THIRD DECADE (20-30 Years Ago) } & & & \\ \text { Tree Species } & \text { City } & \text { Mid } & \text { Far } & \text { OG } \\ \text { Bigleaf Maple } & & & & \\ \text { n } & 2.56(1.03)^{\mathrm{a}} & 2.95(0.74)^{\mathrm{b}} & 2.87(1.06)^{\mathrm{ab}} & 1.26(0.32)^{\mathrm{c}} \\ \text { Red Alder } & 90 & 78 & 70 & 5 \\ \text { n } & 2.44(1.17) & 2.74(0.71) & 2.73(0.83) & 0.0(-) \\ \text { Douglas-firx } & 33 & 50 & 38 & 0 \\ \text { n } & 1.74(0.85)^{\mathrm{a}} & 1.69(0.57)^{\mathrm{a}} & 2.09(0.99)^{\mathrm{a}} & 0.99(0.45)^{\mathrm{b}} \\ \text { Western Hemlock } & 43 & 34 & 33 & 12 \\ \text { n } & 1.62(1.07)^{\mathrm{ab}} & 1.73(0.68)^{\mathrm{ab}} & 1.99(1.07)^{\mathrm{a}} & 1.13(0.60)^{\mathrm{b}} \\ \text { Western Red cedar } & 19 & 4 & 27 & 11 \\ \text { n } & 0.0(-)^{\mathrm{ab}} & 0.77(0.36)^{\mathrm{a}} & 1.68(0.71)^{\mathrm{b}} & 1.41(0.52)^{\mathrm{ab}} \\ \text { Grand fir } & 0 & 6 & 35 & 8 \\ \text { n } & 1.00(0.60) & 1.82(1.48) & 1.98(1.09) & 0.0(-) \\ \text { All trees } & 9 & 8 & 6 & 0 \\ \text { n } & 2.20(1.10)^{\mathrm{a}} & 2.48(0.96)^{\mathrm{b}} & 2.38(1.05)^{\mathrm{ab}} & 1.18(0.51)^{\mathrm{c}} \\ & 196 & 189 & 248 & 37\end{array}$

FOURTH DECADE (30-40 Years Ago)

Tree Species

City

Mid

Far

OG

Bigleaf Maple ${ }^{x}$

$2.54(1.12)^{\mathrm{a}}$

83

$3.01(0.66)^{\mathrm{b}}$

$2.87(0.95)^{\mathrm{ab}}$

$1.35(0.17)^{c}$

$2.78(1.15)$

Red Alder

$\mathbf{n}$

32

$2.85(0.64)$

3.32 (1.22)

33

$0.0(-)$

Douglas-fir $x$

n

$2.11(1.32)^{\mathrm{a}}$

42

$1.83(0.66)^{\mathrm{a}}$

$1.82(0.68)^{\mathrm{a}}$

28

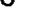

Western Hemlock ${ }^{x}$

$\mathrm{n}$

$1.44(0.79)^{a b}$

$1.58(0.41)^{\mathrm{ab}}$

$2.17(1.26)$

22

$1.03(0.49)^{b}$

17

4

$1.66(0.50)^{\mathrm{a}}$

$0.0(-)^{\mathrm{ab}}$

$1.21(0.28)^{\mathrm{ab}}$

West

0

3

23

12

Grand fir

$0.91(0.37)$

6

$1.50(0.90)$

4

2.05 (1.57)

3

$0.0(-)$
0

All trees $x$

n

$2.33(1.21)^{\mathrm{a}}$

$2.58(0.86)^{b}$

148

$2.47(1.13)^{\mathrm{ab}}$

$1.09(0.38)^{c}$

181

167

34 


\section{FIFTH DECADE (40-50 Years Ago)}

Tree Species
Bigleaf Maple
$n$
Red Alder
$\mathbf{n}$
Douglas-fir $\mathrm{x}$
$\mathbf{n}$
Western Hemiock ${ }^{\mathrm{x}}$
$\mathrm{n}$
Western Red cedar ${ }^{\mathrm{x}}$
$\mathrm{n}$

All trees ${ }^{x}$

n

$\begin{array}{cccc}\text { City } & \text { Mid } & \text { Far } & \text { OG } \\ 2.35(0.78)^{\mathrm{a}} & 3.01(0.72)^{\mathrm{b}} & 2.92(1.01)^{\mathrm{ab}} & 1.61(0.16)^{\mathrm{c}} \\ 61 & 40 & 26 & 4 \\ 2.88(1.42) & 2.78(0.55) & 3.32(1.21) & 0.0(-) \\ 25 & 26 & 19 & 0 \\ 1.99(0.87)^{\mathrm{a}} & 1.95(0.50)^{\mathrm{a}} & 1.81(0.65)^{\mathrm{a}} & 1.01(0.34)^{\mathrm{b}} \\ 35 & 27 & 25 & 12 \\ 1.35(0.57)^{\mathrm{a}} & 1.54(0.54)^{\mathrm{ab}} & 2.09(0.68)^{\mathrm{b}} & 1.18(0.62)^{\mathrm{a}} \\ 15 & 2 & 15 & 9 \\ 0.0(-)^{\mathrm{ab}} & 1.15(0.21)^{\mathrm{ab}} & 2.09(1.19)^{\mathrm{a}} & 1.15(0.35)^{\mathrm{b}} \\ 0 & 2 & 18 & 7 \\ & & & \\ 2.22(1.03)^{\mathrm{a}} & 2.54(0.81)^{\mathrm{b}} & 2.44(1.11)^{\mathrm{ab}} & 1.17(0.44)^{\mathrm{c}} \\ 139 & 103 & 111 & 33\end{array}$

\section{SIXTH DECADE (50-60 Years Ago)}

Tree Species

Bigleaf Maplex

Red Alder $x$

n

Douglas-fir ${ }^{x}$

$\mathrm{n}$

Western Hemlock

n

Western Red cedar ${ }^{x}$

n

All trees ${ }^{x}$

$\mathrm{n}$

$\begin{array}{cccc}\text { City } & \text { Mid } & \text { Far } & \text { OG } \\ 2.36(0.72)^{\mathrm{a}} & 2.95(0.56)^{\mathrm{b}} & 2.68(0.81)^{\mathrm{ab}} & 1.33(0.21)^{\mathrm{c}} \\ 41 & 23 & 17 & 3 \\ 2.10(0.75)^{\mathrm{a}} & 2.78(0.89)^{\mathrm{b}} & 2.74(0.62) & 0.0(-) \\ 15 & 16 & 11 & 0 \\ 1.81(0.58)^{\mathrm{a}} & 1.95(0.49)^{\mathrm{a}} & 1.93(0.55)^{\mathrm{a}} & 1.20(0.42)^{\mathrm{b}} \\ 32 & 24 & 23 & 12 \\ 1.64(0.55) & 1.97(0.30) & 2.07(0.68) & 1.72(0.46) \\ 13 & 2 & 10 & 5 \\ 0.0(-) & 1.64(0.10) & 2.12(0.63)^{\mathrm{a}} & 1.11(0.40)^{\mathrm{b}} \\ 0 & 2 & 13 & 4 \\ & & & \\ 2.05(0.71)^{\mathrm{a}} & 2.46(0.79)^{\mathrm{b}} & 2.29(0.78)^{\mathrm{ab}} & 1.31(0.44)^{\mathrm{c}} \\ 102 & 69 & 80 & 24\end{array}$




$\begin{array}{lcccc}\text { SEVENTH DECADE (60-70 Years Ago) } & & & \\ \text { Tree Species } & \text { City } & \text { Mid } & \text { Far } & \text { OG } \\ \text { Bigleaf Maple } & 2.18(0.70) & 2.61(0.45) & 2.46(0.43) & 1.55(0.35) \\ \text { n } & 24 & 17 & 6 & 2 \\ \text { Red Alder } & 1.79(1.00) & 2.60(0.43) & 2.74(0.37) & 0.0(-) \\ \text { n } & 11 & 5 & 5 & 0 \\ \text { Douglas-fir } & 1.74(0.66)^{\mathrm{a}} & 1.99(0.43)^{\mathrm{a}} & 1.93(0.55)^{\mathrm{a}} & 1.26(0.59)^{\mathrm{b}} \\ \text { n } & 30 & 21 & 22 & 12 \\ \text { Western Hemlock } & 1.56(0.59) & 1.60(-) & 1.98(0.35) & 1.49(0.30) \\ \text { n } & 7 & 1 & 7 & 4 \\ \text { Western Red cedar } & 0.0(-)^{\mathrm{ab}} & 1.50(-)^{\mathrm{ab}} & 1.98(0.26)^{\mathrm{a}} & 1.06(0.28)^{\mathrm{b}} \\ \text { n } & 0 & 1 & 8 & 4 \\ \text { All trees } & & & & \\ \text { n } & 1.88(0.75)^{\mathrm{a}} & 2.22(0.60)^{\mathrm{b}} & 2.16(0.57)^{\mathrm{b}} & 1.29(0.49)^{\mathrm{c}} \\ & 72 & 47 & 51 & 22\end{array}$

Tree species that were present in less than two sections or for which the total $n$ was less than 12 were considered infrequent or rare species and were omitted.

Results of Bonnferoni/Dunn testing is shown for each variable as superscripts for means that are significantly different from one another. For a given variable, means with different superscripts are significantly different from one another (e.g., for any given dependent variable, all means with a superscript of a are significantly different from those with a superscript of b). Significance was determined after the variables were transformed in the same manner as used in multiple regression testing.

A superscript of " $x$ " denotes that the square root of the variable was used; a superscript of "*" denotes that the natural log of the variable +1 was used. 


\section{APPENDIX H}

GUILD STATUS AND MIGRATORY STATUS OF ALL BIRDS OBSERVED IN FOREST PARK AND THE OLD-GROWTH STAND 
TABLE OF BIRD SPECIES BY GUILD STATUS. THE MIGRATORY STATUS OF EACH BIRD IS LISTED

Guild Status / Common Name Migratory Status

Predatory birds:

Sharp-shinned hawk

Cooper's hawk

Red-tailed hawk

Osprey

Bald eagle

Northern pygmy-owl

Western screech-owl

$S$

S

R

$\mathrm{S}$

$\mathrm{R}$

$\mathrm{R}$

$\mathrm{R}$

\section{Ground gleaners:}

Ruffed grouse

California quail

Rock dove

Northern flicker

Scrub jay

Steller's jay

American crow

Common raven

Bewick's wren

House wren

Winter wren

American robin

Varied thrush

Hermit thrush

House sparrow

European starling

Brown-headed cowbird

Evening grosbeak

Purple finch

House finch

Spotted towhee

Dark-eyed junco

Song sparrow

Fox sparrow

White-crowned sparrow

$\mathrm{R}$

$\mathrm{R}$

$\mathrm{R}$

$\mathrm{R}$

$\mathrm{R}$

$\mathrm{R}$

R

$\mathrm{R}$

S

R

$S$

R

$S$

$\mathrm{R}$

R

S

R

R

R

R

R

$S$

S

S 
Guild Status / Common Name

\section{Foliage gleaners:}

Band-tailed pigeon

Mourning dove

Black-capped chickadee

Chestnut-backed chickadee

Bushtit

Swainson's thrush

Golden-crowned kinglet

Ruby-crowned kinglet

Cedar waxwing

Solitary vireo

Warbling vireo

Hutton's vireo

Orange-crowned warbler

Nashville warbler

Yellow-rumped warbler

Hermit warbler

Townsend's warbler

Black-throated gray warbler

McGillivray's warbler

Yellow warbler

Wilson's warbler

Western tanager

Black-headed grosbeak

Pine siskin

\section{Bark gleaners:}

Hairy woodpecker

Downy woodpecker

Pileated woodpecker

Red-breasted nuthatch

White-breasted nuthatch

Brown creeper

$\mathrm{R}$

\section{Aerial gleaners:}

Rufous hummingbird

Olive-sided flycatcher

Pacific-slope flycatcher

$\mathrm{N}$

Western wood-peewee

$\mathrm{N}$

Violet-green swallow

Guild and migratory status as per Ehrlich et al. 1988 


\section{APPENDIX I}

COMMON AND SCIENTIFIC NAMES (AUTHORITIES) OF BIRD SPECIES COUNTED AT SITES, AND ABBREVIATIONS USED IN TEXT AND TABLES 
COMMON AND SCIENTIFIC NAMES (AUTHORITIES) OF BIRD SPECIES

COUNTED AT SITES, AND ABBREVIATIONS USED IN TEXT AND TABLES

\begin{tabular}{|c|c|c|}
\hline Common Name & Scientific Name (Authority) & Abbreviation \\
\hline Canada goose & Branta canadensis (Linnaeus) & CAGO \\
\hline Sharp-shinned hawk & Accipiter striatus (Vieillot) & SSHA \\
\hline Cooper's hawk & Accipiter cooperii (Vieillot) & COHA \\
\hline Red-tailed hawk & Buteo jamaicensis (Gmelin) & RTHA \\
\hline Osprey & Pandion haliaetus (Linnaeus) & OSPR \\
\hline Bald eagle & Haliaeetus leucocephalus (Linnaeus) & BAEA \\
\hline Great blue heron & Ardea herodias (Linnaeus) & GBHE \\
\hline Ruffed grouse & Bonasa umbellus (Linnaeus) & RUGR \\
\hline Califomia quail & Callipepla californica (Shaw) & CAQU \\
\hline Rock dove & Columba livia (Gmelin) & RODO \\
\hline Band-tailed pigeon & Columba fasciata (Say) & BTPI \\
\hline Mourning dove & Zenaida macroura (Linnaeus) & MODO \\
\hline Great-horned owl & Bubo virginianus (Gmelin) & GHOW \\
\hline Northern pygmy-owl & Glaucidium gnoma (Wagler) & NPOW \\
\hline Western screech-owl & Otus kennicottii (Elliot) & WSOW \\
\hline Rufous hummingbird & Selasphorus rufus (Gmelin) & RUHU \\
\hline Northern flicker & Colaptes auratus (Linnaeus) & NOFL \\
\hline Hairy woodpecker & Picoides villosus (Linnaeus) & HAWO \\
\hline Downy woodpecker & Picoides pubescens (Linnaeus) & DOWO \\
\hline Pileated woodpecker & Dryocopus pileatus (Linnaeus) & PIWO \\
\hline Olive-sided flycatcher & Contopus borealis (Swainson) & OSFL \\
\hline Pacific-slope flycatcher & Empidonax difficilis (Baird) & PSFL \\
\hline Western wood-pewee & Contopus sordidulus (Sclater) & WWPE \\
\hline Violet-green swallow & Tachycineta thalasssina (Swainson) & VGSW \\
\hline Scrub jay & Aphelocoma coerulescens (Bosc) & SCJA \\
\hline Steller's jay & Cyanocitta stelleri (Gmelin) & STJA \\
\hline American crow & Corvus brachyrhynchos (Brehm) & AMCR \\
\hline Common raven & Corvus corax (Linnaeus) & CORA \\
\hline
\end{tabular}




\begin{tabular}{|c|c|c|}
\hline Common Name & Scientific Name (Authority) & Abbreviation \\
\hline Black-capped chickadee & Parus atricapillus (Linnaeus) & $\mathrm{BCCH}$ \\
\hline Chestnut-backed chickadee & Parus rufescens (Townsend) & $\mathrm{CBCH}$ \\
\hline Bushtit & Psaltriparus minimus (Townsend) & BUSH \\
\hline Red-breasted nuthatch & Sitta canadensis (Linnaeus) & RBNU \\
\hline White-breasted nuthatch & Sitta carolinensis (Latham) & WBNU \\
\hline Brown creeper & Certhia familiaris (Bonaparte) & BRCR \\
\hline Bewick's wren & Thryomanes bewickii (Audubon) & BEWR \\
\hline House wren & Troglodytes aedon (Vieillot) & HOWR \\
\hline Winter wren & Troglodytes troglodytes (Linnaeus) & WTWR \\
\hline American robin & Turdus migratorius (Linnaeus) & AMRO \\
\hline Varied thrush & Ixoreus naevius (Gmelin) & VATH \\
\hline Swainson's thrush & Catharus ustulata (Nuttall) & SWTH \\
\hline Hermit thrush & Hylocichla guttata (Pallas) & HETH \\
\hline Golden-crowned kinglet & Regulus satropa (Lichtenstein) & GCKI \\
\hline Ruby-crowned kinglet & Regulus calendula (Linnaeus) & $\mathrm{RCKI}$ \\
\hline Cedar waxwing & Bombycilla cedrorum (Vieillot) & CEWA \\
\hline European starling & Sturnus vulgaris (Linnaeus) & EUST \\
\hline Solitary vireo & Vireo solitarius (Wilson) & SOVI \\
\hline Warbling vireo & Vireo gilvus (Vieillot) & WAVI \\
\hline Hutton's vireo & Vireo huttoni (Cassin) & HUVI \\
\hline Orange-crowned warbler & Vermivora celata (Say) & OCWA \\
\hline Nashville warbler & Vermivora ruficapilla (Wilson) & NAWA \\
\hline Yellow-rumped warbler & Dendroica coronata (Linnaeus) & YRWA \\
\hline Hermit warbler & Dendroica occidentalis (Townsend) & HEWA \\
\hline Townsend's warbler & Dendroica townsendi (Townsend) & TOWA \\
\hline Black-throated gray warbler & Dendroica nigrescens (Townsend) & BTGW \\
\hline McGillivray's warbler & Oporomis tolmiei (Townsend) & MCWA \\
\hline Yellow warbler & Dendroica petechia (Linnaeus) & YEWA \\
\hline Wilson's warbler & Wilsonia pusilla (Wilson) & WTWA \\
\hline House sparrow & Passer domesticus (Linnaeus) & HOSP \\
\hline Brown-headed cowbird & Molothrus ater (Boddaert) & $\mathrm{BHCO}$ \\
\hline
\end{tabular}




\begin{tabular}{llc} 
Common Name & Scientific Name (Authority) & Abbreviation \\
\hline Western tanager & Piranga ludoviciana (Wilson) & WETA \\
Black-headed grosbeak & Pheucticus melanocephalus (Swainson) & BHGR \\
Evening grosbeak & Coccothraustes vespertinus (Cooper) & EVGR \\
Purple finch & Carpodacus purpureus (Gmelin) & PUFI \\
House finch & Carpodacus mexicanus (Müller) & HOFI \\
Pine siskin & Carduelis pinus (Wilson) & PISI \\
Spotted towhee & Pipilo erythrophthalmus (Linnaeus) & SPTO \\
Dark-eyed junco & Junco hyemalis (Linnaeus) & DEJU \\
Song sparrow & Melospiza melodia (Wilson) & SOSP \\
Fox sparrow & Passerella iliaca (Merrem) & FOSP \\
White-crowned sparrow & Zonotrichia leucophrys (Forster) & WCSP
\end{tabular}

All scientific names and authorities via Ehrlich et al 1988. Common names conform to those adopted by the Oregon Bird Records Committee 1998. 


\section{APPENDIX J}

REGRESSION COEFFICIENTS FOR BIRD SPECIES ABUNDANCE, RICHNESS, AND DIVERSITY 


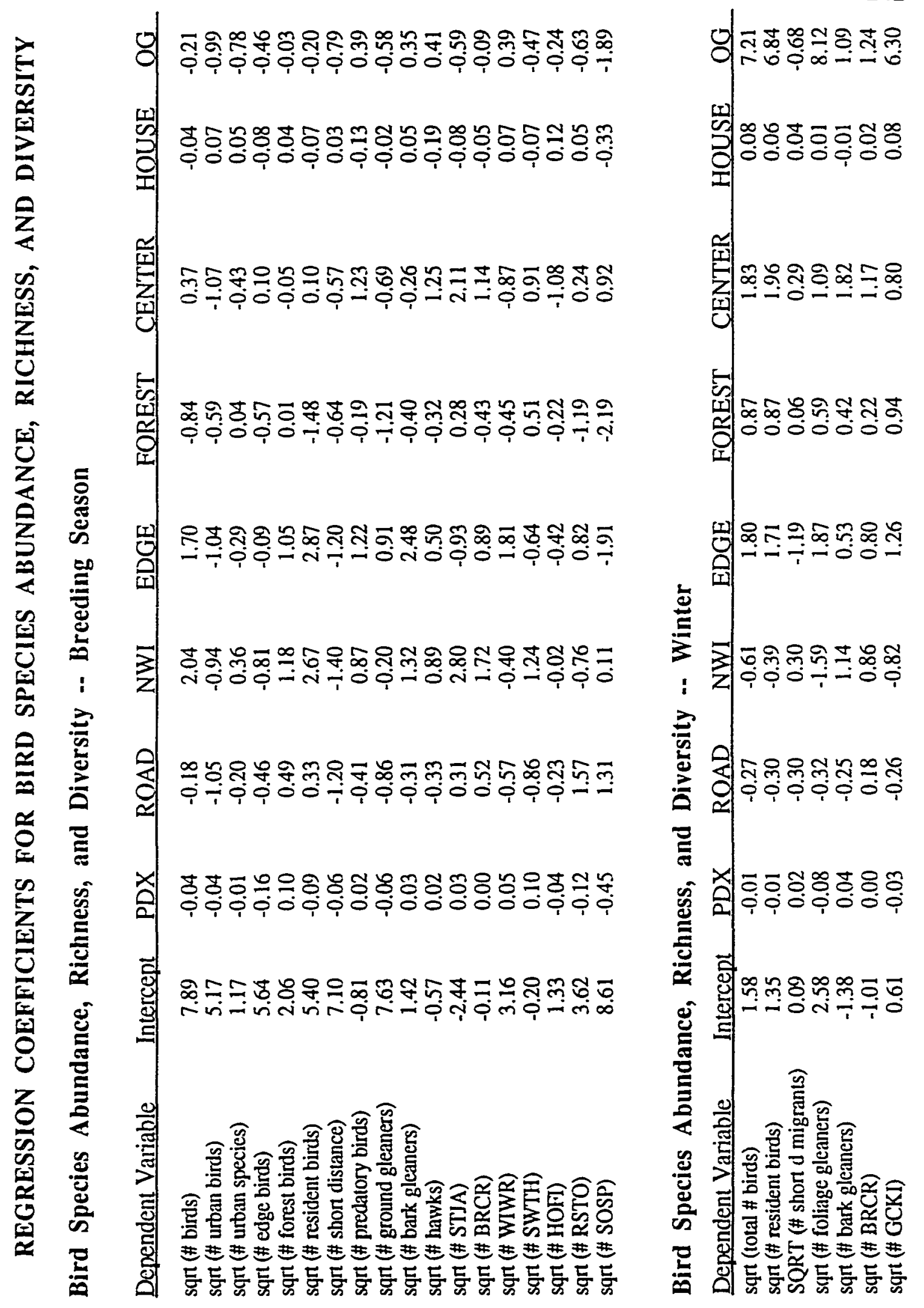


APPENDIX K

REGRESSION COEFFICIENTS FOR PLANT COMMUNITY

CHARACTERISTICS AS APPLIED TO THE AVIAN COMMUNITY 


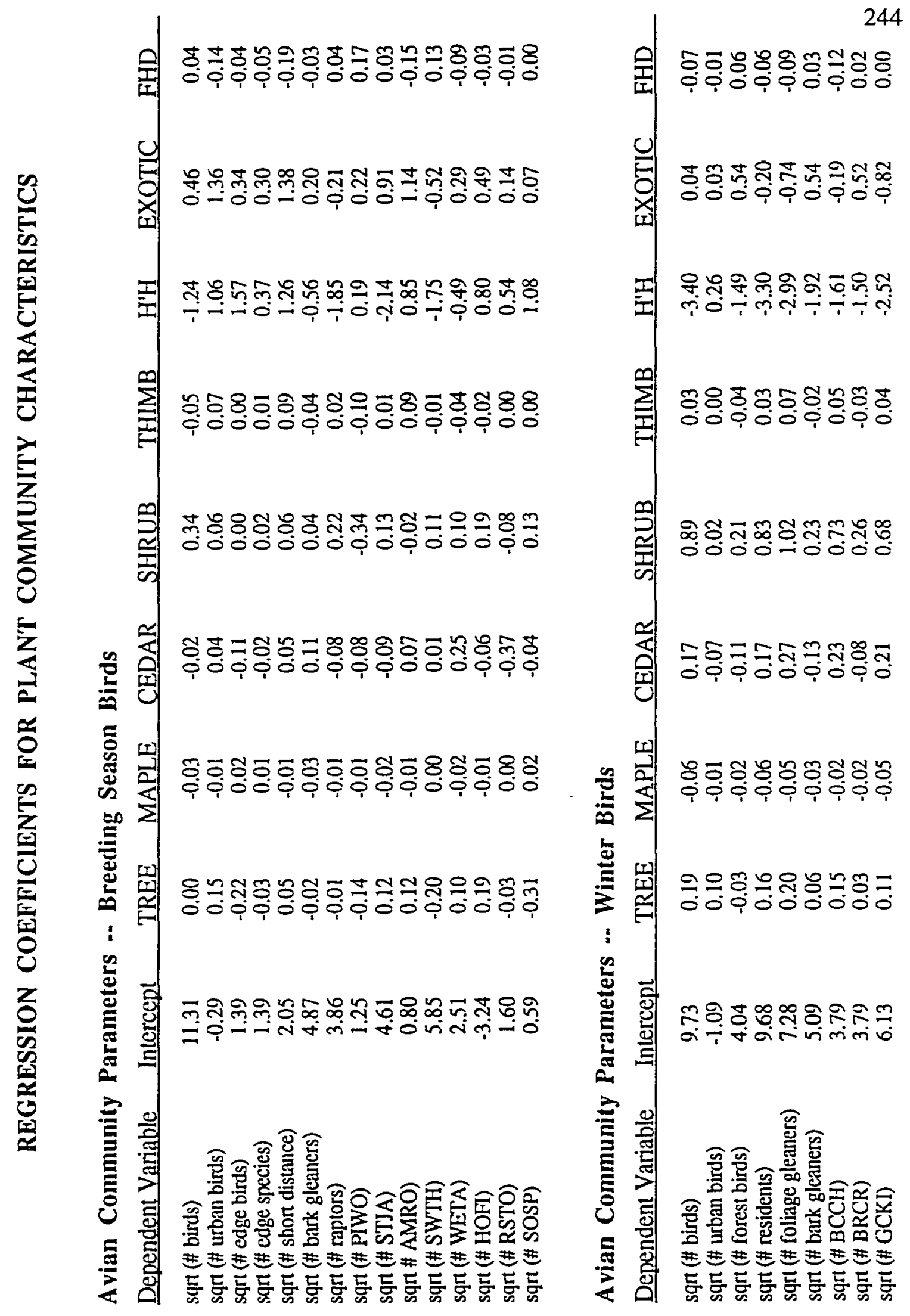

